\title{
Modelo de Gestión para la Prevención de Lavado de Activos en el Sector de Juego de Azar
}

Una Tesis presentada para obtener el título de

Doctora en Ciencias de la Administración

Acreditada por CONEAU en sesión Nro 423/15

Facultad de Ciencias Económicas

Universidad Nacional de La Plata

Argentina

Alumno: Lía Hebe Molinari

Directora: Dra. Elsa Estévez

Co-Director: Lic. Francisco Javier Díaz

Año 2017 


\section{(c) (1) () (2)}

Esta es la licencia Creative Commons.

Usted es libre de:

- copiar, distribuir y comunicar públicamente la obra

- hacer obras derivadas

Bajo las condiciones siguientes:

- Reconocimiento - Debe reconocer los créditos de la obra de la manera

especificada por el autor o el licenciador (pero no de una manera que sugiera que tiene su apoyo o apoyan el uso que hace de su obra).

- No comercial - No puede utilizar esta obra para fines comerciales.

- Compartir bajo la misma licencia - Si altera o transforma esta obra, o genera una obra derivada, sólo puede distribuir la obra generada bajo una licencia idéntica a ésta. 
A mis amores incondicionales: Sofía, Mara y Franco.

A mi familia, los Molinari, mi orgullo y mi refugio. 
Son muchas las personas que contribuyeron a este trabajo, directa o indirectamente. Ya sea con el aporte de conocimientos o experiencias. Ya sea con esa palmada en la espalda, cuando agobiados decimos que vamos a abandonar.

Va mi agradecimiento a:

- mis compañeros del Laboratorio de Investigación en Tecnologías Informáticas (LINTI) de la Facultad de Informática de la Universidad Nacional de La Plata;

- a la DCV Ariadna Alfano, por su colaboración en el formato y mejorar mi estética demasiado informática;

- a mis colegas del equipo de auditoría tecnológica del Centro Superior del Procesamiento de la Información (CeSPI), de la Universidad Nacional de La Plata;

- al Dr. Hernán Najenson, con quien compartí gran parte de las actividades de investigación y difusión;

- a la Facultad de Ciencias Económicas de la Universidad Nacional de La Plata, que me abrió sus puertas y me acompañó en este proceso; a mis profesores, al equipo de la Secretaría de Posgrado y a mis compañeros;

- a Francisco Javier Díaz, que en un acto que inicialmente califiqué de inexplicable, me propuso hacer el curso para certificación antilavado que fue el puntapié inicial para investigar acerca de esta temática;

- a mis directores, Dra. Elsa Estévez y Lic. Francisco Javier Díaz, por su acompañamiento y su paciencia;

y a la Universidad Nacional de La Plata, mi querida UNLP, una institución de la que estoy orgullosa de formar parte. 
Esta tesis se ubica en el contexto de los juegos de azar y el riesgo de esta actividad para el lavado de activos. Con la premisa de desarrollar un enfoque orientado al riesgo, teniendo en cuenta los juegos y tipologías de lavado de dinero y bajo el establecimiento de políticas de prevención, su relación con otros marcos y recomendaciones internacionales, y su aplicación y la normativa a cumplir, esta tesis propone un conjunto de elementos que se consideran relevantes en la construcción de dichas políticas. Se describe cada uno de estos elementos, como así también un modelo de madurez que se obtiene como la integración del nivel de madurez alcanzado por la organización en cada uno de los elementos. En síntesis, esta tesis plantea la definición, implementación y evaluación de un modelo de gestión para la prevención del lavado de activos en el sector de juegos de azar.

Las contribuciones de esta tesis incluyen: a) la definición de un modelo factible y aplicable a corto plazo de políticas y acciones de prevención de lavado de activos en el sector de juego de azar; b) la definición de un marco conceptual que incluye elementos claves en la definición de políticas de prevención de lavado de activos en el sector de juego de azar; c) la definición de una metodología de análisis de riesgo sobre de lavado de activos en el sector; d) análisis de la situación acerca del lavado en nuevos escenarios, como el juego on line; e) la descripción de pautas de auditoría aplicables al uso de las tecnologías de la información y las comunicaciones (TICs) en la prevención, considerando que se quiera implementar una futura certificación orientada a la calidad de las políticas adoptadas.

Todos estos aportes constituyen una base fundamental para la definición e implementación de marcos de referencia para la certificación de cuál es el nivel de una entidad de juegos de azar con respecto a sus políticas de prevención. Por este motivo, esta tesis realiza un aporte que las organizaciones del sector de juego de azar pueden aprovechar para definir sus propias políticas y acciones en la prevención del lavado de activos. 
Las primeras 40 Recomendaciones del Grupo de Acción Financiera Internacional (GAFI) fueron redactadas en el año 1990. En esa oportunidad el objetivo era prevenir el lavado de activos proveniente del tráfico ilícito de drogas. En el año 1996, estas recomendaciones fueron modificadas ante un nuevo panorama del lavado y la necesidad de incorporar otros delitos. Las modificaciones posteriores, ocurridas luego del ataque a las Torres Gemelas en octubre de 2001, en 2003, y posteriormente en el 2008, están directamente relacionadas con el objetivo de prevenir el financiamiento de actos y organizaciones terroristas. Por último, en febrero de 2012 se unificaron las 40 Recomendaciones y las IX Recomendaciones Especiales. El espectro de las mismas ahora incluye el lavado de activos, la financiación del terrorismo y a la proliferación de armas de destrucción masiva.

Esta "evolución" o esta continuidad en la actualización de las recomendaciones, evidencia la necesidad de adaptarse a nuevos escenarios que generan nuevas tipologías de lavado. En particular, el ambiente del juego de azar, por su característica de generar un gran movimiento de dinero, sumado a la dificultad de identificar al jugador al momento de ganar un premio es un contexto que se presta al lavado.

Como antecedentes de experiencias previas en este tema, si bien desde el año 2003 participo en auditorías tecnológicas, entre ellas las que se llevaron a cabo en el contexto del convenio entre la Universidad Nacional de La Plata (UNLP) y el Instituto Provincial de Lotería y Casinos de la Provincia de Buenos Aires (IPLYC), es en el año 2005 cuando comienzo a interesarme en la problemática del lavado de activos. Fue en ese año, cuando junto con otros profesionales de la UNLP, obtuvimos la certificación FIBA/AML". Debo adjudicar esa "visión" al Director del Centro Superior del Procesamiento de la Información (CeSPI), Lic. Francisco Javier Díaz. Lo que para mí era un esfuerzo de dedicación casi inexplicable, con el tiempo fue absolutamente justificado. El lavado de activos era un tema de interés internacional y la problemática había comenzado a preocupar a directivos del sector de juegos de azar. Este fue el comienzo de varias iniciativas en las que participé desde el análisis de la aplicación de la tecnología en diferentes escenarios, orientado a la prevención y a la detección del lavado de activos.

Como parte de mis trabajos, me interesé por la metodología, las técnicas, el uso de las TICs, la aplicación de los estándares y buenas prácticas de la seguridad de los sistemas de información e informática. Parte de mi experiencia proviene de haber colaborado con la Comisión Antilavado de Activos de la Corporación Iberoamericana de Loterías y Apuestas de Estado (CIBELAE) en representación de la Universidad Nacional de La Plata (UNLP), en la definición de un Marco de Prevención. Esta acción por parte de la

\footnotetext{
${ }^{1}$ Florida International Bankers Association (FIBA)/Anti Money Laundering (AML), certificación de FIBA en asociación con Florida International University (FIU).
} 
UNLP es parte de una política de compromiso con el Juego Responsable, que se viabiliza mediante diferentes esfuerzos ${ }^{2}$.

Para dar ejemplos de mis contribuciones en la temática, diserté en eventos organizados por la Asociación de Loterías Estatales Argentinas (ALEA), la Corporación Iberoamericana de Loterías y Apuestas de Estado (CIBELAE), y la UNLP, compartiendo espacios con representantes de la Unidad de Información Financiera (UIF), United Nations Office on Drugs and Crime (UNODC), GAFILAT, INTERPOL, y en eventos internacionales como Brasilian Gaming Congress, o el Seminario Internacional de Juego en Cartagena de Indias, Colombia.

A medida que avancé en mis trabajos, tomé verdadera dimensión de lo que estaba investigando. El tema debe ir más allá de las metodologías y las técnicas, ya que se debe estudiar e investigar acerca de la proveniencia de esos fondos ilegales: la extorsión, el secuestro, el narcotráfico, la trata de personas... toda la miseria que mediante la complicidad de muchos agobia a gran parte de la humanidad.

Una investigación surge de una idea. Esa idea, alimentada por varios colegas con quienes compartí congresos y reuniones, era si se podía definir un modelo en base a políticas anti-lavado con pautas para que las organizaciones de juego de azar, independientemente del país de residencia, lo puedan aplicar. Por eso, este trabajo de tesis trata acerca del establecimiento de políticas de prevención de lavado de activos específicas del sector de juegos de azar, su relación con otros marcos y recomendaciones internacionales, y su aplicación. Asimismo, propone un conjunto de elementos para la evaluación de la madurez de una institución con respecto a la prevención, y pautas de auditoría. Este conjunto se enmarca en un Modelo de Gestión para la Prevención. A modo de aclaración, en este trabajo de tesis se aborda el tema del lavado de activos, no el de financiamiento al terrorismo, lo que se llama en algunos textos "lavado inverso".

La propuesta de esta temática para el trabajo de tesis cristaliza una anhelada obsesión: ofrecer una contribución real, con la esperanza que este trabajo aporte de alguna manera, por mínima que sea, a prevenir el lavado de activos, y, en cierto modo, complicar la ejecución del delito precedente.

${ }^{2}$ http://unlp.edu.ar/articulo/2013/9/3/seminario_lavado_de activos septiembre 2013, http://www.unlp.edu.ar/articulo/2007/9/14/la unlp principal organismo certificador de tragamonedas de sudamerica, http://www.eldia.com/la-ciudad/sellan-un-acuerdo-que-apunta-a-prevenir-la-ludopatia$\underline{111126}$, http://movil.eldia.com/la-ciudad/informatica-crea-un-sistema-de-control-para-los-juegos-de-azar107530 , 


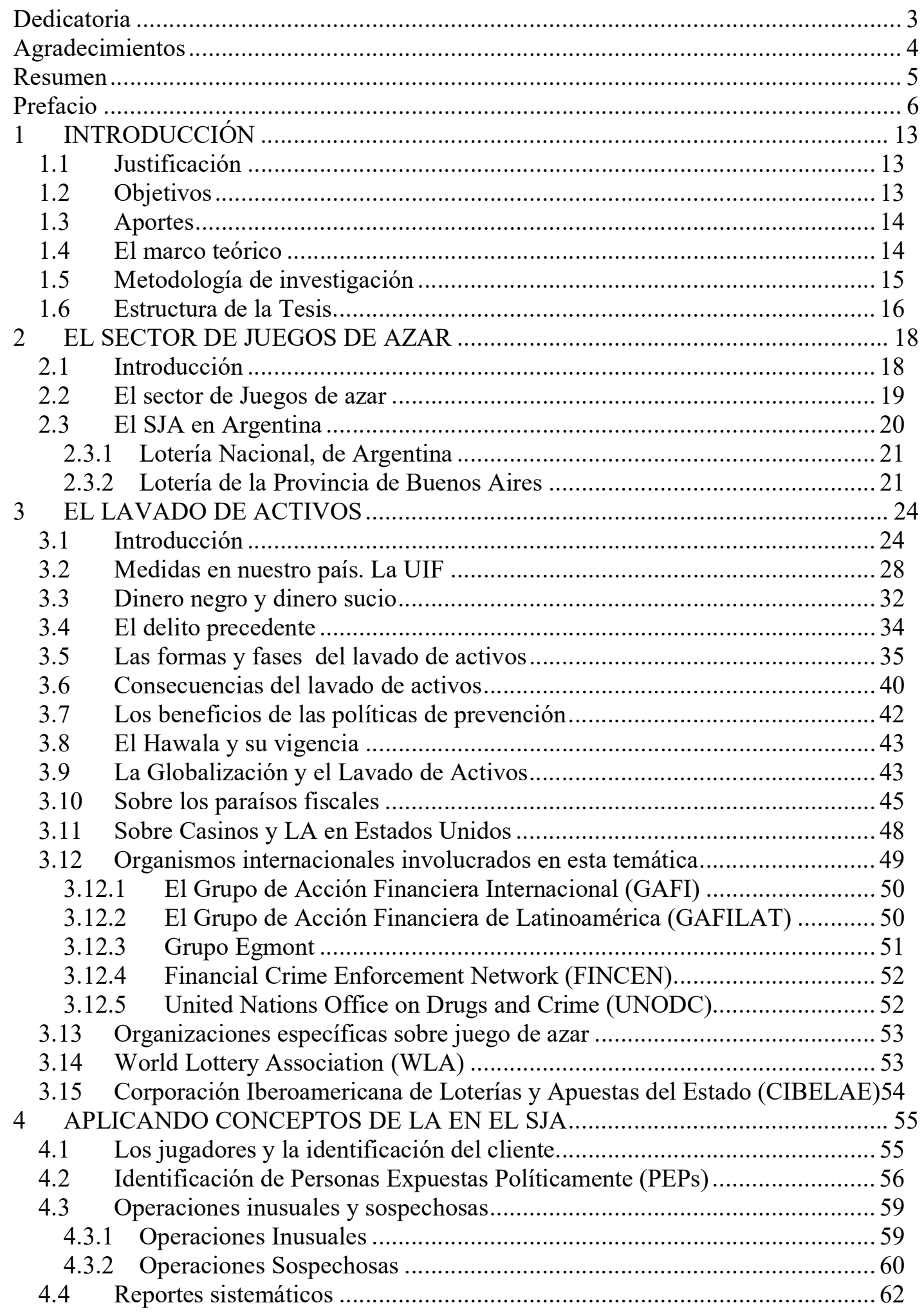




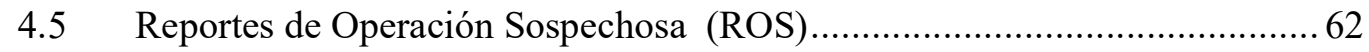

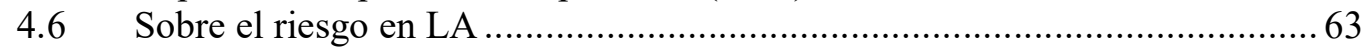

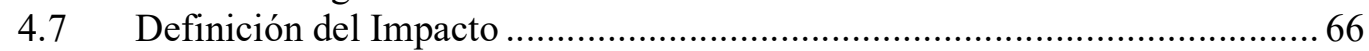

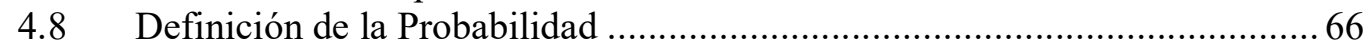

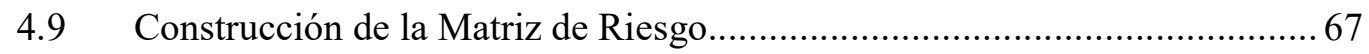

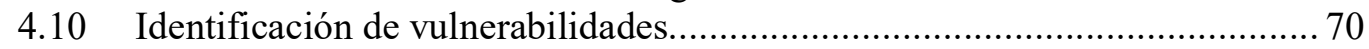

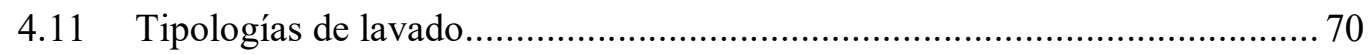

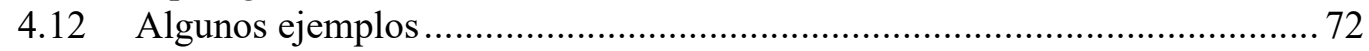

4.13 El rol de las Tecnologías de la Información y las Comunicaciones (TIC)....74

5 JUSTIFICACIÓN DE LA DEFINICIÓN DE UN MODELO DE GESTIÓN DE

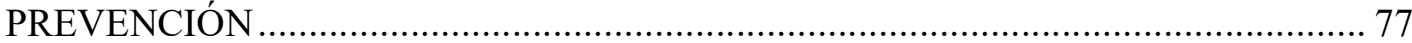

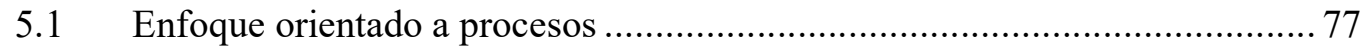

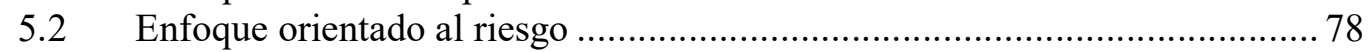

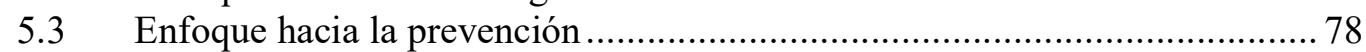

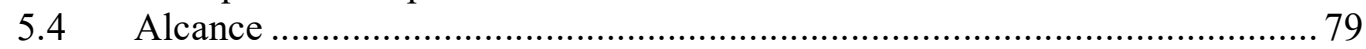

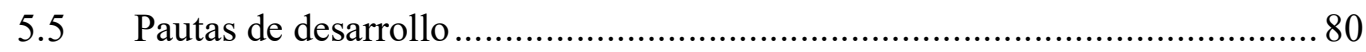

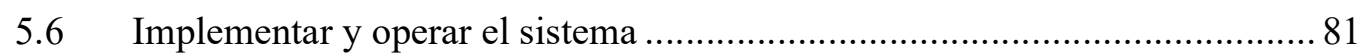

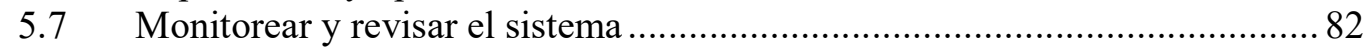

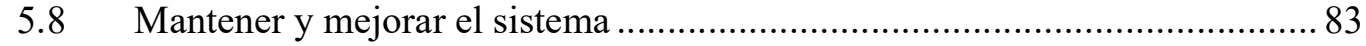

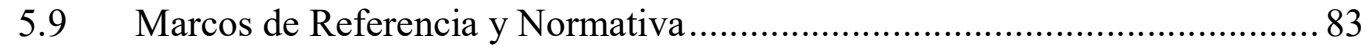

5.9.1 Marcos orientados a Juego Responsable (JR) ..................................... 84

5.9.2 Marco de evaluación de RSC y Gestión Responsable de CIBELAE.........85

5.9.3 Marco de Juego Responsable de la WLA ........................................ 85

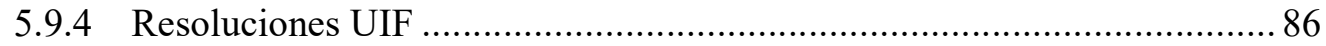

5.10 Discusión y validación de este modelo....................................................... 90

6 PAUTAS PARA EL DESARROLLO DEL SISTEMA DE GESTIÓN ................... 92

6.1 Facilitadores del proceso de desarrollo ..................................................... 92

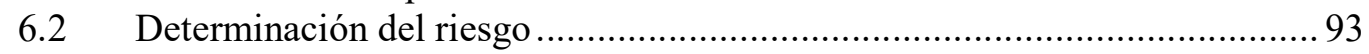

6.3 Formalización y estandarización de los procesos PLA ............................... 94

6.4 Definición de estructura organizacional ..................................................95

6.5 Tratamiento de la información y documentación...................................... 95

6.6 Capacitación y concientización de empleados y público en general...............95

6.7 Control, Monitoreo y Auditoría …............................................................ 95

6.8 Definición e implementación de políticas de debida diligencia ...................96

6.9 Utilización efectiva de recursos tecnológicos ........................................... 96

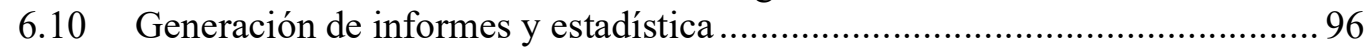

6.11 Interacción con otras organizaciones y organismos competentes..................96

7 PAUTAS DE IMPLEMENTACIÓN DEL MODELO ….................................... 97

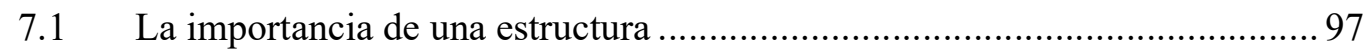

7.2 El Oficial de Cumplimiento ................................................................ 98

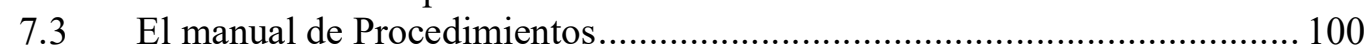

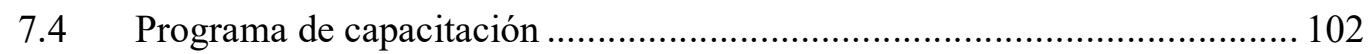

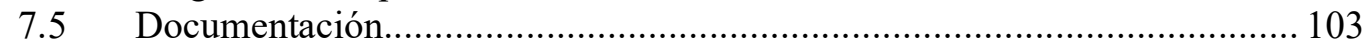

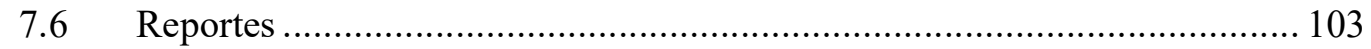

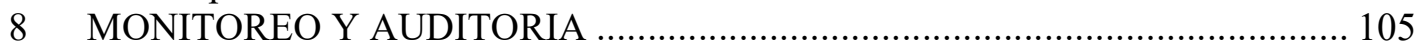

8.1 El monitoreo como promotor de la mejora ............................................ 105

8.2 Caso de análisis: auditoría en el uso efectivo de los recursos tecnológicos . 105 
9 EVALUACIÓN DEL MODELO MEDIANTE NIVELES DE MADUREZ ......... 111

9.1 El nivel de madurez como herramienta de evaluación ............................... 111

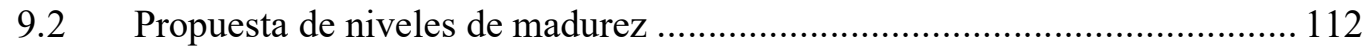

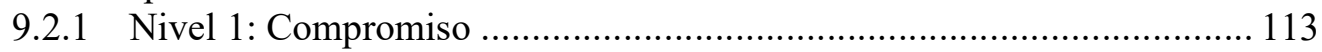

9.2.2 Nivel 2: Conocimiento del contexto y planificación ............................. 113

9.2.3 Nivel 3: Implementación del plan elaborado ..................................... 114

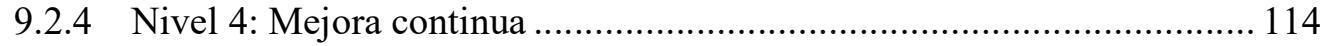

9.3 Requisitos para la determinación del nivel de madurez ........................... 114

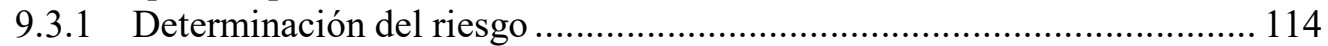

9.3.2 Formalización y estandarización de los procesos PLA .......................... 116

9.3.3 Definición de Estructura Organizacional............................................ 118

9.3.4 Tratamiento de la información y documentación.................................. 120

9.3.5 Capacitación y concientización de empleados y público en general........ 124

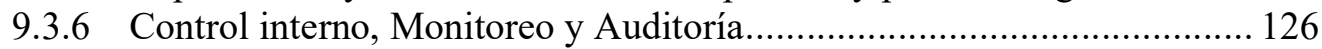

9.3.7 Definición e implementación de Políticas de Debida diligencia.............. 129

9.3.8 Utilización efectiva de Recursos tecnológicos.................................... 132

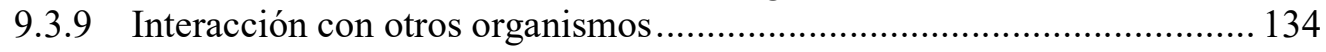

9.3.10 Generación de Informes y estadística ............................................ 137

9.3.11 Determinación del nivel general de madurez de PLA ........................ 139

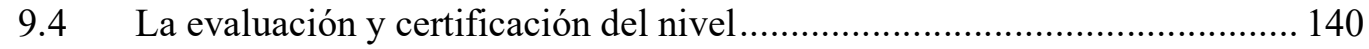

10 LAS TENDENCIAS EN EL PROCESO DE MEJORA.................................... 142

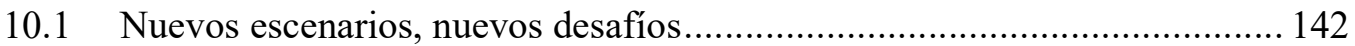

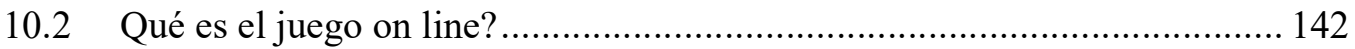

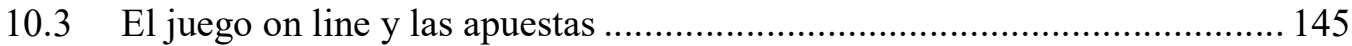

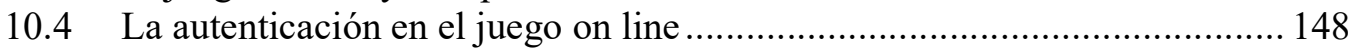

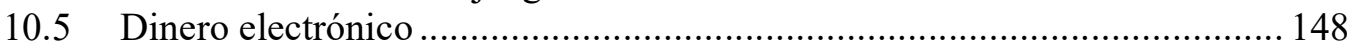

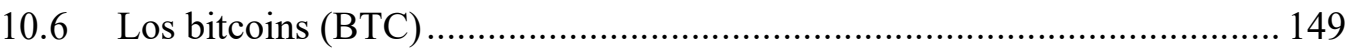

10.7 Uso de dinero electrónico en el juego on line ......................................... 152

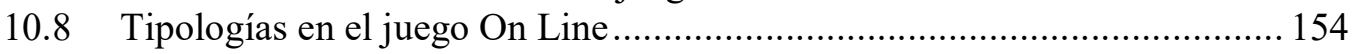

10.9 Buenas prácticas para juego remoto responsable .................................. 156

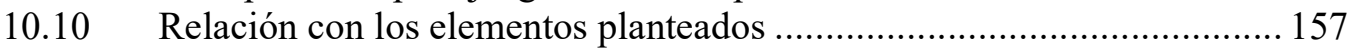

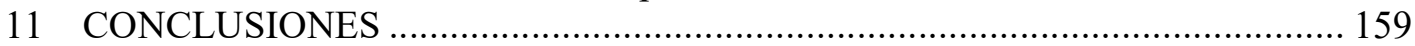

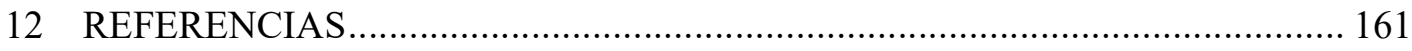

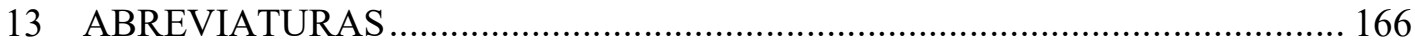

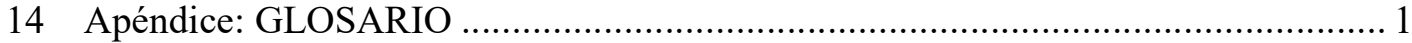




\section{LISTA DE TABLAS}

Tabla 1 - Clasificación de los juegos de azar según Naciones Unidas ....................... 19

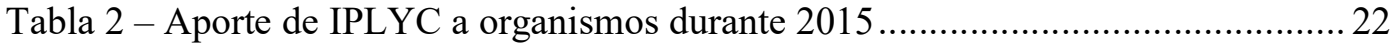

Tabla 3 - Lista de territorios comprometidos con mejorar la transparencia..................46

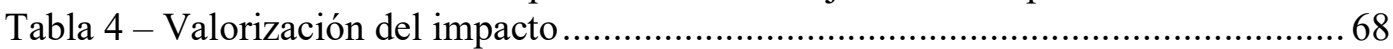

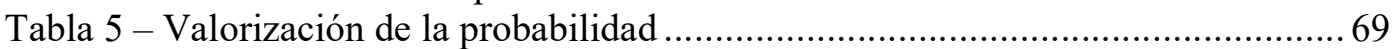

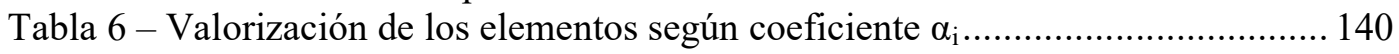




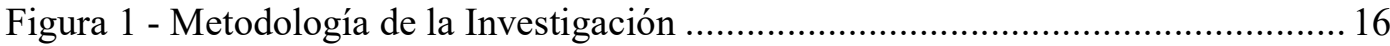

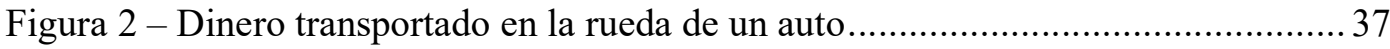

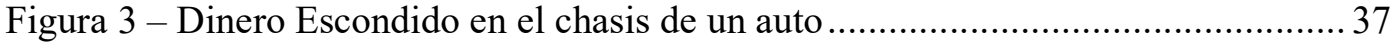

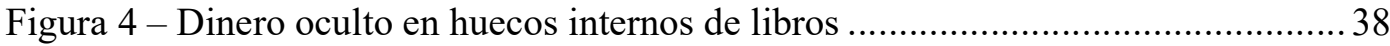

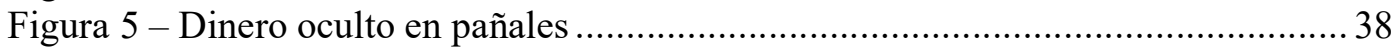

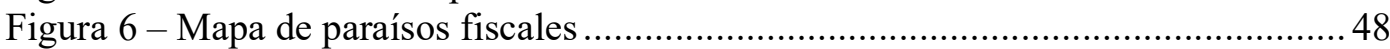

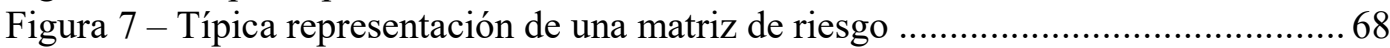

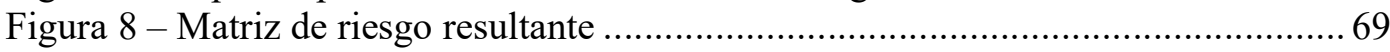

Figura 9 - Sitio en Internet de Microgaming ...................................................... 143

Figura 10 - Pantalla inicial del sitio ARgenBTC .............................................. 151

Figura 11 - Resultado de la búsqueda "bitcoin” en Mercado Libre, Argentina............ 151

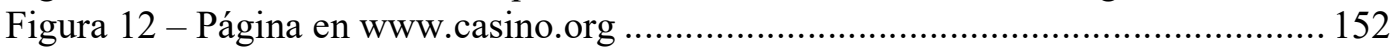

Figura 13 - Página de valorización de casinos por uso de bitcoins........................... 153

Figura 14 - Interacción de jugadores legales e ilegales en un sitio de póker on line... 155

Figura 15 - Control remoto de jugadores en póker on line..................................... 156 


\section{INTRODUCCIÓN}

\subsection{Justificación}

La cantidad de dinero que generan las actividades delictivas es de dimensiones exorbitantes. Pero más allá del dinero en sí y las consecuencias económicas, financieras y sociales, la posibilidad de "limpiarlo" o "blanquearlo" habilita la ejecución de los delitos precedentes y el consecuente crecimiento si no se establecen medidas para minimizar este flagelo. Por este motivo, existen organismos reguladores que con más o menos exigencia establecen normas y prácticas para minimizar su ocurrencia. Sin embargo, cada país debe definir sus propias leyes y regulaciones. La falta de ellas no sólo perjudica a un país sino al conjunto.

Este trabajo analiza y propone un modelo de gestión para la prevención de lavado de dinero que sea aplicable en cualquier organización de juegos de azar, y un conjunto de herramientas para evaluar dicha gestión. La importancia de este modelo radica en que es independiente de las regulaciones existentes en el país. Además, se analizan potenciales amenazas promovidas en el marco de la adopción de nuevas TICs, como es la participación remota en juegos de azar, conocido cono juego on line, y el uso del dinero electrónico para apuestas y cobro de premios.

La propuesta de definir un modelo de gestión es construir un marco de referencia para la definición, desarrollo, implementación de acciones en el contexto de políticas de prevención. Esta prevención se aborda desde la organización, la estructura, los roles y responsabilidades, la formación adecuada de los recursos humanos, la interacción con instituciones similares y organismos nacionales e internacionales.

\subsection{Objetivos}

A continuación, se explica el objetivo general y los objetivos específicos de esta tesis. El objetivo general es elaborar un modelo de gestión para formalizar un marco de prevención del lavado de activos en el sector de juegos de azar, aplicable en cualquier país, que no se base en una regulación determinada sino en las tipologías de juego.

Como objetivos específicos se definen:

- Investigar acerca del lavado de dinero en el sector de juegos de azar, los diferentes escenarios y tipologías, analizando diferentes marcos y guías existentes y documentos producidos por organismos nacionales e internacionales y las consecuencias de este delito.

- Proponer y justificar un marco conceptual que identifique los elementos sobre los cuáles definir las pautas de prevención.

- Establecer un modelo de madurez para que cada organización puede definir cuál es su situación actual.

- Investigar nuevas formas de delito mediante posibilidades que ofrece la tecnología. 
Un objetivo no formalizado pero implícito es dar a conocer y colaborar en la concientización acerca de este problema. En el transcurso del trabajo se analizarán distintos escenarios y tipologías de lavado, y se reconocerán distintos tipos de involucrados y su responsabilidad. En algunos casos, la participación de individuos (lavadores) en la técnica elegida de lavado puede ser consciente, es decir, con conocimiento del acto y sus consecuencias. Sin embargo, también pueden verse involucrados individuos que se prestan al delito sin saberlo, por ejemplo al permitir a una compra de premios, o el uso de su tarjetas de crédito robada para ser utilizada en apuestas on line (robo de identidad).

\subsection{Aportes}

El aporte de esta tesis se mide en función del cumplimiento de los objetivos definidos. En particular, los aportes incluyen:

- la definición de un modelo factible y aplicable a corto plazo de políticas y acciones de prevención de lavado de activos en el sector de juego de azar

- la definición de un marco conceptual que incluye elementos claves en la definición de políticas de prevención de lavado de activos en el sector de juego de azar

- la definición de una metodología de análisis de riesgo de lavado de activos en el sector;

- análisis de la situación acerca del lavado en nuevos escenarios, como el juego on line;

- descripción de pautas de auditoría aplicables al uso de las tecnologías de la información y las comunicaciones (TICs) en la prevención, considerando que se quiera implementar una futura certificación orientada a la calidad de las políticas adoptadas.

\subsection{El marco teórico}

Este trabajo de investigación está sustentado teóricamente por el análisis de diversas fuentes: marcos referenciales, recomendaciones internacionales, artículos publicados y presentados en congresos, y antecedentes expuestos en foros que se ocupan de esta temática. También se analizan y refieren normativas propias y extranjeras. En particular, existen en la actualidad distintos marcos referenciales orientados al juego responsable que aportan organismos como CIBELAE (Corporación Iberoamericana de Loterías y Apuestas de Estado (CIBELAE), 2011), WLA (Word Lottery Association (WLA), 2012) y otros involucrados. 
Adicionalmente, las tipologías de lavado de dinero en el juego adquieren día a día nuevas modalidades ya sea por la incorporación de nuevos juegos sobre diferentes soportes, o por la aparición de contextos emergentes que desafían a los delincuentes en pergeñar otro tipo de técnicas. Por lo tanto, se hace necesario acudir a publicaciones recientes que se encuentran en Internet, y por eso, artículos y noticias publicadas en la Web son también referenciadas en este trabajo.

\subsection{Metodología de investigación}

Este trabajo comienza con una etapa descriptiva de los juegos de azar y de la problemática del lavado de dinero, explicando cómo se manifiesta el lavado en el ámbito de los juegos de azar. Luego, en base a marcos, regulaciones y recomendaciones internacionales existentes, se propone un modelo de gestión para la prevención del lavado de activos.

La metodología adoptada en este trabajo se orienta a lo que Danke (Dankhe, 1976) dio en llamar estudio correlacional. El autor define cuatro tipos de estudios: exploratorios, descriptivos, correlacionales y experimental. (Hernández, Fernández, \& Baptista, 1991) prefiere utilizar el término explicativo en lugar de experimental.

En particular, la metodología consiste de las siguientes etapas:

- Realizar un análisis de contexto del lavado de dinero en general y en el sector de juegos de azar en particular

- Analizar los marcos referenciales, guías y recomendaciones existentes.

- Definir un marco conceptual que incluya los elementos clave para la definición de un modelo de prevención

- Proponer un modelo de madurez para determinar el estado de situación de una organización con respecto a sus políticas de prevención

- Definir pautas para determinar el grado de madurez para cada elemento definido

- Analizar nuevos escenarios y potenciales amenazas considerando las nuevas tecnologías de información y comunicación. 


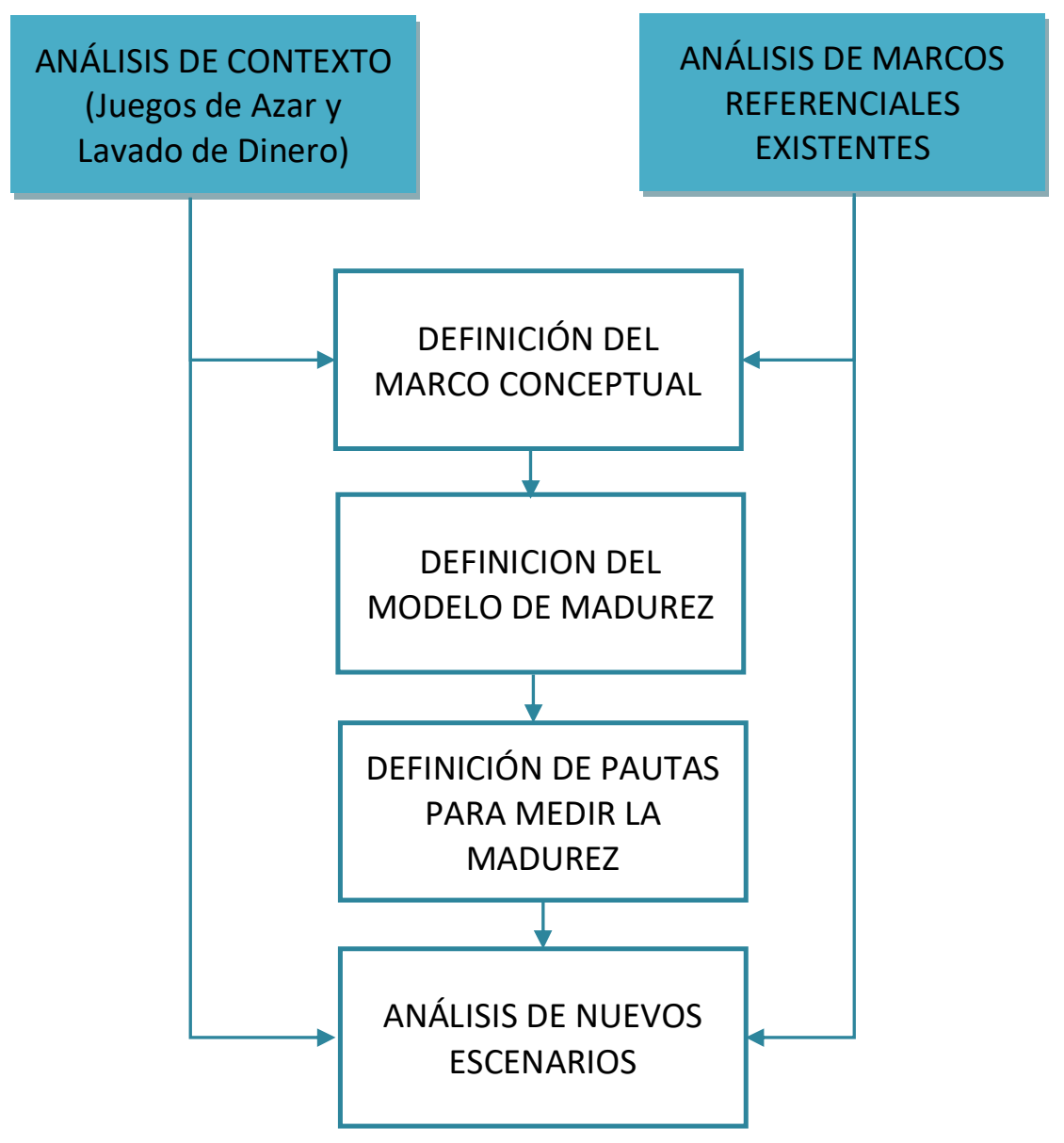

Figura 1 - Metodología de la Investigación

\subsection{Estructura de la Tesis}

En los capítulos siguientes se demostrará la existencia, la cruda realidad del lavado de activos y sus consecuencias. Específicamente se analizará en el sector de juegos de azar. El lavado de activos es un delito global, como se da en llamar a aquellas situaciones que trascienden fronteras. Distintos organismos internacionales publican recomendaciones, guías y buenas prácticas.

El Capítulo 2, "El Sector de juegos de azar", presenta una introducción al sector en nuestro país, con una breve descripción de los organismos reguladores.

El capítulo 3, "El lavado de activos", está orientado al desarrollo de los conceptos relacionados con la temática. Se destaca el carácter de global y se enumeran un conjunto 
de organismos internacionales que definen pautas y recomendaciones para la determinación de políticas propias. También se indican organismos del sector de juegos de azar, que aportan a la problemática planteada desde la generación de guías y marcos de Juego responsable.

El capítulo 4, "Aplicando conceptos de lavado de activos en el Sector de Juegos de Azar", adapta los conceptos generales al sector del juego. Se define el concepto de tipología de juego, que será fundamental en la orientación del modelo que se propone. Se plantea la gestión de riesgo como una herramienta de conocimiento del contexto y determinación de vulnerabilidades y amenazas, el impacto y la probabilidad de ocurrencia. Se analiza el aporte de las Tecnologías de la Información y las Comunicaciones de manera adecuada para centralizar, almacenar y proteger la seguridad de la información, como bien lo requiere la Recomendación 29 del GAFI. Su uso en el sector del juego crea nuevos escenarios del que emergen vulnerabilidades y amenazas que requieren medidas efectivas.

El capítulo 5, "Justificación de la definición de un modelo de gestión de prevención", alinea el modelo de gestión de prevención a modelos existentes desde la seguridad y la calidad y lo adapta al ciclo PDCA (Pla-Do-Check-Act) de Deming (Edward Deming). Se plantean diferentes enfoques, define el alcance, se referencian marcos existentes orientados al juego responsable y resoluciones UIF de Argentina. Por último se justifica el modelo mediante la validación realizada por un organismo del sector.

El capítulo 6, "pautas para el desarrollo del sistema de gestión", es el inicio del aporte original de este trabajo: la definición y justificación de 10 elementos facilitadores del desarrollo de las políticas de prevención.

El capítulo 7, "Pautas de implementación del modelo", valoriza un conjunto de prácticas que se consideran soporte para el desarrollo planteado en el Capítulo 6.

El capítulo 8, "Monitoreo y Auditoria", justifica el monitoreo como un proceso fundamental hacia la mejora. Como caso de análisis, se definen pautas de auditoría en el uso efectivo de los recursos tecnológicos.

El capítulo 9, "Evaluación del modelo mediante niveles de madurez", constituye otro de los importantes aportes de este trabajo de tesis como es la determinación de niveles de madurez en la definición e implementación de políticas de prevención, y la posibilidad de definir un proceso de certificación en base a los elementos facilitadores planteados en el Capítulo 6.

El capítulo 10, "Las tendencias en el proceso de mejora", describe el juego on line como práctica cada vez más adoptada, las tipologías, el uso de dinero electrónico y las nuevas modalidades de apuestas. 
En este capítulo se enuncian algunas características del Sector de Juegos de Azar en Argentina. Se describen los reguladores del Sector desde el Gobierno.

\subsection{Introducción}

El Sector de Juegos de Azar (SJA, de ahora en más) se considera un ámbito vulnerable al lavado de activos (LA) ${ }^{3}$. Lo habilitan para ello la frecuencia y volumen de transacciones que se llevan a cabo diariamente. Esta vulnerabilidad se acentúa en la dinámica de interacción con el jugador, que dificulta determinar su identidad o conocer el origen de los fondos apostados.

En el caso de los Casinos, si bien no son instituciones financieras, en algunos de ellos se realizan actividades similares a las que se llevan a cabo en aquellas instituciones: se pueden aceptar fondos a cuenta, cambio de moneda, cambio de moneda extranjera, almacenar valores, dar facilidades de dinero mediante tarjetas de crédito, uso de cheques, depósito en cajas de seguridad, etc. En algunos casos estos servicios son provistos las 24 horas del día (Grupo de Acción Financiera Internacional, 2009).

En la terminología relacionada con la Prevención del Lavado de Activos (PLA) empleado por Grupo de Acción Financiera Internacional ${ }^{4}$ (GAFI) y organismos similares, el SJA se considera dentro de lo que se define como actividades y profesiones no financieras designadas (APNFD). Las APNFD son institutos no financieros que están en riego de lavado de activos o financiamiento del terrorismo. Se trata de profesiones y actividades que tradicionalmente tratan con clientes que buscan el anonimato y suelen pagar en efectivo: casinos, agentes inmobiliarios, comerciantes de piedras preciosas y metales preciosos, notarios, abogados, contadores públicos, proveedores de servicios societarios y de fideicomisos (GAFISUD, 2003).

El aumento de obligaciones para el SJA incorporadas en la revisión 2003 de las recomendaciones GAFI, evidencia su vulnerabilidad ante las prácticas de LA (Grupo de Acción Financiera Internacional, 2012).

Los marcos referenciales orientados al juego responsable están alineados principalmente a políticas de Responsabilidad Social Corporativa (RSC) o a la Responsabilidad Social Empresarial (RSE).

Adicionalmente a los marcos referenciales, prevenir el lavado de activos demanda la participación responsable de todos los involucrados: las casas de juego de azar, los

\footnotetext{
${ }^{3}$ En este trabajo se consideran sinónimos "lavado de dinero", "lavado de activos". No se utiliza como sinónimo "blanqueo de capitales" para no confundir con el proyecto llamado de "sinceramiento impositivo" en nuestro país.

${ }^{4}$ GAFI, en inglés Financial Action Task Force (FATF). En este trabajo se usará la sigla en español, GAFI.
} 
reguladores, operadores, jugadores. Todas estas pautas de prevención estarían dentro de lo que se da en llamar juego responsable.

\subsection{El sector de Juegos de azar}

Los juegos de azar son juegos en los cuales las posibilidades de ganar o perder no dependen exclusivamente de la habilidad del jugador, sino que interviene también el azar. La mayoría de ellos son también juegos de apuestas, cuyos premios están determinados por la probabilidad estadística de acertar la combinación elegida; mientras menores sean las probabilidades de obtener la combinación correcta, más grande es el premio. (Wikipedia, n.d.)

El fin de una organización del SJA es proporcionar entretenimiento, $y$, en ese marco, establecer un conjunto de actividades. Son juegos de azar, entre otros, la ruleta, la lotería, las apuestas de caballos, las máquinas tragamonedas, los dados, el bingo, las apuestas a resultados deportivos, las rifas, las quinielas.

Según la División de Estadísticas del Departamento de Asuntos Económicos y Sociales de Naciones Unidas, el juego de azar es un entretenimiento o una actividad recreativa. Según su Manual de Clasificación Industrial Internacional Uniforme (CIIU) de todas las actividades económicas, los juegos de azar figuran en la sección $\mathrm{R}$ que agrupa "Actividades artísticas, de entretenimiento y recreativas", y bajo el código R 9200,

"Actividades de juegos de azar y apuestas" (United Nations, 2006).

La clasificación se muestra enTabla 1:

\section{CATEGORÍA: R - ARTS, ENTERTAINMENT AND RECREATION}

\section{SUB-CATEGORÍAS:}

90 - Creative, arts and entertainment activities

91 - Libraries, archives, museums and other cultural activities

92 - Gambling and betting activities

93 - Sports activities and amusement and recreation activities

Tabla 1 - Clasificación de los juegos de azar según Naciones Unidas

En el SJA intervienen reguladores, operadores, proveedores (de máquinas, de juegos, entre otros), y jugadores. Los reguladores de juego administran y regulan las actividades vinculadas con el SJA con el objetivo de controlar que desarrolle una gestión transparente y eficiente que integre aspectos sociales, económicos y medioambientales.

Los operadores son aquéllos quienes han obtenido título habilitante para el desarrollo de actividades de juego. Deben cumplir requisitos jurídicos y técnicos, que se definen por Ley para proteger al jugador y los objetivos planteados por el regulador.

Las organizaciones se constituyen para satisfacer necesidades de la sociedad y sus ciudadanos. En ese objetivo se construye un cotidiano que involucra personas y recursos. No obstante la honorabilidad de sus intenciones, la organización puede, sin conocimiento o intención, prestarse a prácticas que deriven en delitos. 


\subsection{El SJA en Argentina}

(Administración Federal de Ingresos Públicos, 2013), define, en su artículo 2, qué se considera juegos de azar y/o apuestas:

“...todo contrato de juego que se realice a través de procedimientos manuales, mecánicos, electromecánicos, electrónicos, informáticos y/o cualquier otro medio, cuyo resultado dependa en forma exclusiva o preponderante del azar, en la que se participe emitiendo apuestas en dinero o valores, con la finalidad de obtener premios (2.1.) de cualquier especie y naturaleza, desarrollados en salas de juegos (2.2.), a través de portales o sitios virtuales y/o cualquier otra modalidad mediante la cual se perfeccionen las apuestas (vgr. ${ }^{5}$ telefonía fija o móvil, etc.)..."

El artículo 75 de la Constitución Nacional expresa que “... La regulación de los juegos de azar en la Argentina no está incluida dentro de las facultades del Poder Legislativo Nacional...". Esto se ratifica con un fallo dictado por la Corte Suprema de Justicia el 31 de mayo de 1999, cuando resolvió que el régimen en la materia (incluyendo loterías, casinos, bingos y máquinas tragamonedas) y sus posibles infracciones no son una cuestión federal.

\section{La regulación de los juegos de azar en la Argentina es facultad de cada provincia.}

El artículo 37 de la Constitución de la Provincia de Buenos Aires de 1994, establece que "la provincia se reserva, como derecho no delegado al Estado Federal, la administración de todos los casinos y salas de juegos”.

El esquema más extendido es el de concesiones a privados a cambio de un canon y/o una serie de impuestos.

Según lo indicado en el Mapa de Juego ${ }^{6}$ elaborado por la Asociación de Loterías Estatales de Argentina (ALEA):

- entre 2013 y 2014 la rentabilidad bruta de las loterías creció un 25,70\%;

- los aportes de los organismos reguladores de los juegos de azar crecieron un $28 \%$ respecto del año anterior;

- en 2013, la cifra total de los fondos transferidos a los estados provinciales fue $\$ 7100$ millones y en 2014 ascendió a $\$ 9100$ millones;

- la cantidad de puntos de venta incluyendo agencias, subagencias y ambulantes es 25.093;

- se generan puestos y fuentes de trabajo: 11.500 puestos de trabajo directo en los organismos reguladores de todo el país, 70.000 puestos de trabajo en agencias y puntos

\footnotetext{
${ }^{5}$ vgr: abreviatura de verbigracia

${ }^{6}$ El Mapa de Juego es una investigación actualizada de manera semestral por el Área de Estadística de ALEA
} 
de venta, 159.000 fuentes de empleo indirecto en salas y empresas del sector. Durante el 2014 se totalizaron 240.500 fuentes de trabajo.

A continuación se describen dos organismos del sector: Lotería Nacional y Lotería de la provincia de Buenos Aires.

\subsubsection{Lotería Nacional, de Argentina}

En Argentina, Lotería Nacional fue creada en 1893. Administra y regula el mercado de juegos de azar y comercializa en forma directa productos tales como La Quiniela, La Grande Nacional, Quiniela Poceada, Loto, Loto 5, PRODE, La Solidaria, Cash, Turfito. También comercializa productos de otras instituciones provinciales mediante convenios, como es el caso del Quini 6, Toto Bingo, Telekino, etc. Está presidida por un Directorio al que responde una estructura de gerencias y asesorías ${ }^{7}$.

El principal beneficiario del producto de las actividades recreativas es el Ministerio de Desarrollo Social, aunque también reciben beneficios Gobierno de la Ciudad de Buenos Aires, las Loterías de Provincia, la Asociación de Loterías Estatales de Argentina, la Secretaría de Deportes, la Asociación de Fútbol Argentino, el Ministerio de Educación, el Ministerio de Agricultura, Ganadería y Pesca, entre otros.

Lotería Nacional mantiene un conjunto de políticas en el marco de la prevención del lavado de activos.En el año 2003, a partir de la sanción de la primera resolución de la UIF para el Sector Juegos de azar, Lotería Nacional estableció un grupo de trabajo a los fines de cumplir con las regulaciones existentes. En el 2007 se creó la Comisión Especial para la Prevención del Lavado de Activos y Financiación del Terrorismo con la misión de supervisar el cumplimiento de la normativa existente en el ámbito de Lotería Nacional. En febrero de 2009 se firmó un convenio con el Ministerio de Justicia Seguridad y Derechos Humanos para la incorporar a Lotería Nacional a la Agenda Nacional para la Lucha contra el Lavado de Dinero y la Financiación del Terrorismo. En marzo de 2011 se creó la Unidad de Prevención de Lavado de Activos y Financiación al Terrorismo (UPLAFT).

\subsubsection{Lotería de la Provincia de Buenos Aires}

La Provincia de Buenos Aires ocupa el 2do lugar en cuanto a cantidad de salas de juegos del país y la primera en cantidad de loterías y máquinas tragamonedas.

El Instituto Provincial de Loterías y Casinos (IPLYC) es un ente independiente dedicado a la explotación y administración de los juegos de azar en el ámbito de la Provincia de Buenos Aires. Se encarga de la recaudación y control de los recursos obtenidos y de su posterior distribución en beneficio de la comunidad ${ }^{8}$. Su independencia proviene de su carácter descentralizado y autárquico.

\footnotetext{
${ }^{7}$ http://www.loteria-nacional.gov.ar/

${ }^{8} \mathrm{http}: / /$ www.loteria.gba.gov.ar/
} 
Las principales actividades se llevan a cabo mediante Agencias Oficiales, Salas de Bingo, Casinos e Hipódromos.

Los beneficiarios son, entre otros, entidades de amplia repercusión social y de acción directa sobre la comunidad. Gran parte de los recursos que se recaudan se aportan para el desarrollo de los planes sociales, la donación de órganos, la salud y la educación.

En la Tabla 2 se discrimina lo que la Lotería aportó a diferentes Organismos durante el año 2015 (extraído de la Web oficial de Lotería de la Provincia de Bs. As.).

\begin{tabular}{|l|r|}
\hline \multicolumn{1}{|c|}{ ORGANISMO } & \multicolumn{2}{c|}{ MONTO } \\
\hline Ministerio de Economía & $82.3290 .418,11$ \\
\hline Fondo de Trasplante & $49.243 .679,05$ \\
\hline Dirección de Cultura y Educación & $532.652 .483,22$ \\
\hline Ministerio de Desarrollo Social & $1.330 .392 .371,89$ \\
\hline Ministerio de Salud & $88.759 .439,84$ \\
\hline Municipios & $608.616 .087,78$ \\
\hline Policía & $952.070 .822,84$ \\
\hline Fondo Provincial de Educación & $1091.405 .365,69$ \\
\hline Fdo. de Fortalecimiento. de Prog. Social & $85.768 .539,60$ \\
\hline Ministerio de N y SP & $48.162 .355,66$ \\
\hline Fondo Especial del Teatro & $3.208 .333,37$ \\
\hline Secretaria Niñez y Adolescencia & $33.173 .995,09$ \\
\hline Total & \\
\hline
\end{tabular}

Tabla 2 - Aporte de IPLYC a organismos durante 2015

IPLyC aborda un conjunto de medidas orientadas a la prevención del lavado de activos en el juego, a saber (Instituto Provincial de Loterías y Casinos, 2013):

- determina que los titulares de permisos oficiales otorgados por el IPLYC, al momento de efectuar el pago de un premio por cuenta y orden de este Instituto cuyo monto sea superior a pesos cincuenta mil (\$50.000), deberán identificar al apostador mediante el original del documento de identidad de acuerdo a la normativa y copia para certificar con firma y sello del Agenciero, y se le exigirá completar íntegramente el Formulario Anexo a la Resolución $N^{\circ} 354 / 2013$, además del ticket ganador y copia de la validación;

- define el uso de formularios específicos, incluidos en la Resolución, para comunicar los datos citados en el párrafo anterior dentro de las veinticuatro (24) horas posteriores al pago del premio; 
- determina que semanalmente se debe enviar la información en sobre cerrado a la Vicepresidencia del Instituto, Oficial de Cumplimiento para la Prevención del Lavado de Activos y Financiación del Terrorismo;

- indica que en caso que el apostador se niegue a brindar la documentación y datos solicitados o no la tenga consigo, el pago del premio quedará pendiente hasta tanto se cumpla con lo requerido.

Esta resolución se alinea con lo indicado en(Resolución UIF Nro 199, 2011).

El artículo 24 de la Ley $\mathrm{N}^{\circ} 25.246$ fue modificado por la Ley 26.683 en su artículo 19, que establece que: “... La persona que actuando como órgano o ejecutor de una persona jurídica o la persona de existencia visible que incumpla alguna de las obligaciones ante la Unidad de Información Financiera (UIF) creada por esta ley, será sancionada con pena de multa de una (1) a diez (10) veces del valor total de los bienes u operación a los que se refiera la infracción, siempre y cuando el hecho no constituya un delito más grave..."

El Código Penal reprime con prisión de seis meses a tres años el que tras la comisión de un delito ejecutado por otro, en el que no hubiera participado: “...a) ayudare a alguien a eludir las investigaciones de la autoridad o a sustraerse a la acción de ésta..." 
En este Capítulo se presenta la problemática del lavado de activos como delito global y en crecimiento. Se aportan definiciones y referencias desde diferentes organizaciones.

Se refiere también a los organismos internacionales que aportan desde la definición de recomendaciones y la integración de las distintas Unidades de Información Financiera. Por último, se indican las organizaciones específicas sobre juegos de azar, que han definido marcos referenciales acerca de la prevención y que constituyen una referencia decisiva en este trabajo de tesis.

\subsection{Introducción}

La mayoría de los delitos económicos nacionales o globales existen desde los orígenes mismos del capitalismo y, en algunos casos, de la sociedad misma. Pero quizá nunca como ahora se han convertido en piezas constitutivas y básicas del funcionamiento de lo que puede denominarse el capitalismo criminal (Sevares, 2003).

Existen diferentes definiciones de lavado de dinero según provengan del ámbito legal, económico o social. El término "dinero" es incluso cuestionado en algunos ámbitos, que prefieren hablar de ingresos, ganancias o activos.En algunos casos se intenta definir el lavado como el acto de "tratar de esconder la fuente de proveniencia del dinero" ilegal y en otros casos se refuerza el concepto de "hacer que ese dinero aparezca como legal".

GAFI ha hecho un gran esfuerzo para definir el concepto de lavado de dinero, orientados a un estándar internacional que se alinee con las propuestas nacionales.

Según (Duyne, 2003), el término lavado de dinero proviene de cuando el gánster Al Capone hacía pasar sus ganancias obtenidas ilegalmente como producidas por sus lavanderías. Si bien la metáfora es adecuada, vale preguntarse qué significa exactamente "lavar" dinero, ganancias, activos.

En el reporte elaborado para el Ministerio de Finanzas de Australia(Unger \& Rawlings, 2006), se identifican 18 definiciones distintas sobre lavado de dinero. La clasificación se basa en tres aspectos: actividad, asunto/materia y objetivo. Por ejemplo, considérese una de las definiciones:

Lavado de dinero es el proceso por el cual los activos obtenidos o generados por actividades criminales son procesados para ocultar su origen.

La actividad está definida por la palabra proceso; la materia o asunto son "los activos obtenidos o generados por actividades criminales"; y el objetivo es "ocultar su origen".

En esta tesis se propone la siguiente definición, que se considera bastante completa: 
El Lavado de Activos es el proceso tendiente a legalizar recursos, bienes y servicios de origen delictivo tratando de ocultar dicho origen mediante su inserción en los canales económicos normales y en el circuito monetario oficial.

Argentina, Chile, Colombia, Ecuador, Guatemala, Honduras, Nicaragua, Perú, República Dominicana y Uruguay, hablan de lavado de activos. México, Panamá, Nicaragua, Estados Unidosprefieren llamarlo lavado de dinero o money laundering en el último caso; mientras que Costa Rica y Venezuela, hablan de Legitimación de Capitales; Bolivia, de Legitimación de Ganancias Ilícitas; España, de Blanqueo de Activos; Nicaragua, de Lavado de Bienes; Panamá, además de lavado de dinero, también utiliza la palabra blanqueo (de capitales o activos)("ABC antilavado. Entrenamiento virtual," n.d.).

Según el Parlamento de la Unión Europea,las siguientes actividades, realizadas intencionadamente, se considerarán lavado de activos (Ue, Parlamento, \& Del, 2015):

a) la conversión o la transferencia de bienes, a sabiendas de que dichos bienes proceden de una actividad o un hecho delictivo o de la participación en ese tipo de actividad, con el propósito de ocultar o encubrir el origen ilícito de los bienes o de ayudar a personas que estén implicadas en dicha actividad a eludir las consecuencias jurídicas de su acto;

b) la ocultación o el encubrimiento de la naturaleza, el origen, la localización, la disposición, el movimiento o la propiedad reales de bienes o de derechos sobre esos bienes, a sabiendas de que dichos bienes proceden de una actividad delictiva o de la participación en ese tipo de actividad;

c) la adquisición, posesión o utilización de bienes, a sabiendas, en el momento de la recepción de los mismos, de que proceden de una actividad delictiva o de la participación en ese tipo de actividad;

d) la participación en alguna de las acciones a que se refieren las letras a), b) y c), la asociación para cometer ese tipo de acciones, las tentativas de perpetrarlas y el hecho de ayudar, instigar o aconsejar a alguien para realizarlas o de facilitar su ejecución.

Además, la Directiva establece que se considerará que hay lavado de activos aun cuando las actividades que hayan generado los bienes que vayan a "lavarse" se hayan desarrollado en el territorio de otro Estado miembro o en el de un tercer país.

En lavado de activos s importante diferenciar el concepto de encubrir, del de disimular. Encubrir implica la acción dirigida a lograr que el crimen cometido o sus consecuencias queden impunes en cuanto no pueda ser aprehendido el criminal y no pueda ser secuestrado el botín obtenido. Si bien disimular puede ser entendido como encubrir, se diferencia toda vez que no abarca únicamente el concepto clásico del delito de encubrimiento, sino la obstrucción del descubrimiento del origen de una cosa, en el tema en análisis del origen ilícito de los bienes (Pinto \& Chevalier, 2006).

Con respecto a la financiación del terrorismo, la Directiva entiende por ello, el suministro o la recogida de fondos, por cualquier medio, de forma directa o indirecta, 
con la intención de utilizarlos o con el conocimiento de que serán utilizados, íntegramente o en parte, para la comisión de cualquiera de los delitos antes citados.

Las Naciones Unidas definen el lavado de dinero como (United Nations, 1988) ${ }^{9}$ :

"la conversión o la transferencia de bienes a sabiendas de que tales bienes proceden de algún delito, o de un acto de participación en éste, con objeto de ocultar o encubrir el origen ilícito de los bienes o de ayudar a cualquier persona que participe en la comisión del delito a eludir las consecuencias jurídicas de sus acciones, y la ocultación o el encubrimiento de la naturaleza, el origen, la ubicación, el destino, el movimiento o la propiedad reales de bienes, o de derechos relativos a tales bienes, a sabiendas de que proceden de delitos o de un acto de participación en delitos".

Asimismo, las Naciones Unidas describen el lavado de activos como (United Nations, n.d. $)^{10}$ :

“...la conversión o la transferencia de bienes, a sabiendas de que esos bienes son producto del delito, con el propósito de ocultar o disimular el origen ilícito de los bienes o ayudar a cualquier persona involucrada en la comisión del delito determinante a eludir las consecuencias jurídicas de sus actos, y como la ocultación o disimulación de la verdadera naturaleza, origen, ubicación, disposición, movimiento o propiedad de bienes o del legitimo derecho a éstos, a sabiendas de que dichos bienes son producto del delito..."

Grupo de Acción Financiera (GAFI), define el lavado de activos:

"La conversión o transferencia de propiedad, a sabiendas de que deriva de una actividad criminal, con el objeto de disfrazar u ocultar su origen ilícito o ayudar a una persona que está involucrada en la comisión del crimen a evadir las consecuencias legales de sus acciones".

El financiamiento del terrorismo es cualquier forma de acción económica, ayuda o mediación que proporcione apoyo financiero a las actividades de grupos terroristas. Aunque el objetivo principal de los grupos terroristas no es financiero, requieren fondos para llevar a cabo sus actividades, cuyo origen puede provenir de fuentes legítimas, actividades delictivas, o ambas.

La Ley 25.241, en su artículo 1, define hechos de terrorismo como:

\footnotetext{
${ }^{9}$ Esta Convención es habitualmente citada como "Convención de Viena"

${ }^{10}$ Esta Convención es habitualmente citada como "Convención de Palermo"
} 


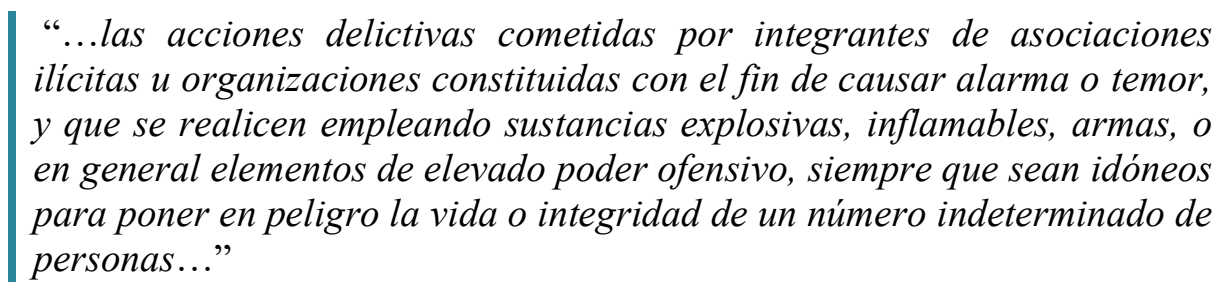

Si bien el lavado de dinero tiene características globales - lo que genera que organismos internacionales definan recomendaciones en el marco de las buenas prácticas - cada país debe establecer las medidas y procedimientos que las personas físicas o jurídicas que como actividad habitual exploten juegos de azar deben observar para prevenir, detectar y reportar los hechos, actos, operaciones u omisiones que pudieran constituir delitos de Lavado de Activos y Financiación del Terrorismo.

La creación de Unidades de Inteligencia (o Información) Financiera y otras iniciativas intenta poner límites a esta industria descomunal que involucra organizaciones no gubernamentales, multilaterales, intergubernamentales, etc. Más aun, muchos países hacen esfuerzos para evitar ser incluidos en la lista de países "no cooperativos" (Non cooperative countries and territories, NCCT) que emite GAFI.

(Morris-Cotterill, 2002)cuestiona que los análisis, reportes y recomendaciones que definían los países presentaban una marcada tendencia a citarse mutuamente, pero que a veces las reglas y buenas prácticas se superponían. Y se preguntaba por qué los países no pueden definir un conjunto de reglas unificada que no permita que quienes llevan a cabo esta actividad criminal no puedan aprovechar las grietas de leyes y regulaciones.

La actualización de las 40 recomendaciones de GAFI que se han ido publicando constituye una importante contribución hacia la unificación de prácticas, incluyendo el sector del SJA.

A pesar de los esfuerzos internacionales, algunos de los desafíos vigentes incluyen: ¿cómo medir el lavado de dinero? ¿En qué se basa la estimación que realizan fuentes internacionales? ¿Qué modelo de estimación se aplica?

Las personas físicas o jurídicas que como actividad habitual exploten juegos de azar deben establecer un conjunto de medidas orientadas para prevenir, detectar y reportar los hechos, actos, operaciones u omisiones que puedan provenir de la comisión de los delitos de Lavado de Activos y Financiación del Terrorismo. En particular, en el marco de la revisión de las 40 Recomendaciones que se realizó en el año 2003, se extendió en la Recomendación 12 el catálogo de los sujetos obligados, incorporando, entre otros, a los Casinos.

Un sujeto obligado es una entidad o individuo obligado a cumplir con las regulaciones antilavado de dinero y que están bajo la supervisión y regulación de alguna entidad estatal.

Son sujetos obligados, entre otros:

- Bancos y entidades financieras

- Casas de cambio de moneda y remesadoras 
- Empresas del sector bursátil

- Comerciantes de metales preciosos, joyas, autos y botes

- Casinos y salas de juego

- Compañías de seguros

Se implementó también la exigencia de identificar y conocer a los clientes, aplicar medidas de debida diligencia y reportar transacciones sospechosas a la UIF.

Las Actividades y Profesiones No-Financieras Designadas (APNFD) fueron identificadas por su contacto con flujos de fondos importantes sea en forma de capital de inversión, precios de mercadería o inmuebles, puestas en juegos o premios ganadores.

\subsection{Medidas en nuestro país. La UIF}

A continuación, se detallan las leyes y regulaciones nacionales relacionadas con el lavado de dinero.

La ley 20.771 fue el primer avance de nuestra legislación en lo relacionado con reprimir el delito de consumo y tráfico de drogas(Camerini, 2010). En el art. 3 refiere a prisión de cinco a quince años y multa de cinco mil a un millón de pesos para el que organice o financie cualquiera de las actividades ilícitas a las que se refiere el art. 2. Se puede inferir que en esa legislación se tuvo presente, en cierto modo, el lavado de dinero, considerando que la producción de estupefacientes podía estar relacionada con una organización, con mecanismos de financiamiento.

Con la sanción de ley 23.468 se sustituyeron algunos artículos y se determinaron nuevos conceptos. En el artículo 277 cita:

"Será reprimido con prisión de seis meses a tres años el que, sin promesa anterior al delito, cometiere después de su ejecución, algunos de los hechos siguientes: 1) ayudare a alguien a eludir las investigaciones de la autoridad o a sustraerse a la acción de ésta, $u$ omitiere denunciar el hecho estando obligado a hacerlo; 2) procurare o ayudare a alguien a procurar la desaparición, ocultamiento o alteración de los rastros, pruebas o instrumentos del delito, o a asegurar el producto o el provecho del mismo; 3) adquiriere, recibiere u ocultare dinero, cosas o efectos que sabía provenientes de un delito, o interviniere en su adquisición, recepción u ocultamiento, con fin de lucro. Si el autor hiciere de ello una actividad habitual, la pena se elevará al doble".

Asimismo, el artículo 278 enuncia:

"El que con fin de lucro, adquiriere, recibiere u ocultare dinero, cosas o efectos que de acuerdo con las circunstancias debia sospechar provenientes de un delito, será reprimido con prisión de tres meses a dos años. Si el autor hiciere de ello una actividad habitual, la pena se elevará al doble". 
La ley 23.737 fue un avance sustancial al tipificar el delito de lavado de dinero proveniente del narcotráfico, y por establecer pautas relacionadas con el secreto bancario.

En particular, el Art. 25 declara:

"Será reprimido con prisión de dos a diez años y multa de quinientos mil australes, el que sin haber tomado parte ni cooperado en la ejecución de los hechos previstos en esta ley, interviniere en la inversión, venta, pignoración, transferencia o cesión de las ganancias, cosas o bienes provenientes de aquéllos, o del beneficio económico obtenido del delito siempre que hubiera conocido ese origen o lo hubiera sospechado. Con la misma pena será reprimido el que comprare, guardare, ocultare o receptare dichas ganancias, cosas o bienes o beneficios conociendo su origen o habiéndolo sospechado. A los fines de la aplicación de este artículo no importará que el hecho originante de las ganancias, cosas bienes o beneficios se hayan producido en el territorio extranjero. El tribunal dispondrá las medidas procesales para asegurar las ganancias o bienes presumiblemente derivados de los hechos descriptos en la presente ley. Durante el proceso el interesado podrá probar su legítimo origen, en cuyo caso el tribunal ordenará la devolución de los bienes en el estado en que se encontraban al momento del aseguramiento o en su defecto ordenará su indemnización. En caso contrario el tribunal dispondrá de las ganancias o bienes en la forma prescripta en el art. 39".

El art. 26 cita que:

"En la investigación de los delitos previstos en esta ley no habrá reserva bancaria o tributaria alguna. El levantamiento de la reserva sólo podrá ser ordenado por el juez de la causa. La información obtenida sólo podrá ser utilizada en relación a la investigación de los hechos previstos en esta ley".

La ley 24.072 aprobó que la Convención de las Naciones Unidas Contra el Tráfico Ilícito de Estupefacientes y Sustancias Psicotrópicas (Convención de Viena de 1988) fuera incorporada a nuestro derecho.

La Ley 24.450 creó la Comisión Mixta de Control de las Operaciones relacionadas con el Lavado de Dinero del Narcotráfico, la cual se integraba con dos representantes de los siguientes organismos: Banco Central de la República Argentina, Secretaría de Programación para la Prevención de la Drogadicción y la Lucha Contra el Narcotráfico, de la Presidencia de la Nación (SPPD), Subsecretaría de Finanzas Públicas y Subsecretaría de Hacienda, Poder Judicial de la Nación, y cuatro representantes del Congreso de la Nación, dos por la Cámara de Diputados y dos por la Cámara de Senadores.

La Ley 25.246 denominada de Encubrimiento y Lavado de Activos de Origen Delictivo, sancionada a principios del 2000, creó la Unidad de Información Financiera, definió los sujetos obligados a informar, estableció el régimen penal administrativo, la actuación del Ministerio Público Fiscal y modificó el Código Penal una serie de artículos relacionados. 
Entre las reformas introducidas por la ley 26.087 vale destacarse la determinación de que los sujetos obligados a informar no podrán oponer a la Unidad de Información Financiera en el reporte de una operación sospechosa el secreto, sea éste bancario, bursátil, profesional $\mathrm{u}$ originado en compromisos legales o contractuales de confidencialidad. A su vez, la Administración Federal de Ingresos Públicos sólo puede revelar el secreto fiscal en aquellos casos en que el reporte de la operación sospechosa hubiera sido realizado por la propia AFIP. Cuando sea la UIF quien requiera el levantamiento del secreto fiscal, deberá solicitarlo al juez competente en materia penal, quien deberá expedirse en un plazo de 30 días (30).

La Ley 26.268 sancionada en julio de 2007 tuvo por finalidad responder a obligaciones internacionales asumidas para fortalecer la lucha contra el terrorismo internacional y, en particular, contra las diversas formas de su financiación.

En Junio del 2011 se sancionó la ley 26.683, como respuesta al informe del GAFI de fines de 2010 que calificaba a la Argentina como "jurisdicción no cooperativa o de alto riesgo" (Víctor Varone, 2013).

La ley 26.683 crea el delito de lavado de activos. Su artículo 5 indica la renumeración de los artículos 303, 304 y 305 del Código Penal, como artículos 306, 307 y 308 respectivamente y su incorporación al Título XIII del Código Penal.

El Artículo 303 indica que: “... Será reprimido con prisión de tres (3) a diez (10) años y multa de dos (2) a diez (10) veces del monto de la operación, el que convirtiere, transfiriere, administrare, vendiere, gravare, disimulare o de cualquier otro modo pusiere en circulación en el mercado, bienes provenientes de un ilícito penal, con la consecuencia posible de que el origen de los bienes originarios o los subrogantes adquieran la apariencia de un origen lícito, y siempre que su valor supere la suma de pesos trescientos mil (\$300.000), sea en un solo acto o por la reiteración de hechos diversos vinculados entre sí...".

Además se determinan agravantes (habitualidad, o el carácter de funcionario público), se reformula la actuación de los sujetos obligados, establece sanción para el "lavador" y para quien colabore, da un amplio poder al magistrado que interviene (fuero federal) y facultades de decomiso de los bienes vinculados con el lavado (art. 305 del Código Penal).

En la última reforma se aplican al régimen de lavado de dinero dos figuras: el "arrepentido" (como se define para el delito de terrorismo, reduciendo la pena al mínimo legal y habilitando la excarcelación) y los "testigos de identidad reservada".

La Procuraduría de Criminalidad Económica y Lavado de Activos (PROCELAC) ${ }^{11}$ se creó en diciembre de 2012 (Resolución PGN $n^{\circ}$ 914/12), formada por fiscales y funcionarios especializados que investigarán delitos vinculados con lavado de dinero. La resolución define funciones del área de Lavado de Activos y Financiamiento del Terrorismo, que se enumeran a continuación:

\footnotetext{
${ }^{11}$ https://www.mpf.gob.ar/procelac/
} 
- "Intervenir en los casos que versen sobre hechos de Lavado de Activos y Financiamiento del Terrorismo, en todas las instancias —según los requisitos exigidos por la resolución PGN 104/03.

- Llevar un registro completo y actualizado de las diferentes manifestaciones de la delincuencia económica, las que deberán ser requeridas a las dependencias correspondientes del Ministerio Público Fiscal.

- Elaborar una base de datos sobre las causas de referencia, con el objeto de detectar patrones comunes que permitan anticipar ámbitos de riesgo institucional y orientar otras investigaciones.

- Elaborar informes periódicos sobre el estado de los procesos, los avances y las dificultades observadas.

- Diseñar estrategias de investigación para el esclarecimiento de hechos de criminalidad económica y el recupero de los activos involucrados.

- Efectuar un seguimiento y estudio permanente de la jurisprudencia nacional e internacional que pueda tener incidencia en el trámite de estas causas.

- Prestar asesoramiento técnico y brindar la colaboración necesaria a las Fiscalías que intervienen en la investigación de los hechos en materia de Lavado de Activos y Financiamiento del Terrorismo.

- Realizar tareas de coordinación entre las distintas Fiscalías que intervienen en casos de Lavado de Activos y Financiamiento del Terrorismo y efectuar el seguimiento de los procesos que incluyan hechos en la materia.

- Disponer enlaces y acciones interinstitucionales con organismos especializados en la materia, con el propósito de mejorar las investigaciones y el juzgamiento de los casos de Lavado de Activos y Financiamiento del Terrorismo.

- Presentar ante las autoridades que correspondan los informes confeccionados por el Área de Asistencia Técnica de la Procuraduría."

La UIF es un ente que recibe los reportes presentados por los sujetos obligados para analizarlos y determinar si las operaciones sospechosas señaladas ameritan la apertura de una investigación mayor adelantada por las autoridades competentes. En algunos casos, tiene la habilidad de ser querellante en los procesos judiciales.

La UIF fue creada, por la Ley $\mathrm{N}^{\circ} 25.246$, luego modificada por la Ley $\mathrm{N}^{\circ} 26.683$, en abril del año 2000. Es un organismo descentralizado en la órbita del Ministerio de Hacienda. En particular, es un ente que recibe los reportes presentados por los sujetos obligados para analizarlos y determinar si las operaciones sospechosas señaladas 
ameritan la apertura de una investigación mayor adelantada por las autoridades competentes. En algunos casos, tiene la habilidad de ser querellante en los procesos judiciales. Es la encargada del análisis, el tratamiento y la transmisión de información a los efectos de prevenir e impedir el lavado de activos y la financiación del terrorismo. Emite directivas e instrucciones que deberán cumplir e implementar los Sujetos Obligados. Según el Artículo 13 de la Ley 25.246 y modificatorias, son competencias de la UIF: “... Recibir, solicitar y archivar las informaciones que podrán ser utilizados en el marco de una investigación; disponer y dirigir el análisis de los actos, actividades y operaciones que puedan configurar actividades de LA o FT y en su caso, poner los elementos de convicción obtenidos a disposición del Ministerio Público Fiscal; colaborar con la justicia y el Ministerio Público Fiscal en la persecución de los delitos reprimidos por la Ley 25.246 y modificatorias y dictar su reglamento interno...”.

\subsection{Dinero negro y dinero sucio}

La primera definición del delito de lavado de dinero en el plano internacional, penalizaba el lavado de dinero sólo proveniente de delitos ligados al tráfico de drogas. Así se indicaba en Convención de Naciones Unidas contra el Tráfico de Drogas y Sustancias Psicotrópicas (Convención de Viena).

El crimen organizado genera el equivalente al 1,5\% del PBI mundial. El movimiento es de 870 mil millones de dólares, según lo estimado por UNODC y difundido en una conferencia en Viena en Mayo de 2014 (UNODC, 2011). Si fuese un país estaría entre los 20 PIB más altos del mundo. Equivale al 7\% de las exportaciones mundiales("El crimen organizado genera el equivalente al 1,5\% del PBI mundial,” 2014).

Las ganancias del negocio del narcotráfico se evidencian considerando que el precio de origen de un kilo de opio en el campo pakistaní es de 90 dólares, y el precio del kilo de heroína en el mercado minorista en los Estados Unidos es de 290000 dólares. O la diferencia entre el precio del kilo de hoja de coca en Bolivia (60 dólares) al precio del kilo de polvo de cocaína en el mercado minorista de Estados Unidos (110000 dólares)(“Big business," 2001).

Según (UNODC, 2013):

"La superficie mundial dedicada al cultivo de coca ascendió a 155.600 hectáreas en 2011, prácticamente sin cambios respecto del año anterior, pero un $14 \%$ por debajo de 2007 y un $30 \%$ menos que en 2000.

Las estimaciones de la cantidad de cocaína fabricada, expresadas en cantidades de cocaina pura al $100 \%$, oscilaron de 776 a 1.051 toneladas en 2011, cifra igual en gran medida a la del año anterior. Las mayores incautaciones de cocaína del mundo (sin ajustar la pureza) se siguen notificando en Colombia (200 toneladas) y los Estados Unidos (94 toneladas). Sin embargo, ha habido indicios en los últimos años de que el mercado de cocaína se ha ido desplazando a varias regiones que antes no se asociaban al tráfico o al consumo. Se han observado aumentos considerables en Asia, Oceanía y América Central y del Sur y el Caribe. 
En América Central, la mayor competencia en el tráfico de cocaína ha dado lugar a niveles de violencia crecientes".

Si bien hay ganancias en toda la cadena de producción y distribución de drogas, las más cuantiosas se obtienen en la etapa final. Casi la mitad del lucro obtenido a lo largo de la ruta principal del tráfico de heroína entre el Afganistán y Europa correspondía a los cuatro mayores mercados europeos de consumo: Alemania, Francia, Italia y el Reino Unido. En Afganistán, el valor total de la economía ilícita basada en los opiáceos fue de 2.800 millones de dólares en 2014, equivalentes al 13\% del producto interno bruto (PIB). Operaciones descentralizadas y en pequeña escala, como giros postales o remesas, uso de empresas pantalla son algunos de los mecanismos para blanquear las ganancias obtenidas (UNODC, 2016).

En forma constante y creciente, grandes flujos financieros circulan por el mundo, provenientes de lucrativas actividades delictivas que fomentan simples y complejas, viejas y nuevas formas de lavado.

Los medios dedican una mayor atención al dinero lavado proveniente del tráfico de drogas, robos y asesinatos, que a los que provienen de delitos de guante blanco (White collar crimes) como los que ocurren en las grandes empresas, bufetes de abogados o escribanos(Unger \& Rawlings, 2006).

Los delitos de "guante o cuello blanco" son definidos (Sutherland, 1940) como los que abarcan "ilícitos penales cometidos por sujetos de elevada condición social en el curso o en relación con su actividad profesional". La idea del "cuello blanco" se relaciona con lo respetado, socialmente aprobado.

Si bien GAFI indica que el narcotráfico es la principal fuente de dinero para lavar, los crímenes financieros (que incluyen fraudes financieros, quiebras fraudulentas, comisiones ilegales) son una fuente de dinero ilegal equiparable (Sevares, 2003).

Otra fuente importante de ganancias en el crimen organizado son las falsificaciones (ropa, complementos, medicamentos) con 250 mil millones de dólares ("El crimen organizado genera el equivalente al 1,5\% del PBI mundial,” 2014).

Algunos expertos diferencian entre dinero negro y dinero sucio(Tondini, 2006).El dinero negro es aquél que surge de una actividad legal y que se esconde para no pagar impuestos, por ejemplo.El dinero sucio es el que proviene de actividades criminales, por ejemplo, narcotráfico, venta de armas, trata de personas.En algunos casos se habla de dinero sucio en sentido estricto y de dinero sucio en sentido amplio, que sería lo que en párrafos anteriores se llamó dinero negro.

Se pueden definir dos categorías en ese proceso de lavado: conversión y movimiento. Hablamos de conversión cuando los productos cambian de una forma u otra, es decir que con el dinero ilegal se compra un automóvil o un inmueble. En el caso del movimiento, las ganancias ilegales cambian de localidades, por ejemplo mediante transferencias o envíos por correo(Montes Farro, 2008). 
La razón por la que es necesario blanquear el dinero ilegal es por los requerimientos contables, tributarios y criminalísticos. Por ejemplo, los traficantes de droga deben realizar todas sus operaciones de comercio en dinero efectivo. Si se usara, por ejemplo, tarjeta de crédito, se podría registrar la identidad del traficante y del consumidor. Incluso, en este último caso, en países donde la legislación no penaliza el consumo personal, este tipo de rastreo podría considerarse una violación a los derechos civiles.

Por eso se hace necesario diversas operaciones y transacciones para ir transformando gradualmente lo ilegal en legal.

El lavado de dinero que surge de la evasión fiscal es un delito menor, circunscripto al país donde se ha realizado la evasión fiscal. Cuando se trascienden fronteras, es un crimen internacional. La lucha contra el lavado de dinero complica la reinversión criminal y debilita a los grupos del crimen al exigir inventar nuevas y complejas formas de lavado; fortalece la economía y los mercados impidiendo la competencia desleal. Indirectamente genera recursos para el Estado ante la confiscación y expropiación de bienes.

En Colombia, durante los años 2012-2013, la UIAF ha detectado bienes y activos de origen ilícito, que alcanzan aproximadamente \$1 Billón de dólares a valor comercial. Se han remitido casos a la Fiscalía General de la Nación de un valor comercial aproximado de \$2.600 millones de dólares. El organismo sostiene que estos resultados son la consecuencia de la articulación adecuada entre los actores del Sistema Nacional de Lucha contra el Lavado de Activos y la Financiación del Terrorismo: Fiscalía General de la Nación, la Policía Judicial, las Superintendencias, la UIAF, y los sectores que reportan a la UIAF. A esto se le suma una fuerte cooperación internacional con instituciones con misiones y funciones similares(Unidad de Información y Análisis Financiero - UIAF, 2013).

Según el mismo informe, solamente el tráfico de drogas mueve unos 320 mil millones de dólares anuales. Las dos sustancias que más dinero generan son la cocaína ( 85 mil millones), y los opiáceos (68 mil millones). Los dos mayores mercados de la cocaína, son Estados Unidos (se generan 35 mil millones de dólares) y Europa occidental (26 mil millones).

\subsection{El delito precedente}

El delito precedente al lavado es la actividad ilegal, primaria, generadora de los ingresos que luego se intentarán reinsertar en el circuito financiero legal. En una segunda etapa, hay una actividad como por ejemplo la constitución de sociedades o compra de inmuebles, que no es ilícita en si misma pero que se constituye en delito, autónomo, por el origen de los fondos, que son obtenidos de forma espuria.

Se pueden citar como delitos precedentes: el narcotráfico; la corrupción; el fraude o la estafa; el tráfico humano, la esclavitud y el secuestro; la evasión fiscal; la falsificación, el contrabando y la piratería; el tráfico de armas; los delitos ambientales; el comercio ilegal de animales exóticos; y la pornografía, entre otros. 
Sobre 12 actividades ilegales, un informe del Global Financial Integrity (GFI) del 2011, identifica a las 5 primeras en cuanto al movimiento de dinero que generan, a saber: 1) Narcotráfico - US\$320.000 millones; 2) Falsificación - US\$250.000 millones; 3) Tráfico Humano - US\$31.600 millones; 4) Tráfico ilegal de petróleo - US\$10.800 millones; y 5) Tráfico de vida salvaje - US\$10.000 millones. Si a estas cifras se le agregan otras actividades, como por ejemplo, desde el tráfico de órganos hasta la venta de obras de arte, la suma se dispara a US\$650.000 millones ("Las cinco actividades del crimen organizado que recaudan más dinero en el mundo," 2016) .

En el año 2000, el delito de Lavado de Activos fue incorporado al Código Penal Argentino mediante la Ley $\mathrm{N}^{\circ}$ 25.246. En ese caso se lo asoció al delito de encubrimiento. Entonces era necesario probar el delito precedente que dio origen a esos fondos, para poder procesar a una persona por lavado de activos. Pero sólo se podía castigar al sujeto que incurría en lavado si encubría a otro responsable del delito anterior. Veamos un ejemplo: si una persona traficaba droga y él mismo se encargaba de darle apariencia lícita al dinero proveniente de ese delito, sólo podía ser penado por el delito de tráfico, pero no por lavado. Con este contexto, sólo una causa prosperó en diez años de aplicación de la Ley.

En la Ley $\mathrm{N}^{\circ}$ 26.683, promulgada el 21 de junio de 2011 se corrigieron algunas falencias. Se estableció la tipificación del Lavado de Activos como delito autónomo, creando un nuevo título en el Libro Segundo del Código Penal llamado "Delitos contra el orden económico y financiero", que se configura como un bien jurídico supraindividual, cuyo titular o sujeto pasivo es la comunidad en general.

Vale mencionar que las personas que ejecutan las operaciones de lavado de activos generalmente no están vinculadas directamente a la ejecución del delito que genera las ilegales utilidades (delito precedente).

El benefício económico de los delitos necesita ser utilizado en los mercados legales. Por lo tanto el lavado de dinero no es una situación novedosa. Pero lo que representó un avance importante fue cuando se concibió como un problema en sí mismo, separándose y distinguiéndolo del delito que le da origen, tratándolo en forma independiente(Tondini, 2006).

\subsection{Las formas y fases del lavado de activos}

Al Lavado de Activos se lo define como el proceso por el cual bienes de origen ilícito se integran en el sistema económico legal, aparentando haber sido obtenidos en forma lícita y procurando ocultar su procedencia, a su titular y el real ejercicio de su control. Según FINCEN entre las formas más comunes de lavado, se pueden citar:

1) Estructurar: Uno o varios individuos hacen múltiples transacciones con fondos ilegales por cierto período de tiempo, en la misma institución o en varias instituciones financieras. 
2) Complicidad de un funcionario u organización: Cuando los empleados de las instituciones financieras o comerciales facilitan el lavado de dinero al aceptar a sabiendas grandes depósitos en efectivo, sin llenar ni presentar los informes de transacciones en efectivo cuando es necesario, llenando formularios falsos, exceptuando, contra las prácticas, a los clientes de llenar los formularios requeridos.

3) Mezclar: Cuando se combina los productos ilícitos con fondos legítimos de una empresa, y después presenta la cantidad total como renta de la actividad legítima de tal empresa.

4) Compañias de fachada: La compañía de fachada puede ser una empresa legítima que mezcla los fondos ilícitos con sus propias rentas. Puede estar ubicada físicamente en una oficina o a veces puede tener únicamente un frente comercial.

5) Compras de bienes o instrumentos monetarios en efectivo: El lavador de dinero compra bienes tangibles (automóviles, propiedades, etc.) o instrumentos monetarios (giros bancarios y postales, cheques de gerencia o de viajero, y valores), con el efectivo originado de la actividad criminal.

6) Contrabando de efectivo: Involucra el transporte físico del efectivo. Puede estar escondido en el equipaje, o ser llevado por la persona que actúa de correo.

7) Transferencias telegráficas o electrónicas: Es la más usada para estratificar fondos ilícitos, en términos del volumen de dinero que puede moverse, y por la frecuencia de las transferencias. Esta modalidad permite enviar fondos a un destino rápidamente, y el monto de la transferencia normalmente no está restringido.

8) Ventas fraudulentas de bienes inmuebles: El lavador compra una propiedad con el producto ilícito por un precio declarado significativamente mucho menor que el valor real.

9) La formación de compañías de portafolio o nominales (denominada en ingles "shell company"): Es una entidad que generalmente existe solamente en el papel; no participa en el comercio (a diferencia de una compañia de fachada).

Con respecto al contrabando de efectivo (inciso 6), a pesar de las limitaciones, los lavadores de dinero han demostrado un alto grado de imaginación al encontrar nuevos medios para mover el producto criminal en efectivo. La Figura 2, la Figura 3, la Figura 4 y la Figura 5muestran imágenes de dinero transportado en una rueda de un auto, escondido en el chasis de un auto, y oculto en huecos internos de libro s y en pañales de bebés, respectivamente. Las imágenes son cortesía de diferentes organismos intervinientes como policía, gendarmería de distintos países. 
Se llama pitufeo o trabajo de hormiga al realizar diversas transacciones en montos pequeños para eludir el registro y reporte respectivo en el caso que la ley establezca la obligación de hacerlo cuando se supera determinada cantidad. Por ejemplo, si por ley existe la exigencia de completar una serie de formularios para la UIF si se gana en juegos de azar más de 50000 pesos, una persona que desea lavar dinero puede evitar completar formularios cobrando el premio en diferentes momentos: en un caso por 30000 y luego por 20000 (si la modalidad de juego lo permite). Se le llama pitufeo porque pueden intervenir uno o más individuos (pitufos) para hacer esas múltiples transacciones.

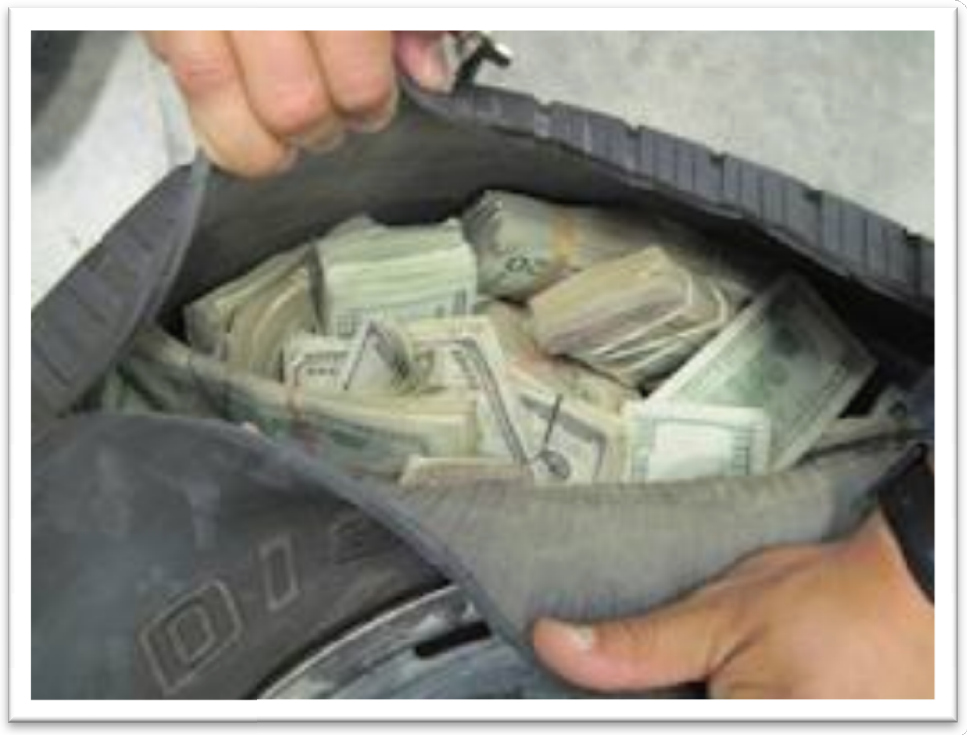

Figura 2 - Dinero transportado en la rueda de un auto

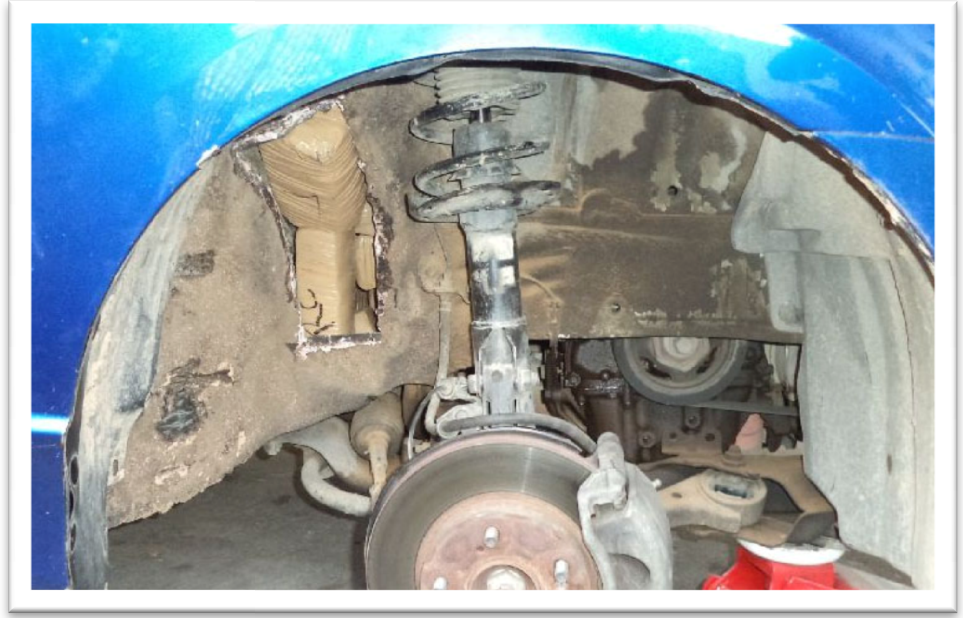

Figura 3 - Dinero Escondido en el chasis de un auto 


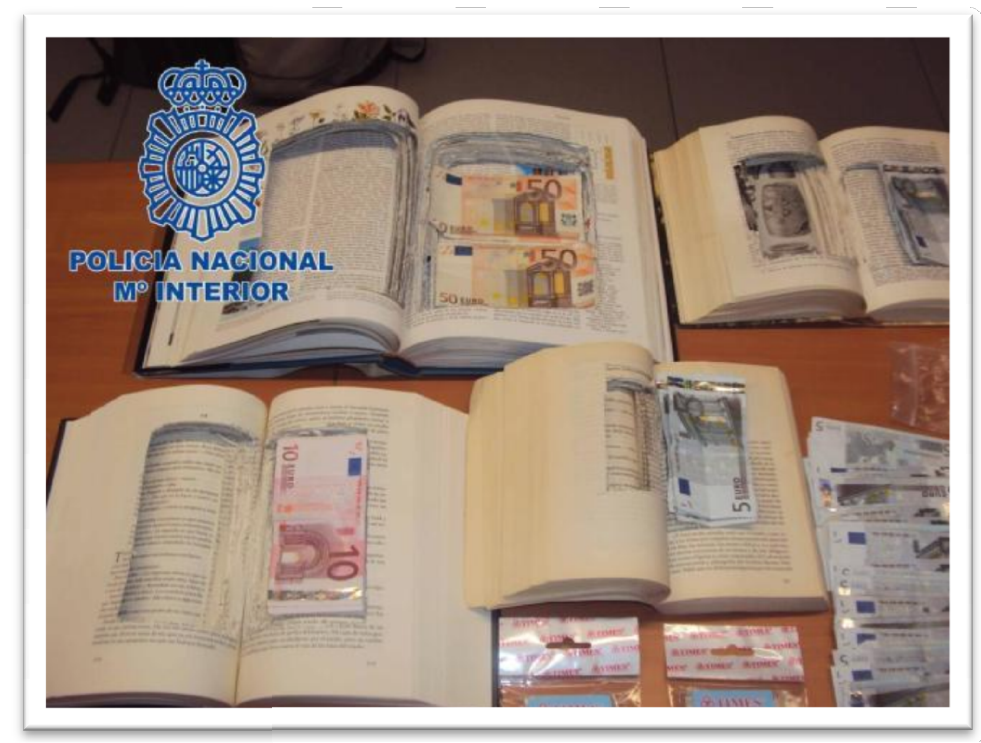

Figura 4-Dinero oculto en huecos internos de libros

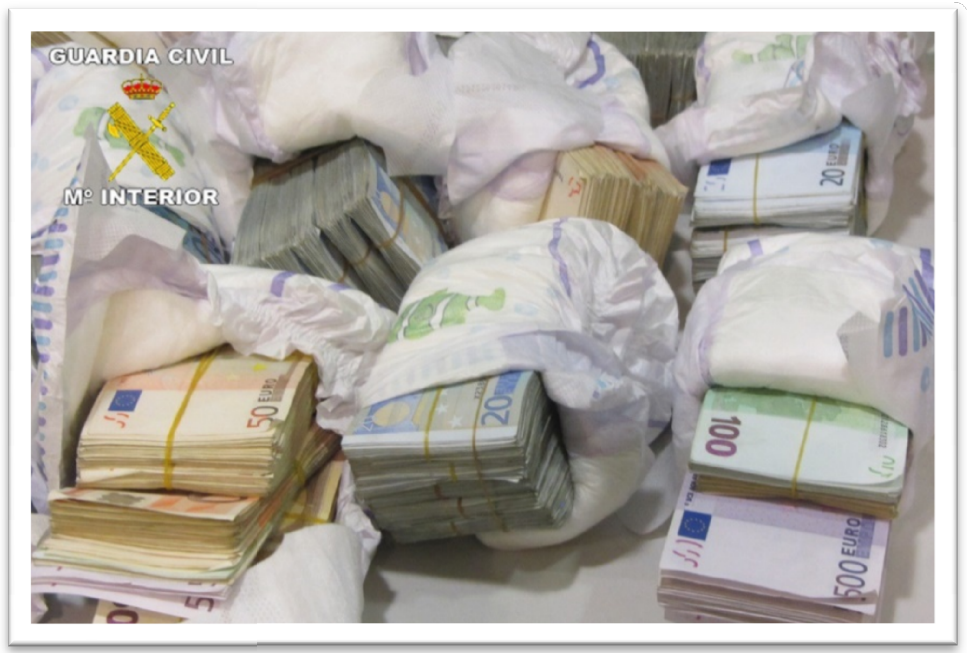

Figura 5 - Dinero oculto en pañales

Un aspecto que caracteriza al lavado de activos de otros delitos penales, lo constituye el hecho de que se efectúa por etapas.

El GAFI identificó tres etapas que intervienen en el proceso del lavado de activos proveniente de actividades ilícitas: 1) Colocación; 2) Estratificación o Enmascaramiento; y 3) Integración. Estas etapas no necesariamente se desarrollan lineal 
y ordenadamente, existiendo la posibilidad de que determinada maniobra de lavado de dinero se complete solamente con alguna de las etapas del proceso(Bautista, Milanés, Huertas, Segarra, \& Rusconi, 2005). Las etapas se explican a continuación.

La Colocación se refiere a insertar el dinero o los bienes producto de una actividad ilegal en el sistema económico formal.

La mayoría de las actividades delictivas complejas obtienen sus ganancias en dinero en efectivo. Por ejemplo, las ganancias del delito de narcotráfico se caracterizan por ser una gran cantidad de billetes de baja denominación. El desafío es transformar en activos estos grandes volúmenes de dinero, para poder manejarlos (y utilizarlos). Se intenta introducir dentro del circuito financiero legal estas sumas, divididas en montos más pequeños, mediante negocios financieros e instituciones financieras, tanto bancarias como no bancarias o en el SJA. El objetivo es separar o diferenciar el dinero de la actividad ilícita que lo originó y mantener el anonimato del verdadero depositante. Para ello se utilizan personas con documentación falsa o empresas "fachada". El dinero se deposita en diferentes lugares, en montos más pequeños o diferentes, para transferirlos en corto tiempo y a distintos países.

Otra alternativa es trasladar el dinero en efectivo a los conocidos paraísos financieros o bancas off-shore, que se ubican en países con reglamentaciones permisivas o con un sistema financiero liberal. Es tal el peligro que representan que la OSCE (OSCE, 2012a), se refirió a esta práctica:

"Alentamos las iniciativas en curso en nuestros países encaminadas a
recuperar y devolver activos robados, asi como que se deniegue en
nuestros países el refugio seguro para las ganancias fruto de la
corrupción, de conformidad con las normas legislativas que
correspondan".

Al depositarse en los bancos, se mezclan las ganancias legítimas con las ilegítimas, muchas veces con la colaboración de autoridades o empleados. Este tema se trata en el punto 3.10.Pero las organizaciones delictivas también utilizan para esta etapa las casas de juego de azar, casa de cambio, etc.

La Estratificación o Enmascaramiento se refiere a separar las ganancias ilícitas de sus fuentes mediante transacciones financieras u operaciones comerciales diseñadas para enmascarar el origen de los fondos y proveer anonimidad.

Cuando el dinero fue "colocado" es necesario efectuar operaciones complejas para que se pierda su rastro y se impida la verificación contable. Estas operaciones se realizan en el ámbito nacional como internacional. El objetivo es cortar la cadena de evidencias por investigaciones que puedan surgir.Se hacen giros a cuentas anónimas en países que se amparan en el secreto bancario, en empresas fantasmas ubicadas en distintos lugares del mundo.Entre las operaciones más comunes en esta etapa están las que se realizan con bancos off-shore, cheques de viajero, giros entre múltiples instituciones bancarias, transferencias electrónicas, compra de instrumentos financieros con posibilidad de 
rotación rápida y continua, compra de activos de fácil disponibilidad, empresas ficticias, entre otras.

En general, el uso de Internet y el dinero digital facilita la concreción de esta etapa al permitir mayor rapidez y anonimato en los mecanismos de transferencia otorgándoles.

La Integración se refiere a volver a colocar el dinero de origen ilícito en la economía en una forma tal que parezcan ser el resultado de una actividad comercial legítima.

El dinero es incorporado formalmente al circuito económico legal sin despertar sospechas. Ejemplos de estas actividades incluyen empresas "fachada" que se prestan servicios entre sí; invierten en inmuebles, generan falsas ganancias por intereses, o realizan otros negocios de supuesta gran rentabilidad, como inversiones en cadenas hoteleras, supermercados, compra de oro, piedras preciosas, obras de arte, etc.

Adicionalmente, es necesario que invertan en negocios que permiten que se continúe con la actividad delictiva, como las empresas de transporte que posibiliten el traslado de dinero, drogas, químicos u otros bienes de contrabando; empresas del ramo de la química, que posibiliten el suministro de precursores químicos, para la elaboración de estupefacientes; agencias de turismo para favorecer la comercialización de mercadería de contrabando; sectores económicos que muevan grandes sumas de dinero en efectivo para poder mezclarlo con el dinero de origen ilícito, como por ejemplo casinos, agencias de juego, hoteles, empresas transportadoras de caudales, etc.

\subsection{Consecuencias del lavado de activos}

Las consecuencias del lavado de activos son graves. Por ejemplo, lavar dinero exitosamente recompensa el crimen y la corrupción; por lo tanto, afecta a toda la sociedad pues se ven lesionados los principios, y se establece una crisis de valores ante la injusticia del enriquecimiento ilícito. A continuación discutimos las mismas en base a enunciados de organismos internacionales. La Organization for Security and Cooperation in Europe (OSCE) enuncia:

"Convenimos en que los problemas en materia de gobernanza, entre ellos la corrupción y el lavado de activos, anulan la capacidad de los Estados participantes de velar de modo efectivo por un desarrollo sostenible social, económico y medioambiental, y socavan la cohesión social, la estabilidad y la seguridad”. (OSCE, 2012b)

En el preámbulo de la Convención de Viena se reconoce que el delito de lavado de dinero proveniente del narcotráfico "socava las economías lícitas", y que "el tráfico ilícito genera considerables rendimientos financieros y grandes fortunas que permiten a las organizaciones delictivas transnacionales invadir, contaminar y corromper las estructuras de la administración pública, las actividades comerciales y financieras". El lavado de dinero perjudica las actividades económicas lícitas, la estabilidad financiera y la soberanía de los Estados, independientemente del bien jurídico afectado por el delito precedente. 
Los sujetos involucrados en el LA generalmente no buscan invertir en donde les sea económicamente más redituable sino más bien donde puedan disimular con mayor eficacia el origen ilícito de los fondos. La presencia de organizaciones delictivas desalienta los planes de inversores que pretendan incorporar capitales legales.

Hay una vinculación directa entre el lavado de activos y la influencia que despliegan el dinero y los bienes de origen delictivo en la economía legal. Esta economía paralela influye de diversas formas, entre otras, fomentando situaciones de abuso de poder y especulaciones financieras y monetarias. Los ataques contra el orden económico y financiero pueden llegar a impactar sobre las monedas de los Estados, perturbando el normal funcionamiento de los mercados de capitales, el tipo de cambio, la libre competencia, y hasta pueden favorecer la existencia de monopolios, si se considera el enorme volumen de dinero que se blanquea. (UIF, de su sitio oficial ${ }^{12}$ ).

Cuando las instituciones,con conocimiento o por negligencia, procesan fondos provenientes de actividades criminales, puede considerarse parte de la red criminal. La integridad es uno de los activos más importante de una institución financiera. Los clientes necesitan percibir que funciona dentro de un marco con estándares legales, profesionales y éticos. La evidencia de complicidad puede incidir en la relación con intermediarios financieros o entidades reguladoras, o con los mismos clientes.

El lavado de dineropresenta facetas criminológicas considerables. A continuación se resume las consecuencias que lo constituyen como un flagelo de enorme gravedad(Bautista et al., 2005):

- Tiene un importante impacto distorsionador que manifiesta en las economías mundiales

- Se expresa como un potenciador y estimulador de la delincuencia organizada

- Se nutre, en sistemas fuertemente globalizados, de las brechas que generan los diferentes niveles de control financiero que rigen las economías involucradas

- Pone en evidencia las contradictorias valoraciones de los países que observan a estos procesos como una alternativa de ingreso de capitales y de inyección económica

- Existe una relación empírica entre el lavado de dinero y los niveles de transparencia en el ejercicio de la función pública

- Las economías nacionales aumentan los niveles de injerencia y regulación, reduciendo el margen de discrecionalidad de la actividad privada.

\footnotetext{
${ }^{12}$ www.uif.gov.ar
} 


\subsection{Los beneficios de las políticas de prevención}

Desarrollar e implementar políticas de prevención de LA y las acciones correspondientes, permite, entre otros, obtener los siguientes beneficios: a) frenar la reinversión criminal y debilitar a los grupos del crimen organizado; b) ayudar a disminuir los niveles delictivos; c) fortalecer la economía y los mercados impidiendo la competencia desleal; d) evitar el disfrute de bienes de procedencia ilícita; y e) generar recursos para los Estados mediante la figura de la confiscación y expropiación de bienes.

Los esfuerzos para combatir el lavado de dinero se efectúan en dos ámbitos: represión y la prevención. Si bien inicialmente parecen ser contradictorios, se complementan. Mediante la prevención se cumplen dos objetivos: 1) proteger la reputación y solvencia de empresas que realizan actividades de naturaleza financiera o empresarial "legales" contra quienes pretenden utilizarlas para legitimar capitales de origen ilegal; y 2) facilitar elementos probatorios ante procesos penales.

La prevención se viabiliza mediante el establecimiento de un conjunto de obligaciones: a) identificación y conocimiento de los clientes; b) registro y reporte de transacciones en efectivo que superen un determinado monto; c) reporte de transacciones sospechosas, sean estas efectuadas o no, con recursos en efectivo; d) conservación de documentos durante un período de tiempo no inferior a cinco años; e) establecimiento de mecanismos y órganos de control, así como la f) capacitación de su personal. Todas estas obligaciones deben ser cumplidas por las actividades comerciales, empresariales y financieras que determine la legislación. El no cumplimiento da lugar a la aplicación de sanciones administrativas, tanto a los funcionarios o empleados directamente responsables del incumplimiento, como a la propia entidad, independientemente de que si como resultado de los mismos se haya incurrido o no en una actividad de lavado de activos (Bautista et al., 2005).

Siendo el lavado de activos una conducta que es considerada delito, quienes la llevan a cabo pueden sufrir (UNODC, 2015): persecución penal, suspensión y cancelación de la personería jurídica, exclusión de fuente de financiación, bloqueo internacional (inclusión en listas internacionales), mala reputación, altos costos de remediación, continuidad del negocio, y pérdida del patrimonio (acción de extinción de dominio).

No obstante, las tanto los beneficios de la prevención del lavado de activos, como las consecuencias de las actividades de lavado dependen de las políticas de cada país y cuan dispuesto se está a cumplir las normativas y recomendaciones internacionales acerca de la prevención y acciones ante la detección de LA. 


\subsection{El Hawala y su vigencia}

En circunstancias normales, es muy difícil seguir la pista del dinero. Si es necesario transportar sumas multimillonarias, a la hora de hacer el pago, varios grupos de traficantes se reparten la transacción entre ellos, o también pueden recurrir a bancos dispuestos a colaborar en paraísos fiscales.

Debido a la dificultad y riesgo de movilizar dinero han surgido prácticas alternativas innovadoras, como por ejemplo, Hawala. La práctica de Hawala (también conocido como Hundi) nació hace varios siglos, y podemos considerarla un predecesor de las transferencias de dinero a larga distancia. Es un método de transferencia informal. Quienes hace siglos transportaban el producto de sus ventas en sus caravanas corrían el riesgo de ser atacados. Se buscó entonces una modalidad de pago de dinero que no demandara el traslado del mismo a través de largas distancias.

Hawala se basa en la palabra de una persona. No es necesario transportar grandes cantidades de dinero de un país, ni completar formularios de banco que puedan ser una evidencia. Una persona entrega dinero en un extremo y lo recibe en el otro. El banquero de Hawala recibe un depósito de parte de quien necesita transferir ese dinero a alguien del exterior, junto con el número de teléfono o la dirección de quien debe recibirlo. El banquero instruye a personas del otro país mediante un llamado telefónico o correo electrónico para que pague la suma necesaria. La transacción se completa mediante una autenticación por contraseña o el reconocimiento de un rostro o una voz. El banquero y sus socios transnacionales tienen claro cuánto le debe cada uno al otro y arreglan sus propias deudas cuando les conviene y en la modalidad que les convenga; por ejemplo, en moneda, oro, o bienes. No hay circulación de dinero por cauces bancarios legales. En síntesis, el traficante de hawala y su socio se limitan a tener claro entre ellos lo que cada uno debe al otro y arreglan sus propias deudas cuando les conviene.

De ser una alternativa de hace muchos siglos para evitar la pérdida de valores por asaltos a las caravanas, luego se transformó en un medio habitual para transacciones que son llevadas a cabo por trabajadores inmigrantes que viven en países desarrollados y que no están bancarizados. Pero hoy, el hawala es una forma cómoda de blanquear dinero, evadir impuestos o mover millones de dólares por el mundo en el financiamiento al terrorismo. En particular, el hawala es efectivo porque genera bajos costos de operación, rapidez, poca documentación, más seguridad, y es menos burocrático que el sistema financiero formal ("Una vieja forma de mover el dinero," 2001).

\subsection{La Globalización y el Lavado de Activos}

Se esgrimen diferentes motivos que propician las actividades delictivas, las corrientes de dinero que generan, y los negocios asociados. Entre otras, se citan una ética de enriquecimiento individual, el deterioro de la capacidad reguladora de los Estados y el abanico de posibilidades que ha abierto la tecnología. Adicionalmente, cuando estas 
actividades se realizan cruzando las fronteras de los países y afectan a varios países y sus comunidades, la situación se torna aún más compleja.

La globalización es un proceso económico, tecnológico, social y cultural a gran escala, que unifica mercados, sociedades y culturas. A nivel internacional integra el capital, la tecnología y la información. Esta integración facilita la rápida comunicación entre organizaciones e individuos generando nuevas oportunidades pero también nuevos riesgos. Sin embargo, como la globalización promueve la libre circulación de capitales (Cruz, 2010), presenta un escenario que se convierte en un desafío para las agencias que se ocupan de hacer cumplir la ley o reguladores financieros, pues el ordenamiento jurídico también siente los efectos de la globalización.

Al ser un fenómeno internacional, la amenaza de lavado de dinero debe también tener un enfoque global. Lograr la evidencia en el camino del dinero y su lavador, donde se atraviesan fronteras internacionales y países con un enfoque dispar acerca de cómo abordar estos actos, es un verdadero desafío para el investigador.

A modo de ejemplo, a continuación se citan algunos casos (Treasury Department, US, 2015):

- En Nueva York, en el año 2013, 34 supuestos miembros de dos grupos de crimen organizado de ruso-americanos fueron acusados de un conjunto de delitos, entre ellos, la operación de como mínimo dos organizaciones internacionales de apuestas que atendían individuos pudientes de Estados Unidos, Rusia y Ucrania.

- Una empresa fue acusada de mover decenas de millones de dólares en ganancias provenientes del juego ilícito de la antigua Unión Soviética mediante empresas fantasma en Chipre a otras empresas fantasma en Estados Unidos.

- Otra empresa fue acusada de lavar las ganancias provenientes del juego mediante bancos de los Estados Unidos y una compañía de plomería del Bronx donde la organización adquirió el $50 \%$ de la propiedad como pago por deudas de juego.

- En el 2008, en la ciudad de Newark, New Jersey, en Estados Unidos, una detective fue acusada por ayudar a un traficante de heroína a lavar dinero proveniente de una red de apuestas ilegales del cual era operador. Las ganancias diarias eran de más de 10.000 dólares, más las ganancias semanales por la venta de heroína.

- En el año 2007, en Nueva York, 12 hombres fueron acusados por juego ilegal y lavado relacionado con un sitio web de juego online y un call center, en nombre de los corredores de apuestas deportivas con sede en Estados Unidos. Quienes manejaban esta "wire room" cobraban una tarifa por cada apuesta que tomaban. Los corredores de EEUU pagaban la tarifa en cash, tarjetas de débito prepagas, o 
transferencia. Incluso en una oportunidad se utilizó el método Hawala desde Pakistán para mover dinero acumulado desde los corredores de apuestas.

En el Boletín del FBI (Schroeder, 2001) se sugieren diez estrategias universalizadas, estandarizadas, que pueden aplicar los países para combatir el lavado de dinero. Las mismas incluyen: 1) Mejorar la cooperación entre las fuerzas de la ley, instituciones financieras y jurídicas, con el objetivo de ofrecer una respuesta coordinada en la implementación de contramedidas y acciones; 2) Adoptar legislación que penalice el lavado de dinero que provenga de cualquier crimen; 3) Establecer una Unidad de Inteligencia Financiera (UIF) de carácter central, constituida por investigadores, expertos bancarios, analistas financieros, que obtenga y analice información indicativa de lavado; 4) Derogar leyes de secreto bancario que restrinjan excesivamente el flujo de la información entre instituciones financieras y fuerzas de la ley; 5) Reportar transacciones sospechosas o que involucren grandes volúmenes de dinero; 6) Identificar los clientes de banco; 7) Registrar información sobre clientes y transacciones, hasta 5 años; 8) Establecer programas anti-lavado en bancos, con entrenamiento en detección para oficiales y empleados; 9) Garantizar cooperación internacional entre autoridades de la ley y adoptar leyes que faciliten la cooperación; y 10) Los países deben adoptar leyes que permitan la confiscación de las propiedades relacionadas a infracciones por lavado.

Reino Unido promulgó la Gambling Act en el 2005 (Gambling Act 2005, 2005) con los siguientes objetivos: a) prevenir que los juegos de azar sean una fuente de crimen o desorden, esté asociado con el crimen o desorden o sean usados para apoyar al crimen; b) asegurar que los juegos de azar se realizan de manera justa y abierta; y c) proteger a los niños y otras personas vulnerables de ser perjudicados o explotados por los juegos de azar.

\subsection{Sobre los paraísos fiscales}

Una de las formas de inyectar el dinero o los bienes producto de la actividad ilegal en el sistema económico formal es trasladarlo en efectivo a los conocidos paraísos financieros o bancas off-shore que se ubican en países con reglamentaciones permisivas o con un sistema financiero liberal. Es tal el peligro que representan que la OSCE (OSCE, 2012a), se refirió a esta práctica:

\begin{abstract}
"Alentamos las iniciativas en curso en nuestros países encaminadas a recuperar y devolver activos robados, así como que se deniegue en nuestros países el refugio seguro para las ganancias fruto de la corrupción, de conformidad con las normas legislativas que correspondan".
\end{abstract}

En 1998, la OCDE definió cuatro factores para determinar si una jurisdicción es un paraíso fiscal (Owens \& Saint-Amans, 2009): 1) Si la jurisdicción no impone impuestos o estos son sólo nominales. La OCDE reconoce que cada jurisdicción tiene derecho a determinar si imponer impuestos directos. Si no hay impuestos directos pero sí 
indirectos, se utilizan los otros tres factores para determinar si una jurisdicción es un paraíso fiscal; 2) Si hay falta de transparencia; 3) Si las leyes o las prácticas administrativas no permiten el intercambio de información para propósitos fiscales con otros países en relación a contribuyentes que se benefician de los bajos impuestos; y 4) $\mathrm{Si}$ se permite a los no residentes beneficiarse de rebajas impositivas, aun cuando no desarrollen efectivamente una actividad en el país.

En la lista de paraísos físcales (países que no respetan las normas internacionales) publicada por la OCDE en el 2009 se realizaron algunas correcciones a la emisión previa, entre ellas, sacar de la lista a Uruguay. Según afirmó en ese momento el Secretario General de la Organización, Ángel Gurría, la decisión se justificaba en que Uruguay había adoptado formalmente los estándares internacionales sobre transparencia. Otras modificaciones tienen que ver con nuevas incorporaciones; en particular, Costa Rica, Malasia y Filipinas.

Había dos listas grises en la que se encuentran aquellos países que cumplen tan sólo algunos acuerdos internacionales. En la lista gris "oscura" en cual estaban, entre otros, Andorra, Gibraltar, Liechtenstein, Barbados, Libera, Bahamas, Bahrein, Belice, Bermudas, Islas Caimán y Panamá. En la lista gris "clara" se encontraban Austria, Bélgica, Brunei, Chile, Guatemala, Luxemburgo, Singapur y Suiza.

En la lista de paraísos fiscales publicada por la OCDE el 2 de noviembre de 2011, se incluye a Nauru y Niue.La Tabla 3 - Lista de territorios comprometidos con mejorar la transparencia muestra los territorios que se comprometieron a mejorar la transparencia e intercambio de información.

- Andorra
- Anguila
○ Antigua y Barbuda
○ Curazao
- Aruba
- Bahamas
- Baréin
- Belice
- Bermudas
- Chipre
- Dominica
- Gibraltar
- Granada
- Guernsey
- Islas Cook
- Isla de Man
- Islas Caimán
- Islas Marshall

Tabla 3 - Lista de territorios comprometidos con mejorar la transparencia

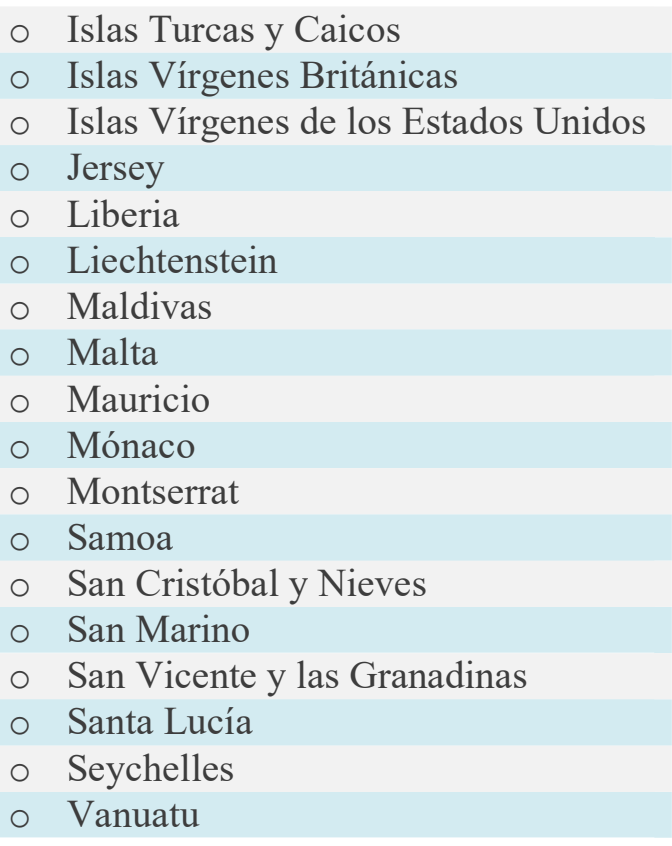


Desde 2009, la OCDE, trabajando en conjunto con el G2013, ha encabezado una ofensiva global contra las prácticas de algunos países acerca de permitir que se oculten los capitales a las autoridades tributarias y policiales de un país extranjero.El Foro Global sobre Transparencia e Intercambio de Información Tributaria controla las normas sobre transparencia fiscal: intercambio de información tributaria previa petición (EOIR) e intercambio automático de información (AEOI). Desde este Foro se ha advertido en forma constante y sistemática acerca de los riesgos que representan los países que no cumplen con las normas internacionales sobre transparencia fiscal.

En los siete últimos años 132 jurisdicciones se han comprometido a cumplir con la norma sobre intercambio de información previa petición. De ellas, 96 pondrán en práctica el intercambio automático de información financiera en los próximos dos años. Casi 100 países firmaron el Convenio Multilateral de la OCDE sobre Asistencia Administrativa Mutua en Materia Fiscal (Multilateral Convention on Mutual Administrative Assistance in Tax Matters). Sin embargo, no todos los territorios tienen la misma posición. En Marzo de 2016, se informó a los Ministros de Finanzas del G20 que Panamá se retractaba de su compromiso para el intercambio automático de información sobre cuentas financieras. De esta forma, las consecuencias de la negativa de Panamá a cumplir con las normas internacionales sobre transparencia fiscal son del conocimiento público. La Figura 6 - Mapa de paraísos fiscalesFigura 6 muestra el mapa de los paraísos fiscales publicado por la ONG Oxfam Intermón ${ }^{14}$.

Por otra parte, la ONG Oxfam Intermón, en un informe publicado el 19 de enero de 2016, indica que nueve de cada diez empresas multinacionales tienen presencia en paraísos fiscales(OXFAM, 2016). Se analizaron 200 empresas, entre las más grandes del mundo según ellos, y las socias estratégicas del Foro Económico Mundial.Tomando en cuenta datos del Fondo Monetario Internacional (FMI), la ONG calcula que la inversión empresarial en paraísos fiscales se ha multiplicado por cuatro entre el año 2000 y 2014 y estima que el dinero oculto en paraísos fiscales ya supera los 7,6 billones de dólares y sigue creciendo. La cifra sobrepasa el PIB del Reino Unido y de Alemania juntos, lo que supone unas pérdidas de 190.000 millones de dólares anuales en ingresos fiscales. La ONG también denuncia que únicamente 62 personas amasan la misma riqueza que la mitad de la población más pobre del mundo, tendencia que va a más puesto que el año pasado eran 80 personas.

\footnotetext{
${ }^{13}$ El G20 (Grupo de los 20) es un foro de cooperación y consultas entre los países que lo componen, en temas relacionados con el sistema financiero internacional. Estudia, revisa y promueve discusiones sobre temas relacionados con los países industrializados y las economías emergentes, con el objetivo de mantener la estabilidad financiera internacional, y de encargarse de temas que estén más allá del ámbito de acción de otras organizaciones de menor jerarquía. Está constituido por Alemania, Arabia Saudita, Argentina, Australia, Brasil, Canadá, China, Corea del Sur, Estados Unidos, Francia, India, Italia, Indonesia, Japón, México, Reino Unido, Rusia, Sudáfrica y Turquía. El vigésimo miembro del G20 es la Unión Europea. Reúne jefes de Estado/Gobierno, gobernadores de bancos centrales y ministros de finanzas.

${ }^{14}$ https://actualidad.rt.com/economia/197467-paraisos-fiscales-ocultan-paises
} 


\section{MAPA DE LOS PARAISOS FISCALES}

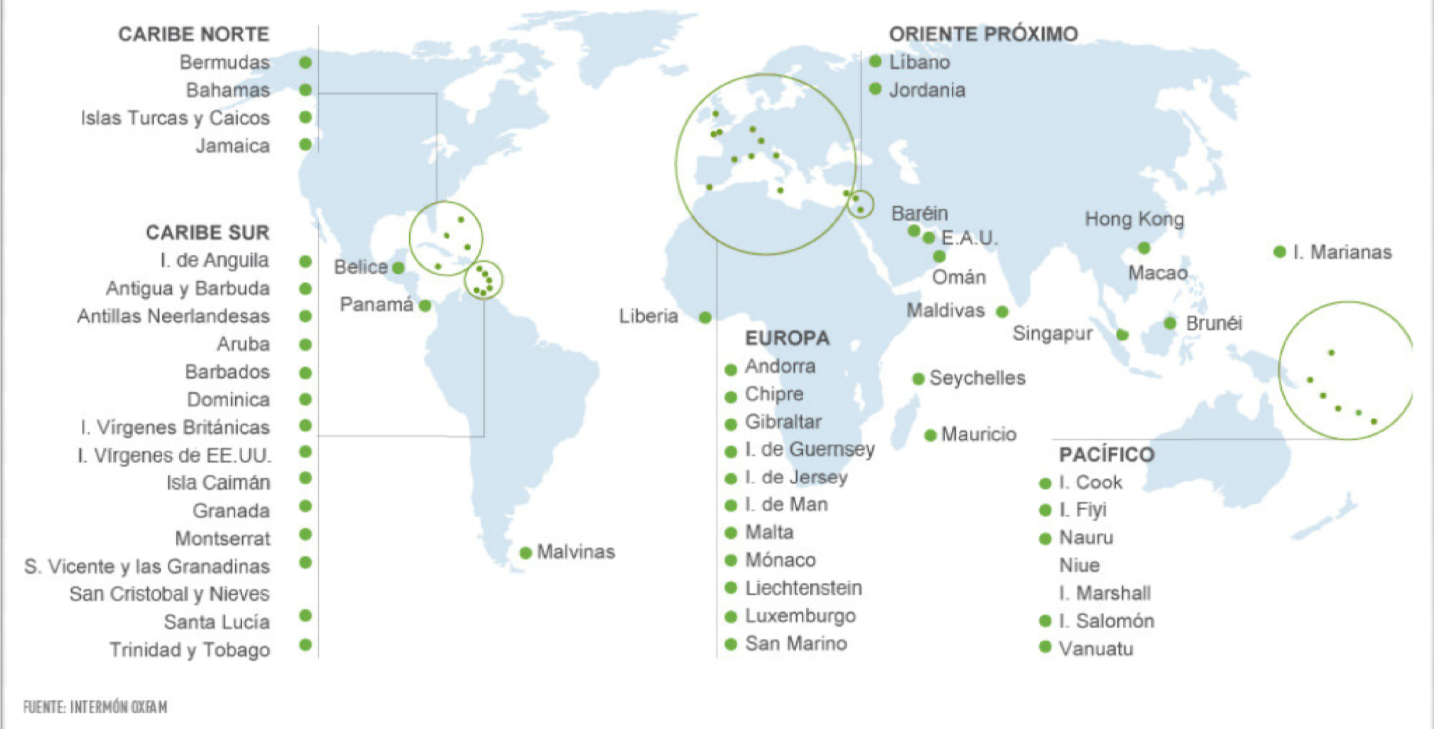

Figura 6-Mapa de paraísos fiscales

\subsection{Sobre Casinos y LA en Estados Unidos}

Las recomendaciones internacionales definidas por GAFI (Grupo de Acción Financiera Internacional, 2012)y otras publicadas por distintos organismos, proveen la base para que cada país dicte sus propias normativas, considerando que el LA es un delito global. La recomendación 28, inciso (a), expresa que los casinos deben estar sujetos a un amplio régimen de regulación y supervisión que asegure que éstos hayan implementado con eficacia las medidas LA/FT necesarias. Como mínimo requiere que:

- Los casinos deben estar licenciados;

- Las autoridades competentes deben tomar las medidas legales o normativas necesarias para prevenir que los criminales o sus cómplices tengan, o sean el beneficiario final de, o que tengan una participación significativa o mayoritaria en, o que ostenten una función administrativa en, o que sean un operador de un casino;

- Las autoridades competentes deben asegurar que los casinos estén supervisados eficazmente en cuanto al cumplimiento con los requisitos LA/FT.

(National Indian Gaming Association, 2013) destaca que American Gaming Association (AGA) contabiliza más de 1300 casinos y salas de juegos de cartas en los 42 estados que tienen algún tipo de legalización sobre el juego en casinos. Las 246 tribus indígenas 
que explotan salas de juego, en el 2012 tuvieron ingresos de aproximadamente \$27 billones de dólares. En el mercado de los casinos, los de Las Vegas y Atlantic City están al tope de la lista en los ingresos del 2012. Los casinos de New Jersey y Nevada acumulan la mayor cantidad de Reportes de Actividades Sospechosas (Suspicious Activity Report, SAR) yson citados más a menudo en investigaciones criminales que involucran lavado de dinero. En el 2013, los casinos y salas de juego (card club) en Estados Unidos produjeron 27000 SARs, donde Nevada y New Jersey aportaron más del $40 \%$.

Si bien los casinos no tienen obligación de tener un programa de identificación del cliente, un casino está sujeto a los requerimientos de la Bank Secrecy Act (BSA) si tiene un ingreso anual de más de un millón de dólares. Casinos y card clubs sujetos a la BSA tienen que desarrollar, implementar, y mantener políticas de prevención de lavado de dinero, y mantener registros de sus SARs y reportes de transacción de moneda (Currency Transaccions Report, CTR) y registros de transacciones en general (Treasury Department, US, 2015).

El programa de prevención incluye la obligación de definir procedimientos para colectar información que sea necesaria para propósitos de reporte y utilizar sistemas computarizados para colaborar en el aseguramiento del cumplimiento. Estos sistemas deben colaborar para identificar transacciones o patrones de transacciones que revisten categoría de sospechosas. En particular, los casinos deben almacenar y retener información acerca del nombre de cliente, dirección y número de seguridad social de cualquier cliente que haga o reciba una transferencia bancaria internacional, independientemente del monto de dicha transferencia.

\subsection{Organismos internacionales involucrados en esta temática}

La característica global del lavado de dinero y las consecuencias sin fronteras en las economías han despertado el interés y la participación de distintas organizaciones internacionales que definen buenas prácticas y recomendaciones para alentar a cada país a establecer políticas y regulaciones. Los marcos o guías publicados permiten también evaluar la situación de cada país o región de acuerdo a su situación.

Dos organismos importantes trabajando en esta temática son GAFI y el denominado "Egmont Group". Asimismo, debe resaltarse el trabajo de la Comisión Interamericana para el Control del Abuso de Drogas (CICAD) de la Organización de Estados Americanos (OEA). Los grupos de expertos de la CICAD formulan recomendaciones a los Estados miembros a los efectos de mejorar su capacidad en el control de estas conductas. Por otro lado, otro organismo multilateral que se ocupa del problema del lavado de dinero es el Comité Europeo de la Lucha contra la Droga (CELAD), que desarrolló un plan para esta materia que fue aprobado por el Consejo Europeo en Roma en el año 1990, y el propio Consejo de Ministros de la Comunidad.

A continuación se ofrece una pequeña síntesis de distintos organismos internacionales, los más relevantes en la lucha contra el lavado de activos. 


\subsubsection{El Grupo de Acción Financiera Internacional (GAFI)}

El Grupo de Acción Financiera Internacional (del inglés, Financial Action Task Force, FATF) ${ }^{15}$ es un organismo intergubernamental establecido en 1989. Su sede está en la Organización para la Cooperación y el Desarrollo Económicos (OCDE), en París. Fue fundado por los Jefes de Estado y de Gobierno del Grupo de los Siete con el objetivo de estudiar y promover las medidas destinadas a combatir el lavado de capitales procedentes en forma protagónica del tráfico de drogas.

Por medio de las primeras 40 recomendaciones, el GAFI se ha ocupado de los sistemas legislativos, de la cooperación multilateral, del papel del sistema financiero, de la relación de los delitos originarios, etc. (Bautista et al., 2005). Si bien GAFI no puede tomar decisiones ejecutivas, sus recomendaciones han tomado gran trascendencia (Grupo de Acción Financiera Internacional, 2012). Por esto, se ha convertido en uno de los mecanismos de evaluación multilateral más relevante.

El propósito de GAFI es desarrollar y promover políticas para combatir el Lavado de Activos y la Financiación del Terrorismo (LA/FT), en los niveles nacional e internacional.

“...El mandato del GAFI es fijar estándares y promover la
implementación efectiva de medidas legales, regulatorias y operativas
para combatir el lavado de activos, el financiamiento del terrorismo y el
financiamiento de la proliferación y otras amenazas a la integridad del
sistema financiero internacional. En colaboración con otras partes
involucradas a nivel internacional, el GAFI también trata de identificar
vulnerabilidades a nivel nacional para proteger el sistema financiero
internacional de usos indebidos...”. (Grupo de Acción Financiera
Internacional, 2012)

El GAFI está compuesto por tres grupos de trabajo - uno dedicado al análisis de la extensión y métodos del banqueo de capitales, otro a cuestiones jurídicas y judiciales y el tercero a la cooperación administrativa y financiera. A julio del 2015 cuenta con 36 miembros plenos (34 jurisdicciones y dos organizaciones internacionales), 8 cuerpos regionales (FATF-Style Regional Bodies, FSRBs), y 25 miembros observadores ${ }^{16}$.

\subsubsection{El Grupo de Acción Financiera de Latinoamérica (GAFILAT)}

Conocido inicialmente como Grupo de Acción Financiera de Sudamérica (GAFISUD), ante la incorporación de nuevos países llegando a 16 países miembros de América Latina, el XXIX Plenario de Representantes y Grupos de Trabajo reunido en Julio de 2014, aprobó por unanimidad el nuevo nombre, Grupo de Acción Financiera de Latinoamérica (GAFILAT).GAFILAT es una organización intergubernamental

\footnotetext{
${ }^{15} \mathrm{http}: / / \mathrm{www}$. fatf-gafi.org

${ }^{16} \mathrm{http}$ ///www.fatf-gafi.org/countries/
} 
constituida por países de América del Sur, Centroamérica y América de Norte. Su objetivo es combatir el lavado de dinero y la financiación del terrorismo. Apela al compromiso de los países miembros acerca de la definición de políticas nacionales e iniciativas contra LA/FT. GAFILAT fue creado a semejanza del GAFI.

GAFILAT fue creado en diciembre de 2000 y el Memorando de Entendimiento constitutivo del grupo fue suscripto por Argentina, Bolivia, Brasil, Chile, Colombia, Ecuador, Paraguay, Perú y Uruguay. Luego se incorporaron México, Costa Rica, Panamá, Cuba, Guatemala, Honduras y Nicaragua.

GAFILAT promueve la implementación de las 40 Recomendaciones del GAFI en los países miembros como leyes nacionales. También sostiene la necesidad de crear un sistema regional de prevención contra el LA/FT.

Las dos herramientas principales son las medidas de capacitación (orientadas a todos los agentes públicos - jueces, fiscales, policía, supervisores y unidades de inteligencia financiera - de sus países miembros en todos los temas relevantes conectados a la prevención de LA/FT) y las evaluaciones mutuas. A modo de ejemplo, en el Centro de documentación que ofrece GAFILAT por web ${ }^{17}$, se puede acceder a las evaluaciones mutuas, entre otra interesante documentación.

\subsubsection{Grupo Egmont}

El Group of Financial Intelligence Units Egmont, conocido como Grupo Egmont ${ }^{18}$ es un organismo internacional conformado por Unidades de Inteligencia Financiera. Se define como una red internacional informal para intercambiar información, conocimientos y tecnología contra el LA/FT. Su nombre proviene del lugar donde se realizó la reunión que se lanzó como grupo: el Egmont Arenberg Palace en Bruselas, Bélgica.

Los objetivos del Grupo Egmont incluyen: a) ampliar, sistematizar y mejorar la eficacia de la cooperación internacional en el intercambio recíproco de información de inteligencia financiera; b) compartir conocimientos y experiencias; c) ofrecer capacitación para incrementar la eficiencia de las UIF; d) incrementar el uso de tecnología; y e) fomentar la autonomía operativa de las UIF.

Para el Grupo Egmont, el intercambio de información se debe basar en los principios de confidencialidad, reciprocidad, celeridad, seguridad e informalidad.

\footnotetext{
${ }^{17} \mathrm{http}$ //gafilat.org.iplan-unix-03.toservers.com/content/biblioteca/

${ }^{18} \mathrm{http}$ ://www.egmontgroup.org/
} 


\subsubsection{Financial Crime Enforcement Network (FINCEN)}

FinCEN $^{19}$ es una dependencia dentro del Departamento del Tesoro de los Estados Unidos que tiene como misión proteger al sistema financiero de prácticas ilícitas y combatir el lavado de dinero, promoviendo la seguridad nacional mediante la recolección y análisis de información para la inteligencia financiera y su uso estratégico por parte de las autoridades. Su Director es designado por el Secretario del Tesoro, y reporta a Treasury Under Secretary for Terrorism and Financial Intelligence. FinCEN actúa como la UIF de los Estados Unidos.

Para cumplir con su misión, FinCEN recibe y mantiene datos relacionados con información financiera y la analiza y difunde con propósitos de aplicación legales, manteniendo una relación de cooperación con otros organismos internacionales.

FinCEN ejerce funciones regulatorias según Currency and Financial Transactions Reporting Act of 1970, actualizada en el Capítulo 3 de la llamada Ley Patriótica (USA Patriot Act) del 2001 y otra legislación. Este marco legislativo es comúnmente conocido como "Bank Secrecy Act" (BSA), ya referido anteriormente.

El Congreso de los Estados Unidos ha otorgado a FinCEN deberes y responsabilidades sobre la recolección, análisis y difusión de datos reportados bajo su regulación y aquéllos relacionados con dar apoyo a instituciones gubernamentales e industria financiera a nivel federal, de estados, local e internacional. Para lograr estos objetivos, FinCen tiene asignadas las siguientes responsabilidades: a) emitir e interpretar regulaciones; b) dar soporte y reforzar la compatibilidad con otras regulaciones; c) mantener, coordinar y analizar datos en relación con funciones de análisis de cumplimiento delegadas a otros reguladores; d) compartir información y coordinar con UIF extranjeras esfuerzos y contramedidas; y e) realizar análisis para quienes definen las políticas de la regulación, las agencias de inteligencia, y otros actores.

\subsubsection{United Nations Office on Drugs and Crime (UNODC)}

UNODC surge en 1997 como fusión de United Nations Drug Control Programme y el Centre for International Crime Prevention y actualmente opera en todo el mundo mediante una red de oficinas. El $90 \%$ de su presupuesto proviene de contribuciones voluntarias principalmente aportadas por gobiernos. Asiste a sus estados miembros en situaciones contra las drogas ilícitas, crimen y terrorismo.

Los tres pilares del programa de trabajo de UNODC son: 1) suscribir proyectos técnicos para mejorar la capacidad de acción de los estados miembros contra las drogas ilícitas, crimen y terrorismo; 2) realizar investigaciones y trabajos analíticos para conocer y entender los asuntos derivados del crimen y drogas, y el desarrollo de evidencia para las decisiones operacionales; y 3) elaborar normativas para asistir a los estados en la

\footnotetext{
${ }^{19}$ https://www.fincen.gov/
} 
ratificación e implementación de tratados internacionales, desarrollo de legislación local acerca de drogas, crimen y terrorismo y la provisión de una secretaría y servicios para colaborar mediante tratados con los gobiernos.

UNODC, mediante el Programa en Prevención del Delito y Fortalecimiento de la Justicia (PROJUST), el Ministerio de Justicia y del Derecho del Gobierno de Colombia, la Embajada Británica en Colombia y la Cámara de Comercio de Bogotá (CCB), han creado Negocios responsables y Seguros $(\mathrm{NRS})^{20}$. Esta alianza brega por la articulación de los sectores público y privado en una estrategia conjunta para prevenir el Lavado de Activos y delitos fuente; construir una cultura antilavado que permita una transformación de la sociedad y sumar esfuerzos a la estrategia nacional de cada país en la prevención del Lavado de Activos. Los objetivos de NRS incluyen: a) incentivar y facilitar la integración de medidas anti-lavado en el modelo de gestión del sector empresarial en Colombia; b) proponer al sector público medidas para mejorar la regulación, el control y la implementación del sistema anti-lavado en el sector empresarial; y c) comprometer al sector empresarial, a ser parte de Negocios Responsables y Seguros.

\subsection{Organizaciones específicas sobre juego de azar}

A continuación introducimos dos organizaciones internacionales dedicadas a los juegos de azar - World Lottery Association (WLA), y la Corporación Iberoamericana de Loterías y Apuestas del Estado (CIBELAE).

\subsection{World Lottery Association (WLA)}

WLA es una asociación profesional mundial de loterías de estado y organizaciones de juegos de azar. La WLA se creó en agosto de 1999 al fusionarse la Asociación Internacional de Loterías de Estado (AILE), la Asociación Internacional de Organizaciones de Toto (Intertoto) y Lotto. Actualmente, representa a 147 loterías provenientes de más de 80 países en 6 continentes.

Los objetivos de la WLA son: hacer progresar los intereses de sus miembros y mejorar la capacidad, el conocimiento común y la situación de cada uno de los miembros. En particular, sus objetivos básicos $\operatorname{son}^{21}$ : a) recopilar y difundir información sobre la industria de la lotería y áreas conexas; b) establecer estándares de mejores prácticas; c) establecer estándares éticos; d) proporcionar servicios de desarrollo académico y profesional (conferencias, seminarios), así como servicios de referencia e información a nuestros miembros; y e) formar una sola voz junto con las asociaciones regionales para que los miembros puedan tener un punto de referencia respetado, así como información y mensajes consistentes para proporcionarle a quienes tienen autoridad.

\footnotetext{
${ }^{20} \mathrm{http} / / /$ negociosresponsablesyseguros.org/

${ }^{21} \mathrm{http}: / / w w w . w o r l d-l o t t e r i e s . o r g /$
} 
Para conducir loterías y/o operaciones de apuestas deportivas, las organizaciones miembros deben ser licenciadas o autorizadas por la jurisdicción en las cuales residen. Para buscar apoyo en estas autorizaciones, o consejo experto en temas específicos, estas organizaciones pueden recurrir a la WLA.

En respuesta a lo solicitado por sus miembros en 2002, acerca del desarrollo de criterios específicos en relación con la responsabilidad social en general y, en particular, con el juego responsable, la WLA adoptó los Principios y el Marco de Juego Responsable (MJR) en el 2006 (Word Lottery Association (WLA), 2012) . Estos principios y el MJR tienen como objetivo proteger a los jugadores de lotería en el mundo. En particular, el MJR consiste en 4 niveles de logro y 10 ítems del programa, en los cuales se explica cómo las loterías pueden demostrar su nivel de compromiso con los Principios del Juego Responsable de la WLA.

\subsection{Corporación Iberoamericana de Loterías y Apuestas del Estado (CIBELAE)}

CIBELAE es una asociación civil internacional, no gubernamental, sin fines de lucro, creada en octubre de 1988. Sus objetivos fundamentales $\operatorname{son}^{22}$ : a) impulsar y promover la realización de las más diversas actividades, estudios e investigaciones en todos los temas que se consideren de interés para la mejora, modernización y optimización de la actividad lúdica estatal, teniendo como meta principal la más amplia colaboración e intercambio de información entre sus miembros; b) instar a la integración de sus miembros a través del desarrollo de vínculos entre las diversas loterías de Estado de los países que integran CIBELAE, así como de los de otras regiones, que desarrollen o se propongan desarrollar estudios en el campo lúdico; c) incentivar la suscripción y mejora de convenios y/o acuerdos de cooperación entre sus asociados, así como con otras instituciones que tengan los mismos fines; d) aconsejar e impulsar la adopción de políticas legislativas homogéneas para la regulación y control de la actividad lúdica por parte de los Estados a los que pertenecen los miembros; e) organizar cursos, encuentros, seminarios, congresos, jornadas, asambleas generales, grupos de trabajo, reuniones especiales, conferencias y coloquios, referentes a los ámbitos señalados e impulsar la coordinación de estas actividades con el fin de intercambiar información y experiencias entre los miembros de CIBELAE; y f) promover la formalización de acuerdos internacionales entre los Estados a los que pertenecen los organismos miembros, o los códigos de conducta entre éstos, tendentes a la preservación territorial o jurisdiccional en la explotación de los juegos de azar, así como al establecimiento de políticas comunes para combatir el juego ilegal o clandestino.

En Octubre de 2011, CIBELAE dio a conocer el Marco de Responsabilidad Social Corporativa y Gestión Responsable del Juego (Corporación Iberoamericana de Loterías y Apuestas de Estado (CIBELAE), 2011), con el fin de optimizar los servicios ofertados a sus miembros.

\footnotetext{
${ }^{22}$ https://www.cibelae.com
} 
En este Capítulo se incluyen conceptos de LA y se los relaciona y aplica en el ambiente del SJA y su problemática. La definición y detección de tipologías es trascendente pues juega un rol fundamental en el conocimiento del contexto y la construcción de las políticas.Se aborda el concepto de Riesgo y su aplicación.Por último, se dedica una sección al rol de las Tecnologías de Información y las Comunicaciones (TICs). Si bien el aporte positivo de las TICs es indiscutible en el SJA, también son viabilizadoras de conductas que faciliten el LA.

\subsection{Los jugadores y la identificación del cliente}

La debida diligencia requiere la implementación de políticas, prácticas y controles adecuados para impedir que la organización y sus productos sean utilizados con fines ilícitos. Incluye la identificación del cliente y la aplicación de los procedimientos reforzados de conocimiento del cliente, ante la detección de señales de alerta.La Identificación del Cliente es clave para la detección de posibles operaciones relacionadas con el Lavado de Activos y el Financiamiento del Terrorismo. Como primer paso para alcanzar el objetivo, se establecen medidas para comprobar la identidad de los clientes. Es responsabilidad primaria de todas las áreas que mantienen contacto directo con el cliente, obtener y verificar la documentación presentada por los clientes a fines de establecer su autenticidad.

La documentación presentada por los clientes debe ser resguardada, a fin de evitar la pérdida o daño de la misma. Se debe confeccionar un Legajo del Cliente que contendrá los datos de identificación establecidos por la normativa vigente y los procedimientos internos, y la documentación acompañada a dichos efectos. No obstante, vale aclarar que (Resolución UIF Nro 2, 2012), de Argentina, exceptúa la confección de legajo del cliente en el caso de que el proveedor de bienes o servicios sea una persona dedicada al juego de azar, lo que se justifica pues que en gran cantidad de juegos el jugador no se identifica.

La recomendación 22 del GAFI, Debida diligencia del Cliente en APNFD, indica que a las APNFD, entre ellas los casinos, se les debería requerir cumplir con la debida diligencia al cliente cuanto éste esté involucrado en una transacción financiera de 3.000 euros o más. En el casino, las transacciones financieras no incluyen las fichas.

(Resolución UIF Nro 199, 2011), de Argentina, define como cliente a todos aquellos apostadores "...que efectúen cobranzas de premios o conversión de valores por montos superiores a los PESOS CINCUENTA MIL (\$50.000) o su equivalente en otras monedas o bienes..."

La misma Resolución indica que en el caso “... que existan elementos que lleven a suponer que los clientes no actúan por cuenta propia, se debe obtener información adicional sobre la verdadera identidad de la persona (titular/cliente final o real) por cuenta de la cual actúa y tomar medidas razonables para verificar su identidad...". 
Adicionalmente especifica que se debe “... prestar atención para evitar que las personas físicas utilicen personas de existencia ideal como un método para realizar sus operaciones...".

\subsection{Identificación de Personas Expuestas Políticamente (PEPs)}

La normativa vigente define a quiénes se considera PEPs, y cómo se lleva a cabo su identificación. También determina qué documentación deben completar en su condición de PEP y a quién debe entregarse. En particular, (Resolución Nro 11, 2011)establece que son personas políticamente expuestas las siguientes:

a) Los funcionarios públicos nacionales que se señalan a continuación que se desempeñen o hayan desempeñado hasta dos años anteriores a la fecha en que fue realizada la operatoria:

- El Presidente y Vicepresidente de la Nación;

- Los Senadores y Diputados de la Nación;

- Los magistrados del Poder Judicial de la Nación;

- Los magistrados del Ministerio Público de la Nación;

- El Defensor del Pueblo de la Nación y los Adjuntos del Defensor del Pueblo;

- El Jefe de Gabinete de Ministros, los Ministros, Secretarios y Subsecretarios del Poder Ejecutivo Nacional;

- Los interventores federales;

- El Síndico General de la Nación y los Síndicos Generales Adjuntos de la Sindicatura General de la Nación, el presidente y los auditores generales de la Auditoría General de la Nación, las autoridades superiores de los entes reguladores y los demás órganos que integran los sistemas de control del sector público nacional, $\mathrm{y}$ los miembros de organismos jurisdiccionales administrativos; así como también el personal de todos estos organismos con categoría no inferior a la de director o equivalente;

- Los miembros del Consejo de la Magistratura y del Jurado de Enjuiciamiento;

- Los Embajadores, Cónsules y funcionarios destacados en misión oficial permanente en el exterior;

- El personal de las Fuerzas Armadas, de la Policía Federal Argentina, de Gendarmería Nacional, de la Prefectura Naval Argentina y del Servicio Penitenciario Federal, con jerarquía no menor de coronel o grado equivalente según la fuerza;

- Los Rectores, Decanos y Secretarios de las Universidades Nacionales;

- Los funcionarios o empleados con categoría o función no inferior a la de director o equivalente, que presten servicio en la Administración Pública Nacional, centralizada o descentralizada, las entidades autárquicas, los bancos y entidades financieras del sistema oficial, las obras sociales administradas por el Estado, las 
empresas del Estado, las sociedades del estado y el personal con similar categoría o función, designado a propuesta del Estado en las sociedades de economía mixta, en las sociedades anónimas con participación estatal y en otros entes del sector público;

- Los funcionarios colaboradores de interventores federales, con categoría o función no inferior a la de director o equivalente;

- Todo funcionario o empleado público encargado de otorgar habilitaciones administrativas para el ejercicio de cualquier actividad, como también todo funcionario o empleado público encargado de controlar el funcionamiento de dichas actividades o de ejercer cualquier otro control en virtud de un poder de policía;

- Los funcionarios que integran los organismos de control de los servicios públicos privatizados, con categoría no inferior a la de director;

- El personal que se desempeña en el Poder Legislativo de la Nación, con categoría no inferior a la de director;

- El personal que cumpla servicios en el Poder Judicial de la Nación y en el Ministerio Público de la Nación, con categoría no inferior a Secretario o equivalente;

- Todo funcionario o empleado público que integre comisiones de adjudicación de licitaciones, de compra o de recepción de bienes, o participe en la toma de decisiones de licitaciones o compras;

- Todo funcionario público que tenga por función administrar un patrimonio público o privado, o controlar o fiscalizar los ingresos públicos cualquiera fuera su naturaleza;

- Los directores y administradores de las entidades sometidas al control externo del Honorable Congreso de la Nación, de conformidad con lo dispuesto en el artículo 120 de la Ley $\mathrm{N}^{\mathrm{o}} 24.156$, en los casos en que la Comisión Nacional de Ética Pública se las requiera.

b) Los siguientes funcionarios públicos provinciales, municipales y de la Ciudad Autónoma de Buenos Aires (CABA) que se desempeñen o hayan desempeñado hasta dos años anteriores a la fecha en que fue realizada la operatoria:

- Gobernadores, Intendentes y Jefe de Gobierno de la CABA;

- Ministros de Gobierno, Secretarios y Subsecretarios; Ministros de Los Tribunales Superiores de Justicia de las provincias y de la CABA;

- Jueces y demás personal que cumpla servicios en los Poderes Judiciales Provinciales y de la CABA, con categoría no inferior a Secretario o equivalente;

- Legisladores provinciales, municipales y de la CABA;

- Máxima autoridad de los Organismos de Control y de los entes autárquicos provinciales, municipales y de la CABA;

- Máxima autoridad de las sociedades de propiedad de los estados provinciales, municipales y de la CABA; 
- Cualquier otra persona que desempeñe o haya desempeñado hasta dos años anteriores a la fecha en que fue realizada la operatoria, en las órbitas provinciales, municipales y de la CABA, funciones idénticas o similares a las enumeradas en el artículo $5^{\circ}$ de la Ley $\mathrm{N}^{\circ} 25.188$.

c) Las autoridades y apoderados de partidos políticos a nivel nacional, provincial y de la CABA, que se desempeñen o hayan desempeñado hasta dos años anteriores a la fecha en que fue realizada la operatoria.

d) Las Autoridades y representantes legales de organizaciones sindicales y empresariales (cámaras, asociaciones y otras formas de agrupación corporativa) y de las obras sociales contempladas en la Ley $\mathrm{N}^{0} 23.660$, que desempeñen o hayan desempeñado dichas funciones hasta dos años anteriores a la fecha en que fue realizada la operatoria. El alcance establecido se limita a aquellos rangos, jerarquías o categorías con facultades de decisión resolutivas; por lo tanto, se excluye a los funcionarios de niveles intermedios o inferiores.

e) Los funcionarios públicos extranjeros, quedando comprendidas las personas que desempeñen o hayan desempeñado dichas funciones hasta dos años anteriores a la fecha en que fue realizada la operación, ocupando alguno de los siguientes cargos:

- Jefes de Estado, jefes de gobierno, gobernadores, intendentes, ministros, secretarios y subsecretarios de Estado y otros cargos gubernamentales equivalentes;

- Miembros del Parlamento/ Poder Legislativo;

- Jueces, miembros superiores de tribunales y otras altas instancias judiciales y administrativas de ese ámbito del Poder Judicial;

- Embajadores, cónsules y funcionarios destacados de misiones oficiales permanentes del exterior;

- Oficiales de alto rango de las fuerzas armadas (a partir de coronel o grado equivalente en la fuerza y/o país de que se trate) y de las fuerzas de seguridad pública (a partir de comisario o rango equivalente según la fuerza y/o país de que se trate);

- Miembros de los órganos de dirección y control de empresas de propiedad estatal;

- Directores, gobernadores, consejeros, síndicos o autoridades equivalentes de bancos centrales y otros organismos estatales de regulación y/o supervisión;

- Cónyuges o convivientes reconocidos legalmente y familiares en línea ascendiente, descendiente o colateral hasta el tercer grado de consanguinidad o de afinidad, de las personas a que se refieren los cinco primeros ítems, durante los plazos que para ellas se indican. 


\subsection{Operaciones inusuales y sospechosas}

Las siguientes dos secciones detallan las consideraciones para clasificar las operaciones como inusuales o sospechosas.

\subsubsection{Operaciones Inusuales}

Se consideran operaciones inusuales:

“... las operaciones tentadas o realizadas en forma aislada o reiterada, sin justificación económica y/o jurídica, que no guardan relación con los usos y costumbres en las prácticas de mercado, ya sea por su frecuencia, habitualidad, monto, complejidad, naturaleza y/o características particulares...” (Resolución UIF Nro 199, 2011)

Las casas de juego modernas no ofrecen solamente la posibilidad de jugar: su oferta incluye cenas, espectáculos en vivo, sorteos, es decir, no es necesario jugar para disfrutar de estas alternativas (Best Practices for Anti-Money Laundering Compliance, 2014). Esto los ha transformado en sitios de entretenimiento, de asistencia masiva, con múltiples actividades. En este contexto se hace dificultoso la identificación de operaciones inusuales. Que una persona esté varias horas sin jugar en una sala, o sea una asidua asistente pero no juegue, no es inusual: puede interesarle la propuesta gastronómica o los espectáculos culturales o de entretenimiento que en ella se llevan a cabo.

A continuación, se enuncian pautas a tener en cuenta para el análisis de operaciones inusuales:

- Verificar el perfil del cliente, analizar la documentación e información disponible relacionada a la operación.

- Analizar en profundidad la/s operaciones realizadas, consultar los sistemas habilitados de monitoreo, y determinar la viabilidad o no de solicitar mayor información y/o documentación adicional.

- Observar la predisposición del cliente a brindar más información y/o documentación.

En (Resolución UIF Nro 199, 2011)se incluyen un conjunto de circunstancias que deben ser especialmente valoradas, por considerárselas operaciones inusuales:

1) Los montos, tipos, frecuencia y naturaleza de las operaciones que realicen los clientes que no guarden relación con los usos y costumbres en las prácticas de mercado;

2) Los montos inusualmente elevados, la complejidad y las modalidades no habituales de las operaciones que realicen los clientes; 
3) Cuando transacciones de similar naturaleza, cuantía, modalidad o simultaneidad, hagan presumir que se trata de una operación fraccionada a los efectos de evitar la aplicación de los procedimientos de detección y/o reporte de las operaciones;

4) Cuando se observe que los clientes efectúan maniobras de fraccionamiento o desdoblamiento de fichas o similares, a efectos de presentar para su cambio valores inferiores a los límites establecidos en la presente resolución;

5) Cuando se detecte que la información suministrada por los clientes se encuentre alterada;

6) Cuando los clientes intenten evitar que se dé cumplimento a la presente normativa u otras normas legales de aplicación a la materia;

7) Cuando el cliente exhibe una inusual despreocupación respecto de los riesgos que asume y/o costos de las transacciones incompatible con el perfil del mismo;

8) Cuando existan personas que reiteradamente solicitan canjear los instrumentos probatorios de supuestas ganancias de juego por instrumentos financieros o cuando solicitan, con frecuencia inusual, un certificado que acredite la ganancia obtenida;

9) Cuando existan personas que adquieran, en cantidades significativas, fichas de juego con billetes de baja denominación;

10) Cuando lo apostado sea desproporcionado con relación a la expectativa del premio;

11) Cuando un jugador obtiene premios en más de un sorteo o con una frecuencia inusual, de acuerdo a las características del juego;

12) Cuando un jugador compra fichas en efectivo y luego de realizar pequeñas apuestas, canjea las fichas restantes en la caja solicitando cobrarlas mediante un medio de pago distinto del efectivo;

13) Cuando una persona solapada o abiertamente mantiene interés por entablar contacto con ganadores de juegos de azar;

14) Cuando una persona se vale de cualquier medio para cobrar ganancias en nombre de terceros;

15) Otras operaciones que, por sus características, en lo que se refiere a las personas involucradas, forma de realización, instrumentos utilizados o por falta de fundamento económico o legal, puedan configurar operaciones sospechosas conforme a la Ley $N^{\circ} 25.246$ y modificatorias;

16) También se deberá prestar especial atención a los empleados del Sujeto Obligado que muestran un cambio repentino en su estilo de vida o se niegan a tomar vacaciones.

La detección de operaciones inusuales debería surgir de los controles establecidos. Es responsabilidad del Oficial de Cumplimiento (OC), el análisis y evaluación de operaciones inusuales para determinar cuáles de estas califican como sospechosas.

\subsubsection{Operaciones Sospechosas}

Se consideran operaciones sospechosas: 
“... aquellas operaciones tentadas o realizadas, que habiéndose identificado previamente como inusuales, luego del análisis y evaluación realizados por el sujeto obligado, las mismas no guardan relación con las actividades lícitas declaradas por el cliente, o cuando se verifiquen dudas respecto de la autenticidad, veracidad o coherencia de la documentación presentada por el cliente, ocasionando sospecha de Lavado de Activos; o aun cuando tratándose de operaciones relacionadas con actividades lícitas, exista sospecha de que estén vinculadas o que vayan a ser utilizadas para la Financiación del Terrorismo”. (Resolución UIF Nro 199, 2011)

Asimismo, se identifican las señales de alerta establecidas por la normativa y las específicas del sector para la detección de operaciones inusuales y/o sospechosas, que deberán ser analizadas. Legalmente, los elementos que integran una operación o transacción sospechosa son aquellas actividades que parezcan no tener justificación económica u objeto lícito por su magnitud, falta de habitualidad, velocidad de rotación, condiciones de complejidad inusitada o injustificada, o apartarse de los usos y costumbres (Camerini, 2010).

El Oficial de Cumplimiento (OC) es quien califica la operación como sospechosa de acuerdo a la magnitud, inusualidad o condiciones particulares. El criterio del OC es fundamental para detectar que estas operaciones podrían estar vinculadas a alguna actividad ilícita o no tengan un origen lícito aparente.

A continuación, se citan algunos casos de penalización.

En el año 2012, la UIF de Argentina aplicó una multa a una casa de juegos tucumana, dedicada a la explotación de máquinas de azar accionadas por pulso y crédito, debido a que no reportó los premios por sumas superiores a $\$ 10.000$ y $\$ 50.000$. En ese momento le correspondía enviar un reporte sistemático de los premios de más de $\$ 10.000$. Luego, la Resolución 199/11 lo elevo a más de \$50.000.

Un bingo de la CABA fue multado por la UIF en 50 mil pesos, al verificar que la sala de juegos incumplía con las políticas y procedimientos para prevenir el lavado de activos y la financiación del terrorismo, pues no contaba con métodos para la identificación de Personas Expuestas Políticamente (PEP), ni pautas a fin de anticipar esos delitos ("La UIF multó a un Bingo," 2015).

En un evento de juego realizado en Buenos Aires en noviembre de 2013, la Dra. Nancy Suárez, representante de la UIF expresó que en el 2010 hubo 11 reportes de operaciones sospechosas y en el 2011, hubo 156, aunque algunas sin fundamento. Indicó también que quienes más reportan son los casinos, seguido de los hipódromos y los bingos. En esa fecha no hubo reportes del juego on line. 


\subsection{Reportes sistemáticos}

Estos reportes contienen la información que obligatoriamente deben remitir los Sujetos Obligados a la UIF en forma mensual, mediante un sistema "on line" conforme a las obligaciones establecidas.

La UIF determina para cada Sujeto Obligado un detalle de las operaciones o informaciones que deben ser reportadas y el plazo de cumplimiento de la presentación de dicha información.

Se definen como reportes sistemáticos:

“...aquellas informaciones que obligatoriamente deberán remitir los Sujetos Obligados a la UNIDAD DE INFORMACIÓN FINANCIERA en forma mensual, mediante sistema "on line", conforme a las obligaciones establecidas en los artículos 14 inciso 1) y 21 inciso a) de la Ley $N^{o}$ 25.246 y modificatorias". (Resolución UIF Nro 199, 2011)

\subsection{Reportes de Operación Sospechosa (ROS)}

Los Reportes de Operaciones Sospechosas (ROS) son los reportes que se realizan ante operaciones, hechos o situaciones que posiblemente están relacionadas con el lavado de activos. Para que una situación sea incluida en el reporte, no se requiere la certeza de que la situación haya ocurrido ya que el ROS no constituye denuncia penal y es absolutamente reservado conforme a la Ley. Quien lo realice se encuentra amparado por la exoneración de responsabilidad consagrada por la Ley.

La Recomendación 20 del GAFI, Reporte de Operaciones Sospechosas (en inglés Suspicious Activity Report, SAR), indica que si una institución financiera sospecha o tiene motivos razonables para sospechar que los fondos son producto de una actividad criminal, o están relacionados al financiamiento del terrorismo, a ésta se le debe exigir, por ley, que reporte con prontitud sus sospechas a la UIF. Incluso aclara que se debería informar aún los intentos de operación, si existe sospecha, no importa la cantidad de dinero que se trate.

El artículo 14 de la Ley 26683 indica que “... La Unidad de Información Financiera (UIF) estará facultada para: 1. Solicitar informes, documentos, antecedentes y todo otro elemento que estime útil para el cumplimiento de sus funciones, a cualquier organismo público, nacional, provincial o municipal, y a personas físicas o jurídicas, públicas o privadas, todos los cuales estarán obligados a proporcionarlos dentro del término que se les fije, bajo apercibimiento de ley. En el marco del análisis de un reporte de operación sospechosa los sujetos contemplados en el artículo 20 no podrán oponer a la Unidad de Información Financiera (UIF) el secreto bancario, fiscal, bursátil o profesional, ni los compromisos legales o contractuales de confidencialidad..." 
En (Encubrimiento y Lavado de Activos de origen delictivo. Reporte de Operaciones Sospechosas "On Line," 2011) se refiere a los ROS en modalidad "On Line". En este documento, se justifica la implementación de esta modalidad, es decir, el envío de los ROS a través de Internet, el hacer "... uso de la tecnología disponible a fin de incrementar el flujo de información entre los sujetos obligados y este Organismo...", “... que asimismo con la implementación del nuevo procedimiento se logrará simplificar tareas, extremo que se traduce en maximizar recursos, contribuyendo a la eficiencia y eficacia en la clasificación, análisis y entrecruzamiento de la información...”, y “... que este sistema permitirá a la UNIDAD DE INFORMACION FINANCIERA recibir la información enviada por los sujetos obligados en tiempo oportuno, resultando a su vez accesible para los distintos sujetos ubicados en todas las regiones del País...".

En el artículo 2 de la Resolución se indica que “... Los sujetos obligados enumerados en el artículo 20 de la Ley $N^{o} 25.246$ y los oficiales de cumplimiento, en su caso, deberán formalizar la presentación del Reporte de Operación Sospechosa de Lavado de Activos a través del sitio www.uif.gov.ar/sro a partir del $1^{\circ}$ de abril de $2011 . . . ”$.

\subsection{Sobre el riesgo en LA}

Considerando las consecuencias antes citadas del lavado de activos, teniendo en cuenta incluso el delito precedente que genera ese dinero sucio o negro, una práctica adecuada para la realización de un análisis de riesgo es la representación de los resultados en una matriz de riesgo.

(ISO/IEC 27005:2011. Information technology -- Security techniques -- Information security risk management, 2011) define al riesgo como la probabilidad de ocurrencia de un evento adverso y su impacto. Este impacto se determina por medio de las consecuencias. La magnitud de la consecuencia se representa por la intensidad del daño causado por el evento. El Grupo Egmont propone otra definición donde el riesgo de una operación sospechosa es: "la probabilidad de la sospecha, de acuerdo a los criterios e indicadores predefinidos, y las consecuencias de las acciones que se producen".

Los factores de riesgo son las circunstancias y características del cliente y la operación que hacen que exista una mayor probabilidad de corresponder con una operación sospechosa de lavado de dinero.

La UIF Argentina, en su guía para la construcción de matrices de riesgo, propone utilizar las recomendaciones planteadas por las Convenciones de Basilea II (2004) y III (2010) para caracterizar el riesgo implícito en las operaciones sospechosas, identificando 5 tipos de riesgo:

- Riesgo Económico: mide el nivel de impacto de una posible operación de LA sobre el orden económico financiero y su probabilidad de ocurrencia. 
- Riesgo de Daño al Orden Público: mide el impacto y la probabilidad de ocurrencia de operaciones sospechosas de financiamiento al terrorismo (FT).

- Riesgo Operativo: indica el riesgo de que operaciones de lavado de dinero/financiamiento al terrorismo (LA/FT), no sean detectadas por la UIF, ya sea por inadecuaciones o fallas en sus procesos administrativos internos o bien por causas operativas externas a la unidad.

- Riesgo de Contagio: es el riesgo de que las operaciones de LA/FT provengan de redes delictivas transnacionales que trasladan sus metodologías al país y que, en virtud de su complejidad y novedad, pueden no ser detectadas por la UIF.

- Riesgo Reputacional: hace referencia a la posibilidad de pérdida de prestigio de la UIF respecto de otras instituciones del Estado y del sector privado (sujetos reportantes), lo que puede generar ineficiencias operativas producto del descrédito o falta de confianza en la Unidad.

Estos cinco riesgos conforman el riesgo de las operaciones sospechosas de LA y de FT del modelo propuesto por UIF. Posteriormente se cuantifica ese riesgo mediante la probabilidad de ocurrencia de la amenaza y el impacto.

GAFI define un proceso de gestión de riesgo para LA/FT, mediante el cual se reconocen e identifican los riesgos, se los "valoriza", y se definen estrategias para minimizarlos. El proceso de gestión de riesgo busca disminuir la probabilidad de que una operación delictiva no sea identificada.

En muchos casos este análisis es sobre una detección, es decir, que el caso de LA ya ha comenzado a ejecutarse. Si N es la probabilidad de que la operación de LA no sea detectada por la unidad, se supone que ese valor va disminuyendo cuando incorporo información y acciones: a mayor cantidad de información respecto la calidad y características de la operación sospechosa, menor será la probabilidad de que el delito no sea detectado. Sin embargo, en muchos casos no es posible obtener toda la información que se desea, por la factibilidad, el costo, tiempo para recolectarla, u otras razones.

A continuación, se indican las características que se deben analizar cuando se valora el riesgo ante reportes de operación sospechosa (Unidad de Informacion Financiera Argentina, 2012):

- Habitualidad: se entiende como la reiteración de operatorias. Esta habitualidad orienta a pensar en una mayor experiencia del sujeto en LA, que conduce a un carácter profesional. También es un indicador acerca de la situación en la organización o área afectada: controles ineficientes o inexistentes. También promueve a analizar si se está ante un caso concreto, si se está en presencia de operaciones diferentes e independientes o de un único caso realizado en etapas. Esta habitualidad está contemplada en el Código Penal Argentino en el artículo 303, inciso $2^{\circ}$, apartado a): "La pena prevista en el inciso 1 será aumentada en 
un tercio del máximo y en la mitad del mínimo, (...) cuando el autor realizare el hecho con habitualidad".

- Asociaciones Ilícitas: la cantidad de personas involucradas en las operaciones de lavado es considerado un agravante. En el Código Penal Argentino, artículo 303 inciso $2^{\circ}$, señala que: “...la pena prevista en el inciso 1 será aumentada en un tercio del máximo y en la mitad del mínimo (...) Cuando el autor realizare el hecho (...) como miembro de una asociación o banda formada para la comisión continuada de hechos de esta naturaleza". Asociación o banda debe entenderse como un grupo de personas que, regularmente actúan coordinadamente para realizar operatorias de LA (Durrieu, 2006). Estas asociaciones, donde alguna de ellas presentan una importante envergadura, deben contar con asesoramientos profesionales y diferentes roles para garantizar un cierto grado de subsistencia donde actúan o incluso para poder actuar en diferentes jurisdicciones.

- Transnacionalidad: La delincuencia transnacional organizada es un fenómeno criminal propio del siglo XXI. Es una de las características principales de los delitos de LA. Promovido por el desarrollo tecnológico donde se viabilizan efectivas e innovadoras formas de comunicación y facilidades para cruzar las fronteras de los estados, los capitales fluyen fácilmente por el sistema financiero mundial. En el artículo 303, inciso 5 (Código Penal Argentino, 2015) trata acerca de esta característica considerando que expresa “...Las disposiciones de este artículo regirán aun cuando el ilícito penal precedente hubiera sido cometido fuera del ámbito de aplicación espacial de este Código, en tanto el hecho que lo tipificara también hubiera estado sancionado con pena en el lugar de su comisión" (extraterritorialidad del delito previo y la doble incriminación).

En cuanto a los agravantes vinculados a los sujetos reportados, las características que aumentan el riesgo son:

- Persona Politicamente Expuesta (PEP):En los casos en los que una PEP está involucrada en una operatoria de LA implica un daño adicional al orden institucional (Convención Interamericana contra la Corrupción, 1996). Cuando estos sujetos, con funciones relevantes por su carácter de servicio público o el interés público comprometido en su desempeño, se ven involucrados en estas operatorias incrementan el impacto al utilizar esa función o cargo para fines delictivos y no para el servicio público. En (Constitución de la Nación Argentina, 1994), artículo 36, quinto párrafo que: "... Atentará asimismo contra el sistema democrático quien incurriere en grave delito doloso contra el Estado que conlleve enriquecimiento, quedando inhabilitado por el tiempo que las leyes determinen para ocupar cargos o empleos públicos...”. (Código Penal Argentino, 2015), artículo 303, inciso 2, apartado b), establece un agravante específico para el caso que el delito de LA sea cometido por un funcionario público: "La pena prevista en el inciso 1 será aumentada en un tercio del máximo y en la mitad del mínimo, en los siguientes casos (...) b) Cuando el 
autor fuera funcionario público que hubiera cometido el hecho en ejercicio $\mathrm{u}$ ocasión de sus funciones. En este caso, sufrirá además pena de inhabilitación especial de tres (3) a diez (10) años...”.

- Sujetos Obligados a reportar operaciones sospechosas: estos sujetos están obligados a informas a la UIF acerca de operaciones sospechosas de las que tomen conocimiento en su actividad. Son el primer filtro en la prevención de los delitos de LA por su presencia en el lugar donde se desarrollan o pueden desarrollarse los hechos y por contar con información privilegiada y evidencia. Cuando un sujeto obligado está involucrado en operatorias de LA, genera un mayor impacto en la matriz.

\subsection{Definición del Impacto}

El impacto busca captar la severidad (o intensidad) del daño que produce una operación de LA. La magnitud está directamente relacionada con el valor de los activos a proteger, las características de la operación y de los sujetos que pueden agravar el daño. Para GAFI, el principal indicador lo constituyen los aspectos relacionados con las características económicas de la operación.

Con respecto a los agravantes, en (United Nations, Office on Drugs and Crime, 1999), se mencionan como agravantes del delito de LA:

- cuando el delito principal esté castigado con una pena privativa de libertad de duración superior a la prevista en los artículos relativos al blanqueo;

- cuando el delito se cometa en el ejercicio de una actividad profesional;

- cuando el delito se cometa en el marco de una organización delictiva.

Los agravantes del impacto de operaciones de LA se agrupan en dos categorías:

- las que se vinculan directamente con la operación sospechosa;

- las relacionadas con los sujetos que intervienen en las mismas.

\subsection{Definición de la Probabilidad}

En el caso específico de la construcción de matrices de riesgo de LA, AUSTRAC y el Grupo Egmont, optan por una concepción instrumental de la probabilidad, relacionándola con "la posibilidad de que un efecto adverso ocurra" (EGMONT, 2008), o bien como "el potencial riesgo de que ocurra una operación de LA en un determinado negocio" (AUSTRAC, 2006).

En el documento guía de la construcción de la matriz de riego publicado por la UIF de Argentina (Unidad de Informacion Financiera Argentina, 2012) se adopta la definición de la probabilidad como el "grado de creencia de que una operación sospechosa de LA 
se verifique como tal, formado a través de un uso racional de la información y de los conocimientos disponibles". Según la UIF, existen determinadas características que incrementan la probabilidad de ocurrencia. Se pueden citar:

- Antecedentes del sujeto: en su experiencia, la UIF ha determinado que los sujetos que presenten antecedentes de investigación previa (administrativa y/o judicial), vinculados a los delitos de LA, incrementan la probabilidad estimada de que la operación sospechosa constituya un ilícito.

- Tipo de actividad: En base a la experiencia de la UIF, se puede elaborar una lista de actividades económicas riesgosas que permitan suponer una mayor probabilidad de que la operación en análisis implique una operación de LA.

- Zonas geográficas riesgosas: Existen determinadas zonas geográficas que incrementan la probabilidad de que una operación sospechosa pueda estar vinculada a delitos de LA. Un ejemplo de tales zonas son: paraísos físcales, países o territorios no cooperantes.

- Estructuras jurídicas: Este indicador se incluye conforme a las recomendaciones del GAFI referidas a la necesidad de adoptar medidas para impedir el uso ilícito de personas y estructuras jurídicas por parte de terroristas y/o lavadores de activos. La falta o ineficiencia de estas estructuras aumentan la probabilidad de ocurrencia de operatorias de lavado.

\subsection{Construcción de la Matriz de Riesgo}

Las matrices - compuestas de filas y columnas donde las filas pueden representar el impacto y las columnas la probabilidad, o viceversa; permiten visualizar el nivel de riesgo a partir de la combinación de estas dos componentes, en base a información disponible.

Como en cualquier propuesta de análisis de riesgo, esta herramienta debe ser revisada periódicamente ante cambios en el contexto. Por ejemplo, en el caso del SJA la aparición de nuevas tipologías a partir de la incorporación de nuevos juegos o modalidades de juego. Por lo tanto, se infiere que es posible construir varias matrices de riesgo acerca del lavado de activos. La organización puede definir distintas matrices orientadas al cliente, como el caso anterior; o netamente relacionada al tipo de juego, o de zona o país donde está ubicada geográficamente la sala.

En laFigura 7 se presenta una típica matriz de riesgo, a nivel cuantitativo.

Vale destacar que en esta matriz es simétrica: se valoriza de la misma forma el impacto y la probabilidad. Por lo tanto, permite clasificar el nivel de riesgo tres niveles que se visualizan con diferentes colores: 1 ) riesgo alto (color rojo) cuando la probabilidad y el impacto tienen valores alto o muy alto; 2 ) riesgo medio (color amarillo) cuando el valor 
del impacto y de la probabilidad es medio; y 3) riesgo bajo (color verde) cuando la probabilidad o el impacto tienen probabilidades baja o muy baja.

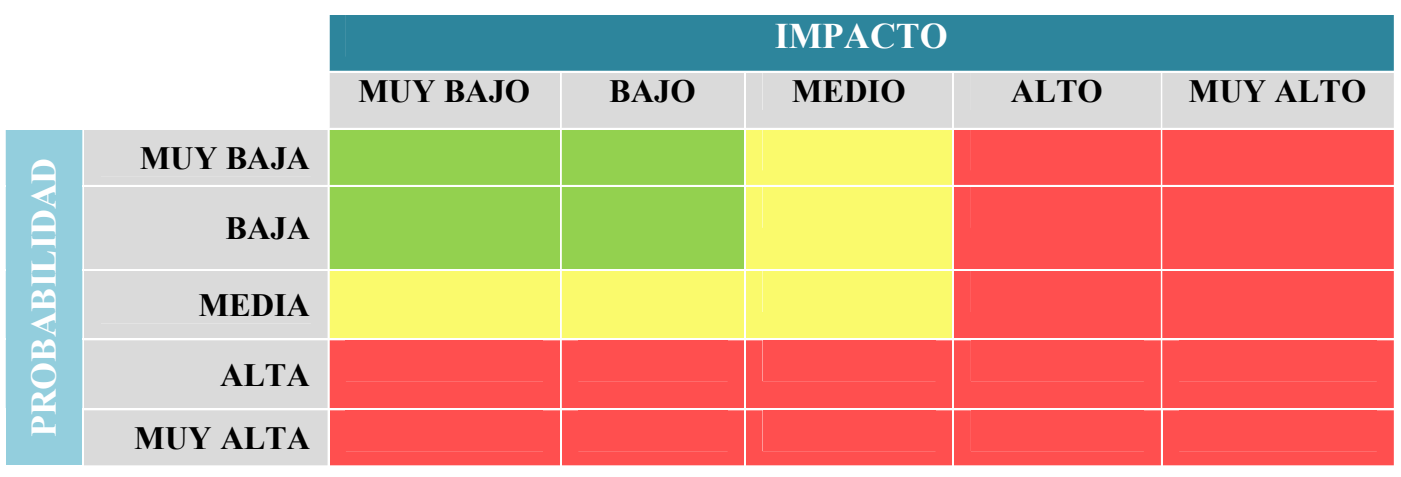

Figura 7 - Típica representación de una matriz de riesgo

Cuando se desea construir una matriz en base a valores cuantitativos se debe establecer una ponderación, tanto para el impacto como para la probabilidad. En la Tabla 4 Valorización del impacto se ejemplifica la determinación de los niveles de impacto en base a una puntuación definida.

\begin{tabular}{|r|l|c|}
\hline \multicolumn{2}{|c|}{ IMPACTO } \\
\hline Clasificación & \multicolumn{1}{|c|}{ Descripción } \\
\hline MUY ALTO & $\begin{array}{l}\text { Grandes consecuencias sobre el orden } \\
\text { económico y financiero }\end{array}$ & $9-10$ \\
\hline ALTO & Efectos moderados, pero significativos & $7-8$ \\
\hline MEDIO & Efectos menores pero significativos & $5-6$ \\
\hline BAJO & Efectos menores & $3-4$ \\
\hline
\end{tabular}

Tabla 4 - Valorización del impacto

En Tabla 5 se detalla la clasificación mediante valores de la probabilidad.

\begin{tabular}{|l|l|l|}
\hline \multicolumn{1}{|c}{ Clasificación } & \multicolumn{1}{c|}{ PROBABILIDAD } \\
\hline Muy Alto (casi certeza) & Plena sospecha de que la operación sea de LA & $9-10$ \\
\hline Alto (Muy probable) & Alta sospecha de que la operación sea de LA & $7-8$ \\
\hline $\begin{array}{l}\text { Medio (Probable) } \\
\text { Bajo (Poco probable) }\end{array}$ & Mediana sospecha de que la operación sea de LA & $5-6$ \\
\hline $\begin{array}{l}\text { Muy bajo } \\
\text { (Muy poco probable) }\end{array}$ & Poco probable que sea una operación de LA & $3-4$ \\
\hline
\end{tabular}


La Figura 8 representa la matriz de riesgo resultante de acuerdo a los valores de impacto y probabilidad definidos previamente.

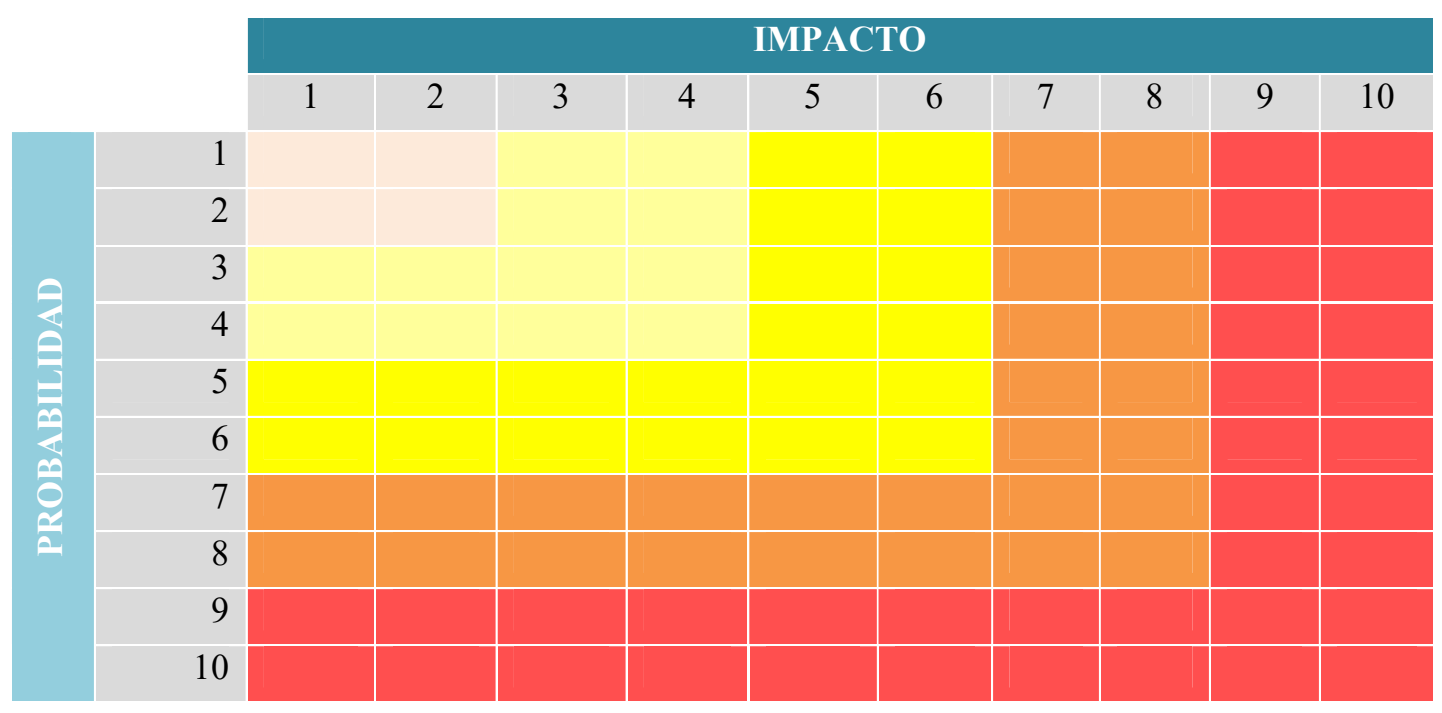

Figura 8-Matriz de riesgo resultante

A modo de ejemplo para construir la matriz, explicamos a continuación los cinco factores que califican el perfil del cliente en el contexto de definición de la matriz de riesgo de LA. Esta clasificación fue presentada por la empresa CODERE en relación a clientes de casinos y salas de juego, en un evento auspiciado por la Asociación de Especialistas Certificados en Antilavado de Dinero (ACAMS). La clasificación de clientes considera:

1. Monto anual de los premios o cambio de valores: el riesgo tiene que ver con la superación de determinados umbrales de valores, considerándose que un cliente que recibe premios o cambios valores altos genera una mayor amenaza.

2. Cliente incluido en listados especiales: el riesgo tiene que ver con la condición especial que adquiere el cliente al estar listado como PEP o como Terrorista, considerándose que esta condición genera una mayor amenaza.

3. País de origen o residencia del cliente: el riesgo tiene que ver con el lugar de origen o residencia del cliente, considerándose que la localización en países definidos por el GAFI como vulnerables a prácticas de LA/FT genera una mayor amenaza.

4. Actividad / profesión del cliente: el riesgo tiene que ver con el tipo de actividad o profesión que realiza el cliente, considerándose que existen algunas de ellas que generan una mayor amenaza. 
5. Modalidad del juego del cliente: el riesgo tiene que ver con el origen de los premios o cambios de valores, considerándose que hay modalidades de juegos, como la ruleta electrónica, que generan una mayor amenaza.

\subsection{Identificación de vulnerabilidades}

Quienes conocen cómo funcionan las salas de juego y la dinámica de los juegos y pagos de premio son las personas indicadas para la identificación de las vulnerabilidades que el sistema puede presentar que permitan que se materialice la amenaza del lavado. Esta actitud colaborativa permite que la organización del SJA optimice su mecanismo de prevención y detección orientado a la mejora y para el regulador es una forma de comprender el contexto y definir políticas efectivas.

A continuación, se detalla un caso de colaboración entre el estado y una empresa de luego de azar en la detección de vulnerabilidades. La empresa Caesars Entertainment del Reino Unido (Caesars Entertainment ( $U K$ ). Failures in anti-money laundering controls public statement, 2015), colaboró con la Gambling Comission, (un organismo público independiente soportado por el Department for Culture, Media and Sport del Reino Unido para la regulación del juego) en la detección de debilidades en los controles existentes para mitigar el lavado de activos. Los Casinos examinados fueron el Playboy Club London Limited y el London Clubs LSQ Ltd. Luego del relevamiento efectuado, la Comisión señaló que los procesos y procedimientos no cumplían con los requerimientos de las regulaciones del 2007 (Money Laundering Regulations). Las fallas detectadas atentaban contra:

- una valoración apropiada del riesgo del cliente;

- la demostración de niveles apropiados de monitoreo en curso;

- atender en forma adecuadamente rigurosa los chequeos de debida diligencia;

- asegurar que los registros intervinientes en la toma de decisiones relacionados con clientes de alto riesgo como PEPs estuvieran completos;

- obtener información adecuada con respecto a la fuente de fondos de los clientes;

- asegurar que la debida diligencia al cliente, los registros y las políticas sobre esos registros sean comprensibles;

- comprometer chequeos de debida diligencia en clientes de otras compañías de ultramar del grupo Caesar.

\subsection{Tipologías de lavado}

Se entiende por tipología de lavado de activos a la clasificación y descripción de las técnicas utilizadas por las organizaciones criminales para dar apariencia de legalidad a los fondos de procedencia ilícita y transferirlos de un lugar a otro o entre personas para financiar sus actividades criminales (Asociación de Loterías, 2014). Cuando una serie de esquemas de lavado de activos (LA) o financiamiento del terrorismo (FT) parecen 
estar construidos de manera similar o usan los mismos o similares métodos, pueden ser clasificados como una tipología (Perez Serpa de Trujillo, 2013).

Investigar acerca de las tipologías es imprescindible para implementar, ajustar y mejorar controles que permitan combatir los delitos. Es una actividad continua para detectar nuevos contextos y situaciones que se van incorporando en el lavado de activos. Una vez determinadas las tipologías de acuerdo al ambiente de juego (tipo de juego, zona, legislación vigente y otros elementos que intervienen), la organización de juego de azar está en condiciones de definir un conjunto de alertas para la detección de situaciones de lavado. Las señales de alerta son elementos que permiten detectar la posible presencia de operaciones de "lavado de activos".

Las tipologías criminales se presentan tanto en el nivel de la participación societaria en las empresas destinadas a la explotación de casinos y otras casas de recreación permitiendo el lavado del dinero ilícito de los accionistas-, como en el nivel del juego propiamente dicho, en el momento del cobro de los premios.

En general las tipologías de LA se agrupan en tres variantes básicas (GAFISUD, 2003): 1) Caso de abuso: se emplea a una de las actividades/profesiones con el fin de lavar fondos sin el conocimiento del profesional; 2) Caso de colusión: cuando el profesional presta sus servicios voluntariamente y conociendo el fin ilícito (intermediario corrompido) o cuando el profesional está involucrado en la actividad criminal en general (miembro de la organización ilícita etc.) lo que constituiría auto-lavado; y 3) Caso de empresa/ entidad de pantalla: cuando se constituye una empresa utilizando fondos ilícitos o se simula la ejecución de una de las profesiones/actividades para camuflar una actividad criminal o se estructuran fondos ilícitos integrándolos en los ingresos/flujos financieros de una empresa que se dedique a una actividad lícita.

Las tipologías se desarrollan de acuerdo a varias componentes que intervienen en hacerlas viables, incluyendo: 1) el lugar donde se ubique la casa de juego de azar (zona franca, una zona limítrofe o una zona conocida por reiteradas y conocidas actividades ilícitas); 2) los juegos que se ofrecen; 3) la inexistencia de normativa o la existencia sin control; y 4) la cultura de juego de la zona o el país.

En el caso del sector de juegos de azar donde se puede jugar utilizando fichas, este proceso permite canjear fondos ilícitos aprovechando del proceso de la compraventa y del cambio de fichas. En algunos casos se ofrecen a los clientes habituales una cuenta de cliente que permita depositar los fondos para jugar y los premios ganados. Tales cuentas pueden ser utilizadas para la estructuración de fondos ilícitos.

El dinero proveniente del narcotráfico genera un flujo de billetes de baja denominación. Este dinero es detectado utilizando perros en aeropuertos, que los descubren por el olor a la droga o por la humedad que presentan debido a haber estado almacenados en depósitos en zanjas o humedales. Esta última modalidad era muy común cuando se escondía en la selva el dinero proveniente de secuestros o extorsiones, según un informe referido a las FARC por UNODC. Una forma de cambiar estos billetes de baja 
denominación por otros valores (y lavarlos) consiste en que el lavador concurra al casino con los billetes de baja denominación y los cambie.

Otra técnica que se suele observar es la compra de comprobantes de premios ganadores con fondos de origen ilícito para recaudar el premio y así justificar los fondos. Otra modalidad ocurre en las máquinas tragamonedas, donde el lavador introduce efectivo, acumula crédito y juega poco, y luego mediante el ticket, se dirige a la caja para cobrar los créditos.

En cuanto a los clientes, se deberá prestar mayor atención a aquellos clientes que habitualmente apuestan montos altos; como a los casos que la misma persona gane de forma repetida montos altos.

Para definir políticas de PLA se hace imprescindible conocer el contexto de juego y analizar cuáles son las tipologías.

\subsection{Algunos ejemplos}

En el informe de la UIAF y en GAFILAT acerca de tipologías, se detallan algunos casos relacionados con el sector de juego de azar (Colombia, 2013).

\section{Compra de "premios" por parte de una organización delictiva}

Esta tipología involucra a una organización delictiva que detecta a ganadores de premios recorriendo salas de juego, o lugares cercanos a ventanillas de cobro. Usando dinero proveniente de sus actividades ilícitas, se le propone al ganador comprar su premio. Esta tipología se puede presentar con cualquier tipo de ingresos ocasionales o premios provenientes de actividades tales como herencias, indemnizaciones de seguros extranjeros, concursos, rifas, loterías, apuestas y juegos de azar. El beneficiario inicial acepta el acuerdo y recibe dinero o bienes de procedencia ilícita. Para ello, entrega el título o cede el derecho de reclamación del premio. Uno de los integrantes de la organización delictiva se encarga de reclamar el premio y pagar los impuestos correspondientes, con el propósito de justificar el incremento de su patrimonio. Por lo general, los bienes recibidos como premio son transferidos o vendidos, con el fin de mantener disponibles los recursos para la organización delictiva.

Para este tipo de modalidad, se definieron las siguientes como señales de alerta:

- personas que incrementan su patrimonio de manera inesperada y manifiestan haberse ganado un premio, sin que exista un registro oficial del pago del mismo;

- personas que incrementan injustificadamente su patrimonio sin una aparente justificación;

- personas que frecuentemente reclaman premios como ganadores de diferentes concursos, eventos, loterías, apuestas, etc.;

- personas que justifican su incremento patrimonial o transacciones financieras en la "venta o cesión" de premios a favor de un tercero. 


\section{Declaración de un premio ficticio obtenido en el exterior, para el ingreso a un país local de dinero ilícito}

Supongamos que una organización delictiva necesita ingresar al país fondos ilícitos obtenidos en el exterior. Esta tipología consiste en que la organización contacta un grupo de personas para viajar al exterior en el marco de algún premio o distinción obtenido (estas personas están al tanto de la situación). La idea es traer el premio obtenido en el exterior e ingresarlo al país local. Este dinero proviene de actividades ilícitas de la organización delictiva realizadas en el exterior.

La organización prepara un contexto que provea historia razonable o creíble para las autoridades del país local, que justifique la obtención de un premio. Además, entrena adecuadamente al personal que viajará proveyendo documentación respaldatoria, documentos de identidad (todo falso o adulterado) para sostener el plan. Una vez en el exterior, la persona contactada recibe las divisas en efectivo o el bien que deben ser llevados al país local mediante un integrante de la organización delictiva. Cuando la persona contactada regresa al país local, realiza los controles aduaneros, cambiarios y tributarios para ingresar las divisas y/o bienes obtenidos como premio, por su supuesta participación en un concurso o evento en el exterior. Esta persona presenta los documentos ilegales que soportan la obtención del premio y cancela los impuestos correspondientes en el país local.

El ingreso de divisas también puede darse mediante una transferencia ordenada por los supuestos organizadores del evento o concurso, a través de los intermediarios que dispongan en el exterior. Para ello, un intermediario en el país local recibe una orden de pago de las divisas a favor del presunto ganador y las convierte en moneda local. Una vez que las divisas o los bienes están disponibles en el país local, se transfieren a la organización delictiva y la persona contactada recibe la comisión pactada.

Para este tipo de modalidad, se definieron las siguientes como señales de alerta:

- personas que registran frecuentes movimientos migratorios y declaran el ingreso de divisas o bienes como producto de premios recibidos en concursos o eventos a los que presuntamente asistieron;

- incremento patrimonial repentino de una persona que lo justifica en presuntos premios obtenidos en el exterior, pero que son rápidamente transferidos;

- transferencia de dinero o propiedades de una persona que aparentemente ganó un concurso o evento en el exterior, a terceras personas de las que no se evidencia una relación clara o una transacción comercial formal.

\section{Tours de juegos para turistas}

Una modalidad es la organización de tours de juegos, donde se desplazan a un conjunto de turistas a jugar en algún lugar. Incluye el traslado de fondos a través de las fronteras e involucra la intermediación de varios operadores, lo que ayuda a evitar la 
identificación de los lavadores De esta manera se hacen circular y se lavan importantes sumas de dinero.

\section{Casinos flotantes en cruceros}

Esta metodología aprovecha vacíos regulatorios de la ley internacional y los espacios extraterritoriales. Se realizan viajes de alta mar con una importante y lujosa oferta de juego.

\subsection{El rol de las Tecnologías de la Información y las Comunicaciones (TIC)}

El uso de las TICs para el juego, tanto presencial como remoto, abrió un nuevo capítulo en la forma de jugar. La posibilidad de engaño en el juego presencial y manual tenía que ver con la habilidad de quien mezclaba y repartía las cartas. Como primera aplicación de las TIC en este sector, el uso de tragamonedas y las ruletas electrónicas eliminaron la interacción con el crupier o tallador. Este hecho facilitó nuevas tipologías para LA. Asimismo, permitió el registro de información para su uso rápido y oportuno para quienes tienen como misión detectar y prevenir acciones de lavado.

La incorporación de la tecnología también introdujo nuevos conceptos; por ejemplo, el CiberLavado y el Crimeware. CiberLavado es el encubrimiento de actos criminales basado en soluciones aportadas por las TICs en los pagos electrónicos o en apuestas on line. Crimeware es el nombre que recibe el software desarrollado para obtener información de usuarios finales para ser utilizados en crímenes posteriores.

En el informe de gestión de la Unidad de Información y Análisis Financiero (UIAF) de Colombia se destaca que los logros que se han alcanzado en materia de prevención y detección están apoyados en unos avances en tecnologías de la información “...que son la base para maximizar y potencializar la capacidad de análisis de la Unidad en niveles aptos para desarrollar un ciclo de inteligencia más eficiente y sólido..." (Unidad de Información y Análisis Financiero - UIAF, 2013).

Ante el surgimiento de distintas fuentes de datos se hace imprescindible un sistema con tecnología de punta adecuada para centralizar, almacenar y proteger la seguridad de la información, como bien lo requiere la Recomendación 29 del GAFI. Se hace necesario acceder de manera ágil a la información recabada, analizarla en contexto, y sustraer las piezas y temáticas clave para entender el panorama y el valor de la información obtenida.

El uso de software que permite detectar movimientos sospechosos o flujos inexplicables de dinero entre cuentas de diferentes bancos, o la compra inusual (o demasiado usual) de bienes por parte de sociedades o particulares ubicados en distintos países o continentes, en el marco de la colaboración internacional, sistematiza la implementación de alertas. No obstante, las medidas las toma cada país. Por eso no es suficiente la colaboración internacional, si no la definición de políticas y normativas locales. 


\section{El robo de identidad}

En aquellos juegos de apuestas donde se puede participar mediante el uso de tarjetas de crédito o débito, es decir, donde el pago es remoto o presencial, pero sin usar efectivo, una de las alternativas para participar para lavar dinero es utilizar una identidad fraudulenta. El robo de identidad (o usurpación de identidad) es la apropiación de la identidad de una persona, es decir, hacerse pasar por esa persona, asumir su identidad ante otras personas en público o en privado. El objetivo es acceder a ciertos recursos o la obtener créditos y otros beneficios en nombre de esa persona. El robo de identidad también es utilizado con el fin de perjudicar a una persona: difamarlo o manchar su nombre con diversos fines que el criminal busque (Wikipedia, 2016).

El caso más común hoy en día se da cuando un atacante, por diferentes medios obtiene la información personal de un tercero y la utiliza ilegalmente para su provecho o para el beneficio de la organización delictiva de la cual forma parte.

La identidad de una persona a los fines de su identificación se constituye por un conjunto de datos que la individualizan, como el apellido y nombre, teléfono, domicilio, fotografías, números de identificación (DNI, pasaporte, CUIT, etc.). También mediante la propiedad de números de cuentas bancarias, patentes de autos, o partidas inmobiliarias. Esta información puede obtenerse en forma fraudulenta para realizar actividades ilegales, con graves consecuencias ("El robo de la identidad y sus consecuencias," n.d.).

Con la información obtenida se pueden realizar numerosas actividades fraudulentas, por ejemplo:

- Pérdida económica: Con los datos de la cuenta bancaria, el usurpador puede sustraer dinero de la cuenta o realizar compras como si fuera la víctima.

- Suplantar la identidad de la víctima: El usurpador puede crear una cuenta nueva, o modificar la contraseña de acceso del usuario a alguna de sus cuentas. De esa forma la víctima no tiene más el control y queda sólo para acceso del atacante. También se puede utilizar esta modalidad para lo que se llama ciber-acoso o ciber-bullying para generar diferentes tipos de contenidos en nombre de la víctima, con la intención de ofrecer una imagen negativa, o para chantajear al usuario legítimo si desea recuperar su cuenta. Aunque no haya pérdida económica, la suplantación de identidad puede ocasionar problemas de credibilidad y afectar a la reputación de la víctima.

Los principales métodos empleados por los delincuentes para adquirir información personal de las víctimas utilizando Internet son:

- Lograr instalar un malware (programa maligno) para la recopilación de información personal en el o los dispositivos de la víctima sin su consentimiento o conocimiento;

- Ingeniería social: hacer que sea la misma víctima quien proporcione sus datos mediante artilugios aprovechando la tendencia natural de la gente a reaccionar 
de manera predecible en ciertas situaciones. La forma más común de ingeniería social es a través de correos electrónicos o sitios web falsos, que tengan la misma apariencia que la entidad que se pretende suplantar. Una de las técnicas más populares es el phishing, donde el atacante se hace pasar por una entidad real, generalmente un banco, o una empresa de tarjetas de crédito, con el objeto de obtener los datos del usuario en recursos contratados con esa empresa (cuenta bancaria, contraseña, número de tarjeta y código de seguridad, etc.)

La mejor manera de evitar el robo de identidad es la prevención. En un contexto de concientización acerca del uso de las TICs, se pueden sugerir algunas prácticas de detección de situaciones sospechosas (revisar el informe bancario, revisar los resúmenes de tarjeta verificando registros de movimientos no habituales o que no se recuerde haber realizado) o más específicas de la prevención, como por ejemplo, usar contraseñas robustas y diferentes para cada cuenta, no proporcionar información personal por teléfono o Internet si no se tiene la certeza de que se está hablando con la persona indicada, teclear la dirección en el navegador en lugar de "clickear" sobre el enlace que aparezca en correo o página Web, entre otras.

Por último, el uso de tarjetas de crédito fraudulentas es una de las tipologías en el juego on line. 


\section{JUSTIFICACIÓN DELA DEFINICIÓN DE UN MODELO DE GESTIÓN DE PREVENCIÓN}

En esta sección se justifica el desarrollo de un modelo de gestión como una herramienta de involucramiento de toda la organización, transversal a sus procesos y utilizando la gestión de riesgos como una metodología para detectar vulnerabilidades y amenazas en base a las tipologías propias de cada casa de juego de azar. Se describen Marcos Referenciales y Resoluciones UIF que aportan en forma directa a este trabajo de tesis.

Por último, se justifica mediante la validación que surge de la discusión de lo aquí planteado en diferentes foros donde la autora expuso y participó.

Se abordan diferentes enfoques: orientado a procesos, al riesgo y a la prevención. Se define el alcance y se encuadra este modelo en las pautas que se sugieren en el contexto de la norma ISO/IEC 27001, aprobada y publicada como estándar internacional en octubre de 2005 por International Organization for Standardization (ISO) y titulado "Information technology - Security techniques - Information security management systems - Requirements", luego actualizado en el año $2013^{23}$. Un marco de prevención de lavado de activos en el sector de juegos de azar está directamente relacionado con la seguridad. Por eso, se considera adecuado relacionar un modelo de gestión para la prevención con lo que se pretende de un modelo de gestión de la seguridad.

Considerando que el espíritu de un marco de PLA es aportar a las buenas prácticas en la temática, y por lo tanto promover su aplicabilidad internacional en el sector del juego de azar, es un requisito fundamental alinearlo con la normativa existente y las exigencias de cumplimiento del país que lo aplique. Por este motivo, cada organización del sector de Juegos de Azar deberá establecer, documentar, implementar y mantener este marco de prevención de LA, mejorándolo continuamente ante la aparición de nuevos escenarios, e involucrando en su cumplimiento a todos sus miembros. Adicionalmente, ante las características globales del delito de LA, la organización debe comprometerse a participar y establecer contactos internacionales formales y fluidos con organizaciones afines, y compartir rápidamente nuevas situaciones detectadas.

\subsection{Enfoque orientado a procesos}

Específicamente, una organización que explota juegos de azar realiza un conjunto de procesos orientados a prevenir el lavado de activos y detectar situaciones sospechosas de serlo. En particular, ISO estipula que una organización del SJA debe establecer, implementar, mantener y mejorar de manera continua un sistema de gestión para la

\footnotetext{
${ }^{23}$ Si bien en la versión 2013 de la ISO/IEC 27001 se ofrece una mayor libertad en la metodología al eliminar el enfoque a procesos, en nuestro modelo lo mantenemos considerando que es una forma que facilita la agrupación e identificación de las actividades, los roles y responsabilidades, el seguimiento, la auditoría y la medición de desempeño.
} 
prevención del LA, documentado dentro del contexto de las actividades generales del negocio de la organización, y de los riesgos que enfrenta (ISO/IEC 27001:2013. Information Security Management, 2013).

Para poder funcionar adecuadamente una organización debe identificar y administrar sus actividades. Estas actividades, son coordinadas en procesos, que transforman entradas en salidas. Los distintos procesos están a su vez relacionados, creando un mapa de proceso y relaciones.Este enfoque de procesos en una organización, permite identificarlos, definir sus interacciones y administrarlos. Es lo que se llama un enfoque orientado a procesos.

Los enfoques orientados a procesos permiten relacionar actividades, con roles y responsabilidades, asignar recursos y establecer métricas e indicadores para poder realizar propuestas de mejoras. Por lo tanto, para construir un enfoque orientado a procesos, se debe:

- entender la organización, su misión, sus objetivos, sus requerimientos;

- realizar un análisis de riesgo, determinar su necesidad de administrar los riesgos, e implementar controles adecuados;

- monitorear las operaciones para garantizar que se cumplen los objetivos y corregir el rumbo, en caso de ser necesario;

- mejorar los procesos y sus relaciones en base a métricas e indicadores adecuados.

\subsection{Enfoque orientado al riesgo}

En febrero de 2012, el GAFI unificó las "40 Recomendaciones" y las "IX Recomendaciones Especiales". Uno de los cambios significativos fue la incorporación de un Enfoque Basado en el Riesgo, concentrado en una sola recomendación. Esto obliga a que los países deban emprender el desarrollo de una evaluación de riesgos a escala nacional, lo que exige un análisis realista de la situación en los diferentes campos y el establecimiento de normativas y controles más efectivos.

El cambio define que se debe designar una autoridad o mecanismo para coordinar acciones para evaluar los riesgos, y aplicar recursos encaminados a asegurar que se mitiguen eficazmente los riesgos. Según esa evaluación, los países deben aplicar un enfoque basado en riesgo para asegurar que las medidas para prevenir o mitigar el lavado de activos y el financiamiento del terrorismo sean proporcionales a los riesgos identificados. (Recomendación 1 GAFI).

\subsection{Enfoque hacia la prevención}

El enfoque orientado a la prevención se basa en la definición y establecimiento de controles preventivos. Para establecer controles efectivos se debe hacer un análisis previo para no: a) sobre-dimensionar el control - lo que puede resultar en un costo 
excesivo o perjudicar al funcionamiento del negocio; ob) sub-dimensionarlo - no llegar a cumplir su función.

La prevención de LA está directamente relacionada con las tipologías que se pueden desarrollar en cada juego. La capacitación y concientización del personal es trascendental pues ellos serán los que detecten actividades o comportamientos inusuales que pueden ocultar maniobras de lavado. En este caso, el personal que esté adecuadamente entrenado sabrá rápidamente como proceder. El enfoque de prevención de LA es un enfoque integrado donde jugadores, empleados, operadores, reguladores y organismos competentes trabajan en conjunto, para estar preparados para abordar situaciones emergentes.

En este modelo debe definirse una estructura con roles y responsabilidades, que sea operativa y proactiva. Según la Recomendación 1 del GAFI se debe designar una autoridad o mecanismo para coordinar acciones para evaluar los riesgos, y aplicar recursos encaminados a asegurar que se mitiguen eficazmente. Según esa evaluación, los países deben aplicar un enfoque basado en riesgo para asegurar que las medidas para prevenir o mitigar el lavado de activos y el financiamiento del terrorismo sean proporcionales a los riesgos identificados.

Las organizaciones del SJA como institución con APNFD, deben identificar, evaluar y tomar acciones eficaces para mitigar sus riesgos de lavado de activos.Para esto se debe tener en cuenta que las características globales del delito, y el avance de la tecnología generan nuevas formas y tipologías. Por ese motivo, las organizaciones deben garantizar la formación, capacitación y concientización de sus empleados en un marco de mejora continua. En este aspecto, el contacto y la colaboración con organismos internacionales ayuda a identificar las acciones eficaces.

El objetivo de desarrollar este sistema es minimizar la concreción de la amenaza del lavado de activos, reducir el impacto en la ocurrencia y garantizar razonablemente la seguridad del jugador.

\subsection{Alcance}

El alcance de esta propuesta comprende las personas físicas o jurídicas que como actividad habitual exploten juegos de azar. A fin de identificar a estas personas, la organización debe establecer un listado de sus "stakeholders" o interesados, es decir las personas $u$ entidades a los que afecta el negocio de la organización. Una vez identificados los interesados, es posible establecer las relaciones entre los mismos y sus responsabilidades en la prevención de LA. Jugadores, empleados, reguladores, operadores, entidades beneficiarias, organismos de control, todos ellos deben ser identificados y establecer cómo se relacionan con la organización y su grado de participación en las políticas de prevención de acuerdo a este marco.

Lo que se detalla en este marco no debe contradecir normativas o regulaciones que establezca cada país. Los requisitos son genéricos y al estar basados en las buenas prácticas reforzarán las pautas de normas existentes o lo que el sentido común y una 
clara definición de responsabilidades aportarán a organización de aquellos países que no tengan aún un marco normativo.

Se intenta que lo propuesto sea aplicable a organizaciones que tienen como actividad habitual la explotación de juegos de azar sin hacer consideraciones de tamaño, tipo y naturaleza. Es posible que las características de algunas organizaciones de SJA sean muy pequeñas como para desarrollar y mantener un sistema de estas características. Si bien lo que se plantea puede aplicarse en pequeñas, medianas o grandes organizaciones, las pequeñas pueden no contar con los recursos económicos y humanos calificados.

Por otra parte, los reguladores pueden establecer un modelo de responsabilidad compartida, de obligaciones definidas, formalizado y documentado, con auditorías periódicas.

A continuación, se describen las pautas para desarrollar, implementar, operar y monitorear este sistema.

\subsection{Pautas de desarrollo}

Adoptando el formato propuesto en (ISO/IEC 27001:2013. Information Security Management, 2013), a continuación se enumeran un conjunto de pautas de desarrollo. Orientado a mantener un sistema de gestión de la prevención, la organización debe:

1) Definir el alcance y los límites del sistema en términos de las características del negocio, la organización, su localización, activos y tecnología, incluyendo detalles de, y justificación por, cualquier exclusión del alcance.

2) Definir una política, aprobada por la máxima autoridad, del sistema de gestión en términos de las características del negocio, la organización, su localización, activos y tecnología que: i) incluya un marco de trabajo para fijar objetivos y establezca un sentido general de dirección y principios de acción; ii) tome en consideración requisitos del negocio, legales y regulatorios, así como obligaciones contractuales que puedan incidir; iii) se alinee con el contexto de gestión de riesgos estratégicos de la organización en el que ocurrirá el establecimiento y mantenimiento del sistema de gestión; y iv) establezca los criterios contra los que el riesgo será valorado.

3) Definir el alcance de la evaluación (análisis y valoración) de riesgos para la organización. Esto incluye: i) identificar una metodología de evaluación de riesgos que sea apropiada para el sistema, y a los requerimientos del negocio, del marco legal y regulatorio;y ii) desarrollar los criterios de aceptación de riesgos e identificar los niveles aceptables de riesgo.

4) Identificar los riesgos. Esta actividad incluye la identificación de: i) los activos dentro del alcance del sistema y a sus propietarios;ii) las amenazas para esos activos 
ante situaciones de LA; iii) las vulnerabilidades que podrían ser explotadas por esas amenazas; y iv) los impactos y consecuencias.

5) Analizar y valorar los riesgos, incluyendo: i) evaluar el impacto del negocio sobre la organización que podría resultar ante la concreción de situaciones de LA, desde daño a la imagen o no cumplimiento de normativas, entre otros escenarios; ii) evaluar la probabilidad de ocurrencia de acciones de LA de acuerdo a las amenazas y vulnerabilidades predominantes, y los impactos asociados con los activos y los controles implementados actuales; iii) estimar los niveles de riesgo; y iv)determinar cuando los riesgos son aceptables o requieren de un tratamiento utilizando el criterio de aceptación de riesgos.

6) Identificar y evaluar las opciones para el tratamiento de riesgos. Las posibles acciones incluyen:i) aplicación de controles apropiados; ii) aceptación de riesgos deliberada y objetiva, proveyendo clara satisfacción a las políticas de la organización y de los criterios de aceptación de riesgos; iii) prevención de riesgos; iv) transferencia de los riesgos asociados al negocio a terceras partes, por ejemplo: empresas de seguridad, y transferencia de fondos, entre otros.

7) Seleccionar los objetivos de control y controles para el tratamiento de riesgos. Los objetivos de control y los controles deben ser seleccionados e implementados para alcanzar los requerimientos identificados en el análisis de riesgos y en el proceso de tratamiento de riesgos. Esta selección debe tener en cuenta los criterios de aceptación de riesgos, así como los requisitos contractuales, legales y regulatorios.

8) Obtener autorización de la máxima autoridad y su apoyo para implementar y operar el sistema.

9) Preparar una declaración formal que incluya: i) los objetivos de control, los controles seleccionados y razones para su selección; y ii) los objetivos de control y controles implementados en la actualidad.

En el capítuloPAUTAS PARA EL DESARROLLO DEL SISTEMA DE GESTIÓN6se definen un conjunto de elementos que consideramos clave en la elaboración de políticas de prevención en este contexto.

\subsection{Implementar y operar el sistema}

A fin de poder implementar y operar el sistema, la organización debe:

1) Formular e implementar un plan de tratamiento de riesgos que identifique la acción apropiada de la administración de recursos, responsabilidades y prioridades para gestionar los riesgos ante situaciones de LA y que alcance los objetivos de control 
identificados, los cuales incluyen consideraciones sobre la inversión y la asignación de roles y responsabilidades.

2) Definir cómo medir la eficacia de los controles seleccionados o grupos de controles y especificar cómo esas medidas se utilizarán para evaluar la eficacia del control para producir resultados comparables y reproducibles.

3) Implementar programas de entrenamiento y concientización.

4) Gestionar la operación del sistema.

5) Gestionar los recursos del sistema.

6) Implementar el manual de procedimientos y otros controles capaces de permitir la detección temprana de los eventos de seguridad y la respuesta a los incidentes de seguridad.

\subsection{Monitorear y revisar el sistema}

Una vez que el sistema está implementado y en operaciones, a fin de monitorearlo y revisarlo, la organización debe:

1) Ejecutar procedimientos de monitoreo y revisión y otros controles para: i) detectar tempranamente los errores (reales o potenciales); ii) identificar tempranamente intentos y brechas e incidentes de seguridad satisfactorios; iii) permitir la gestión para determinar si las actividades se están desarrollando como se espera; iii) ayudar a detectar eventos y de ese modo prevenir incidentes; y iv) determinar si las acciones tomadas para resolver brechas de seguridad fueron eficaces.

2) Realizar revisiones regulares sobre la eficacia del sistema (incluyendo la concordancia de la política del sistema y objetivos y revisión de los controles de seguridad) tomando en cuenta los resultados de las auditorías de seguridad, incidentes, resultados desde la eficacia de las métricas, sugerencias y comentarios de todas las partes interesadas.

3) Medir la eficacia de los controles para verificar que los requerimientos de seguridad se han alcanzado.

4) Revisar las evaluaciones de riesgo a intervalos planificados y revisar los riesgos residuales y los niveles de riesgos aceptables identificados, teniendo en cuenta los cambios para:i) la organización; ii) la tecnología;iii) los procesos y objetivos del negocio; iv) las amenazas identificadas; v) la eficacia de los controles implementados; y vi) eventos externos, tales como cambios legales o regulatorios 
del ambiente, cambios en las obligaciones contractuales y cambios en el clima social.

5) Conducir auditorías internas a intervalos planificados.

6) Emprender una revisión de la dirección del sistema a intervalos regulares para asegurar que el alcance permanece adecuado y se identifican las mejoras al sistema.

7) Actualizar los planes de seguridad para tener en cuenta los hallazgos de las actividades de monitoreo y revisión.

8) Registrar las acciones y eventos que podrían tener un impacto en la eficacia o rendimiento del sistema.

\subsection{Mantener y mejorar el sistema}

La organización debe, regularmente:

1) Implementar las mejoras identificadas en el sistema.

2) Tomar acciones correctivas y preventivas apropiadas. Aplicar las lecciones aprendidas de las experiencias de seguridad de otras organizaciones o de la propia organización.

3) Comunicar las acciones y las mejoras a todas las partes interesadas con el nivel de detalle apropiado a las circunstancias y, cuando sea relevante, acordar cómo proceder.

4) Asegurar que las mejoras alcanzan sus objetivos.

\subsection{Marcos de Referencia y Normativa}

En cualquier organización, el crecimiento económico, la estabilidad política y la seguridad se logran mediante una buena gobernanza en todos los niveles. Según (OSCE, 2012b):

"la buena gobernanza y la gobernanza empresarial, el Estado de derecho $y$ las instituciones consolidadas constituyen lasbases esenciales para una economía sólida que permita a nuestros Estados reducir la pobrezay la desigualdad, potenciar la integración social y las oportunidades para todos, atraer lainversión y proteger el medio ambiente”. 
La metodología sugerida por GAFI indica que un sistema de prevención de LA efectivo requiere ciertos elementos estructurales: estabilidad en las políticas, un alto nivel de compromiso, instituciones estables donde estén presentes la responsabilidad, la integridad, la transparencia; la ley y un sistema judicial eficiente, independiente y competente. La falta o debilidad de estos elementos atentan contra la implementación del sistema de prevención(FATF/OECD, 2013).

Existen hoy diferentes marcos y guías orientados al Juego Responsable, en la mayoría de los casos en el contexto de la Responsabilidad Social Corporativa (RSC) o Responsabilidad Social Empresarial (RSE). También existen guías en el marco de la prevención de LA. Sin embargo, las recomendaciones de GAFI son una guía aprobada internacionalmente y la referencia habitual en todo documento sobre prevención de lavado.

\subsubsection{Marcos orientados a Juego Responsable (JR)}

Entre otros se consultan los siguientes marcos específicos del juego responsable:

- Marco de Evaluación de Responsabilidad Social Corporativa y Gestión Responsable del Juego. Corporación Iberoamericana de Loterías y Apuestas de Estado (CIBELAE). 2012.

- Marco de Juego Responsable. Guía de Adhesión. Word Lottery Association (WLA). Edición 2012-2013

La Prevención de Lavado de Activos está considerada como una política que se encuadra dentro de las de Juego Responsable (JR). Sin embargo, el objetivo es prevenir que pueda materializarse el delito de lavado.

A nivel internacional existen guías, recomendaciones, que se alinean en el concepto de buenas prácticas. Son referencias probadas que deberían tenerse en cuenta al momento que cada país o región define su normativa relacionada. Entre otras se citan:

- Anti-Money Laundering Guidelines. Recommended Anti-Money Laundering (AML) Practices for Lottery Operators Worldwide. WLA.

- American Gaming Association (2014). Best Practices for Anti-Money Laundering Compliance.

- Recomendaciones de GAFI. Grupo de Acción Financiera Internacional (GAFI).

- National Money Laundering and Terrorist Financing Risk Assessment. GAFI. Febrero 2013

Plantear políticas de PLA se relaciona con estándares o marcos que están orientados a las mejoras de los procesos y a una garantía razonable de la seguridad de los sistemas de información en sus tres criterios (confidencialidad, integridad, disponibilidad), entre otros:

- Norma ISO/IEC 27001:2013. Information technology - Security techniques Information security management systems — Requirements. 
- National Institute of Standards and Technology, NIST. NIST Special Publication 800-39. Managing Information Security Risk. Organization, Mission, and Information System View.

- Norma ISO/IEC 27005:2011

\subsubsection{Marco de evaluación de RSC y Gestión Responsable de CIBELAE}

En el Marco de Juego responsable de CIBELAE se indica que:

"“...Las Loterias de Estado que apliquen políticas de RSC y Gestión Responsable del Juego se deben caracterizar por las siguientes prácticas:

1) Ser una organización abierta y orientada a todos sus grupos de interés, manteniendo diálogo con todos ellos.

2) Tener una vocación de permanencia en el tiempo, lo que las obliga a una adecuada gestión de sus bienes tangibles e intangibles y a evaluar los riesgos, asi como a integrar la sostenibilidad en su estrategia....".

En este marco se describen una serie de requisitos para RSC y para Juego Responsable, como así también las pautas de certificación. En particular, los requisitos que se exigen acerca de la Responsabilidad Social Corporativa incluyen: 1) Buen gobierno; 2) Transparencia; 3) Financiación a las buenas causas; 4) Relaciones y diálogo con los Grupos de Interés; 5) Conciencia medioambiental; 6) Buena administración de proveedores y suministradores; 7) Política de comunicación institucional y comercial; y 8) Incentivo al voluntariado corporativo.

En cuanto a los requisitos acerca de la Gestión Responsable del Juego, se indican: 1) Investigación sobre aspectos de Juego Responsable; 2) Formación de empleados; 3) Gestión de puntos de venta; 4) Diseño de nuevos juegos; 5) Incorporación de nuevos canales; 6) Publicidad y marketing; 6) Información a los participantes; y 7) Cooperación con otras organizaciones.

Los niveles que considera para la certificación son:Nivel 1: Autoevaluación; Nivel 2: Planificación; Nivel 3: Implementación; y Nivel 4: Maduración.

\subsubsection{Marco de Juego Responsable de la WLA}

El Marco de Juego Responsable (MJR) de la WLA define 4 niveles de logro y 10 ítems del programa, en los cuales se explica cómo las loterías pueden demostrar su nivel de compromiso con los Principios del Juego Responsable (JR) de la WLA, enunciados en el MJR. Considera las diferencias tanto culturales como regionales y ha sido diseñado con el fin de complementar y mejorar- no reemplazar- las medidas de juego responsable que cada operador de lotería ha adoptado. 
Cada uno de los cuatro niveles de logro refleja cuán exitosa ha sido la implementación de los Principios del JR en las operaciones cotidianas de una determinada lotería. Mientras más avanzado sea el programa de juego responsable, más alto será el nivel de logro. La lotería miembro debe implementar programas específicos en sus operaciones cotidianas y mejorar continuamente sus programas. Los cuatro niveles identificados para el MJR son los siguientes: Nivel 1: Compromiso; Nivel 2: Autoevaluación y análisis de brechas; Nivel 3: Planificación e implementación; y Nivel 4: Mejora continua.

Estos niveles se definen en los 10 ítems o elementos del programa del MJR, que incluyen: 1) Investigación; 2) Capacitación de empleados; 3) Programa de minoristas; 4) Diseño de juegos; 5) Canales de juego a distancia; 6) Publicidad y mercadotecnia; 7) Información al jugador; 8) Referencia a proveedores de tratamiento; 9) Implicación de los grupos de interés; y 10) Informes y medición.

Una vez que se haya determinado el nivel apropiado para la organización, se deben compilar y organizar los documentos de soporte que se enviarán al Panel Independiente de Evaluación de Juego Responsable (PIEJR) para su revisión. El PIEJR determinará si se ha cumplido con los requisitos del nivel para el cual se presentó la solicitud.

\subsubsection{Resoluciones UIF}

El artículo $7^{\circ}$ de la Ley 26.683, sancionada el 1 de Junio de 2011 y promulgada parcialmente el 17 de Junio de 2011, sustituye el artículo $5^{\circ}$ de la ley 25.246 y sus modificatorias, por el siguiente texto" "... Créase la Unidad de Información Financiera (UIF) que funcionará con autonomía y autarquía financiera en jurisdicción del Ministerio de Justicia y Derechos Humanos de la Nación, la cual se regirá por las disposiciones de la presente ley...”.

El artículo $8^{\circ}$ de la Ley 26.683, sustituye el artículo $6^{\circ}$ de la ley 25.246 y sus modificatorias, por el siguiente: “... La Unidad de Información Financiera (UIF) será la encargada del análisis, el tratamiento y la transmisión de información a los efectos de prevenir e impedir:

1) El delito de lavado de activos (artículo 303 del Código Penal), preferentemente proveniente de la comisión de:

2) Delitos relacionados con el tráfico y comercialización ilícita de estupefacientes (ley 23.737);

3) Delitos de contrabando de armas y contrabando de estupefacientes (ley 22.415);

4) Delitos relacionados con las actividades de una asociación ilícita calificada en los términos del artículo 210 bis del Código Penal o de una asociación ilícita terrorista en los términos del artículo 213 ter del Código Penal; 
5) Delitos cometidos por asociaciones ilícitas (artículo 210 del Código Penal) organizadas para cometer delitos por fines politicos o raciales;

6) Delitos de fraude contra la administración pública (artículo 174, inciso 5, del Código Penal);

7) Delitos contra la Administración Pública previstos en los capítulos VI, VII, IX y IX bis del título XI del Libro Segundo del Código Penal;

8) Delitos de prostitución de menores y pornografia infantil, previstos en los artículos 125, 125 bis, 127 bis y 128 del Código Penal;

9) Delitos de financiación del terrorismo (artículo 213 quáter del Código Penal);

10) Extorsión (artículo 168 del Código Penal);

11) Delitos previstos en la ley 24.769;

12) Trata de personas..."

La UIF ha dictado diferentes resoluciones en materia de PLA para el SJA.

(Resolución UIF Nro 2,2012) indica acerca de la excepción del legajo del cliente):

“...Se conceden plazos para la confección del Legajo del cliente para el caso de que el proveedor de bienes o servicios sea una persona jurídica, excepto que se trate de operaciones a través de internet y aquellas dedicadas al juego de azar..."

(Resolución UIF Nro 70, 2011) establece la presentación de Reportes Sistemáticos de Operaciones "on line":

Artículo $7^{\circ}-$ A partir del $1^{\circ}$ de agosto de 2011 las personas físicas o jurídicas que como actividad habitual exploten Juegos de Azar definidas como Sujetos Obligados en la Resolución UIF $N^{o} 18 / 2011$ (B.O. 20/01/2011), deberán informar hasta el día QUINCE (15) de cada mes las operaciones que realicen los apostadores que efectúen cobranzas de premios o cambios de valores o cambio de fichas o equivalente por montos superiores a PESOS CINCUENTA (\$50.000), realizadas en el mes calendario inmediato anterior.

Esta resolución determina el umbral de premio para la presentación de reportes. Quienes tienen la intención de lavar activos no desean completar ningún formulario que pueda identificarlos. Si se ha obtenido un premio igual o mayor a ese umbral, el potencial lavador intentará fraccionar el premio para no completar los reportes. Es una de las tipologías que se detallarán más adelante.

\section{Resolución UIF N 199/2011}

(Resolución UIF Nro 199, 2011)establece “...las medidas y procedimientos que las personas físicas o jurídicas que como actividad habitual exploten juegos de azar deben observar para prevenir, detectar y reportar los hechos, actos, operaciones u omisiones que pudieran constituir delitos de Lavado de Activos y Financiación del Terrorismo..." 
En su Capítulo I, Definiciones, determina que se consideran sujetos obligados de informar:

1) Casinos nacionales, provinciales, municipales o privados, bajo cualquier forma de explotación;

2) Bingos y Loterías;

3) Hipódromos y lugares donde se exploten a riesgo, apuestas vinculadas a las carreras de animales;

4) Sujetos que exploten juegos de azar a través de Internet o cualquier otro medio electrónico;

5) Cualquier otra persona física o jurídica que explote habitualmente juegos de azar;

6) Los intermediarios en la venta de juegos explotados por los Sujetos Obligados del Estado Nacional o Provincial, a través de autorizaciones, permisos o cualquier otra figura jurídica de acuerdo a las reglamentaciones locales, se encuentran exceptuados de la presente resolución. Sin perjuicio de ello, al momento de efectuar el pago de un premio por cuenta y orden del Sujeto Obligado, deberán identificar a los clientes conforme las pautas mínimas contenidas al efecto en la presente.

7) Los concesionarios y permisionarios de juegos de azar, y cualquier otra figura jurídica que conforme las reglamentaciones locales establezca derechos y obligaciones similares a los supuestos mencionados en el presente apartado, son Sujetos Obligados independientes del concedente a los efectos de la aplicación de la presente Resolución y en lo que respecta al juego concesionado.

En su Capítulo II, Artículo $3^{\circ}$, expresa que las personas físicas o jurídicas que como actividad habitual exploten juegos de azar deberán adoptar una política de prevención en materia de Lavado de Activos y Financiación del Terrorismo, de conformidad a la normativa vigente.

Para ello deben contemplar por lo menos los siguientes aspectos:

1) La elaboración de un manual que contendrá los mecanismos y procedimientos para la prevención de Lavados de Activos y Financiación del Terrorismo que deberá observar las particularidades de su actividad;

2) La designación de un Oficial de Cumplimiento conforme lo establece el artículo 20 bis de la Ley $N^{\circ} 25.246$ y sus modificatorias, para los casos en que los Sujetos Obligados se encuentren constituidos como personas jurídicas.

3) La implementación de auditorías periódicas;

4) La capacitación del personal; 
5) La elaboración de registros de análisis y gestión de riesgo de lavado de activos $y$ de financiación del terrorismo de las operaciones inusuales detectadas y aquellas que por haber sido consideradas sospechosas hayan sido reportadas. La información contenida en el aludido registro deberá resultar suficiente para permitir la reconstrucción de cualquiera de tales operaciones, y servir de elemento probatorio en eventuales acciones judiciales entabladas. El mencionado registro tendrá tratamiento confidencial, amparado conforme las previsiones del artículo 22 de la Ley $N^{o} 25.246$ y modificatorias;

6) La implementación de herramientas tecnológicas acordes con su desarrollo operacional, que le permita establecer de una manera eficaz el sistema de control y prevención de Lavado de Activos y Financiación del Terrorismo;

7) La implementación de medidas que les permitan consolidar electrónicamente las operaciones que realizan con sus clientes, asi como herramientas tecnológicas tales como software, que les permitan analizar o monitorear distintas variables para identificar ciertos comportamientos y visualizar posibles operaciones sospechosas;

8) Llevar un registro de premios entregados y de conversión de valores efectuados por los clientes.

9) La implementación de sistemas de control para detectar y evitar maniobras de desdoblamiento de fichas o equivalentes utilizadas en juegos de paño, tendientes a evadir el control establecido en la presente resolución.

El Artículo $4^{\circ}$ trata acerca del Manual de Procedimientos.

En el artículo $8^{\circ}$ se indica que los Sujetos Obligados “... que sean personas jurídicas, deberán prever un sistema de auditoría interna anual que tenga por objeto verificar el cumplimiento efectivo de los procedimientos y políticas de prevención contra el Lavado de Activos y la Financiación del Terrorismo.

Los resultados que arrojen los procedimientos de auditoría aplicados deberán ser comunicados anualmente al Oficial de Cumplimiento. En el caso de que este último detecte deficiencias en cuanto a la implementación y cumplimiento de las políticas de prevención de Lavado de Activos y la Financiación del Terrorismo, deberá adoptar las medidas necesarias para corregirlas..." 
Desde el año 2012, el grupo de auditores en tecnología informática del Centro Superior del procesamiento de la Información (CeSPI) de la UNLP participamos de diferentes actividades orientadas a la prevención de lavado de activos, en el marco del Juego Responsable, convocados por IPLyC, ALEA o CIBELAE. De esta convocatoria continua a la Universidad por parte de reguladores y asociaciones, se puede inferir la relevancia que tiene esta problemática en el SJA.

Entre otras, la autora de este trabajo realizó las siguientes presentaciones:

- "Prevención de Lavado de Activos en el Sector de los Juegos de Azar". Organizado por ALEA (Asociación de Loterías, Quinielas y Casinos Estatales de Argentina) y UIF. Corrientes, 23 y 24 de Agosto, Buenos Aires (Mar del Plata), 30 y 31 de agosto. Neuquén (V. La Angostura), 3 y 4 de Septiembre.

- "Tecnología aplicada y juego responsable". Seminario-Taller: Responsabilidad Social y Juego Responsable. Organizado por el Instituto Provincial de Juegos y Casinos de Mendoza y ALEA (Asociación de Loterías, Quinielas y Casinos Estatales de Argentina). Septiembre 2012

- "Fiscalización y Auditoría on line. Seguridad y Auditoría". Mg. Lía Molinari, Dr. Darío Piccirilli. Seminario de Gestión Integral de Juegos. Organizado por ALEA (Asociación de Loterías, Quinielas y Casinos Estatales de Argentina). Marzo 2012.

- "Normas de seguridad en el marco de los juegos de azar". Seminario de Seguridad de la Información, organizado por el Instituto de Juegos de Azar de Neuquén (IJAN) y por Asociación de Loterías, Quinielas y Casinos Estatales de Argentina (ALEA), específicamente por las comisiones de Capacitación y de Asuntos Informáticos, Telemáticos y de Telecomunicaciones. Octubre 2013.

- "Juegos de azar: nuevos retos en materia de prevención de lavado de activos". Encuentro Argentino para Reguladores de Juegos de Azar. Organizado por la Universidad Nacional de La Plata y Gaming Laboratories International (GLI). Noviembre 2013.

- "Anti-money laundering measures. identifying, tracking and detecting fraudulent activity in gaming". Dr Hernán Najenson (Lotería de la Pcia de Bueno Aires) y Mg Lía Molinari (Universidad Nacional de La Plata). Brasilian Gaming Congress. Río de Janeiro, 18-20 Noviembre de 2013.

- "Procesos de certificación y auditoría de control on line". Seminario Internacional de Juego. 7, 8 y 9 de Octubre de 2014. Cartagena de Indias, Colombia.

- "La estandarización de procesos en materia de prevención de lavado de activos: proyecto CIBELAE". Seminario Internacional en Prevención de Lavado de Activos. Puerto Madryn, Chubut, del 28 al 30 de Octubre de 2014.

Además, participó como moderadora del panel "Certificación en Prevención de Lavado de Activos del Sector Juegos de Azar" en el Tercer Seminario Internacional de Loterías, 10 al 12 de marzo de 2015, en la ciudad de Mar del Plata. 
El modelo que se presenta fue avalado por los miembros de la Comisión Antilavado de CIBELAE, compuesta por representantes de Uruguay, Brasil, Portugal, España y Argentina, y presentado en el Plenario realizado en la Ciudad de Mendoza en Octubre del 2015 dentro del XV Congreso organizado por la institución. Allí, la autora de este trabajo de tesis expuso y discutió con los asistentes, la importancia de contar con un marco de prevención para el lavado de activos, las pautas de su definición de acuerdo a los elementos propuestos, como así también una propuesta de certificación según el modelo de madurez. Con una votación por unanimidad de los representantes de las diferentes loterías y agencias de Iberoamérica que forman parte de CIBELAE, se aprobó el esfuerzo realizado.

En el último Plenario, de octubre de 2016, la autora fue convocada para participar en el evento de CIBELAE en Portugal para la exposición de una propuesta de modelo de certificación. Principalmente por razones económicas no se pudo participar de este evento.

Los trabajos relacionados con la temática desarrollada aceptados en congresos internacionales y presentados por la autora - "Money Laundering Prevention in Gaming: a Practical Approach for Determining Maturity Levels" en el First American Academic Research Conference on Global Business, Economics, Finance and Social Sciences (AAR16 New York Conference) en New York, Estados Unidos, en Mayo de 2016; y "Auditing Guidelines for Money Laundering Prevention in the Gambling Sector" en el 3rd International Conference on Economy and Society (EAS 2016), China, en septiembre de 2016 - evidencian el interés que la prevención del lavado de activos genera hoy en el mundo y la validez del modelo que se plantea.

Habiendo planteado este modelo de gestión para la prevención de LA, y habiendo descripto en capítulos anteriores la problemática del LA en el SJA, los capítulos siguientes aportan elementos para su desarrollo, implementación, operación $\mathrm{y}$ monitoreo. 


\section{PAUTAS PARA EL DESARROLLO DEL SISTEMA DE GESTIÓN}

En este capítulo se presentan uno de los más importantes aportes de este trabajo de tesis: la definición de un conjunto de elementos que son facilitadores para la definición, implementación, monitoreo y mejora de las políticas de prevención.

\subsection{Facilitadores del proceso de desarrollo}

De acuerdo a lo expresado en la Sección5.5, la definición de una política de prevención es uno de los puntos clave para el desarrollo. Dicha política debe ser aprobada por la máxima autoridad. Su compromiso con estas políticas es la base para el alineamiento de la organización. El desafío es definir un conjunto de facilitadores que colaboren en la definición de las políticas para que sean realistas, viables, oportunas y beneficiosas para todos los stakeholders.

La prevención no puede ser un objetivo en sí mismo. Considerando todos los stakeholders del SJA, debe encuadrarse dentro de un objetivo más general que trascienda la organización misma. Por ejemplo, el beneficiario de estas políticas es también el jugador que mediante la difusión y concientización de las tipologías de LA, puede evitar prestarse a maniobras de lavado.

Estas políticas darán sentido a la dirección y acciones. Como se indicó en la Sección 1.1, el modelo que se define debe poder aplicarse a cualquier organización de juegos de azar, independiente de las regulaciones existentes en el país; e incluso en diferentes países. Cada país tiene sus requisitos legales y regulatorios. En caso que el país no tuviera legislación, una organización del SJA puede definir sus políticas de prevención en el contexto de RSE o para alinearse en las buenas prácticas internacionales.

Cuando al inicio de este documento se justificó el porqué era necesario plantear un modelo de gestión para la prevención, se propuso construir un marco de referencia para la definición, desarrollo, implementación de acciones en el contexto de políticas de prevención. Para ello es necesario abordar diferentes factores como la estructura organizacional, los roles y responsabilidades, la formación adecuada de los recursos humanos, la interacción con instituciones similares y organismos nacionales e internacionales.

La determinación de las variables que inciden en un marco de prevención es un paso trascendental para definir las políticas y estrategias, y establecer métricas e indicadores que faciliten la evaluación de una organización del SJA con respecto a dicha prevención.

Uno de los documentos fuente para este marco es el Marco de Juego Responsable (MJR, de ahora en más) de la WLA(Word Lottery Association (WLA), 2012). En él se definen 4 niveles de logro y 10 ítems del programa, en los cuales se explica cómo las loterías pueden demostrar su nivel de compromiso con los Principios del Juego 
Responsable de la WLA, enunciados en el MJR. Considera las diferencias tanto culturales como regionales y ha sido diseñado con el fin de complementar y mejorar- no reemplazar- las medidas de juego responsable que cada operador de lotería ha adoptado.

A continuación, se detalla uno de los aportes más importantes de este trabajo: la determinación de un conjunto de elementos que colaboran, a criterio de la autora, para la definición de políticas PLA, acciones y medición de resultados. Para llegar a enunciarlos fue necesario realizar un análisis exhaustivo de marcos existentes, de la existencia de tipologías, de los factores antes enunciados y del carácter internacional que tiene hoy el lavado de dinero en el SJA. El análisis y la propuesta de estos elementos fueron validados por los miembros de la Comisión Antilavado de CIBELAE.

Se determinaron los siguientes elementos facilitadores de la definición de políticas de prevención:

1. Determinación del riesgo

2. Formalización y estandarización de los procesos PLA

3. Definición de estructura organizacional (roles, responsabilidades, funciones, formalización)

4. Tratamiento de la información y documentación

5. Capacitación y concientización de empleados y público en general

6. Control, monitoreo y auditoría

7. Definición e implementación de políticas de debida diligencia

8. Utilización efectiva de recursos tecnológicos

9. Generación de informes y estadística

10. Interacción con otras organizaciones y organismos competentes

A continuación se hace una pequeña descripción de cada elemento. Luego se desarrolla cada uno de ellos en cuanto a los objetivos a cumplir para alcanzar cada nivel de madurez.

\subsection{Determinación del riesgo}

Administrar el riesgo dentro de una organización es una tarea compleja, que requiere el compromiso de toda la organización. La administración del riesgo es un proceso que requiere que la organización determine el riesgo mediante la identificación y evaluación de su realidad en el ámbito de las Loterías y Apuestas, establezca controles efectivos, monitoree el estado de situación y minimice el riesgo. Ese monitoreo permitirá generar alertas que disparen acciones orientadas a minimizar el impacto ante la ocurrencia de incidentes. 
La máxima autoridad provee la visión estratégica y los objetivos de alto nivel; los mandos medios la planificación, ejecución y desarrollo de los diferentes proyectos y los individuos son quienes interactúan en campo, operando los sistemas de información que soportan las misiones y funciones.

El riesgo operacional $(\mathrm{RO})$ es la posibilidad de ocurrencia de pérdidas financieras, originadas por fallas o insuficiencias de procesos, personas, sistemas internos, tecnología, y en la presencia de eventos externos imprevistos. No incluye el daño a la imagen. Por ello en este documento trataremos con el concepto de riesgo más abarcativo, pues el daño a la imagen es una variable relevante en el marco de las actividades que se analizarán.

Para evaluar el Riesgo generalmente se toman en cuenta dos variables: 1) la frecuencia o probabilidad de suceso de un evento de riesgo, que consiste en el número de ocasiones en la que se detecta la presencia de eventos causales de riesgo; y 2) la severidad, o importancia del impacto de los eventos de riesgo sobre los resultados o el patrimonio de la empresa.

Por lo tanto realizar un análisis de riesgo exige conocer profundamente el contexto para poder determinar vulnerabilidades y amenazas. En base a dicho análisis se establecerán los controles efectivos de acuerdo al apetito de riesgo de la organización. En el caso de la PLA, el tratamiento del riesgo y la definición de los controles son determinados por la normativa vigente o el acatamiento a recomendaciones internacionales, o a ambas.

La organización debe realizar este análisis de acuerdo a los juegos que provee, el volumen de la organización, la normativa/recomendaciones antes citadas, y su propio contexto y cultura.

\subsection{Formalización y estandarización de los procesos PLA}

Trabajar con un enfoque orientado a procesos, facilita la determinación de las actividades involucradas, recursos asignados, relación con otros procesos, establecer métricas por proceso, auditar y corregir.En este enfoque es imprescindible que la organización identifique cuáles son los procesos en el marco PLA.

Una vez determinados dichos procesos, se definen: actividades, recursos, costos, cómo se medirá el desempeño con el objetivo de determinar indicadores que colaboren en la corrección del rumbo, si fuera necesario.Se establecen los procedimientos y los roles y responsabilidades inherentes a dichos procesos.

Al estandarizar se acuerda acerca de la "mejor forma" de definir o realizar un proceso, basándose en objetivos y experiencia, garantizando que los procesos se ejecuten de una manera uniforme por todos los involucrados en él, para asegurar la calidad de los productos/servicios. La estandarización permite que el regulador pueda definir acciones de auditoría y evaluación generales, coherentes y consistentes. 
La existencia de un manual de procedimientos efectivo y actualizado es clave en la formalización y estandarización de los procesos PLA.

\subsection{Definición de estructura organizacional}

Para cumplir adecuadamente con este marco, la organización debe definir una estructura que sea funcional a los objetivos.Mediante la definición de la estructura y la individualización de los procesos se pueden determinar roles, responsabilidades, funciones, en forma adecuada.Esta estructura debe formalizarse mediante una comunicación interna que garantice que cada miembro sepa quién es el referente, a quién debe informar o involucrar ante una situación o un incidente.

\subsection{Tratamiento de la información y documentación}

La información que se consulta, se genera y se transmite debe ser administrada según lo determinan los criterios de la seguridad de la información garantizando su confidencialidad, integridad y disponibilidad en forma razonable.La implementación de las políticas de PLA produce documentación que deber ser preservada digitalmente por el tiempo que determina la normativa correspondiente.

\subsection{Capacitación y concientización de empleados y público en general}

La organización debe garantizar que el personal está capacitado para llevar a cabo su tarea satisfactoriamente y que, ante su ausencia, temporal o definitiva, esa función puede ser realizada rápidamente por otro empleado.Este elemento incluye la definición y puesta en práctica de un plan de capacitación para todos los niveles, incluyendo ingresantes.Importantes razones hacen imprescindible la concientización o el entrenamiento del personal, y la administración efectiva acerca de este delito, entre ellas, minimizar el riesgo de ser manipulados por quienes lo llevan a cabo, daños a la reputación, etc.

\subsection{Control, Monitoreo y Auditoría}

Este elemento tiene que ver con el seguimiento que se debe realizar para determinar si los controles implementados son efectivos. Incluye también la definición y atención adecuada de alertas que permitan detectar rápidamente tanto vulnerabilidades como amenazas.

La auditoría tiene como objetivo asegurar que se cumplen los objetivos enunciados. El plan que proponga la organización debe ser auditado como mínimo anualmente o ante cualquier cambio como la incorporación de nuevos juegos, normativa, cambios de reguladores/operadores, etc. 


\subsection{Definición e implementación de políticas de debida diligencia}

Uno de los pilares en la PLA es la implementación de políticas de debida diligencia, que desarrolle acciones para identificar a los clientes y cumplir con todas y cada una de las obligaciones establecidas en la normativa vigente.Para determinar cuál es la política adecuada, la entidad del sector de Loterías y Apuestas, debe realizar un análisis de acuerdo a los juegos que ofrecen.

\subsection{Utilización efectiva de recursos tecnológicos}

La evolución de la tecnología y su uso masivo, tanto en el ámbito del entretenimiento como en función de la gestión, es un desafío para la industria del juego.En el ámbito de la organización, el uso de la tecnología para la gestión (sistemas de control on line, software especializado, transferencia de comunicación utilizando distintos medios) si bien es un elemento que facilita la tarea diaria, puede transformarse en una amenaza si no es administrado en forma adecuada.Como recursos tecnológicos se incluye lo que se conoce como infraestructura tecnológica, recursos humanos dedicados, datos y aplicaciones.

Si bien cada organización define su infraestructura tecnológica, sus aplicaciones y otros recursos según sus objetivos de negocio, aquellos recursos que estén involucrados directa o indirectamente en los procesos PLA o en la comunicación con organismos competentes, deben ser identificados y controlados mediante una política de seguridad adecuada.

No obstante, la adquisición y uso de la tecnología debe ser el resultado de un proceso de decisión que justifique la inversión y defina claramente el valor que aporta a la organización. La inversión en TI debe estar alineada a los objetivos de negocio ser el resultado de una decisión elaborada (Molinari, Estevez, \& Díaz, 2012).

\subsection{Generación de informes y estadística}

Este elemento es imprescindible para contar con información adecuada para la toma de decisiones.Para ello debe definirse qué tipo de informes se elaborarán, que métricas e indicadores se proponen y cómo serán obtenidos para que sean realmente representativos de la situación.

\subsection{Interacción con otras organizaciones y organismos competentes}

LA es un delito global. La interacción con otras organizaciones de SJA y organismos internacionales permiten identificar nuevos escenarios y detectar nuevas tipologías de LA.La posibilidad de aprender de las experiencias vividas en otros lugares, dentro o fuera del país, son oportunidades que no deben despreciarse.

Las organizaciones de Loterías y Apuestas deben estar atentas para el cumplimiento de las normativas que se exijan en su país, y analizar las buenas prácticas que surgen de las nuevas situaciones detectadas y compartidas. 


\section{PAUTAS DE IMPLEMENTACIÓN DEL MODELO}

En este capítulo se describen algunos lineamientos que viabilizan la implementación de las políticas de prevención. La definición de una estructura organizacional adecuada, la designación de un Oficial de Cumplimiento, la creación y mantenimiento de un manual de procedimientos aprobado por la máxima autoridad, la existencia de programas de capacitación y concientización son algunas de las acciones que sostienen y formalizan los enunciados de la política.

\subsection{La importancia de una estructura}

Las organizaciones del SJA deben definir claramente las responsabilidades y los mecanismos para dar cuenta de las actividades que se realizan y sus consecuencias, asegurando que las políticas, los procedimientos y los controles implementados son adecuados para prevenir y detectar situaciones de lavado. Deben definir una estructura adecuada para asignar roles y responsabilidades en la lucha contra el LA y garantizar que se cumple la normativa y buenas prácticas al respecto.

Por ejemplo, el Titular del Organismo, en su carácter de autoridad máxima de la entidad, es el responsable del deber de informar. De acuerdo a como se definan roles y responsabilidades, aprueba el dictamen de Operación Sospechosa, cuando corresponda, y ordena su reporte. Para arribar a tal decisión contará con el análisis y la documentación de respaldo de las operaciones detectadas como sospechosas, que efectuará y elevará el Oficial de Cumplimiento. Si no existe una estructura bien definida, estas actividades pueden no cumplirse o no hacerse de forma efectiva (Asociación de Loterías, 2014).

El organismo debe garantizar que facilitará los medios necesarios para contar con recursos humanos capacitados y en relación formal de dependencia, para cumplir con los distintos roles. En el caso que algún agente del organismo se halle en una situación comprometida por proceder de acuerdo a lo definido, el organismo debe garantizar los medios necesarios para su protección y resguardo.

Se debe destinar un presupuesto que asegure que se contará con los recursos necesarios para cumplir con las políticas de prevención. Por ejemplo, si el organismo desea tercerizar servicios relacionados con la política de prevención, debe establecer acuerdos de niveles de servicios, llamados Service Level Agreements (SLAs) que definan el marco de confidencialidad, integridad y disponibilidad de la información, garantizando que será considerado su grado de criticidad y sensibilidad.

En el marco de las políticas de prevención, la selección del personal no puede dejarse de lado. (Resolución UIF Nro 199, 2011), artículo 10, indica que los Sujetos Obligados deberán adoptar sistemas adecuados de preselección para asegurar normas estrictas de contratación de empleados y de monitoreo de su comportamiento, proporcionales al riesgo vinculado con las tareas que los empleados lleven a cabo, conservando 
constancia documental de la realización de tales controles, con intervención del responsable del área de Recursos Humanos.

Si bien en una primera lectura de este párrafo determinadas palabras pueden llevar al lector a considerar lo enunciado como un excesivo control, se escribe en el marco de la obligación del Sujeto Obligado a establecer programas de concientización, para que el empleado sea partícipe efectivo de las acciones de prevención. El personal de la organización debe asumir con responsabilidad su participación en el sistema de prevención. Para ello debe ser comunicado de las decisiones, acciones y expectativas aportan a seguir el sistema en el cotidiano.

La definición de una estructura organizacional debe ser adecuada a los objetivos de prevención, con los roles y responsabilidades claramente definidos, con personal (jeráquico y de sala) capacitado en las tipologías y con interacción dinámica con otras organizaciones de sector.

\subsection{El Oficial de Cumplimiento}

Cada organización debe incluir un responsable con la necesaria autoridad para implementar efectivamente los controles enunciados en los párrafos anteriores. Para llevar a cabo esto es imprescindible que, en cada organización, una persona asuma esta responsabilidad con la necesaria autoridad para hacerlo. Para cubrir este rol se propone la designación de un Oficial de Cumplimiento (OC), quien, además, es el punto central de contacto con las autoridades de la organización para la supervisión de las actividades antilavado.

El OC es el empleado encargado de velar por la implementación y el cumplimiento de los procedimientos internos, que le permitan a la empresa cumplir adecuadamente con todas las obligaciones establecidas en las leyes y regulaciones.

En (Grupo de Acción Financiera Internacional, 2012), la nota interpretativa de la recomendación 18 (controles internos y sucursales y filiales extranjeras) indica:

“...Los programas de las instituciones financieras contra el lavado de activos y el financiamiento del terrorismo deben incluir: (a) el desarrollo de políticas, procedimientos y controles internos, incluyendo acuerdos apropiados de manejo del cumplimiento y procedimientos adecuados de inspección, para asegurar elevados estándares a la hora de contratar a los empleados; (b) un programa continuo de capacitación a los empleados; y (c) una función de auditoría independiente para comprobar el sistema. 2. El tipo y alcance de las medidas a tomar debe corresponderse a la consideración del riesgo de lavado de activos y financiamiento del terrorismo y a las dimensiones de la actividad comercial. 3. Los arreglos sobre el manejo del cumplimiento deben incluir la designación de un oficial de cumplimiento a nivel administrativo..." 
Es decir que aunque no exista específicamente una normativa en el país de residencia de la entidad, el alineamiento con las recomendaciones GAFI exige mínimamente considerar la designación del oficial de cumplimiento.

En el ítem "Implementación" del marco de Juego responsable de (Corporación Iberoamericana de Loterías y Apuestas de Estado (CIBELAE), 2011), entre las acciones orientadas a la mejora continua, se indica:

"Designar una persona oficial de contacto para el seguimiento de la implementación de las acciones de mejora para el grupo de trabajo de CIBELAE”.

La designación de una persona responsable de una determinada actividad sugiere la necesidad de definir una mínima estructura para poder encauzar las decisiones que se hace necesario tomar.

El OC será el "responsable de velar por la observancia e implementación de los procedimientos y obligaciones establecidos en virtud de esta resolución y de formalizar las presentaciones ante la UIF" (Resolución UIF Nro 199, 2011). Se indica también que el OC debe gozar de absoluta independencia y autonomía en el ejercicio de las responsabilidades y funciones que se le asignan, “...debiendo garantizársele acceso irrestricto a toda la información que requiera en cumplimiento de las mismas...”.

Una vez designado, la organización debe comunicarle a la UIF sus datos personales, incluidos nombre y apellido, tipo y número de documento de identidad, cargo en el órgano de administración, fecha de designación y número de CUIT o CUIL, los números de teléfono, fax, dirección de correo electrónico y lugar de trabajo de dicho funcionario).

Podrán designar un suplente, quien desempeñará las funciones del titular en caso de ausencia, impedimento o licencia de este último. A estos fines deberán cumplirse los mismos requisitos y formalidades que para la designación del titular.

La misma resolución en su artículo $7^{\circ}$ define las funciones del OC. Tendrá mínimamente, las siguientes funciones:

1) Velar por el cumplimiento de los procedimientos y políticas implementadas para prevenir, detectar y reportar operaciones que puedan estar vinculadas a los delitos de Lavado de Activos y Financiación del Terrorismo;

2) Diseñar e implementar los procedimientos y controles, necesarios para prevenir, detectar y reportar las operaciones que puedan estar vinculadas a los delitos de Lavado de Activos y Financiación del Terrorismo.

3) Diseñar e implementar políticas de capacitación formalizadas a través de procedimientos de entrenamiento y actualización continuos en la 
materia para los funcionarios y empleados del Sujeto Obligado, considerando la naturaleza de las tareas desarrolladas.

4) Analizar las operaciones realizadas para detectar eventuales operaciones sospechosas examinando a tal efecto el registro de premios entregados y de conversión de valores efectuados por los clientes.

5) Formular los reportes sistemáticos y de operaciones sospechosas, de acuerdo a lo establecido en la presente resolución.

6) Llevar el registro del análisis y gestión de riesgo de operaciones inusuales detectadas, que contenga e identifique aquellas operaciones que por haber sido consideradas sospechosas hayan sido reportadas.

7) Dar cumplimiento a los requerimientos efectuados por la UNIDAD DE INFORMACIÓN FINANCIERA en ejercicio de sus facultades legales.

8) Controlar la observancia de la normativa vigente en materia de prevención de Lavado de Activos y Financiación del Terrorismo.

9) Asegurar la adecuada conservación y custodia de la documentación.

10) Prestar especial atención a las nuevas tipologías de Lavado de Activos y Financiación del Terrorismo a los efectos de establecer medidas tendientes a prevenirlas, detectarlas y reportar toda operación que pueda estar vinculada a las mismas, como asimismo a cualquier amenaza de Lavado de Activos o Financiación del Terrorismo.

\subsection{El manual de Procedimientos}

El manual de procedimientos es un instrumento administrativo fundamental para coordinar, dirigir, evaluar y controlar las actividades de una organización. Sirve para comunicar, registrar, transmitir la organización y funcionamiento de una dependencia, dado que comprende la organización de los sectores involucrados, las funciones específicas y las responsabilidades asignadas.

Los procedimientos que se definan deben estar formalizados: escritos, acordados, comunicados y actualizados. Deben ser revisados, como mínimo, una vez al año, o ante cualquier cambio de la organización que lo justifique (incorporación de nuevos juegos, ampliación del parque de máquinas, mudanza, nuevos socios, cambios de software, etc.).

Segúnel Manual de Procedimientos vigente del IPLyC, Provincia de Buenos Aires, sus principales objetivos en el contexto de la prevención de LA son:

- Evidenciar el compromiso asumido por el Instituto en relación a la prevención de los delitos de lavado de activos.

- Cumplir con los estándares exigidos en el ámbito internacional.

- Implementar las Políticas de Prevención del LA definidas.

- Garantizar la aplicación y correcta implementación de los procedimientos. 
- Establecer las políticas de la organización para la identificación y conocimiento del cliente, pautas para la detección y registro de operaciones inusuales, los procedimientos específicos para los procesos principales y los mecanismos a seguir en el análisis y seguimiento de las operaciones inusuales dentro de los distintos niveles de responsabilidades establecidas en la estructura de control y prevención.

- Adoptar las medidas apropiadas para evitar que la organización y sus productos sean utilizados con fines ilícitos.

- Garantizar un ambiente propicio para el cumplimiento de los procesos de Prevención del LAy FT.

- Cumplir con el deber de informar, a las autoridades competentes sobre toda operación sospechosa de lavado de activos o financiamiento del terrorismo.

- Prevenir riesgos en el daño de la imagen de la organización, protegiendo y manteniendo su buen nombre.

- Velar por el cumplimiento de las obligaciones y deberes de los funcionarios, empleados y colaboradores en general con el fin de evitar sanciones de tipo administrativo, comercial, civil y penal.

El artículo 4 de la Resolución UIF 199/2011 indica que el Manual de Procedimientos deberá contemplar los siguientes aspectos:

a) Políticas de prevención del Lavado de Activos y Financiación del Terrorismo, adoptadas por la máxima autoridad, en el caso de personas jurídicas.

b) Políticas coordinadas para el control y monitoreo.

c) Funciones de la auditoría y los procedimientos de control interno que se establezcan tendientes a evitar el Lavado de Activos y Financiación del Terrorismo.

d) Funciones asignadas al Oficial de Cumplimiento.

e) Plazos y términos en los cuales cada empleado debe cumplir, según las responsabilidades propias del cargo, con cada uno de los mecanismos de control de prevención.

f) Programa de capacitación.

g) Políticas y procedimientos de conservación de documentos.

h) Proceso a seguir para atender a los requerimientos de información que pudiera efectuar la UIF y el Oficial de Cumplimiento.

i) Metodologías y criterios para analizar y evaluar la información que permita detectar operaciones inusuales y sospechosas, así como también el procedimiento para el reporte de las mismas.

j) Desarrollo y descripción de otros mecanismos que el Sujeto Obligado considere conducentes para prevenir y detectar operaciones de Lavado de Activos y Financiación del Terrorismo.

k) El régimen sancionatorio para el personal de los Sujetos Obligados, en caso de incumplimiento de los procedimientos específicos contra el Lavado de Activos y Financiación del Terrorismo, en los términos previstos por la legislación laboral vigente. 
En cuanto a su disponibilidad, el Artículo $5^{\circ}$ de la misma resolución indica que el manual de procedimientos debe estar siempre actualizado y disponible en todas las dependencias de los Sujetos Obligados, para todos los funcionarios y personal, considerando la naturaleza de las tareas que desarrollan, y debiendo establecerse mecanismos que permitan constatar la recepción y lectura por parte de estos últimos. Asimismo deberá permanecer siempre a disposición de la UIF.

\subsection{Programa de capacitación}

Los stakeholders son los actores de la prevención de LA. Jugadores, empleados, reguladores, operadores, entidades beneficiarias, organismos de control, todos ellos deben ser concientizados acerca de las tipologías y cómo actuar ante la detección de alguna situación de riesgo.

En Argentina, los Sujetos Obligados deberán desarrollar un programa de capacitación dirigido a sus funcionarios y empleados en materia de prevención de Lavado de Activos y Financiación del Terrorismo que debe contemplar (Resolución UIF Nro 199, 2011):

a) La difusión de dicha resolución y de sus modificaciones, así como la información sobre técnicas y métodos para prevenir y detectar operaciones sospechosas;

b) La adopción de un plan de capacitación de funcionarios y empleados sobre las políticas de Prevención de Lavado de Activos y Financiación del Terrorismo adoptadas por el Sujeto Obligado.

La organización debe garantizar que el personal que dedica a cada uno de los roles definidos, está capacitado para llevar a cabo su tarea satisfactoriamente y que, en caso de ausencia temporal o definitiva de algún empleado, esa función puede ser realizada rápidamente por otro empleado.

Se debe proponer un Plan Anual de Capacitación para todos los niveles. Y se debe definir un curso de inducción para aquellos ingresantes a la organización. Importantes razones hacen imprescindible la concientización y la administración efectiva acerca de este delito, entre ellas, minimizar el riesgo de ser manipulados por quienes lo llevan a cabo, daños a la reputación, etc.

El Oficial de Cumplimiento junto con el Sector de Capacitación debe evaluar la modalidad adecuada para cada actividad de capacitación, atento a las necesidades y perfiles de los distintos puestos de trabajo. Se podrá contar para las distintas actividades de capacitación con recursos externos. Los contenidos de estos programas de capacitación deben incluir: 1) Difusión de la normativa vigente en la materia; 2) Implementación de los procedimientos internos establecidos; 3) Información sobre técnicas y métodos para prevenir y detectar operaciones sospechosas; e 4) Información sobre tipologías específicas del sector. Adicionalmente, se deben registrar todas las actividades de capacitación que se lleven a cabo, así como los resultados obtenidos. 
Los empleados, contratados, funcionarios y/o cualquier colaborador involucrado en los procesos de Prevención de Lavado de Activos y Financiamiento del Terrorismo, están obligados a guardar secreto de la información recibidas en razón de su cargo, al igual que de las actuaciones que se están realizando en cumplimiento de la normativa vigente en la materia.

\subsection{Documentación}

(Ley $N^{\circ} 25.246$ de la Nación Argentina, 2000), Capítulo IV, , Artículo 21, se refiere a la conservación de la documentación. En este Artículo se expresa:

“...los Sujetos Obligados deberán conservar para que sirva como elemento de prueba en toda investigación en materia de Lavado de Activos y Financiación del Terrorismo, la siguiente documentación de manera suficiente que permita la reconstrucción de la operatoria:

a) Respecto de la identificación del cliente, el legajo y toda la información complementaria que haya requerido, durante un periodo de DIEZ (10) años, desde la efectivización del pago a los clientes;

b) Respecto de las transacciones u operaciones, los documentos originales o copias certificadas por el Sujeto Obligado, durante un período de DIEZ (10) años, desde la efectivización del pago a los clientes;

c) El registro del análisis de las operaciones inusuales o sospechosas reportadas deberá conservarse por un plazo de DIEZ (10) años;

d) Los soportes informáticos relacionados con transacciones $u$ operaciones deberán conservarse por un plazo de DIEZ (10) años a los efectos de la reconstrucción de la operatoria, debiendo los Sujetos Obligados garantizar la lectura y procesamiento de la información digital.

\subsection{Reportes}

(Ley $N^{\circ} 25.246$ de la Nación Argentina, 2000), Capítulo V, se refiere a los reportes sistemáticos. El Artículo 18 indica que los Sujetos Obligados deberán comunicar a la UIF, las informaciones previstas en la Resolución vigente en la materia.

Se indican a continuación algunos artículos del Capítulo VI, Reporte de operaciones sospechosas.

ARTÍCULO 19.- Reporte de Operaciones. En caso de detectarse operaciones inusuales los Sujetos Obligados deberán profundizar el análisis de las mismas, con el fin de obtener información adicional que corrobore o revierta la/s inusualidad/es, dejando constancia por escrito de las conclusiones obtenidas y de la documentación respaldatoria verificada, conservando copia de la misma.

ARTíCULO 20.- Plazo de Reporte de Operaciones Sospechosas de Lavado de Activos. El plazo máximo para reportar los hechos u operaciones que consideren sospechosos 
de Lavado de Activos es de CIENTO CINCUENTA (150) días corridos, contados desde la fecha de la operación realizada o tentada.

ARTÍCULO 21.- Plazo de Reporte de Operaciones Sospechosas de Financiación del Terrorismo. El plazo para reportar hechos u operaciones sospechosas provenientes de la Financiación del Terrorismo será de CUARENTA Y OCHO (48) horas a partir de la operación realizada o tentada, habilitándose dias y horas inhábiles a tal efecto. A tales fines deberá estarse a lo dispuesto en la resolución UIF vigente en la materia.

ARTÍCULO 22.- Confidencialidad del Reporte. Los reportes de operaciones sospechosas, no podrán ser exhibidos ante los organismos de control de la actividad, ni ante terceros, de conformidad a lo dispuesto en los artículos 21 inciso c) y 22 de la Ley $N^{\circ} 25.246$ y modificatorias.

ARTÍCULO 23.- Deber de Fundar el Reporte. El reporte de operaciones sospechosas debe ser fundado y contener una descripción de las circunstancias por las cuales se considera que la operación detenta tal carácter.

ARTÍCULO 24.- Modo de efectuar el Reporte de Operaciones Sospechosas. Los reportes de operaciones sospechosas se efectuarán de forma electrónica en la página web de la UNIDAD DE INFORMACIÓN FINANCIERA (www.uif.gob.ar), conforme lo dispuesto en la Resolución UIF $N^{\circ} 51 / 2011$ (o la que en el futuro la complemente, modifique o sustituya). Los Sujetos Obligados deben conservar toda la documentación de respaldo de los mismos, la que permanecerá a disposición ante el requerimiento de este organismo y deberá ser remitida dentro de las CUARENTA Y OCHO (48) horas de solicitada.

ARTÍCULO 25.- Independencia de los Reportes. En el supuesto que una operación de reporte sistemático sea considerada por el Sujeto Obligado como una operación sospechosa, éste deberá formular los reportes en forma independiente.

ARTICULO 26.- Informe sobre la calidad del Reporte. Con la finalidad de mejorar la calidad de los reportes sistemáticos y de operaciones sospechosas, la UNIDAD DE INFORMACION FINANCIERA anualmente emitirá informes sobre la calidad de los mismos.

Por último, las instituciones que administran estos reportes deben garantizar al declarante que la información ofrecida es resguardada adecuadamente. Quienes no tienen como objetivo o intención el lavado de activos y han sido beneficiados por el azar tienen derecho a mantener ese hecho en el ámbito de su privacidad.

La difusión de la identidad del proveedor de premios puede poner en riesgo su patrimonio y su vida si es conocida por organizaciones delictivas o personas de intenciones cuestionables. 
En este Capítulo se describen una serie de definiciones y acciones inherentes al monitoreo que se debe hacer en la organización de las decisiones y actividades que se realizan en el marco de prevención y las posibles acciones de auditoría que pueden llevarse acabo desde los reguladores.

\subsection{El monitoreo como promotor de la mejora}

Una vez conocido el contexto y las tipologías, las normativas y las exigencias de cumplimiento, la organización está en condiciones de definir sus políticas y elaborar un plan para el desarrollo.

Una vez implementado, corresponde monitorear su funcionamiento para verificar si se cumplen con los objetivos de prevención enunciados. Para ello la organización debe definir cómo se llevará a cabo este monitoreo, es decir, el alcance, la metodología, cuáles son los indicadores que representan el comportamiento ante la prevención.

La ejecución de procedimientos de monitoreo y revisión y otros controles permite la detección temprana de nuevas vulnerabilidades y amenazas no detectadas o probables en un nuevo escenario o de incidentes de seguridad. También permiten evaluar la eficacia de las acciones tomadas. La revisión de la efectividad de los controles establecidos en el análisis de riesgo debe ser parte de este proceso de monitoreo. La detección de vulnerabilidades y amenazas definen la propuesta de mejora.

Estas revisiones deben ser regulares, definidas en un cronograma por fecha o por determinadas situaciones que pueden ameritar el monitoreo. Deben incluir revisiones específicas del plan de riesgo que se haya definido, teniendo en cuenta los cambios en la organización, la tecnología, los procesos y objetivos del negocio, como así también cambios legales o regulatorios del ambiente, en las obligaciones contractuales o en el clima social. Este monitoreo deben formalizarse y aportar a las auditorías internas que deben estar planificadas y apoyadas desde la máxima autoridad.El resultado de este monitoreo y las auditorías internas debe promover acciones de mejora que se evidencian en actualización de los diversos planes, del manual de procedimiento, de los programas de capacitación/concientización.

\subsection{Caso de análisis: auditoría en el uso efectivo de los recursos tecnológicos}

A continuación se realiza un análisis acerca de la auditoría del uso efectivo de los recursos tecnológicos en el $\mathrm{SJA}^{24}$.

\footnotetext{
${ }^{24}$ Este análisis es parte del artículo "Auditing Guidelines for Money Laundering Prevention in the Gambling Sector" aprobado para su exposición en 3rd International Conference on Economy and Society (EAS 2016), China, en Septiembre de 2016.
} 
Las TICs juegan hoy un rol muy importante en el funcionamiento de una organización del SJA. Es por ello que su uso debe estar alineado con los servicios que se pretende prestar. A continuación se propone una metodología para la administración de estos recursos aplicados al ámbito del SJA utilizando COBIT.

COBIT 5 (ISACA, 2012) provee un marco global que asiste a las organizaciones en lograr sus objetivos para la gobernanza y la administración de las TICs. Es aplicable a todo tipo de empresa en cuanto a tamaño, o actividad. Crea valor desde las TICs manteniendo un balance entre obtener beneficios y optimizar el riesgo haciendo el mejor uso de los recursos.

En este contexto, la materia de auditoría es acerca de información específica, prácticas y controles objeto de la auditoría y revisión del aseguramiento, verificación y reporte.En la temática que se aborda en esta sección, el objeto de auditoría es el uso de las TICs con respecto a las políticas de prevención del lavado de activos. Las buenas prácticas son derivadas de las enunciados en los marcos ya citados, de WLA o CIBELAE (Molinari \& Díaz, 2016a).

COBIT 5 provee dos perspectivas para el aseguramiento ${ }^{25}:$ 1) Perspectiva de función: describe qué es necesario en una organización para construir y proveer funciones de aseguramiento; y 2) Perspectiva de evaluación (assessment): describe el asunto (subject matter) sobre el cual el aseguramiento necesita ser provisto. En este caso el asunto son las TICs en su aplicación sobre políticas de prevención.

Las dos perspectivas se sostienen sobre los siete facilitadores (enablers) del marco que propone COBIT 5: 1) Principios, políticas y marcos; 2) Procesos; 3) Estructuras organizacionales; 4) Cultura, Ética y Comportamiento; 5) Información; 6) Servicios, Infraestructura y Aplicaciones; y 7) Personas, Capacidades (skills) y competencias.

Se analizan a continuación como estas perspectivas y facilitadores aplican en un ámbito de prevención como el que trata esta tesis, con respecto al uso de las TICs.

Desde la perspectiva de la función, las organizaciones necesitan recursos humanos calificados, procesos claramente definidos, tecnología apropiada, alineada con los objetivos de negocio, y tipologías de lavado identificadas.Desde la perspectiva de evaluación, el asunto es el uso de recursos de TI, donde la información es uno de ellos.

Los recursos tecnológicos en el SJA, involucran: servidores (de aplicaciones, de datos, web, etc.), redes de comunicaciones, máquinas de juego (ruletas, lotería, apuestas de carreras de caballos, maquinas slots, entre otras, incluyendo hardware y software), aplicaciones, bases de datos, equipos de vigilancia (cámaras de video, software de

\footnotetext{
${ }^{25}$ En el ámbito de la auditoría de los sistemas de información, y particularmente en COBIT, se habla de aseguramiento, como traducción de assurance, aunque existen discusiones acerca de la traducción adecuada. Es interesante la descripción del término que realiza Samuel Alberto Mansilla. Entre otras características, el aseguramiento incorpora la administración de riesgos.
} 
reconocimiento de facial, etc.). También se incluyen los recursos humanos: ellos deben tener capacidades adecuadas para la administración y operación de las TICs.

El análisis debe orientarse a las tipologías de lavado y situaciones cotidianas o excepcionales que puedan ocurrir.

Veamos algunos casos:

- Las aplicaciones deben estar desarrolladas con un alto grado de seguridad para garantizar razonablemente que se respetan las necesarias pautas de confidencialidad, integridad y disponibilidad. Las bases de datos de consulta deben estar actualizadas. Los procedimientos deben estar definidos y los recursos tecnológicos que involucren deben estar adecuadamente disponibles.

- Tanto las máquinas de juego como su software deben estar certificados y verificados, para posteriormente procederse a su homologación, por parte de un organismo oficial y verificación.

Es importante definir y acordar acerca de los términos certificación, homologación, verificación y auditoría en el ámbito del SJA. Certificación, es el proceso mediante el cual un ente u organismo reconocido analiza y contrasta que un objeto o proceso cumple con la normativa técnica establecida, emitiendo un certificado o declaración de conformidad. Homologación, es el proceso de aprobación oficial de un producto, proceso o servicio realizada por un organismo, que tiene esa facultad por el marco legal vinculante. Verificación, es la validación en campo de algunos valores especificados en las resoluciones técnicas que permitan corroborar que la máquina en análisis se corresponde con el modelo oportunamente homologado. En la Auditoría se comprueba lo antes verificado en el ámbito del SJA. Cada país, provincia o región define la existencia de todos, algunos o ninguno de estos procesos de acuerdo a su legislación.

Un programa de auditoria/aseguramiento para la prevención, tiene tres fases: 1) Fase A: determinar el alcance de la auditoría; 2) Fase B: comprender qué o quiénes son los facilitadores (enablers, en COBIT), fijar los criterios adecuados y realizar la evaluación; y 3) Fase C: comunicar y reportar los resultados de la evaluación.

Para determinar la Fase B, se deben analizar los 5 componentes de una iniciativa de aseguramiento (IFAC, 2005): 1 ) Relación de 3 partes (three party relationship), 2) Asunto (subject matter), 3) criterios adecuados (suitable criteria), 4) Ejecución, y 5) Conclusión.

La relación de tres partes la constituyen: el auditor (practitioner), la parte responsable (responsible party) y destinatarios (intended users).El término auditor puede referirse a una persona o una empresa. La parte responsable es la persona o personas que son responsables directos del asunto, o de la información relacionada por el asunto (en este caso de las TICs aplicadas a la prevención).Los destinatarios son la/las persona/personas para las cuales el auditor prepara el reporte de aseguramiento. 
En el caso que se tercerice el juego de azar (empresas privadas), las partes intervinientes en un proceso de aseguramiento son: las empresas que explotan el juego de azar (operador); y los reguladores de la actividad de juego (gobierno).

Las auditorías pueden ser llevadas a cabo por el regulador, o por una empresa contratada con ese fin. En este caso el destinatario de la auditoria es el propio gobierno.

Las empresas de juegos de azar tienen sus recursos tecnológicos. Estos recursos tecnológicos se deben aplicar de acuerdo a criterios (normativas, estándares o buenas prácticas) determinadas por el regulador. Por ejemplo, se debe tener en cuenta: 1) si se utiliza un sistema de control on line (como ocurre en la Provincia de Buenos Aires con las Salas de Bingo) el operador debe instalar una red de comunicaciones, servidores y aplicaciones; si se consultan online los reportes de actividad sospechosa (RAS), o las listas de OFAC, se debe tener conexión a Internet; si se realizan controles desde videocámaras; y si se establece una conexión on line con otros involucrados, como indica el punto 4.1.4 del Marco del Juego responsable de CIBELAE (relaciones y diálogo con grupos de interés), donde se indica que las organizaciones pueden relacionarse o dialogar con jugadores, empleados, organizaciones similares, proveedores, reguladores, para definir un entorno de colaboración.

Además, en la elección del uso de las TICs no debe dejarse de lado el impacto en el ambiente, como se indica en el punto 4.1.5 (Concientización sobre el medioambiente) del Marco antes citado.

Las recomendaciones 15 y 16 del GAFI se refieren a las nuevas tecnologías y a las transferencias electrónicas. La recomendación 15 indica que las instituciones financieras deberían identificar y evaluar los riesgos de lavado de activos y financiamiento al terrorismo que pueden surgir en relación al uso de las TICs (actuales o emergentes). Esta evaluación de riesgo debería realizarse antes de lanzar un producto, para implementar controles apropiados para su mitigación. En cuanto a la recomendación 16, se refiere a la importancia de las TICs en la identificación y beneficiarios de las transferencias. Los países deberían asegurar que las instituciones financieras monitorean las transferencias electrónicas para detectar aquéllas donde se hace dificultoso determinar origen y destinatario, y tomar las medidas adecuadas.

En este contexto sobre evaluar el uso de los recursos tecnológicos los criterios pueden sostenerse en los marcos ya citados. COBIT define atributos de calidad en la selección de los criterios. Ellos son: objetividad, que sean medibles, comprensibles, completos y relevantes (objectivity, measurability, understandability, completeness, relevance). Adicionalmente, consideramos que deben considerarse la buena gobernanza, transparencia, aporte a buenas causas (caso de entidades beneficiarias), contacto frecuente con grupos de interés, concientización ambiental; así como, los definidos en los marcos específicos del juego (WLA, CIBELAE, etc.). Sin embargo, el principal criterio es el determinado por las leyes y normativas que la industria del juego debe cumplir. 
A continuación, se aplica lo planteado sobre los siete facilitadores (enablers) del marco que propone COBIT 5:

\section{Principios, políticas y marcos}

Las pautas de evaluación del elemento con respecto a este facilitador están definidas por políticas, marcos o buenas prácticas ya existentes en el organismo. Considerando que el elemento trata específicamente con TI debería analizarse si la organización ha adoptado COBIT, ITIL o alguna otra referencia. No se deben descartar normas de calidad establecidas por el organismo o marcos propios. Es imprescindible que, en caso de adoptar algún marco o estándar, exista documentación aprobada por el máximo estamento para su desarrollo, implementación y mantenimiento. Considerando que el elemento se analiza en el contexto de políticas de PLA, deben enunciarse si las acciones que se lleven a cabo se alinean con algún marco (WLA, CIBELAE, etc.)

\section{Procesos}

Las políticas de prevención son aplicadas a procesos bien definidos. Esta definición es necesaria para enunciar las actividades que se llevan a cabo en cada proceso, los roles y responsabilidades de las personas que participan. Trabajar con procesos facilita también la evaluación. La tecnología participa directa o indirectamente en todos los procesos. Por ejemplo, si hay un proceso de restringir la entrada a un casino de determinadas personas, podría usarse un software de reconocimiento facial. Si se debe enviar un reporte de actividad sospechosa via web, o consultar las listas de OFAC online, se utilizará Internet, o enlaces definidos y aplicaciones correspondientes.

\section{Estructuras organizacionales}

Las casas de Loterías y Apuestas deben definir claramente las responsabilidades y los mecanismos para dar cuenta de las actividades que se realizan y sus consecuencias, asegurando que las políticas, los procedimientos y los controles implementados son adecuados para prevenir y detectar situaciones de lavado. Para llevar a cabo esto es imprescindible que en cada organización, una persona asuma esta responsabilidad con la necesaria autoridad para hacerlo. Para cubrir este rol se propone la designación de un oficial de cumplimiento, quien además, será el punto central de contacto con las autoridades de la organización, para la supervisión de las actividades antilavado. Las organizaciones deben definir una estructura adecuada para asignar roles y responsabilidades en la lucha contra el LA y garantizar que se cumple la normativa y buenas prácticas al respecto.

Con respecto al elemento de análisis, el área de tecnología debe contar también con una estructura, donde quede separado gobernanza (políticas tecnológicas, estrategia) de gestión y operación. Cada operación debe estar en el marco de procedimientos, directrices y aun políticas de TI definidas. El desconectar una slot machine de una isla es una acción en el marco de una decisión superior. Habilitar nuevos usuarios para el tratamiento de los SAR, también. 


\section{Cultura, Ética y Comportamiento}

La cultura de uso de la tecnología está definida por cada organización, ya sea formal o informalmente. Puede ser que incorpore mails o SMS para comunicarse con los clientes e informarles de nuevos juegos, promociones o eventos. Y ese uso debe estar amparado por una ética orientada a la concientización del uso seguro y consciente de la tecnología. Vemos el caso del uso del software de reconocimiento facial para detectar personas que no se desea que ingresen a un casino. Deben existir pautas claras que el objetivo único es detectar determinadas personas y no filmar y registrar otras personas que acuden, lo que podría ser utilizado posteriormente para algún tipo de extorsión.

\section{Información}

El tratamiento de la información se realiza actualmente mediante la tecnología. En el ámbito PLA la información comprende la relacionada al conocimiento del cliente (Know your client, KYC), a listas de OFAC o similares, RAS, cobros de premios, auditorías previas, reportes de incidentes, etc. Esta información debe estar adecuadamente protegida según los criterios de seguridad: confidencialidad, integridad y disponibilidad. Deben definirse también quienes son los responsables de la información y qué acciones y en qué situaciones se llevan a cabo.

\section{Servicios, Infraestructura y Aplicaciones}

GAFI destaca que si bien los casinos, por definición no son instituciones financieras, en algunos de ellos se realizan algunas actividades similares a las que se llevan a cabo en instituciones financieras en el marco de su oferta de entretenimiento: se pueden aceptar fondos a cuenta, cambio de moneda, cambio de moneda extranjera, almacenar valores, dar facilidades de dinero mediante tarjetas de crédito, uso de cheques, depósito en cajas de seguridad, etc. En algunos casos estos servicios son provistos las 24 horas del día. El registro de estas acciones y el control on line son parte de las políticas PLA. Los servicios e infraestructuras tecnológicas inherentes al juego deben estar claramente definidas, con responsables asignados y controles efectivos.

\section{Personas, Capacidades (skills) y competencias}

La organización debe garantizar que el personal está capacitado para llevar a cabo su tarea satisfactoriamente y que, ante su ausencia, temporal o definitiva, esa función puede ser realizada rápidamente por otro empleado.

Para determinar las capacidades del personal deben definirse qué tareas TI se llevan a cabo. Debe establecerse un plan de continuidad de negocio (Business Continuity Plan, $\mathrm{BCP})$ que contemple probables situaciones de desastre o interrupción de la operación, donde cada miembro de personal esté capacitado para llevar a cabo su rol.La evolución de la tecnología y su uso masivo exige analizar en forma continua cuáles son las capacidades y competencias del personal. Adicionalmente, los procesos de selección de personal deben estar orientados a contratar individuos que acompañen las acciones de PLA. 


\section{EVALUACIÓN DEL MODELO MEDIANTE NIVELES DE MADUREZ}

En este capítulo se describe el uso de niveles de madurez como una herramienta de evaluación de la dedicación, esfuerzo y efectividad de las acciones que llevan a cabo las organizaciones en el marco de la prevención de LA.Se definen los cuatro niveles de madurez generales y se describen las acciones que determinan dichos niveles para cada uno de los elementos propuestos.Por último se proveen pautas orientadas a la certificación de cada nivel, como un reconocimiento al esfuerzo y logros obtenidos por una organización en la definición y aplicación de políticas de prevención.

\subsection{El nivel de madurez como herramienta de evaluación}

Un nivel de madurez de un proceso es un esfuerzo evolutivo bien definido para alcanzar lograr un estado determinado o deseado. Una organización puede plantearse obtener un determinado nivel de madurez sobre un proceso (nivel esperado) a partir del estado real (nivel actual). En cada caso, se definen las características de cada nivel, lo que debe cumplir un proceso para estar en ese nivel.

Si bien el término es de gran aplicación en el ámbito del desarrollo de software existen diferentes modelos para acompañar la madurez de otros tipos de procesos: Modelo de Madurez de Capacidades en la Ingeniería de Sistemas (SE-CMM), Modelo de Madurez de Capacidades para el Desarrollo Integrado de Productos (IPD-CMM), Modelo de Madurez de Capacidades para Recursos Humanos (P-CMM), Modelo de Madurez de Capacidades para la Adquisición de Software (SA-CMM), Modelo de Madurez de Capacidades para el mantenimiento del software (S3M), CMMI que integra diferentes modelos. Gartner ${ }^{26}$, desde su página propone diferentes modelos de madurez: para seguridad, internet de las cosas, para el desarrollo y entrega de aplicaciones móviles, etc.

Una organización tiene distintos procesos interrelacionados, y en algunos, dependientes. Por eso se debe definir claramente cómo se establecerá el nivel de madurez.El objetivo es que la organización construya una cultura hacia la mejora continua, teniendo muy claro dónde está y a dónde quiere llegar. De este modo, que la organización priorice esfuerzos.

El Modelo de Madurez de Capacidades o CMM (Capability Maturity Model), es un modelo que se utiliza para la evaluación de los procesos de una organización. Fue desarrollado por el Software Engineering Institute (SEI), que es un centro de investigación y desarrollo gestionado por la Universidad Carnegie-Mellon. "CMM" es una marca registrada del SEI. Según lo define el SEI, un modelo de madurez y capacidad:

\footnotetext{
${ }^{26}$ www.gartner.com
} 
“... contiene los elementos esenciales de procesos efectivos para una o más disciplinas y describe un camino de mejoramiento evolutivo desde procesos caóticos hasta procesos maduros con calidad y efectividad mejorada".

Los cinco niveles de madurez que define el CMM son:

1. Inicial - Ambiente inestable para el desarrollo y mantenimiento de software, falta de planificación, el éxito de los proyectos se basa la mayoría de las veces en el esfuerzo personal. Hay fracasos, retrasos y gastos excesivos. El resultado de los proyectos es impredecible.

2. Repetible-Se dispone de prácticas institucionalizadas de gestión de proyectos. Se han definido métricas básicas y pautas de calidad. Hay sistematización en el trato con interesados externos, como subcontratistas y clientes.

3. Definido- Hay una buena gestión de proyectos. Se han definido procedimientos correctos de coordinación entre grupos, formación del personal, técnicas de ingeniería más detalladas. Se ha avanzado en cuanto a métricas de los procesos.

4. Administrado o gestionado - se dispone de un conjunto de métricas significativas de calidad y productividad, que se usan de modo sistemático para la toma de decisiones y la gestión de riesgos. El software resultante es de alta calidad.

5. Optimizado - La organización completa está volcada en la mejora continua de los procesos. Se hace uso intensivo de las métricas y se gestiona el proceso de innovación.

Cobit 4.1 (ITGI), toma los niveles de CMM pero agregando un nivel 0 (no existente).Como se indicó párrafos arriba, el MJR de la WLA considera 4 niveles: Compromiso, Autoevaluación y análisis de brechas, Planificación e implementación, Mejora continua.

\subsection{Propuesta de niveles de madurez}

El siguiente es otro importante aporte de este trabajo. Se trata de la determinación de los niveles de madurez y los requisitos para alcanzarlos. De acuerdo a lo analizado hasta el momento y según los factores que considero que inciden en LA, se proponen los siguientes niveles:

- Nivel 1: Compromiso

- Nivel 2: Conocimiento del contexto y planificación

- Nivel 3: Implementación del plan elaborado

- Nivel 4: Mejora continua 


\subsubsection{Nivel 1: Compromiso}

Objetivo de nivel: la organización debe demostrar su compromiso para definir políticas PLA, de acuerdo a su contexto, es decir, juegos que ofrece, cumplimiento de normativas del país y buenas prácticas internacionales. Debe garantizar que esas políticas serán definidas en un período no menor a un año.

En este nivel, la organización de SJA se compromete a:

- definir, implementar y mejorar políticas de prevención de LA y acciones conducentes a su cumplimiento;

- declarar conocer y enunciar las normativas que debe cumplir de acuerdo a regulaciones del país, del sector y marcos internacionales que se ha decidido adoptar;

- declarar conocer y enunciar cuáles deben ser los circuitos para garantizar la entrega de la información a la dependencia correspondiente;

- declarar conocer y enunciar las tipologías LA de acuerdo a los juegos que promueve;

- dar los lineamientos de un plan de gestión de riesgos: cómo lo elaborará, que marcos o estándares adoptará para su elaboración, y definir su apetito de riesgo.

Este compromiso se refleja en una serie de documentos y acuerdos entre reguladores, operadores, y organismos intervinientes como la UIF o similares, que constituyen la evidencia para la evaluación del nivel.Este nivel es declarativo.

\subsubsection{Nivel 2: Conocimiento del contexto y planificación}

Objetivo del nivel: Promover la autoevaluación y la planificación de actividades en el marco PLA.

En este nivel, la organización debe llevar a cabo una gestión de riesgos para determinar el apetito de riesgo y el riesgo inherente. El análisis se elaborará tomando como base los 10 elementos, determinando por cada uno de ellos amenazas y vulnerabilidades, impacto y probabilidad, y teniendo en cuento los juegos que ofrece y las tipologías LA asociadas.

Una vez determinado el riesgo, se debe definir el conjunto de controles adecuados. Se determinarán los indicadores claves de rendimiento (Key performance indicators, KPI), los indicadores claves de éxito (key goal indicators, KGIs) y los factores críticos de éxito (Critical Success Factors, CSF). Se definirá cuáles son las variables intervinientes.

Lo antes descripto se debe aplicar a cada uno de los elementos enunciados arriba. La organización debe redactar las políticas de PLA, las que deben estar aprobadas por la alta gerencia/dirección/presidencia. Debe mostrar evidencia que se han comunicado al 
resto de la organización y su publicación en la página Web y en diferentes lugares de la sala de juego.

\subsubsection{Nivel 3: Implementación del plan elaborado}

Objetivo del nivel: La organización implementa las acciones enunciadas en el marco de sus políticas.

En este nivel, la organización debe demostrar que se han implementado los planes establecidos en el nivel 2. Se deben evidenciar acciones preventivas ante nuevas amenazas y correctivas sobre aquellos controles inadecuados. Se ratifica o rectifica el documento de políticas presentado en el Nivel 2. Lo antes descripto se debe aplicar a cada uno de los elementos enunciados arriba.

\subsubsection{Nivel 4: Mejora continua}

Objetivo del nivel: La organización hace uso de indicadores y otra información relevante para la toma de decisiones y optimización de sus procesos.

La organización debe demostrar que ha automatizado actividades orientadas a la prevención, que los indicadores son aprovechados mediante el establecimiento de umbrales y alertas para la detección temprana de nuevas amenazas. El conjunto de información que se genera es alimento para la mejora y la optimización de los procesos. Lo antes descripto se debe aplicar a cada uno de los elementos enunciados arriba.

\subsection{Requisitos para la determinación del nivel de madurez}

El nivel de madurez con respecto a PLA surge de integrar los niveles de madurez del conjunto de los 10 elementos enunciados. Para ello es necesario definir pautas de madurez para cada uno de los elementos.

El único nivel que es declarativo es el inicial, pues consiste en que la entidad declare su compromiso con definir e implementar políticas de PLA. Por lo tanto, la descripción de las pautas a cumplir por cada elemento en cada nivel se enunciará a partir del nivel 2.

Para determinar el nivel general de madurez se propone definir un promedio de los niveles de madurez obtenidos para cada elemento. Si se desea darle mayor relevancia a algunos de ellos, se puede incluir un coeficiente o correlación entre elementos.

\subsubsection{Determinación del riesgo}

En el marco de determinar el nivel de madurez de las distintas entidades del SJA en la prevención de lavado de activos (PLA), se analiza el elemento "Determinación del riesgo" en sus diferentes niveles.En este documento se describen las acciones que se deben cumplir para alcanzar cada nivel de madurez para este elemento. También se 
sugieren estándares y herramientas existentes para que la organización solicitante defina su proceso de gestión de riesgos.

A modo de unificar terminología y definiciones, se aclaran los distintos tipos de riesgos:

- Riesgo Inherente: - el riesgo de un proceso, sin considerar los controles que tenga. Es el inherente al negocio.

- Riesgo de Control- riesgo de que los controles definidos no sean eficientes.

- Riesgo de Detección - riesgo que los procedimientos de auditoría sean insuficientes (no detecten diferencias "materiales")

- Riesgo de Auditoría -es el riesgo de que las conclusiones no estén correctamente soportadas (aseveraciones equívocas materiales)

En esta tesis se define organización solicitante como la organización que solicita o postula para la evaluación.

\section{Niveles de madurez}

\section{| Sobre el nivel 2 de este elemento}

Este nivel se basa en la etapa de análisis del proceso de gestión de riesgos. Este análisis debe abarcar todos los juegos que la entidad ofrece.En este nivel, la organización solicitante, debe entregar documentación que indique:

- Metodología que se utiliza para conocimiento del contexto (evaluaciones nacionales o internacionales, reportes de tipologías, reportes de evaluación, etc.)

- Listado de riesgos potenciales o factores de riesgo

- Metodología que se ha seguido para la detección de vulnerabilidades y amenazas

- Metodología que se seguirá para el análisis de riesgo

- Propuesta de la capacitación y concientización del personal

\section{| Sobre el nivel 3 de este elemento}

En este nivel la organización avanza más sobre el proceso de gestión, ofreciendo una descripción más detallada.Se debe entregar documentación que indique:

- Metodología acerca de cómo se realiza la evaluación del riesgo

- Propuesta de Matriz de Riesgo

- Resultados de la capacitación y concientización del personal

\section{| Sobre el nivel 4 de este elemento}

Este nivel debe representar cuán dinámicamente la organización incluye en su gestión de riesgos nuevas situaciones de vulnerabilidad o amenaza que se detectan.Por lo tanto, en este nivel se evalúa: 
- la administración efectiva de las alertas;

- la automatización de las tareas;

- la administración formal de la documentación.

\subsubsection{Formalización y estandarización de los procesos PLA}

En el marco de determinar el nivel de madurez de las distintas entidades del SJA en la prevención de lavado de activos (PLA), se analiza el elemento "Formalización y esndarización de los procesos PLA" en sus diferentes niveles.La estandarización de procesos consiste en establecer un acuerdo acerca de la "mejor forma" de hacer algo que pueden determinar quiénes están involucrados. Esta estandarización se logra:

- determinando cuáles son los procesos, sus entradas, sus salidas, sus objetivos, quienes participan y cómo se evalúa su desempeño

- estableciendo una metodología para la determinación y tratamiento de situaciones comunes

- definiendo mecanismos de comunicación entre los involucrados

- concientizando al personal acerca de la importancia de respetar la estandarización

- adaptar la estandarización según nuevas situaciones detectadas

Para poder funcionar adecuadamente una organización debe identificar y administrar sus actividades. Estas actividades, coordinadas en un proceso, transforman entradas en salidas. Los distintos procesos están a su vez relacionados, creando un mapa de proceso y relaciones.Este sistema de procesos, que los identifica, define sus interacciones y los administra es lo que se llama un enfoque orientado a procesos.Los enfoques orientados a procesos permiten relacionar actividades, con roles y responsabilidades, asignar recursos y establecer métricas e indicadores para poder realizar propuestas de mejoras.

Por lo tanto, para construir este enfoque se hace necesario:

- Entender la organización, sus objetivos, sus requerimientos;

- Realizar un análisis de riesgo, determinar su apetito, e implementar controles adecuados;

- Monitorear para garantizar que se cumplen los objetivos o corregir el rumbo;

- Mejorar los procesos y sus relaciones en base a métricas e indicadores adecuados.

Se recomienda adoptar el modelo "Plan-Do-Check-Act" (PDCA), o ciclo de Deming, al efecto de administrar en forma ordenada y mediante la observación y evidencia, el plan de mejora que se aplique. En las recomendaciones del GAFI, si bien no hay una sección específica dedicada a procesos, el concepto aparece una y otra vez, de lo que se infiere su aplicabilidad. 


\section{Procesos relacionados con PLA}

A modo de ejemplo se indican algunos procesos relacionados con PLA:

- Proceso de identificación del cliente

- Proceso de información a autoridades pertinentes

- Proceso ante la detección de vulnerabilidades o amenazas

- Proceso de administración de la documentación

- Proceso de administración de alertas

- Proceso de generación y mantenimiento del manual de procedimientos

- Proceso de monitoreo

\section{Niveles de madurez}

A continuación se detalla cuáles son los requisitos para cada nivel, en el elemento "Formalización y estandarización de los procesos PLA".

| Sobre el nivel 2 de este elemento

En este nivel, la organización solicitante, debe entregar documentación que evidencie:

- Identificación de procesos relacionados PLA

- Determinación de responsables por cada proceso

- Propuesta de la capacitación y concientización del personal

\section{| Sobre el nivel 3 de este elemento}

En este nivel la organización avanza más sobre el desarrollo del elemento, ofreciendo una descripción más detallada.Se debe entregar documentación que indique, por cada proceso:

- Objetivos

- Recursos que insume: personal, tecnología, infraestructura

- Entradas y salidas del proceso

- Indicadores para evaluar desempeño de los procesos

- Resultados de la capacitación y concientización del personal

\section{| Sobre el nivel 4 de este elemento}

Este nivel debe representar cuán dinámicamente la organización mejora la estandarización de procesos en práctica y se adapta a nuevas situaciones.Por lo tanto en este nivel se evalúa:

- Mecanismos ante la actualización de los procesos 
- Mecanismos de difusión

\subsubsection{Definición de Estructura Organizacional}

En el marco de determinar el nivel de madurez de las distintas entidades del SJA en la prevención de lavado de activos (PLA), se analiza el elemento "Definición de Estructura Organizacional" en sus diferentes niveles.

Las entidades de SJA deben definir claramente las responsabilidades y los mecanismos para dar cuenta de las actividades que se realizan y sus consecuencias, asegurando que las políticas, los procedimientos y los controles implementados son adecuados para prevenir y detectar situaciones de lavado.Para llevar a cabo esto es imprescindible que, en cada organización, una persona asuma esta responsabilidad con la necesaria autoridad para hacerlo. Para cubrir este rol se propone la designación de un oficial de cumplimiento, quien, será el punto central de contacto con las autoridades de la organización, para la supervisión de las actividades antilavado.

Las organizaciones deben definir una estructura adecuada para asignar roles y responsabilidades en la lucha contra el LD y garantizar que se cumple la normativa y buenas prácticas al respecto.En la nota interpretativa de la recomendación 18 (controles internos y sucursales y filiales extranjeras) de las Recomendaciones GAFI, se indica:

“...Los programas de las instituciones financieras contra el lavado de
activos y el financiamiento del terrorismo deben incluir: (a) el desarrollo
de políticas, procedimientos y controles internos, incluyendo acuerdos
apropiados de manejo del cumplimiento y procedimientos adecuados de
inspección, para asegurar elevados estándares a la hora de contratar a
los empleados; (b) un programa continuo de capacitación a los
empleados; y (c) una función de auditoría independiente para comprobar
el sistema. 2. El tipo y alcance de las medidas a tomar debe
corresponderse a la consideración del riesgo de lavado de activos y
financiamiento del terrorismo y a las dimensiones de la actividad
comercial. 3. Los arreglos sobre el manejo del cumplimiento deben incluir
la designación de un oficial de cumplimiento a nivel administrativo..."

Es decir, aunque no exista específicamente una normativa en el país de residencia de la entidad, el alineamiento con las recomendaciones GAFI exige considerar la designación del oficial de cumplimiento, mínimamente.

En el ítem "Implementación" del marco de Juego responsable de CIBELAE, entre las acciones orientadas a la mejora continua, se indica:

"Designar una persona oficial de contacto para el seguimiento de la implementación de las acciones de mejora para el grupo de trabajo de CIBELAE”. 
La designación de una persona responsable de una determinada actividad sugiere la necesidad de definir una mínima estructura para poder encauzar las decisiones que se hace necesario tomar.

\section{Niveles de madurez}

A continuación, se detalla cuáles son los requisitos para cada nivel, en el elemento "Definición de Estructura Organizacional".

\section{Sobre el nivel 2 de este elemento}

En este nivel, la organización solicitante, debe entregar documentación que indique:

- Cuál es la estructura actual de la organización

- Si existe normativa del país de residencia que exija una estructura definida con roles y responsabilidades.

Realizando un análisis de contexto y de situaciones vividas en el pasado, se solicita indicar:

- Vulnerabilidades que presenta la estructura actual

- Propuesta de mejora en el marco de vulnerabilidades o nuevas amenazas detectadas, o detección de controles ineficientes.

\section{Sobre el nivel 3 de este elemento}

En este nivel la organización avanza más sobre el desarrollo del elemento, ofreciendo una descripción más detallada en cuanto a la implementación de mejoras sugeridas en el nivel anterior.

\section{Sobre el nivel 4 de este elemento}

Este nivel debe representar cuán dinámicamente la organización mejora su estructura en función de las buenas prácticas y se adapta a nuevas situaciones.Como mínimo, la organización debe designar:

- Comité de Cumplimiento (CC)

- Oficial de Cumplimiento (OC) Personal jerárquico o director de establecimiento

- Oficial de cumplimiento suplente

- Gerencia de la Unidad ejecutora de las políticas de prevención de LA (puede o no ser el OC)

- Unidad ejecutora de las políticas de prevención de LA

Por cada rol deben indicarse las características de su designación y sus incumbencias; las relaciones entre los diferentes roles y la relación con organismos competentes, qué 
compromisos se definen con la organización y cómo se penaliza la falta al compromiso y a la ética.

\subsubsection{Tratamiento de la información y documentación}

En el marco de determinar el nivel de madurez de las distintas entidades del SJA en la prevención de lavado de activos (PLA), se analiza el elemento "Tratamiento de la información y documentación" en sus diferentes niveles.

Dado el uso de nuevas tecnologías para la información y las comunicaciones (TIC) el tratamiento de la información se extiende a todos los medios a través de los cuales se representa, ya sea en papel o publicable por medios electrónicos (celulares, tablets, computadoras, páginas WEB). La información puede representarse en papel, o mediante imágenes o voz.

La ISO/IEC 27001: 2013 trata acerca de establecer, implementar, mantener y mejorar un Sistema de Gestión de Seguridad de la Información (SGSI) dentro del contexto de las actividades generales del negocio de la organización, y de los riesgos que enfrenta. La información es considerada el activo más importante de una organización. Este estándar dedica una sección (Section 7.5 - Documented information) a la documentación de la información. Si bien está referido al sistema de gestión de la seguridad, es una buena práctica su aplicación en toda documentación que, como la que se almacena, genera y transfiere en el marco de políticas PLA, debe ser protegida adecuadamente. En la norma se destaca que la información que utilice una organización está directamente relacionada a su medida, tipo de actividad, procesos, productos y servicios, y la competencia de los recursos humanos que las componen.

La información debe estar adecuadamente identificada, descripta, formateada de acuerdo al medio que la representa (sea un papel o electrónico) sea en cuanto al lenguaje que se utiliza, versión de software, gráficos, y debe estar revisada y aprobada por los organismos o dependencias correspondientes.Debe estar, además, controlada adecuadamente para asegurar que esté disponible para su acceso y uso donde y cuando se la necesite, protegida contra la pérdida de confidencialidad, uso impropio o pérdida de integridad. Para ello las actividades en el marco de los requisitos antes planteados deben orientarse a la distribución, acceso, recuperación y uso, almacenamiento y preservación (incluyendo preservación de legibilidad), control de cambios, retención y disposición final.

En cuanto a los Principios de Juego Responsable definidos por la WLA, el elemento en análisis es referenciado en los principios $2,3,6$ y 7 :

Principio 2. Los miembros de la WLA garantizarán que sus prácticas y procedimientos reflejen una combinación de regulaciones gubernamentales, autorregulación en la industria y responsabilidad individual, dentro del contexto y marco legal, económico, político, ético y cultural en que ocurren. 
Principio 3. Los miembros de la WLA desarrollarán sus prácticas relacionadas con el juego responsable con el más pleno entendimiento posible de la información relevante $y$ análisis de investigación documentada.

Principio 6. Los miembros de la WLA proporcionarán al público información en forma correcta y equilibrada para permitir a los individuos que hagan elecciones con información sobre las actividades de juego en el ámbito de la jurisdicción de las loterías. Este compromiso requiere lo siguiente:a) que el mercadeo de las actividades y productos de loterías esté sujeto a una autorregulación razonable, y que se promuevan prácticas de juego responsable y elecciones informadas; $y$ b) que los programas educativos desempeñen un rol importante para proporcionar a los individuos información correcta sobre el juego y los riesgos a él asociados.

Principio 7. Los miembros de la WLA harán un esfuerzo razonable para controlar, probar y revisar, cuando sea apropiado, aquellas actividades y prácticas relacionadas con el juego responsable informando públicamente de sus conclusiones.

El elemento 10 del marco de la WLA "Información al jugador", que se describe como "Un enfoque sistemático para evaluar y presentar informes sobre las acciones, compromisos y progresos de su lotería en materia de JR a grupos de interés internos y externos", se alinea con este elemento en sus objetivos. Por lo tanto, vale considerarlos para este marco.

De los requisitos para la certificación en Responsabilidad Social Corporativa y Juego Responsable de CIBELAE, descritos en el Marco de Certificación de Responsabilidad Social Corporativa y Gestión Responsable del Juego, el elemento "Tratamiento de la información y documentación" contribuye directamente al Buen Gobierno y a la Transparencia. Indirectamente aporta al resto de los requisitos pues todo proceso se alimenta, genera o consume información.

En el ítem 4.2.7 - Información a los participantes, indica que:

“... Cada organización debe difundir información relacionada con la buena praxis en materia de Juego Responsable a sus Grupos de Interés. Asimismo, cada Institución que tenga histórico de ludopatía asociada a las loterías y juegos que comercializa deberá de disponer y facilitar un listado de prestadores de servicios de tratamiento...".

Uno de los objetivos de las Recomendaciones del GAFI es mejorar la transparencia y la disponibilidad de la información de titularidad de beneficio de las personas y estructuras jurídicas.En la recomendación 10, Debida Diligencia al Cliente (DDC), se indica que identificar al cliente y verificar su identidad se realiza "...utilizando documentos, datos $\mathrm{o}$ información confiable, de fuentes independientes..." y “...entender, y cuando 
corresponda, obtener información sobre el propósito y el carácter que se pretende dar a la relación comercial..." (Debida Diligencia y mantenimiento de Registros, Recomendaciones GAFI).

En las recomendaciones de la GAFI se aclara que los requisitos de debida diligencia del cliente y el mantenimiento de registros establecidos en las Recomendaciones 10, 11, 12 , 15 y 17, se aplican a las APNFD, entre las que se indican casinos, específicamente cuando "... los clientes se involucran en transacciones financieras por un monto igual o mayor al umbral designado aplicable..."

La recomendación 11, Mantenimiento de registros, expresa:

"Debe exigirse a las instituciones financieras que mantengan, por un periodo de al menos cinco años, todos los registros necesarios sobre las transacciones, tanto locales como internacionales, para que éstas puedan cumplir con rapidez con las peticiones de información solicitadas por las autoridades competentes. Estos registros tienen que ser suficientes para permitir la reconstrucción de transacciones individuales (incluyendo los montos y tipos de moneda involucrada, de haber alguna) de manera tal que se ofrezca evidencia, de ser necesario, para el enjuiciamiento de una actividad criminal. Debe exigirse a las instituciones financieras que conserven todos los registros obtenidos a través de medidas de DDC (ej.: copias o registros de documentos oficiales de identificación como pasaportes, tarjetas de identidad, licencias de conducción o documentos similares), expedientes de cuentas y correspondencia comercial, incluyendo los resultados de los análisis que se hayan realizado (ej.: investigaciones preliminares para establecer los antecedentes y el propósito de transacciones complejas, inusualmente grandes), por un período de al menos cinco años luego de terminada la relación comercial o después de la fecha de efectuada la transacción ocasional. Debe exigirse a las instituciones financieras, por ley, que mantengan los registros sobre las transacciones y la información obtenida mediante las medidas de DDC. La información de DDC y los registros de transacciones deben estar a disposición de las autoridades competentes locales con la debida autorización".

\section{Información en el marco PLA}

El elemento "Tratamiento de la información y la documentación" que se analiza en este documento define un conjunto de acciones.Para ello debe partirse del interrogante: Qué información y documentación se utilizan en el marco PLA?Las actividades en el marco de PLA son registradas en diversos formularios y planillas. Sirvan como ejemplo:

- Política de identificación y Conocimiento del Cliente (sea Persona Física o Jurídica)

- Declaraciones Juradas (por ejemplo, sobre la Condición de Persona Expuesta Políticamente (PEP).

- Documentos internos y externos válidos

- Comunicaciones internas y con terceros 
- Planes (Capacitación, concientización, de contingencia, etc.)

- Información relacionada con la buena praxis en materia de Juego Responsable a sus Grupos de Interés.

- Si existe un histórico de ludopatía asociada a las loterías y juegos que comercializa, debe presentar el listado de prestadores de servicios de tratamiento...".

También se debe considerar la información que provenga de las exigencias de cumplimiento de acuerdo a la normativa vigente, como informes de actividades sospechosas $\mathrm{u}$ otras obligaciones que los sujetos obligados deban entregar a la dependencia gubernamental pertinente.

\section{Niveles de madurez}

A continuación se detalla cuáles son los requisitos para cada nivel, en el elemento "Tratamiento de la información y documentación".

\section{Sobre el nivel 2 de este elemento}

Para satisfacer este nivel, la organización debe:

- Identificar la documentación generada y recibida relacionada con sus actividades de prevención y prevención de lavado de activos. Presentar un listado de documentos que la entidad se compromete a elaborar y mantener en el futuro.

- Identificar y proponer los procesos de tratamiento de información y documentación.

- Proponer metodologías de preservación para todo tipo de información (escrita o electrónica) de acuerdo a la normativa existente. En caso que no hubiera normativa que lo indique específicamente, la entidad se guiará por las buenas prácticas existentes para la preservación de la información.

\section{Sobre el nivel 3 de este elemento}

En este nivel la organización demuestra su avance sobre la planificación e implementación del compromiso adoptado en el nivel 2.

Del listado propuesto en el nivel 2, se debe presentar un listado completo que indique:

- Identificación del documento

- Versión

- Fecha

- Autores

- Quienes lo aprobaron

- Vigencia

- Carácter público o privado 
- Grado de confidencialidad

- Metodología de difusión en caso de ser público.

De los procesos indicados en el nivel de compromiso se debe presentar un mapa de procesos, donde se represente la relación entre ellos.Por cada proceso se debe indicar quienes participan, que información y/o documentación ingresa, que información y/o documentación se genera, su grado de confidencialidad y disponibilidad.

Sobre el nivel 4 de este elemento

Este nivel debe representar cómo la entidad sistematiza el tratamiento de la información y documentación.

Esto se refleja es la automatización de las tareas y la existencia de repositorios que permitan el acceso a la información de acuerdo a su criticidad (relacionado con la disponibilidad) y sensibilidad (relacionada con la sensibilidad.También se evalúa el grado de respuesta de la entidad a la exigencia de cumplimiento de normativas relacionadas con este elemento.

\subsubsection{Capacitación y concientización de empleados y público en general}

En el marco de determinar el nivel de madurez de las distintas entidades del SJA en la prevención de lavado de activos (PLA), este documento analiza el elemento "Capacitación y concientización de empleados y público en general" en sus diferentes niveles.

En (Corporación Iberoamericana de Loterías y Apuestas de Estado (CIBELAE), 2011)se destaca en diferentes párrafos la necesidad de capacitación y concientización hacia el juego responsable. Dentro de la sección 4.2, Gestión Responsable del Juego, en el ítem 4.2.2, Formación de empleados, se indica expresamente:

Cada organización debe “...Desarrollar campañas de formación e información que faciliten una correcta aplicación de los principios de Juego Responsable por todos los empleados de la organización..."

En el ítem 4.2.3 - Puntos de venta, indica:

“... Desarrollar campañas de formación e información que faciliten una correcta aplicación de los principios de Juego Responsable por todos los empleados de los puntos de venta..."

El Marco de Juego responsable de la WLA, en el elemento Programa de empleados indica que el programa es: 
“...Un enfoque sistemático que asegura y apoya de manera efectiva y eficiente la aplicación de principios del Juego Responsable por parte de todos los empleados interesados..."

Esto no puede ser logrado sin una adecuada capacitación y concientización acerca de las tipologías de lavado de activos en los distintos juegos y la detección de operaciones inusuales que pueden conducir a una operación sospechosa de lavado.

En la nota interpretativa de la Recomendación 18 (controles internos y sucursales y filiales extranjeras) del Grupo de Acción Financiera Internacional (GAFI), se indica:

“... Los programas de las instituciones financieras contra el lavado de activos y el financiamiento del terrorismo deben incluir: (a) el desarrollo de políticas, procedimientos y controles internos, incluyendo acuerdos apropiados de manejo del cumplimiento y procedimientos adecuados de inspección, para asegurar elevados estándares a la hora de contratar a los empleados; (b) un programa continuo de capacitación a los empleados...".

El control A.8.2.2. de la ISO 27001 se refiere específicamente a la "Concientización, educación y entrenamiento en seguridad de la información”, y enuncia:

"Todos los empleados de la organización y, cuando sea relevante, los usuarios contratistas y de terceras partes deben recibir entrenamiento adecuado sobre concientización y sobre actualizaciones regulares a políticas y procedimientos, de acuerdo con la función desempeñada".

Por lo tanto, aunque no exista una normativa específica en el país de residencia de la organización, los estándares y las buenas prácticas recomiendan que debe existir un programa de concientización para empleados, jugadores y agencieros o intermediarios acerca de las situaciones que pueden encubrir lavado de dinero, y acerca de cómo actuar ante la detección de estas situaciones.

\section{Niveles de madurez}

A continuación se detalla cuáles son los requisitos para cada nivel, en el elemento "Capacitación y concientización de empleados y público en general".

\section{Sobre el nivel 2 de este elemento}

En este nivel la entidad debe presentar cuál es su situación actual con respecto a la formación de empleados, jugadores y agencieros o intermediarios acerca de las situaciones que pueden encubrir lavado de dinero, y acerca de cómo actuar ante la detección de estas situaciones.Debe realizar una propuesta mejoradora a cumplir en el próximo nivel, donde se incluyan seminarios, encuentros, cursos con evaluación para los diferentes niveles. 
Es recomendable el asociarse en la capacitación con centros de formación de prestigio, con conocimiento de la temática.

Debe informarse acerca de la metodología que se utilice o se prevé utilizar para acercar al jugador, acerca de situaciones donde puede verse involucrado en una operación de lavado.

\section{Sobre el nivel 3 de este elemento}

La organización solicitante informa sus adelantos en el marco de la propuesta presentada en el nivel 2.

En este nivel se debe identificar el equipo de trabajo dedicado a PLA, indicando la formación de cada uno de los miembros. El equipo debe contar con personal con experiencia y nuevas incorporaciones.Se debe facilitar un listado de las actividades de capacitación realizadas, indicando equipo docente, curriculums, duración de la actividad, frecuencia, audiencia (jugadores, personal, agenciero, etc).Se deben presentar fotos acerca de las evidencias de concientización en las salas (carteles, indicadores, regalos, etc.).

\section{Sobre el nivel 4 de este elemento}

Este nivel debe representar cuán dinámicamente la organización define las pautas de capacitación y concientización ante nuevas situaciones de vulnerabilidad o amenaza que se detectan.

La organización debe presentar un plan de capacitación integral que incluya a empleados, jugadores, operadores e intermediarios, que incluya cursos, boletines, y una actualización ante la incorporación de nuevos juegos o situaciones emergentes.

\subsubsection{Control interno, Monitoreo y Auditoría}

En el marco de determinar el nivel de madurez de las distintas entidades del SJA en la prevención de lavado de activos (PLA), este documento analiza el elemento "Control interno, Monitoreo y Auditoría" en sus diferentes niveles.

El Control Interno es un proceso, afectado por la dirección, gerencia, y el resto del personal, diseñado para proveer un aseguramiento razonable de que los objetivos de la organización se van a cumplir. Cuando el control interno se cumple aceptablemente, se reduce a un nivel aceptable el riesgo de no cumplir con los objetivos de la organización. En la nota interpretativa de la Recomendación 18 (controles internos y sucursales y filiales extranjeras) del Grupo de Acción Financiera Internacional (GAFI), se indica: 
“... Los programas de las instituciones financieras27 contra el lavado de activos y el financiamiento del terrorismo deben incluir: (a) el desarrollo de políticas, procedimientos y controles internos, incluyendo acuerdos apropiados de manejo del cumplimiento y procedimientos adecuados de inspección, para asegurar elevados estándares a la hora de contratar a los empleados...".

En la nota interpretativa de la recomendación 26 (regulación y supervisión de las instituciones financieras), acerca del enfoque basado en riesgo en materia de Supervisión, se expresa:

"...los supervisores: (a) deben entender con claridad los riesgos de lavado de activos y financiamiento del terrorismo presentes en el país; $y$ (b) deben tener acceso in-situ y extra-situ a toda la información relevante sobre los riesgos especificos internos e internacionales asociados a los clientes, productos y servicios de las instituciones supervisadas, incluyendo la calidad de la función de cumplimiento de la institución financiera o grupo (o grupos, cuando sea aplicables los Principios Centrales). La frecuencia e intensidad de la supervisión in-situ y extrasitu ALA/CFT de las instituciones/grupos financieros, debe basarse en los riesgos de lavado de activos y financiamiento del terrorismo, así como en las políticas, controles internos y procedimientos asociados a la institución/grupo, según lo identificado por la evaluación del supervisor del perfil de riesgo de la institución/grupo y acerca de los riesgos de lavado de activos y financiamiento del terrorismo presentes en el país..."

En (Corporación Iberoamericana de Loterías y Apuestas de Estado (CIBELAE), 2011)el Buen Gobierno es uno de los requisitos que se citan en el marco de la Responsabilidad Social Corporativa, uno de los ejes sobre el que se sustenta el marco.Con respecto al Buen Gobierno, en el punto 4.1.1, el marco indica que:

“...Las Organizaciones deben contar con politicas eficaces y eficientes para la ejecución de prácticas de gobierno sólidas y transparentes, en consonancia con los valores empresariales. La combinación de las obligaciones operativas de los Directores, Gerentes y empleados, con las responsabilidades de contralor a cargo de las unidades de Auditoría Interna y Externa, de Fiscalización, y Auditoría de la Nación en los casos que corresponda, deben estar correctamente articuladas, ser flexibles, establecer controles y funcionar protegiendo a la organización previniendo irregularidades no permitidas por la normativa empresarial, legal o ética...".

\footnotetext{
${ }^{27} \mathrm{Si}$ bien en el párrafo se citan las instituciones financieras, las Recomendaciones 18 a la 21 del GAFI se aplican a todas las APNFD, entre ellas, los casinos.
} 
Los controles surgen del análisis de riesgo. Si el análisis fue realista, y se tuvieron en cuenta la normativa local o buenas prácticas, los controles serán efectivos. Pero para mantener su efectividad deben revisarse para cubrir nuevas situaciones que viabilicen amenazas no contempladas.

La auditoría tiene como objetivo asegurar que se cumplen los objetivos enunciados. Se puede realizar en forma interna o por parte de un externo.

En el mismo párrafo 4.1 .1 citado arriba, se referencia acerca de "...Las responsabilidades de contralor a cargo de las unidades de Auditoría Interna y Externa, de Fiscalización, y Auditoría de la Nación en caso que corresponda...”.

En la nota interpretativa de la Recomendación 18 citada párrafos arriba, se indica que los programas de las instituciones financieras contra el lavado de activos y el financiamiento del terrorismo deben incluir una función de auditoría independiente para comprobar el sistema.Es decir, aunque la normativa del país no lo exija, la recomendación la transforma en una buena práctica para contar con una visión externa acerca si la organización se gestiona de acuerdo a sus objetivos.Por ejemplo, siendo DDC un punto clave dentro de las políticas PLA se deben definir procedimientos para controlar si estas políticas se están llevando a cabo adecuadamente y son efectivas.

En cuanto a la normativa (regional, nacional o internacional) existente o estándares o buenas prácticas adoptados por la organización, se deben definir procedimientos para controlar el alineamiento a dichos marcos. Esto incluye el tratamiento que se realiza de los reportes de operaciones sospechosas (ROS).

Otro punto a tener en cuenta en la auditoría es la estructura organizativa, incluyendo roles y habilidades, que la entidad haya adoptado para llevar a cabo sus tareas de prevención. Ya sea por normativa o por buena práctica, la entidad debe definir la estructura que sostendrá las políticas PLA adoptadas.

\section{Niveles de madurez}

A continuación se detalla cuáles son los requisitos para cada nivel, en el elemento "Control interno, Monitoreo y Auditoría".

\section{| Sobre el nivel 2 de este elemento}

De acuerdo a las tipologías de LA detectadas e informadas en el nivel 1, en este nivel la organización debe presentar un listado de los controles necesarios por cada juego y por el conjunto de tipologías asociadas a ese juego.

Por cada control, se deben indicar el conjunto de procedimientos en el marco de su implementación.En esta instancia no se exige que los controles estén totalmente implementados. En este nivel se debe indicar:

- grado de implementación del control (directamente relacionado con el grado de implementación de sus procedimientos) 
- roles y responsabilidades del personal involucrado

- cómo se medirá su efectividad

- tiempo estimado de la implementación completa del control

En este nivel, la organización definirá un plan de auditoría que incluya claramente, sin nivel de detalle:

- Objeto de la auditoría (elementos que serán auditados, tales como procedimientos, recursos afectados, estructura operativa, tecnología aplicada, etc.).

- La frecuencia mínima de la auditoría será anual. Si se debe realizar antes por cambios relevantes en el contexto del negocio, indicar qué motivos lo exigen.

- Metodología de la auditoría

- Responsables de la auditoría

Considerando que según la recomendación 18 los programas contra el lavado de activos deben incluir una función de auditoría independiente para comprobar el sistema, en este nivel se debe indicar cómo se llevará a cabo dicha auditoría, quien la realizará, cuál será la metodología de realización y cómo se tratarán los hallazgos, frecuencia, etc.

\section{Sobre el nivel 3 de este elemento}

En este nivel la organización presenta un informe de auditoría con respecto a las políticas, controles y procedimientos, hallazgos y acciones en el marco de la prevención de lavado de activos de acuerdo a lo enunciado en el nivel 2, realizada por autoridad competente en el marco de las normativas que debe cumplir o buenas prácticas.

Considerando que en el período transcurrido entre la presentación de la documentación del nivel 2 y la del nivel 3 pueden haber surgido nuevas situaciones (vulnerabilidades o amenazas que no había sido contempladas, incorporación de nuevos juegos, cambios en la estructura organizacional, etc.), se espera que además del reporte de situación de acuerdo a lo informado en nivel 2 , se incorpore un informe de actualización de la situación.

\section{| Sobre el nivel 4 de este elemento}

Este nivel debe representar cuán dinámicamente la organización adapta su plan de auditoría y sistematiza mediante un software que incorpore alertas, realice el seguimiento de acciones y hallazgos.

\subsubsection{Definición e implementación de Políticas de Debida diligencia}

En el marco de determinar el nivel de madurez de las distintas entidades del SJA en la prevención de lavado de activos (PLA), este documento analiza el elemento "Definición e implementación de Políticas de Debida diligencia” en sus diferentes niveles. 
La debida diligencia requiere la implementación de políticas, prácticas y controles adecuados para impedir que la organización y sus productos sean utilizados con fines ilícitos. Incluye la identificación del cliente y la aplicación de los procedimientos reforzados de conocimiento del cliente, ante la detección de señales de alerta.

Cada organización definirá sus políticas de debida diligencia del cliente (DDC) de acuerdo al contexto definido por la normativa a cumplir o buenas prácticas, al tipo de juego que ofrece y la tipología de lavado que viabiliza.

En la implementación de la política, entonces, se debe considerar:

- Justificación de la modalidad de identificación de cliente según el juego.

- Identificación del cliente: qué información se le solicita al cliente para el juego o el cobro de premios

- Detección en el momento del cobro acerca si quien cobra el premio es una persona que se encuentre procesada o haya sido condenada por la Justicia por delitos relacionados con el LA, o que hayan sido declaradas terroristas estén incluidas en las listas de la Office of Foreign Assets Control (OFAC) o semejante

- Detección en el momento del cobro acerca si quien cobra el premio es una Persona Políticamente Expuesta (PEP)

- Comunicación y establecimiento de circuitos en la participación de 3ros (Bancos, reguladores, Unidad de Información Financiera - UIF - pertinente u organismo que cumpla con dicha función, agencias) en la identificación de quien cobra premios (definición de alertas y acciones)

Las Recomendaciones del Grupo de Acción Financiera Internacional (GAFI) determinan un estándar internacional que los países deberían implementar por medio de medidas adaptadas a sus circunstancias particulares. La recomendación 22 , se refiere a las acciones relacionadas con debida diligencia del cliente en las APNFD e indica:

“...Los requisitos de debida diligencia del cliente y el mantenimiento de registros establecidos en las Recomendaciones 10, 11, 12, 15 y 17, se aplican a las Actividades y Profesiones No Financieras Designadas (APNFD) en las siguientes situaciones..."

Entre las situaciones que plantea se refiere a los casinos

“... cuando los clientes se involucran en transacciones financieras por un monto igual o mayor al umbral designado aplicable...”.

Se debe tener en cuenta que la recomendación GAFI que contemplaba DDC previa a la modificación es la Recomendación 5. Actualmente es la recomendación 10.En esta últimarecomendación se indica que las organizaciones deben emprender medidas de DDC cuando, entre otras situaciones, exista una sospecha de lavado de activos o 
financiamiento del terrorismo, si se tienen dudas sobre la veracidad o idoneidad de los datos de identificación sobre el cliente obtenidos previamente.

La Recomendación 11 se refiere a la necesidad de mantener por un período de al menos cinco años, todos los registros necesarios sobre las transacciones, para que éstas puedan cumplir con rapidez con las peticiones de información solicitadas por las autoridades competentes.

\section{Niveles de madurez}

A continuación se detalla cuáles son los requisitos para cada nivel, en el elemento "Definición e implementación de Políticas de Debida diligencia".

| Sobre el nivel 2 de este elemento

Dentro del análisis de contexto que se realizó en la presentación por parte de la organización solicitante para lograr en nivel 1 de certificación, se indican cuáles son las actividades (juegos) que la entidad realiza dentro de su clasificación como lugar de Loterías y Apuestas.

Para certificar el nivel 2 para este elemento, se debe presentar los resultados del proceso de autoevaluación que la organización ha realizado en cuanto a las políticas implementadas, su alineamiento con la normativa de su país y las recomendaciones internacionales, teniendo en cuenta los ítems arriba citados. En este punto es trascendental definir el estado actual ("as is") y el estado deseado o esperado ("to be"), y proponer un plan para lograr superar esa brecha.

En este nivel, la organización solicitante debe indicar de acuerdo a cada juego y tipologías de lavado de activos relacionadas, como se debería llevar a cabo, en qué grado se puede efectivizar la identificación del cliente, cómo se debe registrar, cómo se debería realizar ese registro e informa a las autoridades competentes si se han definido umbrales en el monto de la ganancia para la declaración de información relacionada con identificación del cliente.

| Sobre el nivel 3 de este elemento

Para certificar el nivel 3 se debe presentar los resultados de las actividades propuestas en el nivel 2, y la evidencia de su implementación, junto con un análisis de resultados.

| Sobre el nivel 4 de este elemento

Para certificar nivel 4 (mejora continua) se debe presentar una estructura sistematizada de mejora continua, con responsabilidades claramente definidas, actualización dinámica ante nuevas normativas o recomendaciones, contacto comprobado con los organismos nacionales e internacionales (mediante foros, participación en seminarios, etc.) 
relacionado con este elemento, definición de políticas de debida diligencia ante nuevos juegos o amenazas o tendencias que se denuncien.

Este nivel se caracteriza por demostrar que la organización cuenta con un equipo dedicado a realizar seguimiento (tanto de las situaciones locales como las internacionales que representen una tendencia) y actuar rápidamente. En este nivel la organización debe presentar un informe acerca de la efectividad de la metodología implementada en el 2do nivel.Esto incluye el plan de mejoras de acuerdo a fallas o vulnerabilidades detectadas.

\subsubsection{Utilización efectiva de Recursos tecnológicos}

En el marco de determinar el nivel de madurez de las distintas entidades del SJA en la prevención de lavado de activos (PLA), este documento analiza el elemento "Utilización efectiva de Recursos tecnológicos" en sus diferentes niveles.

La incorporación de la Tecnologías de la Información y las Comunicaciones (TICs) permite producir, obtener, procesar, almacenar y transferir información de manera rápida y sistematizar y automatizar las tareas. No obstante para que la administración de la información sea efectiva debe realizarse un análisis de riesgo para protegerla adecuadamente según los criterios de la seguridad: confidencialidad, integridad y disponibilidad.Para ellos deben establecerse controles efectivos. Por lo tanto este elemento está directamente relacionado con el elemento "Determinación del riesgo" y "Control Interno, Monitoreo y Auditoría".

La inversión en TIC que hace una organización puede ser exigida por la normativa o como opción para mejorar el servicio. En este último caso, la inversión debe ser coherente con los beneficios que permitiría su uso.

La manera de minimizar el riesgo es mediante la implementación de controles efectivos. En el caso de las TICs se definen controles propios de TI.COBIT define a los recursos de TI como: infraestructura, datos, aplicaciones y recursos humanos.

La organización utiliza las TICs según los servicios que debe o quiere ofrecer.Si es parte de un sistema on line, se le exigirá instalar una red y servidores, además de algunas aplicaciones. Si está organizada para enviar los Reportes de Operación Sospechosa (ROS) vía Web, o consultar listas como la OFAC en forma on line, deberá contar con una conexión a Internet. Puede instalar cámaras de video para monitoreo, o utilizar las TICs para relacionarse con el entorno. Por ejemplo, en este último caso, en el punto 4.1.4 - Relaciones y Diálogo con los Grupos de Interés - (Corporación Iberoamericana de Loterías y Apuestas de Estado (CIBELAE), 2011), se indica que las Organizaciones deben entablar diálogo con sus grupos de interés (jugadores, empleados, red comercial, beneficiarios, medios de comunicación, proveedores, organizaciones homólogas, regulador, proveedores de tratamiento, etc.), para “...Permitir la combinación de recursos (conocimiento, personas, dinero y tecnología) que resuelva 
los problemas y alcance objetivos que las organizaciones no pueden lograr de forma independiente..:", entre otras finalidades.

No obstante, en la decisión de utilizar TICs no debe dejarse de lado la incidencia de su uso en el medioambiente. En el punto 4.1.5 - Conciencia medioambiental, se indica que

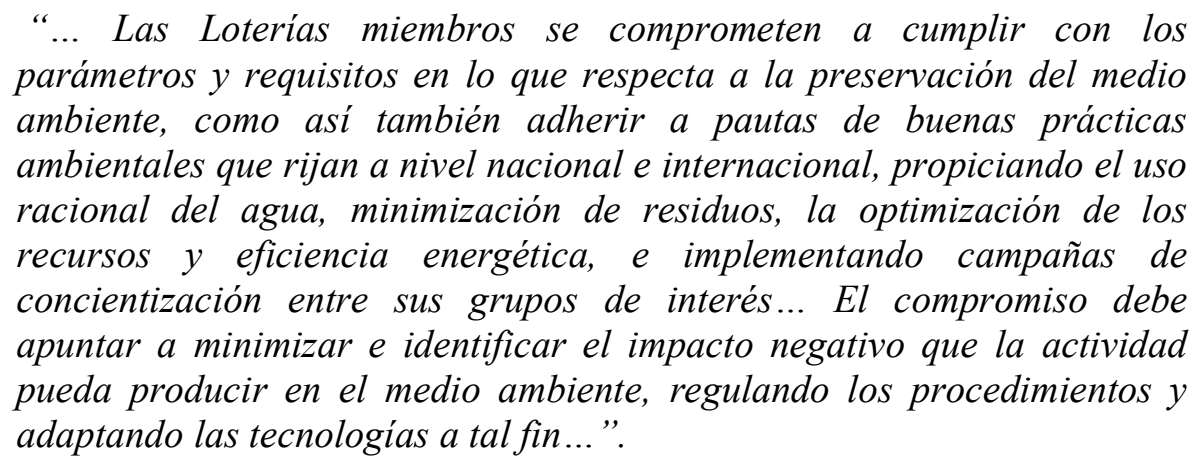

Las Recomendaciones 15 y 16 del GAFI se refieren a las nuevas tecnologías y las transferencias electrónicas.La Recomendación 15 destaca que las organizaciones deben identificar y evaluar los riesgos de lavado de activos o financiamiento del terrorismo que pudieran surgir con respecto al uso de nuevas tecnologías o tecnologías en desarrollo para productos tanto nuevos como los existentes. La evaluación del riesgo debe hacerse antes del lanzamiento de los nuevos productos, prácticas comerciales o el uso de tecnologías nuevas o en desarrollo. Los países y las instituciones financieras deben tomar medidas apropiadas para administrar y mitigar esos riesgos.La Recomendación 16, si bien se refiere a las instituciones financieras, evidencia la importancia del uso de las TIC en las transferencias para identificar a quienes las originan, el beneficiario, etc. Los países deben asegurar que las instituciones financieras monitorean las transferencias electrónicas con el propósito de detectar aquellas que carezcan de la información requerida sobre el originador y/o beneficiario, y tomar las medidas apropiadas.

\section{Niveles de madurez}

\section{Sobre el nivel 2 de este elemento}

Para certificar este nivel, la organización debe describir con qué infraestructura tecnológica cuenta: características de su red de comunicaciones, servidores, aplicaciones y personal para administrar esta infraestructura.

La organización debe hacer una propuesta de inventario de su infraestructura tecnológica.

Debe informar de qué manera gestiona los incidentes.Se evaluará si los recursos tecnológicos son los adecuados de acuerdo al tipo, tamaño, complejidad de juegos y modalidades.En caso de no considerarse adecuado, se definirán las acciones correctivas y preventivas necesarias.Se considerará el grado de cumplimiento. Si las 
vulnerabilidades encontradas no ponen en peligro la confidencialidad, integridad y disponibilidad, se le otorgará la certificación de nivel.

Sobre el nivel 3 de este elemento

En este nivel la organización presentará el plan de mejoras establecido y cumplido luego de la certificación de nivel 2.

Deberá presentar una propuesta de alineamiento a marcos referenciales o estándares relacionados con seguridad de los sistemas de información.Debe además gestionar sus incidentes mediante un sistema informático, o presentar lo que pretende implementar con respecto a este punto en su certificación de nivel 4.

| Sobre el nivel 4 de este elemento

En este nivel la organización debe presentar:

- sistema de inventario de infraestructura tecnológica

- listado del personal capacitado para mantenerla

- sistema de gestión de incidentes implementado

- sistema de gestión de la seguridad (no es necesario certificar) de acuerdo aestándares o buenas prácticas.

\subsubsection{Interacción con otros organismos}

En el marco de determinar el nivel de madurez de las distintas entidades del SJA en la prevención de lavado de activos (PLA), este documento analiza el elemento "Interacción con otros organismos" en sus diferentes niveles.

En la Recomendación 2 de la GAFI se destaca específicamente la importancia de la colaboración nacional

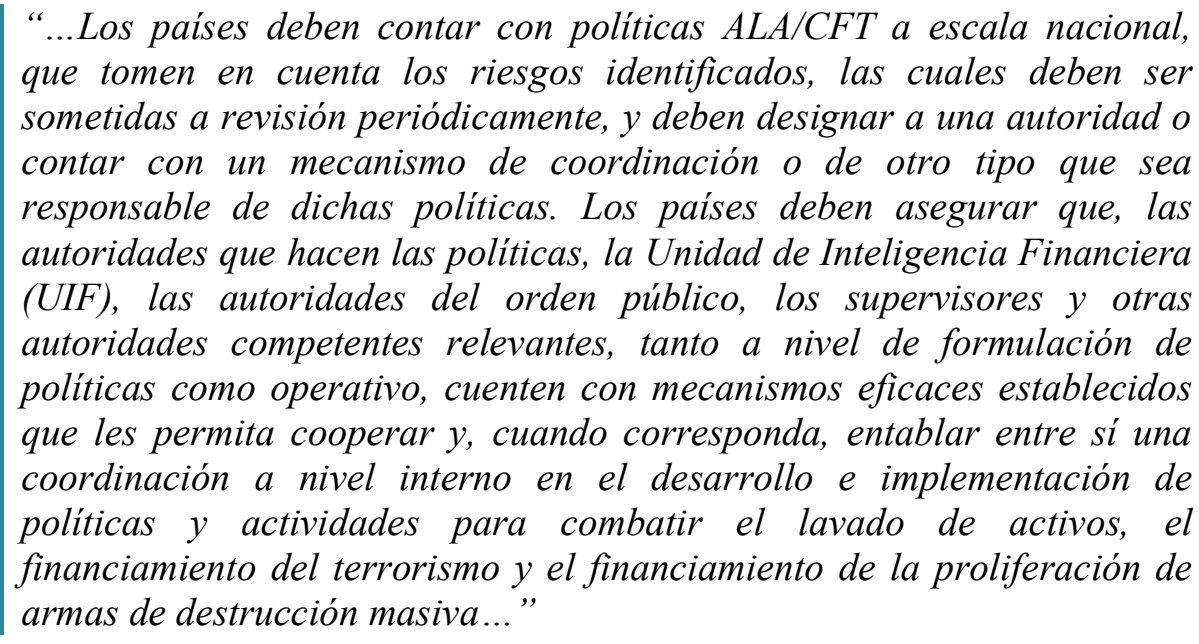


Las Recomendaciones 36 a 40, dentro del Grupo G, "Cooperación Internacional", establecen una serie de acciones conducentes a promover e implementar la colaboración internacional.Se destacan a continuación algunos párrafos

Los países deben tomar medidas inmediatas para cumplir con diferentes convenciones: "...Convención de Viena, 1988; la Convención de Palermo, 2000; la Convención de las Naciones Unidas contra la Corrupción, 2003; y el Convenio Internacional para la Represión de la Financiación del Terrorismo, 1999. Cuando corresponda, se exhorta también a los países a ratificar e implementar otras convenciones internacionales relevantes, como la Convención del Consejo de Europa sobre el Crimen Cibernético, 2001; la Convención Interamericana contra el Terrorismo, 2002; y el Convenio del Consejo de Europa sobre Blanqueo, Detección, Embargo y Decomiso de los Productos de un Delito y sobre el Financiamiento del Terrorismo, 2005..."

“...Los países deben prestar rápida, constructiva y eficazmente, el mayor rango posible de asistencia legal mutua con relación a investigaciones, procedimientos judiciales y procesos relacionados con el lavado de activos, delitos determinantes asociados y el financiamiento del terrorismo..."

“...Los países deben contar con una base jurídica adecuada para prestar asistencia y, cuando corresponda, deben tener establecidos tratados, acuerdos u otros mecanismos para mejorar la cooperación... ".

“...Los países deben asegurar que sus autoridades competentes puedan, rápida, constructiva y eficazmente, prestar el mayor rango de cooperación internacional con relación al lavado de activos, delitos determinantes asociados y el financiamiento del terrorismo....”.

En el punto 4.2.8 de (Corporación Iberoamericana de Loterías y Apuestas de Estado (CIBELAE), 2011), se indica que:

"Cada organización se compromete a compartir sus experiencias en el campo de juego responsable y responsabilidad social corporativa con el resto de miembros de CIBELAE, a través de una participación activa en seminarios, congresos o publicaciones."

En el MJR de WLA(Word Lottery Association (WLA), 2012), se define el elemento "Implicación de los grupos de interés", describiéndolo como:

"Un enfoque sistemático para identificar, entender e integrar intereses de quienes toman decisiones, de quienes influyen en la toma de decisiones y otros miembros de la sociedad, en las decisiones comerciales claves relacionadas con el JR". 
En todos estos casos se promueva la interacción con grupos de interés u organismos competentes para mantenerse actualizado acerca de nuevas tipologías o casos de aplicación de políticas PLA y determinar su efectividad.

\section{Niveles de madurez}

A continuación se detalla cuáles son los requisitos para cada nivel, en el elemento "Interacción con otros organismos".

| Sobre el nivel 2 de este elemento

Para certificar este nivel, la organización debe:

- enumerar y describir organismos (internacionales, nacionales, provinciales, regionales) y modalidad de interacción, con los que la organización ha establecido relación en el marco de PLA

- indicar si existen programas y políticas actuales de relación con organismos/grupos de interés en el marco PLA

- indicar si se comparten las experiencias con respecto a PLA en el sector y por qué medio (congresos, seminarios, jornadas, foros)

- evaluar cuál es la efectividad actual acerca de este elemento y hacer una propuesta de mejora.

\section{Sobre el nivel 3 de este elemento}

Se analizará la propuesta presentada en el nivel 2 y se verificará su cumplimiento.

Se presentarán diferentes programas, y por cada uno de ellos se debe presentar:

- el/los cargo(s) de la(s) persona(s) responsable(s) de la implementación del programa

- objetivos del programa

- público objetivo

- tácticas (cómo se lograrán los objetivos)

- cronología

- participación de organismos competentes y grupos de interés.

Sobre el nivel 4 de este elemento

En este nivel la organización debe demostrar que se establecen formalmente acuerdos con otros organismos y su participación activa en esa interacción. 
Para cumplir este nivel debe demostrarse interacción formal, con organismos internacionales, nacionales, provinciales, regionales, locales; organismos reguladores y grupos de interés.Debe demostrar su participación en foros, en la implementación de acciones derivadas de esa participación.Debe establecer programas periódicos que garanticen que se mantiene la interacción en forma activa.Debe contar con herramientas tales como foros, newsletters y participar en eventos para garantizar la cooperación y colaboración a todo nivel.

\subsubsection{Generación de Informes y estadística}

En el marco de determinar el nivel de madurez de las distintas entidades del SJA en la prevención de lavado de activos (PLA), este documento analiza el elemento "Generación de Informes y estadística" en sus diferentes niveles.Este elemento se construye en base a las actividades que comprende cada una de estas líneas: la generación de informes y la generación de estadística.Está directamente relacionado a la esperada mejora continua de procesos. La generación de informes surge del monitoreo y la observación acerca de la efectividad de los controles existentes y la aparición de situaciones emergentes.Las estadísticas se definen mediante variables relevantes y son imprescindibles para la detección de indicadores que se van a constituir en el estado de la gestión.

El monitoreo continuo de los procesos es una de las fases primordiales en la gestión.En el cotidiano de las tareas relacionadas con PLA se producen un conjunto de hechos que deben ser registrados y que contribuirán a la generación de informes posteriores. Esos informes no deben ser meramente narrativos de una situación: el objetivo es detectar vulnerabilidades o amenazas, controles ineficientes o incidentes.El informe debe ser material en el sentido que debe ser relevante a la problemática de LA que se está tratando.

En el marco de Juego Responsable de la WLA, el elemento 10 del programa, "Informes y medición”, plantea “...un enfoque sistemático para evaluar y presentar informes sobre las acciones, compromisos y progresos de su lotería en materia de JR a grupos de interés internos y externos...”.

El monitoreo y la generación de informes y estadísticas se plantean en diferentes estándares y buenas prácticas en el marco de la evaluación de la gestión. Las Recomendaciones del Grupo de Acción Financiera Internacional (GAFI) determinan un estándar internacional que los países deberían implementar por medio de medidas adaptadas a sus circunstancias particulares. En el inciso F, "Facultades y responsabilidades de las autoridades competentes y otras medidas institucionales", entre Requisitos generales, se incluye la Recomendación 33, "Estadísticas".

“... Los países deben mantener amplias estadísticas sobre los asuntos relevantes a la eficacia y eficiencia de sus sistemas ALA/CFT. Esto debe incluir estadísticas sobre los ROS recibidos y divulgados; acerca de las 
investigaciones, procesos y condenas de lavado de activos $y$ financiamiento del terrorismo; sobre los bienes congelados, incautados y decomisados; y acerca de la asistencia legal mutua u otras solicitudes internacionales de cooperación..."

Si bien la recomendación está dirigida a los países, no sería posible determinar estadísticas si cada entidad no aportara las propias, las que surgen del cotidiano de la actividad. Más aún si en ese país existe normativa que la constituya como sujeto obligado de informar a las autoridades pertinentes.

\section{Niveles de madurez}

A continuación se detalla cuáles son los requisitos para cada nivel, en el elemento "Generación de Informes y estadística".

\section{Sobre el nivel 2 de este elemento}

Para la certificación la organización debe presentar un documento de políticas aprobadas orientadas a la generación de informes y estadística. Se deben definir variables de medición e indicadores para poder evaluar la gestión PLA. Se debe indicar también el conjunto de informes internos y externos que la organización elevará en el marco de esa política PLA. Incluye los informes a autoridades competentes de acuerdo a la normativa existente.En este nivel, se presenta la propuesta, es decir, no es necesario que se haya implementado.

\section{Sobre el nivel 3 de este elemento}

Para la certificación de este nivel, debe presentarse un estado de situación acerca del avance de la propuesta aprobada en el nivel 2.Ese estado de situación debe ser un enfoque realista, y si fuera necesario, plantear las mejoras necesarias. De acuerdo a las variables y consecuentes indicadores, la organización debe presentar estadísticas por juego y tipología de acuerdo a los escenarios actuales.

\section{| Sobre el nivel 4 de este elemento}

En este la organización debe demostrar una administración eficiente de sus informes, incluyendo versionado y condición de activo, destinatarios y si fuera necesario, envíos y respuestas posteriores. Debe comprobar que las estadísticas obtenidas permiten un análisis de gestión en el marco PLA, como herramientas para la toma de decisiones en la gestión. Por ejemplo, se debe demostrar en cualquier momento, que se puede contar con estadísticas actuales acerca de la situación en cada juego, cada tipología. Se espera que la organización publique un informe externo formal acerca situaciones detectadas en LA, para compartir con el resto de las organizaciones. 


\subsubsection{Determinación del nivel general de madurez de PLA}

Cuando se desea determinar el nivel de madurez en una organización, se define el estado actual y el esperado o deseado. Para ello se definen un conjunto de variables, que serán las evaluadas para determinar tanto el estado actual como también el esperado. Conocer acerca de su estado de situación y cuál es su posición dentro de lo esperado, permite definir cursos de acción en el marco de un plan de mejora. En este modelo esas variables las constituyen los elementos enunciados. No obstante, para que el modelo sea útil para diferentes contextos, en la determinación del nivel de madurez general debe definirse cuál es el peso que cada una de estas variables tiene en la entidad del SJA.

El modelo que se propone comprende un marco genérico y una serie de herramientas para su gestión y evaluación. Consideremos las siguientes variables:

$\mathrm{X}_{1}$ : nivel de madurez del elemento "Determinación del riesgo"

$\mathrm{X}_{2}$ : nivel de madurez del elemento "Formalización y estandarización de los procesos PLA"

$\mathrm{X}_{3}$ : nivel de madurez del elemento "Definición de Estructura (roles, responsabilidades, funciones, formalización)"

$\mathrm{X}_{4}$ : nivel de madurez del elemento "Tratamiento de la información y documentación"

$\mathrm{X}_{5}$ : nivel de madurez del elemento "Capacitación y concientización de empleados y público en general"

$\mathrm{X}_{6}$ : nivel de madurez del elemento "Control, Monitoreo y Auditoria"

$\mathrm{X}_{7}$ : nivel de madurez del elemento "Definición e implementación de Políticas de Debida diligencia"

$\mathrm{X}_{8}$ : nivel de madurez del elemento "Utilización efectiva de Recursos tecnológicos"

$\mathrm{X}_{9}$ : nivel de madurez del elemento "Generación de Informes y estadística"

$\mathrm{X}_{10}$ : nivel de madurez del elemento "Interacción con otras organizaciones y organismos competentes"

Por lo tanto podríamos expresar la relación de estas variables en una función del tipo:

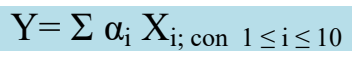

Donde $\alpha \mathrm{i}$ es el coeficiente que expresa un factor de ponderación para representar la importancia del elemento i en el contexto de evaluación, de manera tal que si se consideran que todos los elementos revisten la misma importancia, entonces el valor de todos los $\alpha_{\mathrm{i}}$ será 1 .

Se plantea el siguiente ejemplo, donde cada elemento ha obtenido un nivel de madurez en su evaluación. En el caso que la entidad no presente logros en ese nivel, el valor será 1, es decir, el correspondiente al compromiso. En este caso se le da el mismo valor en importancia a cada variable, por lo tanto, se les asigna un valor 1 a $\operatorname{los} \alpha_{\mathrm{i}}$.

En Tabla 6 se indican los valores asignados a cada elemento según su nivel y un coeficiente $\alpha_{i}=1$. 
Para este conjunto de valores, $\mathrm{Y}=28$.

El máximo valor que puede tomar $\mathrm{Y}$, si todos los niveles de madurez tienen el valor máximo, es 40. El mínimo valor que puede tomar Y, si no se han desarrollado los elementos, será 10 .

Consideremos que el nivel de madurez general es representado por estos valores:

Nivel 1, cuando el valor $\mathrm{Y} \leq 10$

Nivel 2, cuando $10<Y \leq 20$;

Nivel 3, cuando $20<Y \leq 30$;

Nivel 4, cuando $30<Y \leq 40$.

\begin{tabular}{|l|c|c|c|}
\hline & $\mathbf{X}_{\mathbf{i}}$ & $\boldsymbol{\alpha}_{\mathbf{i}}$ & $\mathbf{X}_{\mathbf{i}} * \boldsymbol{\alpha}_{\mathbf{i}}$ \\
\hline Elemento 1 & 1 & 1 & 1 \\
\hline Elemento 2 & 2 & 1 & 2 \\
\hline Elemento 3 & 4 & 1 & 4 \\
\hline Elemento 4 & 3 & 1 & 3 \\
\hline Elemento 5 & 3 & 1 & 3 \\
\hline Elemento 6 & 2 & 1 & 2 \\
\hline Elemento 7 & 3 & 1 & 3 \\
\hline Elemento 8 & 3 & 1 & 3 \\
\hline Elemento 9 & 3 & 1 & 3 \\
\hline Elemento 10 & 4 & 1 & 4 \\
\hline
\end{tabular}

Tabla 6 - Valorización de los elementos según coeficiente $\alpha_{i}$

En este caso, el nivel de madurez general de la entidad en sus políticas PLA es 3.En el caso que se quiera dar peso a las distintas componentes, se plantea el siguiente ejemplo.

$1 \leq \alpha \leq 3$ de acuerdo al valor de ese elemento en la evaluación, donde:

$\alpha=1$, se le asigna al elemento un valor no relevante;

$\alpha=2$, se le asigna al elemento un valor medio de relevancia;

$\alpha=3$, se le asigna al elemento un valor muy relevante.

\subsection{La evaluación y certificación del nivel}

El esfuerzo que cada organización del SJA dedica a cumplir con los lineamientos enunciados en su política de PLA merece ser reconocido. Certificar el nivel de madurez en que la organización visibiliza el compromiso con el Juego Responsable (JR) y la Responsabilidad Social Empresarial (RSE) constituye su formalización(Molinari \& Díaz, 2016b). 
Para lograr los niveles específicos, las organizaciones solicitantes deberían cumplir con los requisitos que se definen para cada elemento en ese nivel. Por ejemplo, para lograr el nivel 2, la entidad debe cumplir los requisitos que se detallan para cada uno de los 10 elementos para el nivel 2.

En el marco de una certificación, se debería definir cuál sería el organismo certificador, que productos se deben entregar como evidencia de lo efectuado en el nivel por el que se solicita la certificación. El organismo certificador debe definir su política de auditoría para la certificación y recertificación. Puede realizarlo con personal de la organización o permitir la participación de empresas auditoras. Debe también definir si quienes hacen la solicitud de certificación pueden elegir a la empresa auditora o si lo determina el certificador.

Asimismo, se debe determinar el período de vigencia de la certificación sobre cada nivel. Por ejemplo, si una organización obtuvo el nivel 1, debe establecerse un tiempo máximo de vigencia. Se espera que la organización debe, en un contexto de mejora, desear alcanzar el nivel siguiente en un tiempo prudencial. Si cumplido el tiempo de vigencia la entidad no presentó la solicitud para un nivel superior, debe recertificar el nivel obtenido.

Se debe establecer si luego de un nivel se puede certificar necesariamente el nivel siguiente o si se puede solicitar un nivel superior. Por ejemplo, si la entidad está certificada nivel 2, sólo puede solicitar certificar el 3 o puede directamente solicitar certificar el nivel 4.Otro punto a determinar son las tarifas por cada nivel y para certificación o recertificación.

El organismo certificador debe designar un Comité de Certificación que se encargará de recibir las solicitudes y definir y administrar el ciclo de certificación/recertificación. Por cada solicitud se debe controlar si se ha presentado la documentación necesaria. Una vez realizada la auditoría para establecer si la organización solicitante cumple los requerimientos definidos para el nivel al que se presentó, el auditor elevará un informe al Comité concluyendo si recomienda otorgar la certificación o no. En caso negativo, se detallarán las no conformidades encontradas y se sugerirá un tiempo estimado para llevar a cabo las acciones correctivas. 
En este capítulo se aborda el juego on line por considerarse una tendencia que gana cada vez más adeptos. Se analiza el uso del dinero electrónico, las tipologías, situaciones detectadas y la aplicación con los elementos definidos en la6.1para el desarrollo de las políticas.

\subsection{Nuevos escenarios, nuevos desafíos}

Las características propias de la no presencialidad dificultan la implementación de determinadas prácticas y facilita la concreción de conductas y acciones de lavado.El uso de dinero electrónico, la dificultad, o prácticamente la imposibilidad, de determinar la ubicación de los servidores de aplicaciones y datos en un lapso de tiempo específico, el uso de paraísos fiscales, son elementos que agravan este panorama.Si bien es innegable que el juego remoto es una alternativa de entretenimiento para gente con movilidad restringida o en soledad, no por ello puede descuidarse las importantes y complejas vulnerabilidades y amenazas que presentan.

En el punto 5.8, se planteó el conjunto de acciones que una organización debe cumplir en un contexto de mejora.Las vulnerabilidades o amenazas detectadas, por la propia experiencia o aprendida de experiencias de otras organizaciones, son elementos que justifican y definen, en parte, ese proceso de mejora.Otrafuente de análisis deben ser los posibles escenarios emergentes de acuerdo a tendencias.

\subsection{Qué es el juego on line?}

Los antecedentes de juego on line se pueden establecer en Antigua y Barbuda cuando se aprobó la ley "Free Trade and Processing Act" que daba a esa nación el derecho a otorgar licencias para casinos on line(Free Trade and Processing Act, 1994).

La empresa de tecnología Microgaming ${ }^{28}$ fue la primer compañía en desarrollar software para el juego on line. Aún hoy es una de las empresas que produce software que se considera de los más confiables en la industria del juego. La Figura 9 muestra su sitio web.

Norteamérica fue la primera región en adoptar el juego on line. Esta adopción se vio favorecida considerando que, en 1995, uno de cada 10 norteamericanos tenía acceso a Internet, mientras que en Europa la relación se daba en uno cada 100. No obstante, la tecnología del momento no permitía una representación gráfica atractiva de los juegos. Lo mismo ocurría con los protocolos de comunicación que no mantenían la persistencia necesaria para sostener sucesivas conexiones al servidor.

\footnotetext{
${ }^{28} \mathrm{https}$ ://www.microgaming.co.uk/
} 


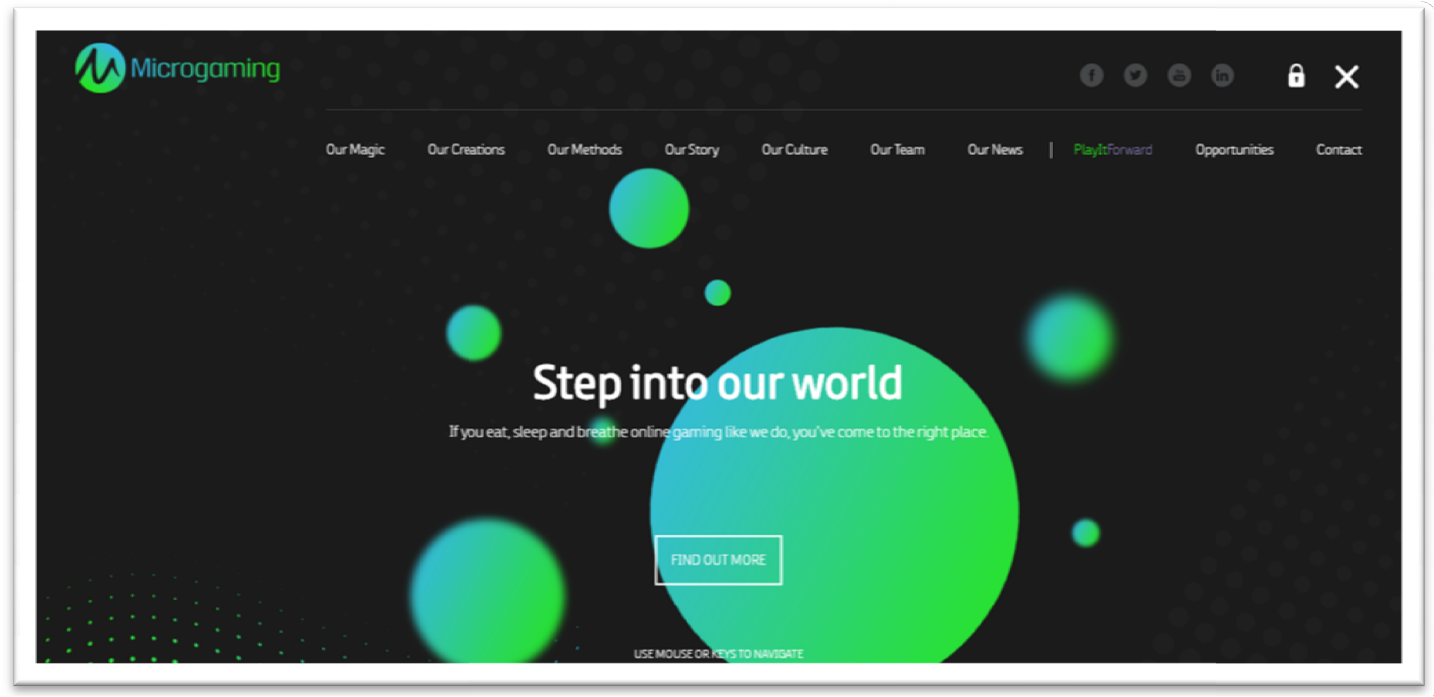

Figura 9 - Sitio en Internet de Microgaming

El Acta de Juego del Reino Unido (UK Gaming Act) del 2005 define juego remoto (remote gambling) al juego donde los participantes lo hacen mediante comunicación remota. Por comunicación remota incluye la que se realiza por Internet (internet gambling), o mediante teléfono, radio o cualquier clase de electrónica o tecnología para facilitar la comunicación.

No obstante, algunos destacan la característica de anonimato del juego, más que la posibilidad de conexión desde diferentes dispositivos.Estos nombres, entre otros, se consideran sinónimos de juego on line: igaming, egaming, remote gaming, remote gambling e interactive wagering.(GSA, 2012) lo define de la siguiente manera:

"...Playing a game of chance on an electronic device that is connected
remotely to a gaming system via a digital communication network. All
events concerning player management, financial transactions and game
management happen online without any physical interaction between the
player and the operator..."

El uso masivo e intensivo de celulares ha habilitado formas de juego donde una persona puede estar físicamente dentro de un casino, pero utilizando el celular para jugar. Por lo tanto, la ubicación del jugador ya no es la determinación única para darle categoría de remoto a un juego. Lo que le da su carácter de on line, más que la ubicación del jugador, es el uso del dispositivo para acceder al juego.(Gambling Act 2005, 2005), incluye las siguientes áreas de actividad dentro del e-gaming o remote gambling, entre otros:

- Apuesta remota a carreras de caballos

- Juego de apuestas en forma remota

- Competencias y apuestas deportivas mediante vía telefónica 
- Juego de poker multijugador mediante espacios virtuales interactivos (interactive poker rooms)

- Juego online mediante juegos como blackjack en casinos on line.

- Betting Exchanges

- Interactive Gambling, que incluye las formas tradicionales de apuestas y otras interactivas como bingo, o en deportes en vivo.

En el acta sdel Reino Unido se indica (sección 33) que la aplicación es sobre la provisión de servicios para juego remoto sólo si como mínimo una pieza del equipamiento usado en la provisión de esos servicios está en Gran Bretaña, sin importar si esos servicios se proveen para uso en todo o parte del Reino Unido.Si una persona comete un delito si hace algo en Gran Bretaña o usa equipamiento para juego remoto ubicado en Gran Bretaña para invitar o habilitar el juego de otra persona en un territorio donde el juego está prohibido.

Mediante Internet podemos acceder a un número cada vez mayor de páginas de apuestas deportivas online. Desde información útil para apostar al fútbol, al tenis, al baloncesto, etc., a pronósticos deportivos, opiniones sobre casa de juego, consejos, estrategias, métodos y sistemas para operar con nuestro dinero.La posibilidad de jugar desde nuestro hogar, a cualquier hora y desde prácticamente cualquier dispositivo que tenga acceso a Internet, lo hace una alternativa muy atractiva. En el marco de estas ventajas, pensemos en la gente que teme desplazarse (por razones de seguridad, por ejemplo) o no puede hacerlo por algún tipo de discapacidad o enfermedad.

En el sitio apostar-y-futbol.com ${ }^{29}$ se definen categorías para la información que se encuentra en la red:

- Casas de apuestas deportivas. Enlaces a las páginas de las casa de apuestas más prestigiosas, así como a reseñas y opiniones sobre su uso y recomendaciones para ganar con ellas

- Tipsters, picks y pronósticos. Predicciones de fútbol y todo tipo de eventos deportivos, realizadas por expertos que publican desinteresadamente sus análisis en la red

- Estadísticas deportivas. Las cifras básicas con las que apostar. Bases de datos con resultados históricos de la liga española, ligas internacionales, competiciones europeas y mundiales desde donde inferir la frecuencia y la probabilidad de los finales de los encuentros, goles, puntos, faltas.

- Blogs y páginas generales. Links correspondientes a páginas más generales, con documentación amplia sobre cómo apostar y jugar

- Foros. Lugares virtuales para compartir experiencias, conocimientos y anécdotas.

- Recursos para apostar online. Calculadoras y otras herramientas para evaluar los partidos, comparar cuotas, manejar probabilidades.

- Noticias actuales relacionadas con el juego.

\footnotetext{
${ }^{29} \mathrm{http}: / /$ apostar-y-futbol.com/paginas-de-apuestas/
} 
Según (GSA, 2012) para que una actividad califique como de juego on line, debe cumplir con los siguientes requerimientos, fundamentalmente:

- Involucrar transacciones que no sean en efectivo. Los medios de pago son similares a los utilizados en e-commerce. En algunos casos, como en nevada, la transacción puede ser en efectivo, bajo determinadas licencias.

- El jugador se debe registrar inicialmente con el operador on line para abrir una cuenta.

- Cada jugador tiene su propio nombre de usuario (username) y clave (password).

- Cada vez que el jugador vuelve a jugar, se debe "loguear", es decir, conevtar usando su cuenta con usuario y clave. Se recomienda el uso de métodos de autenticación robustos.

- El operador debe identificar al jugador y realizar las verificaciones y chequeos antes de darle acceso a la cuenta.

- El jugador debe hacer un depósito de dinero en su cuenta que será utilizado para apuestas y el cobro de sus premios.

- La sesión de juego debe tener lugar en un ambiente tecnológico sano y seguro.

- El juego debe tener tres elementos fundamentales: consideración ${ }^{30}$, chance y precio. Si falta alguno de estos elementos, no se considera juego.

- Cuando un jugador requiere un retiro de dinero desde su cuenta, el operador lleva adelante verificaciones para asegurarse que los fondos están siendo transferidos desde una cuenta legítima perteneciente al jugador.

\subsection{El juego on line y las apuestas}

Hoy, las apuestas deportivas mueven muchísimo dinero mediante operadores y casas de apuestas.En el resumen que se presenta para la promoción de su libro "Así se ganan las apuestas", Ismael Chanclón declara(Chanclon, 2015):

"Los últimos años han sido testigos del auge imparable de las apuestas deportivas. De la mano de Internet y de las nuevas tecnologías móviles, esta modalidad de juego ha venido para quedarse entre nosotros. Apostar parece relativamente fácil: basta con abrir una cuenta online o acercarse a un local. Sin embargo, ganar no resulta tan sencillo. ¿Sabías que, a menudo, es más conveniente apostar por la derrota del favorito? ¿O que en ocasiones no hace falta ni siquiera acertar quién ganará o perderá un partido para obtener un beneficio? ¿O que es tan importante o más determinar exactamente cuánto dinero apostamos a un resultado como el

\footnotetext{
${ }^{30}$ Consideración indica que el que juega arriesga algo de valor. Hay una chance de ganar o de perder. "Consideration is any "right, interest, profit or benefit accruing to one party, or some forbearance, detriment, loss or responsibility given, suffered or undertaken by the other". Attorney General of New York regarding the "Good as Gold" real estate sales incentive (Opn. No. 96-F1, Jan 29, 1996 http://www.oag.state.ny.us/lawyers/opinions/96_f1.htm.
} 
propio pronóstico? ... Apostar bien es un auténtico arte que requiere dedicación, esfuerzo y un inevitable periodo de aprendizaje. La única manera de ganar es la información, el análisis y el conocimiento profundo no solo del deporte, sino sobre la dinámica del mundo de las apuestas y sus particularidades. Apostar es estudiar. Pero si te gusta el deporte y sigues con afición las competiciones, es una materia divertidísima con la que puedes obtener excelentes resultados”.

Con la llegada del juego online, apostar hoy solo se trata de contar con un dispositivo para acceder a Internet.

De la misma manera que negocios e individuos buscan y encuentrannuevas formas de comunicarse y relacionarse, con el mundo de las apuestas ocurre lo mismo: surgieron las apuestas cruzadas, también llamadas intercambio de apuestas (betting exchanges).Buscando en Google por "betting exchanges" se encontrarán varios sitios: Bet365, Betfair (con más de 10 años en el mercado), Betdaq, Matchbook, Bwin, entre otros.Las apuestas cruzadas son un tipo de apuesta deportiva que se realiza mediante los sitios de apuestas, intermediarios entre un usuario que crea una apuesta (layer) con una cuota determinada y otro usuario (back) la acepta.

Lo interesante de esta propuesta es que el apostador juega contra otros usuarios que mantienen un punto de vista opuesto al suyo, en lugar de jugar contra la casa de apuestas. No habiendo límite de beneficios, puede producir ganancias elevadas.

Veamos cómo funciona. Supongamos que se va a disputar un partido de futbol entre Estudiantes de La Plata (EDLP) y Gimnasia y Esgrima de La Plata (GELP).

Horacio es un entusiasta simpatizante de EDLP y cree firmemente que EDLP ganará y decide apostar mediante un sitio de apuestas cruzadas.El será el usuario layer.

Tras indagar en las cuotas que hay en las casas de apuestas tradicionales para así ofrecer una cuota mejor, Horacio ofrece la siguiente apuesta:

Apuesta creada por Horacio

Equipo GELP gana

Cuota: 6

Máximo apostado: 50 dólares

A esto se le llama apostar en contra (lay betting) pues Horacio, siendo simpatizante del EDLP, apuesta que GELP ganará. La forma tradicional de apostar, a favor de, es llamada backing.

Elsa lleva en su corazón los colores de GELP, y, por lo tanto, que cree que su equipo ganará, por lo tanto, acepta esta apuesta. Es un usuario back. Vale destacar que es uno de los varios usuarios back potenciales.

Veamos las alternativas de acuerdo al resultado del partido:

- Si el GELP gana, Elsa gana la apuesta y se lleva 50 dólares x $6=300$ dólares.

- Si el EDLP gana, Horacio gana los 50 dólares apostados porElsa.

- Si los EDLP y GELP empatan, Horacio gana los 50 dólares apostados por Elsa. 
Quien desee crear una apuesta debe calcular qué probabilidades tiene el equipo de ganar, y luego determinar la cuota. Siempre hay que tratar que la apuesta sea superior a la que ofrezcan las casas tradicionales.El sitio de apuestas cobra una comisión. La comisión la pagará únicamente el que gane. En el caso de Betfair estará entre el 2\% al 5\%.Cuando se accede al sitio de apuestas Betfair, se plantea que los aspectos positivos de las apuestas cruzadas son:

- Mayores cuotas - son los usuarios quienes deciden los tipos de cuotas. Comúnmente las cuotas de los sitios de apuestas cruzadas con superiores que las de las casas de apuestas tradicionales (bookmakers).

- Sin restricciones - no hay un límite de dinero apostar por parte de los jugadores. En las casas de apuesta tradicionales puede haber restricciones.

- Lay bet - apostar en contra es una novedad como mecanismo de apuesta. El apostador participa en eventos de su interés.

Como inconvenientes se plantean:

- Liquidez - encontrar un evento para que la apuesta se haga efectiva puede ser complicado. Tiene que haber un apostador que sostenga lo contrario, y quiera apostar por ello. Es más probable en eventos conocidos.

- Complejidad - Se debe contar con conocimientos básicos previos para poder usar las diferentes modalidades de apuesta.

Los métodos de pago pueden ser tarjetas de crédito y débito, transferencias bancarias, cupones prepago o sistemas de monedero electrónico (ewallets).

El 30 de julio de 2014 se aprobó en España la reglamentación básica de las apuestas cruzadas(Reglamentación básica de las apuestas cruzadas, n.d.).No obstante se determinaron algunas restricciones:

- El participante deberá señalar antes de comenzar a jugar lo que durará la sesión de su juego. Además, sólo se podrán acumular botes (dinero que no se ha repartido en un sorteo por no haber aparecido acertantes y que se acumula para el siguiente) progresivos y nunca garantizados.

- Los operadores, por su parte, tendrán que avisar periódicamente del tiempo de juego así como informar de los máximos y los mínimos de cada partida, el saldo del juego, los premios obtenidos.

- Los usuarios que quieran realizar apuestas cruzadas desde el portal de Betfair en España, al menos al comienzo, sólo podrán hacerlo con otros usuarios de Betfair España. 
Uno de los pilares en las políticas de prevención de LA es la debida diligencia al cliente. El determinar quién es el apostador o apostadores en el juego on line, está directamente relacionado al mecanismo de autenticación que se utilice. En estos sitios quien quiera participar define su usuario y su clave. Si bien son mecanismos que permiten identificarse y autenticarse en el sitio, no necesariamente aportan información de la verdadera identidad del jugador.

Algunos sitios permiten la autenticación mediante huella dactilar. Entre ellos está el sitio bet365. El software se llama TouchID y está disponible en dispositivos Apple compatibles con sistema operativo iOS 8.0 o posterior. El software permite escanear y guardar su huella dactilar desde el celular. Cuando se inicia la sesión en bet365 aparecerá una ventana emergente de Touch ID. Una vez habilitado Touch ID, pulse el botón de 'Inicio' y en caso de que su huella dactilar coincida, se puede acceder a la cuenta.

Las empresas proponen mejorar la autenticación con software que permite el uso de dos factores. Por ejemplo Saaspass Industries, propone un producto que utiliza el celular del jugador para reforzar la autenticación por conocimiento que provee el mecanismo usuario-clave.

\subsection{Dinero electrónico}

El dinero electrónico es un valor monetario almacenado en forma electrónica, que mediante algún tipo de terminal puede ser usado para hacer pagos. No requiere necesariamente la utilización de cuentas bancarias para realizar la transacción.El diccionario del Banco Central de la República Argentina (BCRA) lo define como:

"Es un valor pre-almacenado en una tarjeta inteligente o en un disco rígido de una computadora personal. Puede ser transmitido a otra tarjeta, a otra computadora o a otro país a través de Internet. Es esencialmente, el pasivo de una "institución emisora", como todo otro tipo de dinero. El pago con dinero electrónico es final, a diferencia del pago con una tarjeta de crédito, que después requiere un proceso ulterior de pago."

La definición debe extenderse tanto al dinero electrónico contenido en un dispositivo de pago en poder del titular del dinero electrónico como al almacenado a distancia en un servidor y gestionado por el titular del dinero electrónico mediante una cuenta específica. Esta extensión es necesaria para acompañar nuevas propuestas en el marco de la innovación tecnológica.

Los mecanismos de pago que se utilizan reciben diferentes denominaciones: dinero electrónico, e-Money, digital cash, cybermoney, cybercurrency, cyberpayment. En algunos casos el mismo término puede tener sentidos diferentes según el contexto y circunstancia en que se lo utilice. El dinero electrónico desmaterializa el dinero físico. 
Surge en respuesta a una demanda cada vez mayor de adaptarse a nuevas formas de contratación por vía electrónica, reducir los costos de efectivo, y cada vez mayor facilidad de uso.

Las tarjetas inteligentes, como las que se utilizan para el pago de pasajes en distintos medios de transporte (como es caso de la SUBE, en varias ciudades de Argentina) son una forma de dinero electrónico. El usuario que quiera utilizar este tipo de dinero debe adquirir previamente los productos que lo representan y que se almacenan como valores en un banco de datos, lo que permite luego disponer de ellos mediante el dispositivo electrónico que utilice para su posterior uso.

FinCEn elaboró una guía (Financial Crimes Enforcement Network, 2013) para la moneda virtual "convertible", es decir la moneda virtual que tiene un valor en moneda real o que actúa como un substituto de la moneda real.Las regulaciones de FinCen, definen moneda (currency o "real" currency) como(Financial Crimes Enforcement Network, 2013):

"the coin and paper money of the United States or of any other country that [i] is designated as legal tender and that [ii] circulates and [iii] is customarily used and accepted as a medium of exchange in the country of issuance"

La moneda virtual es un medio de cambio en algunos ambientes, pero no tiene los atributos de la moneda real. No tienen curso legal en ninguna jurisdicción.

\subsection{Los bitcoins (BTC)}

Un bitcoin es una forma de dinero digital, creado y sostenido de forma electrónica. Como es un sistema descentralizado, ninguna institución lo controla. No hay un Banco Central o banco emisor. BTC permite enviar pagos online directamente entre las partes y sin pasar a través de una institución financiera.

Las transacciones que utilizan los BTC se hacen de forma Peer to Peer (P2P, par a par) en internet, lo que significa que transferencias de BTC se pueden hacer, nacional o internacionalmente, transfiriendo cantidades entre dos dispositivos, sin pasar por un banco o institución que medie la transacción. BTC es un proyecto de software libre basado en tecnología P2P. El protocolo BTC y su software se publican abiertamente y cualquier programador en cualquier lugar del mundo puede revisarlo o crear su propia versión modificada del software. Para interactuar con otros usuarios BTC se requiere el uso de un software y sitios web de terceros que actúan como verificador de transacciones y proveedor de cuentas basadas en lo que se llama la nube BTC.

Hay muchas especulaciones acerca de quien creó el BTC. Satoshi Nakamoto es, aparentemente, el seudónimo asociado con la persona o el grupo de personas que lo definieron en 2008 y que trabajan en el software original que se conoció en el año 2009(Nakamoto, n.d.). Según el sitio elbitcoin.org: 
"Es el único sistema que te permite transferir cualquier cantidad de riqueza de manera instantánea, a cualquier persona, desde y hacia cualquier lugar $y$ en cualquier momento, sin tener que pagar tarifas abusivas, sin tener que preocuparte por el fraude o por el envilecimiento de la moneda, sin tener que pedir permiso a nadie y sin estar obligado a identificarte. $" 31$

Para comenzar a utilizarlo hay que instalar una cartera o billetera BTC en la computadora o móvil. Esta cartera contiene pares de direcciones públicas y sus correspondientes llaves privadas. Las direcciones públicas son las que se dan a conocer para interactuar con otros usuarios BTC. En esas direcciones públicas todos pueden depositar BTC, que sólo el dueño puede abrir con sus llaves privadas. Las llaves privadas quedan en un archivo (en el archivo wallet.dat). Por ejemplo, si el usuario recibe 1 BTC que fue enviado a una de sus direcciones públicas, la única forma de "enviárselo" o emitirlo a otro usuario BTC (transferencia) es usando la clave privada del emisor.

Los BTC no se imprimen como el dinero fiduciario. Se obtienen mediante un proceso denominado "minería". Para ello se utiliza la capacidad de procesamiento de computadoras conectadas a una red mundial distribuida, donde participan desarrolladores voluntarios de software. Todas las operaciones que se han realizado se enumeran en la red en una versión de lo que sería un libro mayor de contabilidad: la cadena de bloques.

Una de las ventajas que ven los usuarios de BTC es que no hay posibilidad de un embargo de pagos por diferentes motivos o confiscación pues la contabilidad pública de bitcoin es descentralizada(Rotman, 2014).

En el mundo de los BTC se incluye una herramienta llamada provably fair que permite que el jugador verifique diferentes etapas de la transacción y reduzca la posibilidad de ser engañado, involucrando funciones de hash y otras variables. Tanto el servidor (del lado del sitio on line) como el jugador mediante su navegador, generan números randoms, o seeds. Estos sedes se combinan generando un nuevo número. Ese número nuevo depende no sólo del sitio si no del seed generado por el jugador ${ }^{3233}$.El seed del sitio recibe el nombre de Serverseed. El seed del cliente, provista por el navegador del dispositivo del jugador y ajustada por él, recibe el nombre de Clientseed. La variable nonce, un número que se incrementa con cada apuesta que se realiza. Cuando se realiza la primer apuesta en un sitio, la variable nonce toma el valor 0 o 1, según el sitio. Con cada apuesta el valor de nonce se incrementa en 1.

En la Figura 10Figura 10 - Pantalla inicial del sitio ARgenBTCse muestra la pantalla inicial del sitio ArgenBTC, el sitio argentino de compra y venta de bitcoins.

\footnotetext{
${ }^{31} \mathrm{http} / /$ elbitcoin.org/bitcoin-preguntas-frecuentes/

$32 \mathrm{http} / / /$ www.bit88.co/provably-fair-gambling/

${ }^{33} \mathrm{http}: / / w w w . t h e p o k e r b a n k . c o m /$ bitcoin/learn/provably-fair/
} 
Realizando una búsqueda mediante la palabra bitcoin en el sitio Mercado Libre de Argentina, se mostraron los resultados que se aprecian en Figura 11.

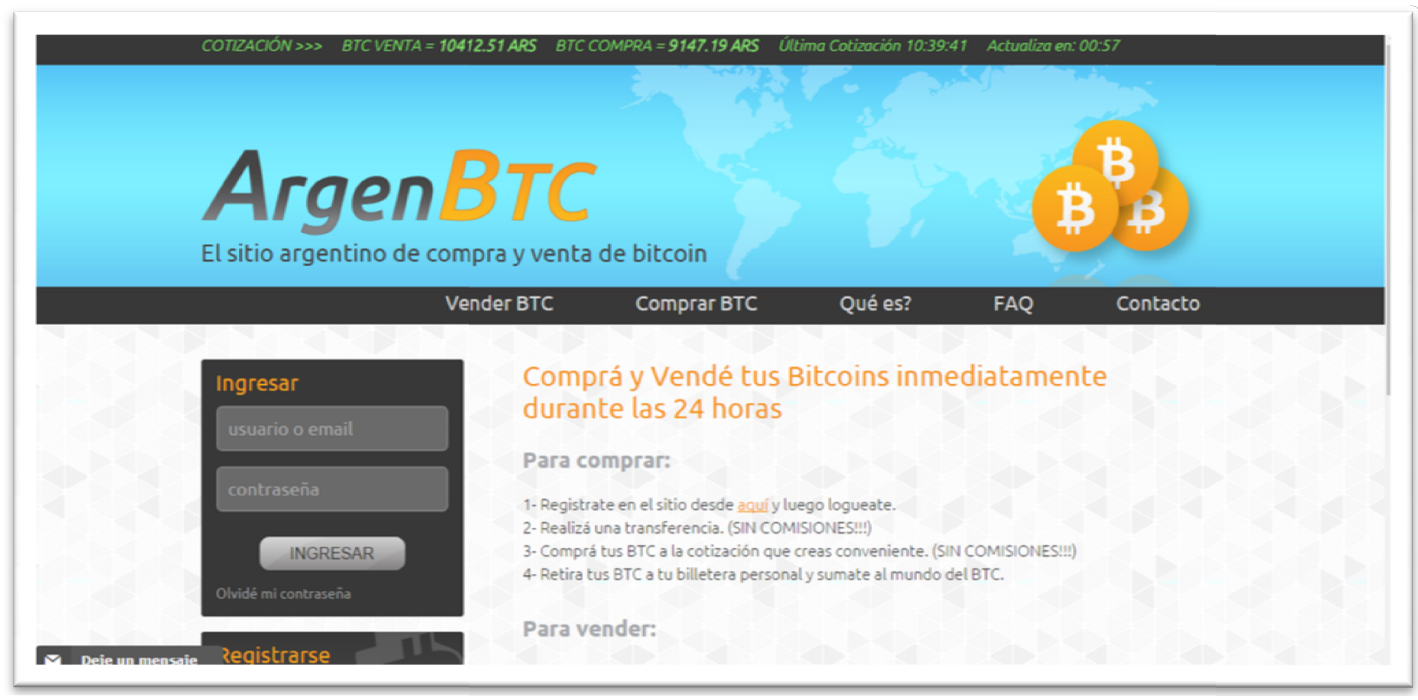

Figura 10 - Pantalla inicial del sitio ARgenBTC

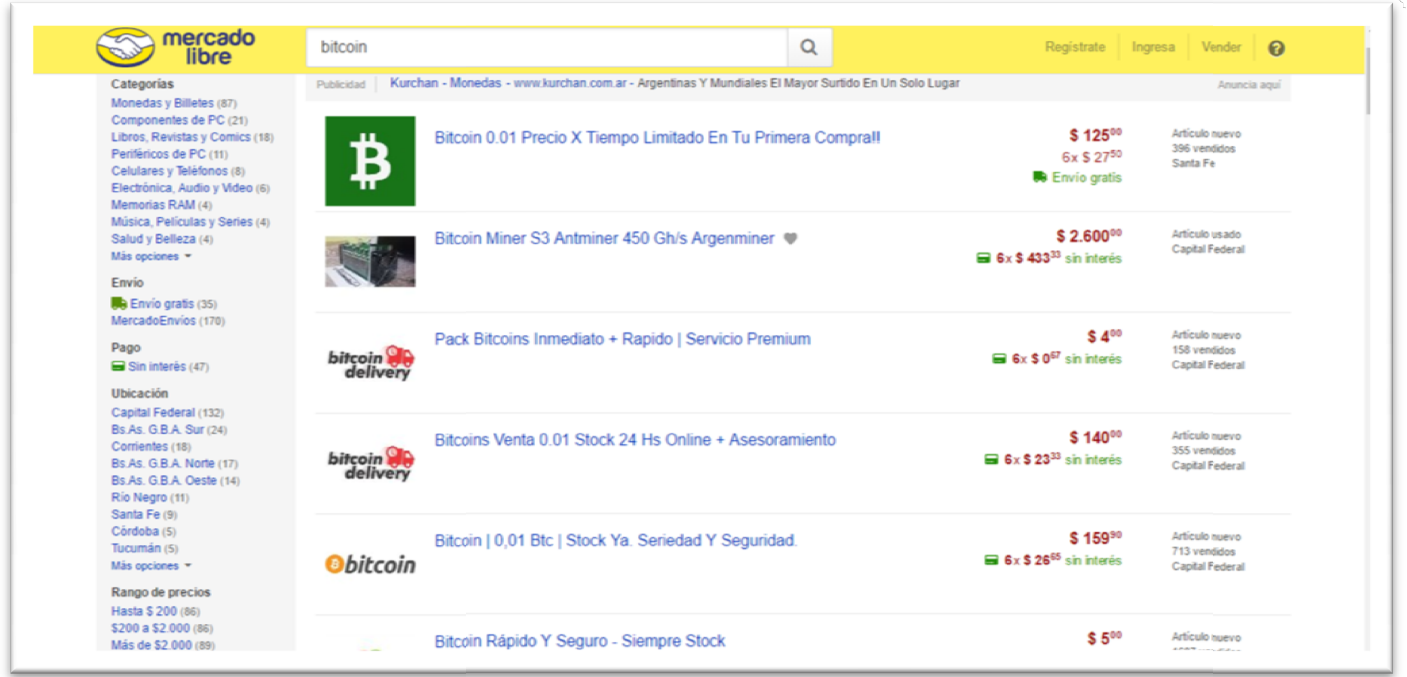

Figura 11 - Resultado de la búsqueda "bitcoin” en Mercado Libre, Argentina. 


\subsection{Uso de dinero electrónico en el juego on line}

Aún muchas personas son reticentes a utilizar la tarjeta de crédito en Internet. Pero cuando quieren comenzar a utilizar un sitio on line de juego/apuestas, habitualmente se usa la tarjeta de crédito sobre otros medios disponibles como la transferencia bancaria o monedero electrónico, principalmente por desconocimiento acerca de cómo utilizarlos.

Visa y MasterCard son las dos compañías que dominan el mercado en los sitios de apuestas online. Usan una tecnología de autenticación, 3DSecure, que perfecciona y valida los pagos realizados en la red, y protege la información confidencial durante su transmisión. Básicamente, opera contra el fraude y a favor de garantizar la seguridad del consumidor, emplean un sistema de pago fiable y seguro.

En los sitios de juego se dan indicaciones acerca del uso de tarjetas crédito, como se muestra en la Figura 12, del sitio www.casino.org

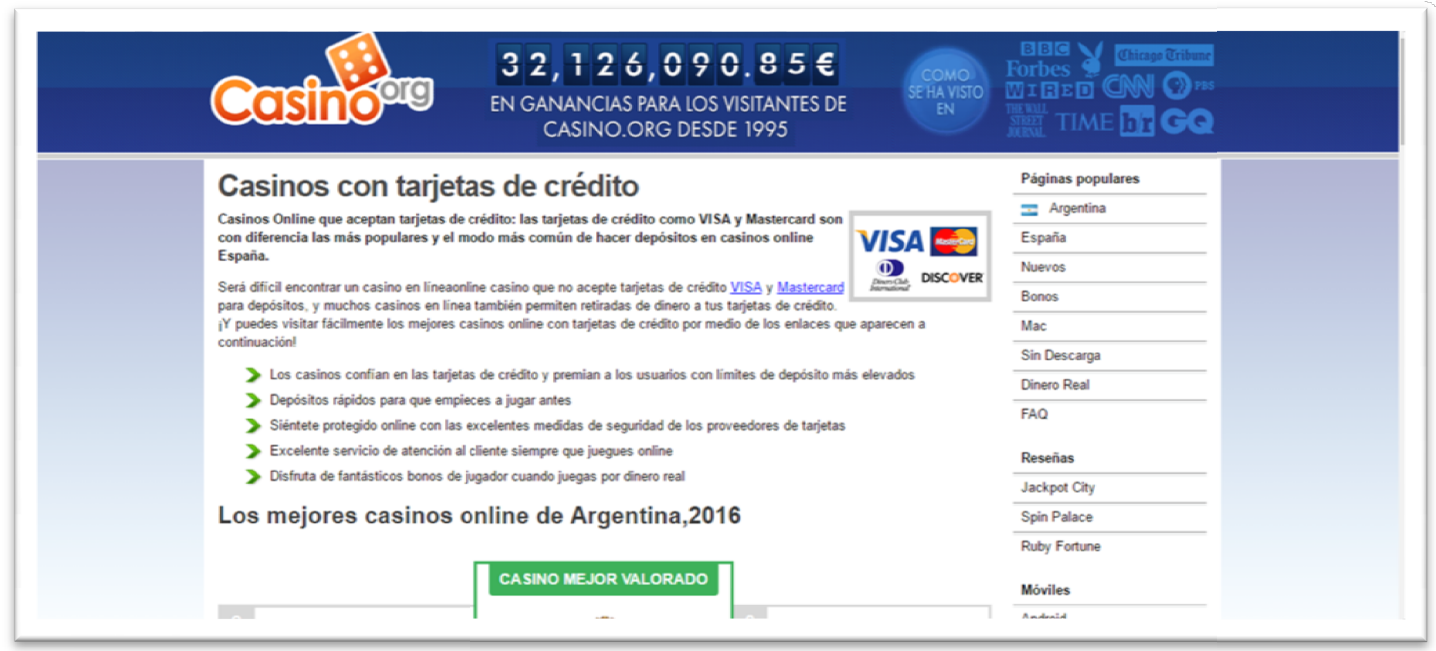

Figura 12 - Página en www.casino.org

Si un sitio de apuestas o juegos on line acepta BTC, el jugador usa su cuenta de BTC para transferir dinero a la cuenta del sitio. Los pagos del sitio al jugador serán mediante transferencias de BTC. Por temas de exigencias contables estas operaciones pueden ser trazables. Pero si el país no reconoce como legales las apuestas en línea, puede ser que estas transferencias se consideren ilegales.

El uso de BTC para juegos on line aporta las ventajas propias de los BTC antes enunciadas pero también complejiza la aplicación de los controles habituales en el marco de la prevención del LA. Consideremos que algo tan decisivo como la identificación del cliente no puede cumplirse(Treasury Department, US, 2015), (FATF, 
2015). Para los operadores de juego online, los BTC proveen inmediatez de pago para empresa y jugador. Una transacción se cierra en menos de una hora.

Hay muchos lugares en Internet que dan información acerca de los sitios de juego que aceptan bitcoins (mem's Bitcoin Gambling List). Como muestra la Figura 13 - Página de valorización de casinos por uso de bitcoins, en el sitio bestbitcoincasinos.net, se comparan los diferentes casinos que permiten utilizar BTC en las apuestas.

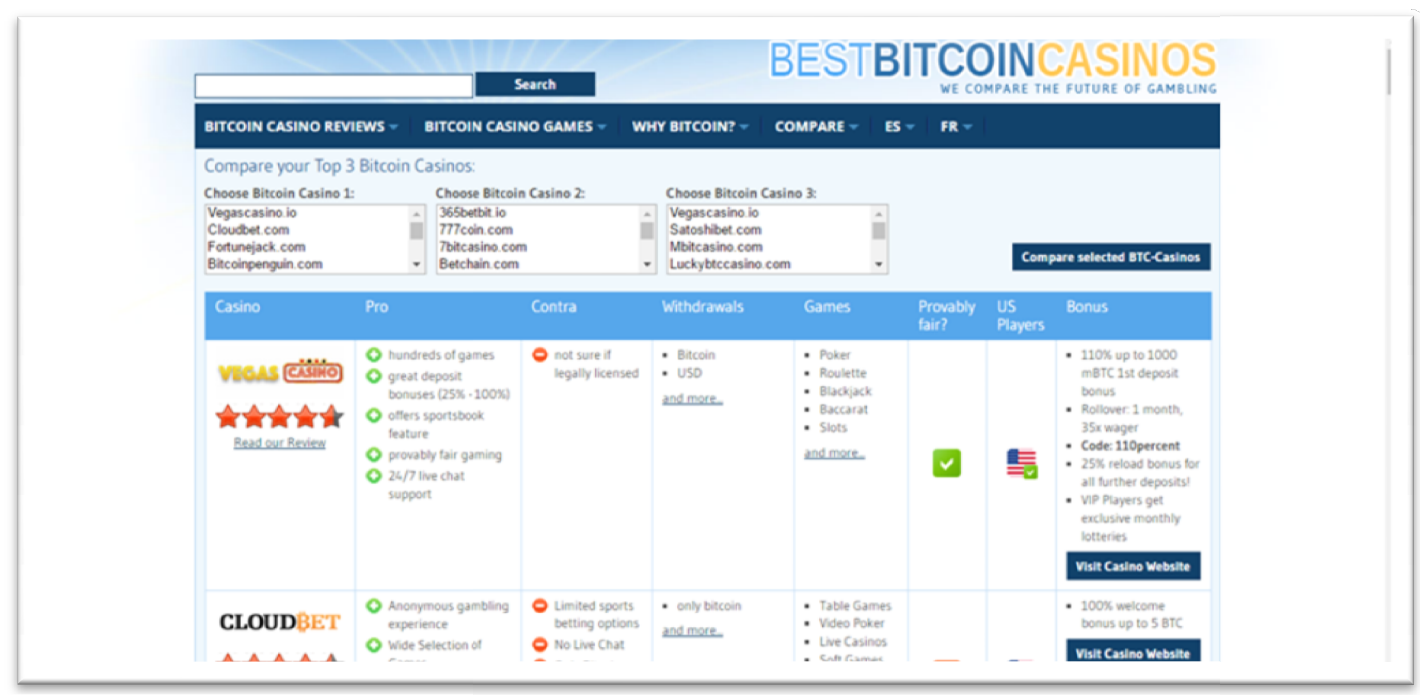

Figura 13 - Página de valorización de casinos por uso de bitcoins

CloudBet es uno de los sitios de apuestas que utilizan BTC. Acepta jugadores de cualquier parte y no es necesaria ninguna información de identificación para operar una cuenta. También Nitrogen Sports, Jetwin, Betcoin Sports, Casino Bitcoin.

En algunas casas de juego han retardado la adopción de BTC al no tener una contención desde los reguladores. Aún no hay una demanda por parte de los jugadores que justifique asumir los riesgos. Esta actitud es más común en las grandes empresas de juego. Pero las más chicas o jóvenes están más dispuestas a captar este tipo de innovaciones.No obstante, los BTC son una alternativa interesante en aquellos países donde no se puede jugar online con tarjetas de crédito o sistemas de pago como Paypal. En 2013 eran más de 60 países los que estaban en estas condiciones, con penetración bancaria débil. Los BTC están accesibles con sólo tener una conexión a Internet.

(Financial Crimes Enforcement Network, 2013)responde a las cuestiones planteadas a la FinCEN por las instituciones financieras, agencias de cumplimiento y supervisores en relación al tratamiento de las personas que usan las monedas virtuales convertibles. De este modo, la Guía viene a considerar el uso de las divisas o monedas convertibles desde la perspectiva de las diferentes categorías que establece el FinCEn para los Money 
Services Bussinesses (MSBs).En el caso de aquellos que son intermediarios en la transferencia de monedas virtuales de una persona a otra o de un lugar a otro, son remesadores de dinero que deben registrarse en FinCEn como MSB a menos que se aplique una excepción.

La creciente demanda de BTC durante el mes de marzo de 2013, alertó acerca de su uso potencial para el blanqueo de dinero y las actividades ilegales (Perez Serpa de Trujillo, 2013)

\subsection{Tipologías en el juego On Line}

Algunas situaciones que pueden prestarse al lavado de dinero en el ambiente on line son:

- Collusion, cuando dos o más jugadores plantean una estrategia común para en la apuesta intencionalmente algunos "pierdan" (y por lo tanto cedan o transfieran valores) a quienes "ganen". Estos luego pueden declarar la ganancia como obtenida legalmente en un sitio on line. También cuando hay acuerdo entre algunos jugadores y personal del sitio que tiene acceso a información del contrincante (sus cartas, por ejemplo, en el caso del póker on line) y la facilite para permitir ganar.

- Jugar con identidad fraudulenta, obtenida mediante robo de identidad, y creación de cuentas fraudulentas en paraísos fiscales

- Uso de robots, es decir, software en lugar de jugadores "humanos"

- Usar moneda electrónica para ocultar identidad

Algunos sitios de juego on line exigen la instalación de un software cliente con georreferenciación para verificar que se juega dentro de un lugar geográficamente predeterminado y permitido.

En casos para realizar el lavado de dinero por collusion entre jugadores, la computadora que tiene el software de verificación es una pantalla (en el gráfico, legal players) de una conexión remota (ilegal players) conectado a centro de control y comando (command control server) que define las jugadas y las transferencias de valores para luego declararlos como ganados en el juego.Esta situación se representa en la Figura 14. 


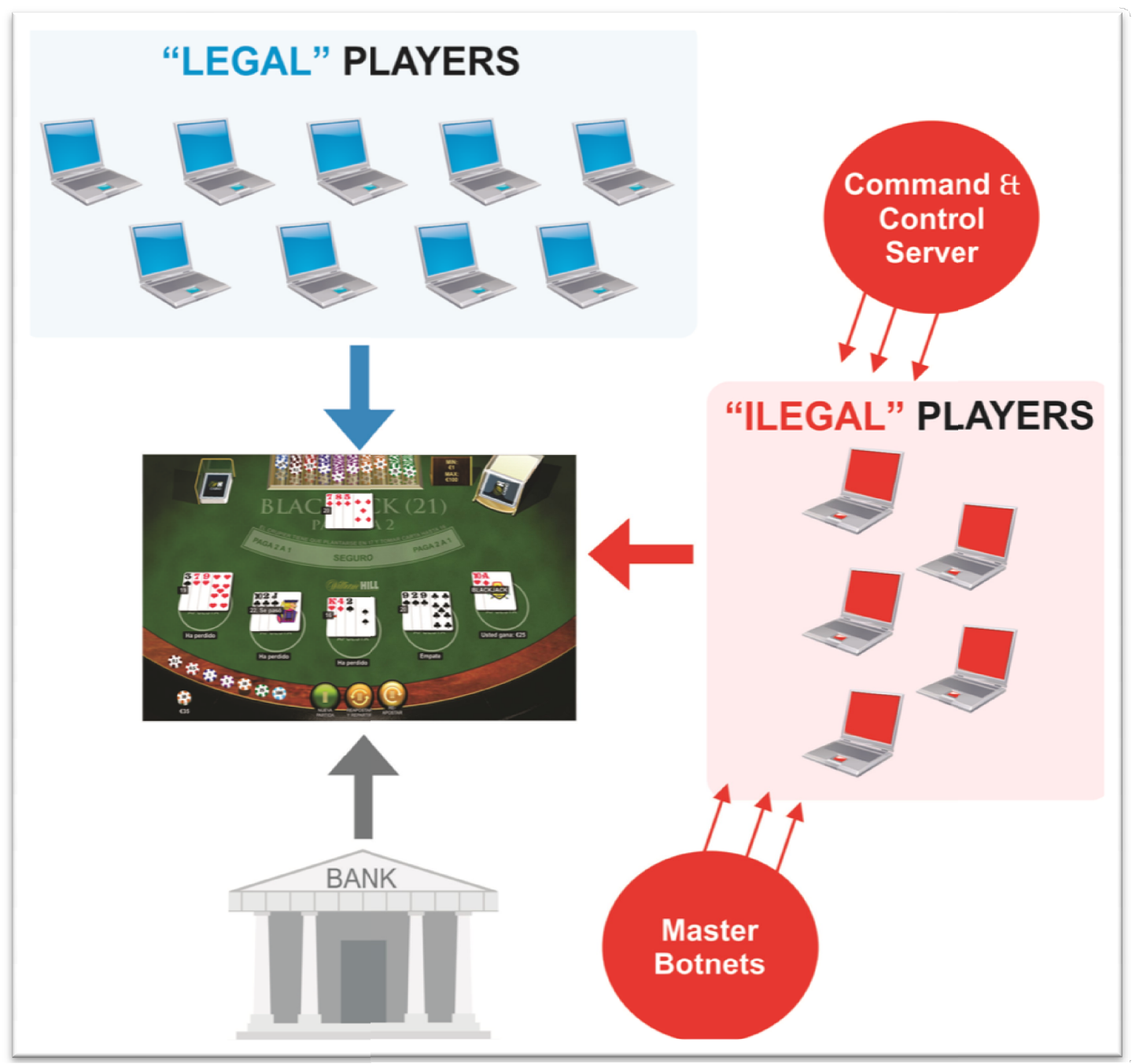

Figura 14 - Interacción de jugadores legales e ilegales en un sitio de póker on line

En Figura 15 (presentado por la autora en el Brasilian Gaming Congress, en Río de Janeiro en el 2013) se pone como ejemplo como pueden actuar 4 jugadores presentes en una mesa de póker on line, donde dos de ellos tomaran el rol de perdedores y los otros dos, de ganadores. Cada uno de estos jugadores tiene dos PCs: una limpia, con el cliente de juego instalado y si es exigido con el software de georreferenciación) y una "corrupta" conectado en forma remota a un centro donde se analizan las jugadas. 
We can suppose...this: 4 "mule"players at the poker table:

-2 donors

-2 recipients

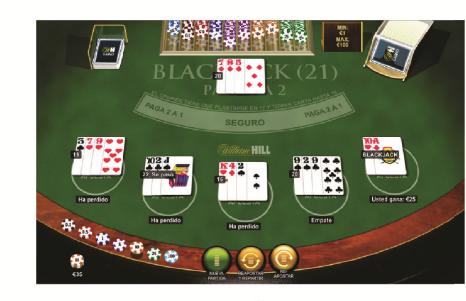

Each "mule" has two Pcs: the clean and the

corrupted
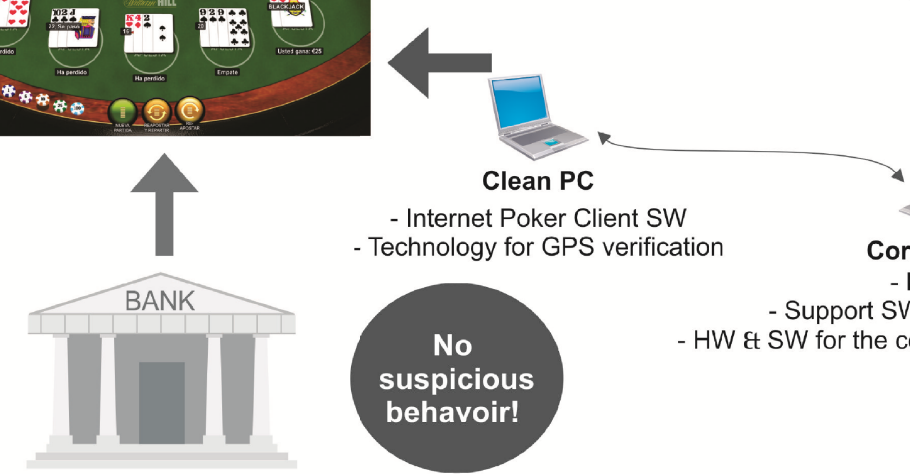

Internet Poker Client SW - Technology for GPS verification

Figura 15 - Control remoto de jugadores en póker on line

En el Brasilian Gaming Congress Dale Sheehan, de Interpol, un disertante invitado, citó:

"Investigators from law enforcement should receive specialized training on: Investigation techniques, Illegal betting market, Coordination with international partners". La capacitación especializada en técnicas de detección y prevención sólo puede ser eficiente si se construye en el contexto de la investigación constante y la colaboración de organismos a nivel regional, nacional e internacional

\subsection{Buenas prácticas para juego remoto responsable}

European Committee for Standardization (CEN) es una organización sin fines de lucro bajo la ley Belga. Entre otros, provee una plataforma para el desarrollo de estándares europeos.Es la única organización europea, de acuerdo a la Directiva 98/34/EC que puede planificar, desarrollar y adoptar estándares en todas las áreas de actividad económica, con excepción de electrotecnología (se ocupa CENELEC) y telecomunicaciones (se ocupa ETSI).

Una de las iniciativas en el año 2007, fue el establecimiento del CEN Workshop Agreement (CWA) en Políticas de Juego Responsable (Responsible Gaming Policy).Este Workshop Agreement "Responsible Remote Gambling Measures" es un conjunto de 134 medidas prácticas para proteger al consumidor (el jugador) y que los operadores sostienen un comportamiento responsable. Fueron publicadas en Febrero del 2011, por el European Committee for Standarization bajo el título "CEN Workshop Agreement 16259:2011”. Sólo cubre juego on line(GSA, 2012). 
CWA informa a quienes definen las políticas acerca de los estándares para mantener un ambiente de juego remoto responsable, sano y seguro. Está basado en más de 600 contribuciones aportadas por participantes. El documento inicial fue publicado para propuestas durante 3 meses. CWA es válido por 3 años.Los principios fundamentales de CWA son: proteger a los clientes vulnerables, entre ellos los menores de edad; combatir las conductas fraudulentas y criminales; proteger la privacidad del cliente y la información; y promover el pago adecuado, el juego limpio (Fair gaming), el marketing responsable, el compromiso con la satisfacción del cliente y la operación confiable, sana y segura ene 1 ambiente.

BTC es para muchos una alternativa válida debido a la pérdida de confianza en el papel moneda y los sistemas bancarios tradicionales. Ahora, al aplicar las normas de lavado de dinero, los operadores de BTC tienen que cumplir con los requisitos contables exigidos por el Tesoro de los Estados Unidos, y la notificación obligatoria para las transacciones que involucran BTC y por transferencias superiores a 10.000 dólares o más. La reglamentación se aplicará a todas las entidades online que participan en la emisión y el intercambio de dinero real o virtual, en particular los que no tienen enlaces o acreditación con las instituciones gubernamentales.

La Comisión de Control de Juego de Alderney (Alderney Gambling Control Commission, AGCC) fue creada para establecer pautas para la regulación del juego on line ("ALDERNEY GAMBLING CONTROL COMMISSION," 2005). Alderney es una de las Islas del Canal. Es una dependencia de la Corona Británica. En Alderney se han establecido algunas compañías de juego on line, como Pinnacle sports, Bet at Home, Unibet, Sportingbet, Mecca Bingo, PKR, Totesport, y Winagames ${ }^{34}$.AGCC es respetada en el ámbito de los operadores del juego on line.Los objetivos que se enuncian son (Gambling \& Commission, 2015), (Gambling \& Commission, 2016): proteger y mejorar la reputación de Alderney y el centro de juego; garantizar que eGambling es manejado en forma honesta y limpia y alineado con el buen gobierno; prevenir que eGambling no sea fuente de crimen, o asociado con él, proveyendo algún tipo de soporte; y proteger a los jóvenes y otras personas vulnerables de ser perjudicadas o explotadas por Gambling.

\subsection{Relación con los elementos planteados}

Los diez elementos propuestos para la definición de políticas PLA, acciones y medición de resultados en el capítulo 6 son de difícil aplicación en el juego de apuestas on line sin el establecimiento de recomendaciones a nivel internacional y la normativa que establece cada país.Considerando lo complejo que es identificar al jugador, la "Definición e implementación de Políticas de Debida diligencia", si quiere ser efectiva, es prácticamente imposible si el jugador tiene la intención (y la tecnología apropiada) para ocultar su identidad.

\footnotetext{
${ }^{34} \mathrm{http}$ //casinobonusestoday.com/license/alderney/
} 
La determinación del riesgo se ha planteado en distintos documentos, principalmente basados en la anonimización, el uso de dinero electrónico, la imposibilidad de garantizar el territorio de juego, entre otras características.

Considerando que en algunos casos son sitios web que van migrando y donde es dificultoso determinar cuál es la empresa que está detrás, el elemento "Definición de Estructura (roles, responsabilidades, funciones, formalización)" tampoco podría ser aplicado. Si bien, existen sitios de juego de apuestas on line que hacen un gran esfuerzo por su formalización. 


\section{CONCLUSIONES}

El lavado de activos es una práctica que no puede analizarse sólo desde el ámbito local. $\mathrm{Su}$ incidencia en la economía mundial, exige que organizaciones internacionales y nacionales acuerden y establezcan instancias de colaboración para su detección y contención. Un país laxo en la normativa pertinente es un punto para el establecimiento de centros que actúen remotamente en la concreción exitosa del delito.

El lanzamiento de nuevas formas de juego (por ejemplo, on line, o utilizando nuevos dispositivos) y de juegos, traen consigo nuevas tipologías para lavado. Por lo tanto, la capacitación y formación de todos los involucrados en el SJA debe ser constante. Sólo una vez determinadas las tipologías de acuerdo al ambiente de juego (tipo de juego, zona, legislación vigente y otros elementos que intervienen) la organización de juego de azar está en condiciones de definir un conjunto de alertas pertinentes.

En el juego on line hay un riesgo inherente que es la falta de presencialidad. No se puede determinar en forma certera quiénes están participando en el juego. Robo de identidad o la participación de robots son algunas de las situaciones que se pueden presentar. La amenaza del lavado está presente con la complicidad de bancos de paraísos fiscales. El uso de dinero electrónico complejiza seguir la ruta del dinero. Intentos como la exigencia de una georreferenciación que garantice que el jugador está jugando dentro del país o estado permitido son fácilmente superados con el uso de software que simula y provee una ubicación geográfica falsa. La falta de regulación para el juego on line hace prácticamente imposible detectar una situación de lavado.

La capacitación especializada en técnicas de detección y prevención sólo puede ser eficiente si se construye en el contexto de la investigación constante y la colaboración de organismos a nivel regional, nacional e internacional.

Como en otros ámbitos de la vida cotidiana, las TICs están teniendo un lugar decisivo en el juego. Realidad virtual, juego on line, y pago por Web son ofertas sumamente atractivas que hacen que millones de personas en el mundo tengan al juego de azar como un entretenimiento habitual. La evolución de la tecnología y el acceso a sofisticadas innovaciones por parte de grupos dedicados al lavado (que además, cuentan con los medios para adquirirlos o incluso fabricarlos) es un desafío que debe enfrentarse en conjunto: reguladores, operadores, jugadores, entidades beneficiarias, fuerzas de seguridad, entre otros.

Por eso no es suficiente la colaboración internacional, si no la definición de políticas y normativas locales. No obstante, como ocurre en los ámbitos donde se almacena, procesa o transmite información, su uso para accionar o tomar decisiones debe ser cuidadoso. En este afán, la línea de invadir o lesionar la privacidad de las personas es muy delgada. Si se establecen medidas sin analizar el contexto, o protegiendo adecuadamente la información que se procesa, puede perjudicarse a quienes tienen al juego de azar como entretenimiento, sin la intención de lavar de dinero.

Para establecer y promover una cultura de prevención, es necesario que aquellas entidades de SJA que tomen las medidas inherentes, definiendo políticas, 
implementándolas en base a un análisis de riesgo frecuente y en un proceso constante de mejora, sean reconocidas.

Los trabajos relacionados con la temática desarrollada presentados por la autora y aceptados en congresos internacionales: 1) "Money Laundering Prevention in Gaming: a Practical Approach for Determining Maturity Levels" en el First American Academic Research Conference on Global Business, Economics, Finance and Social Sciences (AAR16 New York Conference) en New York, Estados Unidos, en Mayo de 2016; y 2) "Auditing Guidelines for Money Laundering Prevention in the Gambling Sector" en el 3rd International Conference on Economy and Society (EAS 2016), China, en septiembre de 2016 - evidencian el interés que la prevención del lavado de activos genera hoy en el mundo, y las contribuciones de este trabajo.

En este marco, esta tesis aporta con la definición de un modelo factible y aplicable a corto plazo de políticas y acciones de prevención de lavado de activos en el sector de juego de azar, y de un marco conceptual que incluye elementos claves en la definición de políticas de prevención de lavado de activos. Los elementos planteados junto con el modelo de madurez pueden ser la base para un marco de certificación que evalúe a la entidad en cuanto a sus políticas y acciones de PLA. Por ejemplo, una entidad certificada con un alto nivel de madurez podría acceder a algunos beneficios desde el regulador (por ejemplo, impositivos), y exponer esa situación como una pauta de calidad para que sea conocida por el resto de los involucrados.

En el inicio de este trabajo, se lo describió como un estudio correlacional. La pregunta a responder era si la existencia de un modelo de gestión facilita la detección de maniobras de lavado a nivel internacional y conduce a una métrica o índice de prevención que pueda utilizarse también a nivel internacional. Se puede concluir que el definir políticas y acciones en el contexto de cada uno de los elementos definidos garantiza un conocimiento del negocio, de las tipologías y la capacitación y formación adecuada para que todos los involucrados estén concientizados tanto en la detección como el contar con información pertinente para la toma de decisiones. La relación con otras organizaciones es una alternativa para conocer acerca de nuevas formas de delito y cómo detectarlas.

Los trabajos futuros para extender este trabajo de investigación se evidencian en el capítulo 10, donde se destacan las tendencias, principalmente acerca del juego on line. La aparición de nuevos escenarios, facilitados por el uso de las TICs, crea nuevas vulnerabilidades, que se potencian ante la falta de normativas locales, inexistentes en algunos casos, y poco efectivas en otros. Desarrollar profundamente los elementos planteados para el entorno on line es un interesante y necesario trabajo a futuro.Otra propuesta es el desarrollo de un plan de auditoría que se corresponda con el modelo planteado, estableciendo controles y metodologías de evaluación, mediante indicadores claves de éxito y desempeño. Por último, establecer políticas de prevención de lavado de activos se corresponde con la determinación e implementación de políticas de Juego Responsable. 
- $A B C$ antilavado. Entrenamiento virtual. (n.d.). Retrieved from http://www.lavadodinero.com/varios/seminarios/Pres_ABC_Antilavado.pdf

- Administración Federal de Ingresos Públicos, A. Procedimiento. Juegos de azar y/o apuestas. Registro de Operadores de Juegos de Azar. Régimen Informativo. Su implementación. (2013).

- ALDERNEY GAMBLING CONTROL COMMISSION. (2005).

- Asociación de Loterías, Q. y C. E. de A. (ALEA) y U. C. de P. de L. de A. (UCPLA). (2014). Manual de Prevención de Lavado de Activos. Tipologías del Sector de Loterías y Apuestas.

- AUSTRAC. Australia's antimoney laundering and counter-terrorism financing regulator and specialist financial intelligence unit (2006). Australia.

- Bautista, N., Milanés, H. C., Huertas, O. R., Segarra, A. M., \& Rusconi, M. (2005). Aspectos dogmáticos, criminológicos y procesales del lavado de activos, 287. Retrieved from http://www.oas.org/juridico/pdfs/mesicic4_repdom_libro.pdf

- Best Practices for Anti-Money Laundering Compliance. (2014).

- Big business. (2001, July 26). The Economist. Retrieved from http://www.economist.com/node/708500

- Caesars Entertainment (UK). Failures in anti-money laundering controls public statement. (2015). Retrieved from http://www.gamblingcommission.gov.uk/pdf/Public-statements/14-1215-Caesars-Entertainment-UK-Ltd-Failures-in-anti-money-laundering-controls-publicstatement-FINAL.pdf

- Camerini, M. A. (2010). Introducción a las cuestiones relativas al lavado de dinero y la actividad bancaria. Resistencia, Chaco, Argentina. Retrieved from ftp://ftp.justiciachaco.gov.ar/Biblioteca/TERRORISMO Y NARCOTRAFICO/LEY 26268 - LEY ANTITERRORISMO/Delitos contra la Administraci\%F3n P\%FAblica. Encubrimiento. Lavado de Activos.doc

- Chanclon, I. (2015). Asi se gana en las apuestas deportivas. (Plataforma, Ed.). Plataforma.

- Código Penal Argentino (2015). Argentina.

- Colombia, U. de I. y A. F. de. (2013). COMPILACIÓN DE TIPOLOGÍAS DE LAVADO DE ACTIVOS Y FINANCIACIÓN DEL TERRORISMO 2004 - 2013. Retrieved from

http://www.urosario.edu.co/observatorio-de-lavado-deactivos/Archivos_Lavados/TIPOLOGIAS-DE-LAVADO-DE-ACTIVOS-Y-FINANCIACION-DEL/

- Constitución de la Nación Argentina (1994).

- Convención Interamericana contra la Corrupción, Pub. L. No. B-58 (1996). OEA -

Organización de los Estados Americanos. Retrieved from

http://www.oas.org/es/sla/ddi/tratados_multilaterales_interamericanos_B-

58_contra_Corrupcion.asp

- Corporación Iberoamericana de Loterías y Apuestas de Estado (CIBELAE). (2011). Marco de evaluación de Responsabilidad Social Corporativa y Gestión Responsable del Juego. Retrieved from https://www.cibelae.com/index.php/es/2015-06-16-04-50-20/marco-de-juegoresponsable 
- Cruz, N. (2010). El EFECTO DE LOS TRATADOS DE LIBRE COMERCIO EN EL CRECIMIENTO ECONÓMICO DE LOS PAÍSES INTEGRADOS A LOS ACUERDOS DEL MERCADO COMÚN DEL SUR (MERCOSUR) Y LA UNIÓN EUROPEA. Revista Empresarial Inter Metro / Inter Metro Business Journal, 6(1), 1.

- Dankhe, G. L. (1976). Investigación y comunicación. In McGraw Hill (Ed.), La comunicación humana: ciencia social (pp. 385-454). México.

- Durrieu, R. (2006). El lavado de dinero en Argentina. (N. Lexis, Ed.) (1ra ed.). Buenos Aires.

- Duyne, P. C. van. (2003). Money-Laundering Policy: Fears and Facts (p. 69). Wolf Legal

Publishers. Retrieved from http://petrusvanduyne.nl/files/Witwassen Fears and Facts.pdf

- EGMONT, G. (2008). Evaluación de Riesgo y Definición de Prioridades.

- El crimen organizado genera el equivalente al 1,5\% del PBI mundial. (2014, May 16). INFOBAE. Retrieved from http://www.infobae.com/2014/05/16/1564867-el-crimenorganizado-genera-el-equivalente-al-15-del-pbi-mundial/

- El robo de la identidad y sus consecuencias. (n.d.). Retrieved August 18, 2016, from https://www.osi.es/es/actualidad/blog/2011/06/02/el-robo-de-identidad-y-susconsecuencias.html

- Encubrimiento y Lavado de Activos de origen delictivo. Reporte de Operaciones Sospechosas "On Line," Pub. L. No. Resolución 51/2011 (2011). Argentina. Retrieved from http://www.uif.gov.ar/uif/index.php/es/resoluciones/161-resolucion-5111

- FATF. (2015). Guidance for a Risk-Based Approach to Virtual Currencies, (June), 48. Retrieved from http://www.fatf-gafi.org/publications/fatfgeneral/documents/guidance-rbavirtual-currencies.html

- FATF/OECD. (2013). Methodology for Assessing Compliance with the FATF Recommendations and the Effectiveness of AML/CFT Systems, updated 2016, (February). Retrieved from http://www.fatf-gafi.org/media/fatf/documents/methodology/FATF Methodology 22 Feb 2013.pdf

- Financial Crimes Enforcement Network, F. (2013). Application of FinCEN's Regulations to Persons Administering, Exchanging, or Using Virtual Currencies. Retrieved from https://fincen.gov/statutes_regs/guidance/html/FIN-2013-G001.html

- Free Trade and Processing Act, Pub. L. No. 12/1994 (1994). Antigua y Barbuda. Retrieved from http://www.laws.gov.ag/acts/1994/a1994-12.pdf

- GAFISUD. (2003). Tipologías Regionales de GAFISUD. Actividades y Profesiones NoFinancieras Designadas (APNFD) (GAFISUD 10/II GTCD 4 Anexo 8). Retrieved from http://www.gafilat.org/

- Gambling, A., \& Commission, C. (2015). Technical Standards and Guidelines for Internal Control Systems and Internet Gambling Systems, (March).

- Gambling, A., \& Commission, C. (2016). ALDERNEY GAMBLING CONTROL COMMISSION Standards and Guidelines for eGambling Cloud, (April), 1-30.

- Gambling Act 2005, Stationery Office (2005). United Kindom: Parliament of UK. Retrieved from http://www.legislation.gov.uk/ukpga/2005/19/pdfs/ukpga_20050019_en.pdf

- Grupo de Acción Financiera Internacional, G. (2009). Vulnerabilities of Casinos and Gaming Sector. Retrieved from http://www.fatf-gafi.org/media/fatf/documents/reports/Vulnerabilities of Casinos and Gaming Sector.pdf 
- Grupo de Acción Financiera Internacional, G. (2012). Recomendaciones de GAFI. Retrieved from http://www.fatf-gafi.org/media/fatf/documents/recommendations/pdfs/FATF-40-Rec2012-Spanish.pdf

- GSA. (2012). Online Gaming A Strategy for GSA. Retrieved from

https://www.gamingstandards.com/pdfs/white_papers/GSA_Report_Online_Gaming_201209. pdf

- Hernández, R., Fernández, C., \& Baptista, P. (1991). Metodología de la investigación (p. 497).

- IFAC. (2005). International Framework for Assurance Engagements. Retrieved from http://www.ifac.org/system/files/downloads/b003-2010-iaasb-handbook-framework.pdf

- Instituto Provincial de Loterías y Casinos, I. Resolución $N^{\circ} 354 / 13$, Pub. L. No. Resolución $N^{\circ}$ 354/13 (2013). Argentina.

- ISACA. Control Objectives for Information and Related Technologies (2012). Estados Unidos.

- ISO/IEC 27001:2013. Information Security Management (2013). ISO. Retrieved from http://www.iso.org/iso/iso27001

- ISO/IEC 27005:2011. Information technology -- Security techniques -- Information security risk management (2011). ISO. Retrieved from http://www.iso.org/iso/catalogue_detail?csnumber $=56742$

- La UIF multó a un Bingo. (2015, April). El Diario Del Juego. Retrieved from http://eldiario.deljuego.com.ar/submenunoticiadelaregion/12820-2015-04-09-14-47-33.html

- Las cinco actividades del crimen organizado que recaudan más dinero en el mundo. (2016, March 31). Diario La Nación. Retrieved from http://www.lanacion.com.ar/1884943-las-cincoactividades-del-crimen-organizado-que-recaudan-mas-dinero-en-el-mundo

- Ley N²5.246 de la Nación Argentina (2000). Argentina.

- Molinari, L., \& Díaz, F. J. (2016a). Auditing Guidelines for Money Laundering Prevention in the Gambling Sector. Frontiers in Finance.

- Molinari, L., \& Díaz, F. J. (2016b). Money laundering prevention in gaming: a practical approach for to determine the maturity level. In Proceedings of the First American Academic Research Conference on Global Business, Economics, Finance and Social Sciences (AAR16New York Conference) New York, USA. New York.

- Molinari, L., Estevez, E., \& Díaz, F. J. (2012). Technology Innovation - A Reference Model for Decision-Making Processes. In A. Universidad Nacional del Sur (Ed.). Bahía Blanca: Universidad Nacional del Sur, Argentina. http://doi.org/ISBN 978-987-1648-34-4

- Montes Farro, E. A. (2008). El sector financiero y el lavado de dinero. UNMSM, 15(30). Retrieved from http://revistasinvestigacion.unmsm.edu.pe/index.php/quipu/article/view/5249

- Morris-Cotterill, N. (2002). Think Again: Money Laundering. Retrieved from http://foreignpolicy.com/author/nigel-morris-cotterill/

- Nakamoto, S. (n.d.). Bitcoin: un sistema de dinero electrónico entre iguales, 12. Retrieved from

https://www.google.com.ar/url?sa=t\&rct=j\&q=\&esrc=s\&source=web\&cd=4\&ved=0CDEQFjAD \&url=https://bibliolibertaria.org/files/230-satoshi-nakamoto-bitcoin-un-sistema-de-dineroelectronico-entre-iguales-p2p.pdf\&ei=AZ4pVI39GMuuggS1oYG4Ag\&usg=AFQjCNFbmAB

- National Indian Gaming Association. (2013). Annual Report 2013. 
- OSCE. Declaración sobre el fortalecimiento de la buena gobernanza y la lucha contra la corrupción, el blanqueo de capitales y la financiación del terrorismo, Pub. L. No.

MC.DOC/2/12/Corr.1 (2012). Dublin, Irlanda: Organización para la Seguridad y la Cooperación en Europa (OSCE). Retrieved from http://www.osce.org/es/cio/146786?download=true

- OSCE. Declaración sobre el fortalecimiento de la buena gobernanza y la lucha contra la corrupción, el blanqueo de capitales y la financiación del terrorismo, Pub. L. No.

MC.DOC/2/12/Corr.1 (2012). Dublin, Irlanda: Organización para la Seguridad y la Cooperación en Europa (OSCE).

- Owens, J., \& Saint-Amans, P. (2009). Countering OffShore Tax Evasion.

- OXFAM, O. (2016). Una Economía al servicio del 1\%. Retrieved from

https://www.oxfam.org/sites/www.oxfam.org/files/file_attachments/bp210-economy-onepercent-tax-havens-180116-es_0.pdf

- Perez Serpa de Trujillo, I. (2013). MODUS OPERANDI EN EL LAVADO DE DINERO. Universidad Nacional de La Plata. Retrieved from http://sedici.unlp.edu.ar/handle/10915/33630

- Pinto, R., \& Chevalier, O. (2006). El Delito De Lavado De Activos Como. Retrieved from www.cicad.oas.org

- Reglamentación básica de las apuestas cruzadas, Pub. L. No. Orden HAP/1369/2014.

España: Boletín Oficial de España (BOE). Retrieved from

https://www.boe.es/diario_boe/txt.php?id=BOE-A-2014-8134

- Resolución Nro 11 (2011). UIF, Argentina.

- Resolución UIF Nro 199, Pub. L. No. Resolución 199 (2011). Argentina: UIF, Argentina.

- Resolución UIF Nro 2 (2012). Argentina: UIF, Argentina.

- Resolución UIF Nro 70 (2011). Argentina: UIF, Argentina.

- Rotman, S. C. (2014). El bitcoin versus el dinero electrónico. Grupo Consultivo de Ayuda a Los Pobres (CGAP), (2012), 1-4. Retrieved from

http://www.microfinancegateway.org/sites/default/files/mfg-es-documento-el-bitcoin-versusel-dinero-electronico-1-2014.pdf

- Schroeder, W. (FBI). (2001). MONEY LAUNDERING: A Global Threat and the International Communitys Response.

- Sevares, J. (2003). El capitalismo criminal. (G. E. Norma, Ed.) (1ra ed.). Buenos Aires.

- Sutherland, E. H. (1940). The White-collar criminal. American Sociological Review, 1-12. http://doi.org/DOI: 10.2307/2083937

- Tondini, B. M. (2006). Blanqueo de capitales y lavado de dinero: su concepto, historia y aspectos operativos. Centro Argentino de Estudios Internacionales. Programa de Derecho Internacional, 38. Retrieved from

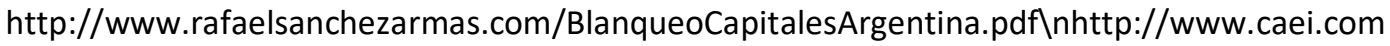
.ar/sites/default/files/20_7.pdf

- Treasury Department, US. (2015). National Money Laundering Risk Assessment 2015.

- Ue, D., Parlamento, D. E. L., \& Del, E. Y. (2015). DIRECTIVA (UE) 2015/849 DEL PARLAMENTO EUROPEO Y DEL CONSEJO de 20 de mayo de 2015 relativa a la prevención de la utilización del sistema financiero para el blanqueo de capitales o la financiación del terrorismo, y por la que se modifica el Reglamento (UE, 2014.

- Una vieja forma de mover el dinero. (2001, October 14). El País. Retrieved from http://elpais.com/diario/2001/10/14/internacional/1003010414_850215.html 
- Unger, B., \& Rawlings, G. (2006). The amounts and the effects of money laundering. Retrieved from http://www.urosario.edu.co/observatorio-de-lavado-deactivos/imagenes/Report-for-the-Ministry-of-Finance-(2006).pdf

- Unidad de Informacion Financiera Argentina. (2012). Guía para la construcción de matrices de riesgo de lavado de activos y financiamiento del terrorismo. Una propuesta en base a la experiencia argentina, 1-50. Retrieved from http://www.uif.gov.ar/uif/images/Documento_Final_Guia_Matriz_LA-FT.pdf

- Unidad de Información y Análisis Financiero - UIAF. (2013). Informe de gestión.

- United Nations. (n.d.). CONVENCIÓN DE LAS NACIONES UNIDAS CONTRA LA DELINCUENCIA ORGANIZADA TRANSNACIONAL Y SUS PROTOCOLOS. Retrieved from https://www.unodc.org/pdf/cld/TOCebook-s.pdf

- United Nations. (1988). CONVENCIÓN DE LAS NACIONES UNIDAS CONTRA EL TRÁFICO ILÍCITO DE ESTUPEFACIENTES Y SUSTANCIAS SICOTRÓPICAS. Retrieved from https://www.unodc.org/pdf/convention_1988_es.pdf

- United Nations. Clasificación Industrial Internacional Uniforme de todas las actividades económicas (CIIU) (2006). Retrieved from http://unstats.un.org/unsd/cr/registry/regcst.asp?Cl=2\&Lg=3

- United Nations, Office on Drugs and Crime, G. P. A. M. L. Ley modelo sobre blanqueo, decomiso y cooperación internacional en lo relativo al producto del delito (1999). Austria: United Nations. Retrieved from http://www.infodrogas.gub.uy/html/lavadoactivos/docs/juicio_simulado/comunidad_europea/Naciones_Unidas_UNODC/Ley Modelo Sobre Blanqueo 1999.pdf

- UNODC. (2011). Estimación de las corrientes financieras ilícitas provenientes del tráfico de drogas y otros delitos organizados transnacionales: informe de investigación. Viena. Retrieved from

www.unodc.org/documents/data-and-analysis/Studies/Illicit_financial_flows_2011_web.pdf - UNODC. (2013). Informe Mundial sobre las Drogas. Retrieved from https://www.unodc.org/documents/lpobrazil//Topics_drugs/WDR/2013/World_Drug_Report_2013.pdf

- UNODC. (2015). Consecuencias del lavado de activos. Retrieved from http://negociosresponsablesyseguros.org/lavado-de-activos/consecuencias/

- UNODC. (2016). Informe Mundias sobre las Drogas. Resumen Ejecutivo. Retrieved from http://www.unodc.org/doc/wdr2016/WDR_2016_ExSum_spanish.pdf

- Víctor Varone. (2013, April 20). Lavado de dinero: esquema y tratamiento en la Argentina. INFOBAE. Buenos Aires. Retrieved from http://opinion.infobae.com/victorvarone/2013/04/20/lavado-de-dinero-esquema-y-tratamiento-en-la-argentina/

- Wikipedia. (n.d.). Juegos de azar. Retrieved August 4, 2016, from https://es.wikipedia.org/wiki/Juegos_de_azar

- Wikipedia. (2016). Robo de identidad. Retrieved August 17, 2016, from https://es.wikipedia.org/wiki/Robo_de_identidad

- Word Lottery Association (WLA). (2012). Marco de Juego Responsable. Guía de adhesión. Retrieved from http://www.worldlotteries.org/cms/index.php?option=com_content\&id=393\&ltemid=100191\&lang=es 


\section{ABREVIATURAS}

\begin{tabular}{|c|c|}
\hline AGA & American Gaming Association \\
\hline ALEA & Asociación de Loterías Estatales Argentinas \\
\hline AML & Anti-Money Laundering \\
\hline $\mathrm{AML} / \mathrm{CFT}$ & $\begin{array}{l}\text { Anti-Money Laundering / Countering the Financing of Terrorism } \\
\text { (O Combating the financing of terrorism) }\end{array}$ \\
\hline APNFD & Actividades y Profesiones No Financieras Designadas \\
\hline BCRA & Banco Central de la República Argentina \\
\hline BSA & Bank Secrecy Act (Ley del Secreto Bancario) \\
\hline BTC & Bitcoin \\
\hline CCPLA & Comité de Certificación \\
\hline CeSPI & Centro Superior para el Procesamiento de la Información \\
\hline CTR & Currency Transaction Report \\
\hline CIBELAE & Corporación Iberoamericana de Loterías y Apuestas de Estado \\
\hline CMM & Capability Maturity Model \\
\hline COBIT & Control Objectives for Information and Related Technology \\
\hline DDC & Debida Diligencia del Cliente \\
\hline FATF & Financial Action Task Force \\
\hline FT & Financiamiento dell Terrorismo \\
\hline GAFI & Grupo de Acción Financiera Internacional \\
\hline GAFILAT & Grupo de Acción Financiera de Latinoamérica (antes GAFISUD) \\
\hline GAFISUD & Grupo de Acción Financiera de Sudamérica (hoy GAFILAT) \\
\hline GLI & Gaming Laboratories International \\
\hline IPLYC & Instituto Provincial de Loterías y Casinos \\
\hline ISACA & Information Systems Audit and Control Association \\
\hline JR & Juego Responsable \\
\hline LA & Lavado de Activos \\
\hline $\mathrm{LA} / \mathrm{FT}$ & Lavado de Activos y la Financiamiento del Terrorismo \\
\hline MJR & Marco de Juego Responsable \\
\hline ML & Money Laundering \\
\hline NIST & National Institute of Standars and Technology \\
\hline OCDE & Organización para la Cooperación y el Desarrollo Económicos \\
\hline $\mathrm{OF}$ & Oficial de Cumplimiento \\
\hline OFAC & Office of Foreign Assets Control \\
\hline OSCE & Organización para la Seguridad y la Cooperación en Europa \\
\hline PEP & Persona Políticamente Expuesta \\
\hline PIEJR & Panel Independiente de Evaluación de Juego Responsable \\
\hline PJR & Principios de Juego Responsable \\
\hline
\end{tabular}




\begin{tabular}{|l|l} 
PLA & Prevención de Lavado de Activos \\
\hline PMI & Project Management Institute \\
\hline RSC & Responsabilidad Social Corporativa \\
\hline RSE & Responsabilidad Social Empresarial \\
\hline SAR & Suspicious Activity Report \\
\hline SEI & Software Engineering Institute \\
\hline SJA & Sector de Juego de Azar \\
\hline TFS & Targeted Financial Sanctions (sanciones financieras dirigidas) \\
\hline TICS & Tecnologías de la Información y Comunicaciones \\
\hline UNLP & Universidad Nacional de La Plata \\
\hline UNODC & Oficina de las Naciones Unidas contra la Droga y el Delito \\
\hline WLA & Word Lottery Association \\
\hline
\end{tabular}




\section{Apéndice: GLOSARIO}

Debida Diligencia del cliente: Tener un conocimiento efectivo, eficiente y oportuno de todos los clientes actuales y potenciales, así como para verificar la información y los soportes de la misma, es decir de todas personas naturales o jurídicas con la cual la entidad establece y mantiene una relación contractual o legal para el suministro de cualquier producto propio de su actividad.

Delito precedente: es la actividad ilegal, primaria, generadora de los ingresos que luego se intentarán reinsertar en el circuito financiero legal.

Dinero negro: es aquél que surge de una actividad legal y que se esconde para no pagar impuestos, por ejemplo.

Dinero sucio: es el que proviene de actividades criminales, por ejemplo, narcotráfico, venta de armas, trata de personas.

Disimular: no abarca únicamente el concepto clásico del delito de encubrimiento, sino la obstrucción del descubrimiento del origen de una cosa, en el tema en análisis del origen ilícito de los bienes.

Encubrir: acción dirigida a lograr que el crimen cometido o sus consecuencias queden impunes en cuanto no pueda ser aprehendido el criminal y no pueda ser secuestrado el botín obtenido.

Lavado de Activos: es el proceso tendiente a legalizar recursos, bienes y servicios de origen delictivo a través de su inserción en los cauces económicos normales y en el circuito monetario oficial, tratando de ocultar su origen delictivo.

Operaciones inusuales: son las tentadas o realizadas en forma aislada o reiterada, sin justificación económica y/o jurídica, que no guardan relación con los usos y costumbres en las prácticas de mercado, ya sea por su frecuencia, habitualidad, monto, complejidad, naturaleza y/o características particulares.

Operaciones sospechosas: son las tentadas o realizadas, que habiéndose identificado previamente como inusuales, luego del análisis y evaluación realizados por el sujeto obligado, las mismas no guardan relación con las actividades lícitas declaradas por el cliente, o cuando se verifiquen dudas respecto de la autenticidad, veracidad o coherencia de la documentación presentada por el cliente, ocasionando sospecha de Lavado de Activos; o aun cuando tratándose de operaciones relacionadas con actividades lícitas, exista sospecha de que estén vinculadas o que vayan a ser utilizadas para la Financiación del Terrorismo.

Persona Políticamente Expuesta (PEP): son sujetos con funciones relevantes por su carácter de servicio público o el interés público comprometido en su desempeño.

Reporte de Operación Sospechosa (ROS) es el que se realiza ante operaciones, hechos o situaciones que posiblemente están relacionadas con el lavado de activos.

Reportes sistemático: es aquella información que obligatoriamente deberán remitir los Sujetos Obligados a la UIF en forma mensual, mediante sistema "on line". 
Sujeto obligado: es una entidad o individuo obligado a cumplir con las regulaciones antilavado de dinero y que están bajo la supervisión y regulación de alguna entidad estatal.

Tipología de lavado de activos: es la clasificación y descripción de las técnicas utilizadas por las organizaciones criminales para dar apariencia de legalidad a los fondos de procedencia ilícita y transferirlos de un lugar a otro o entre personas para financiar sus actividades criminales. 